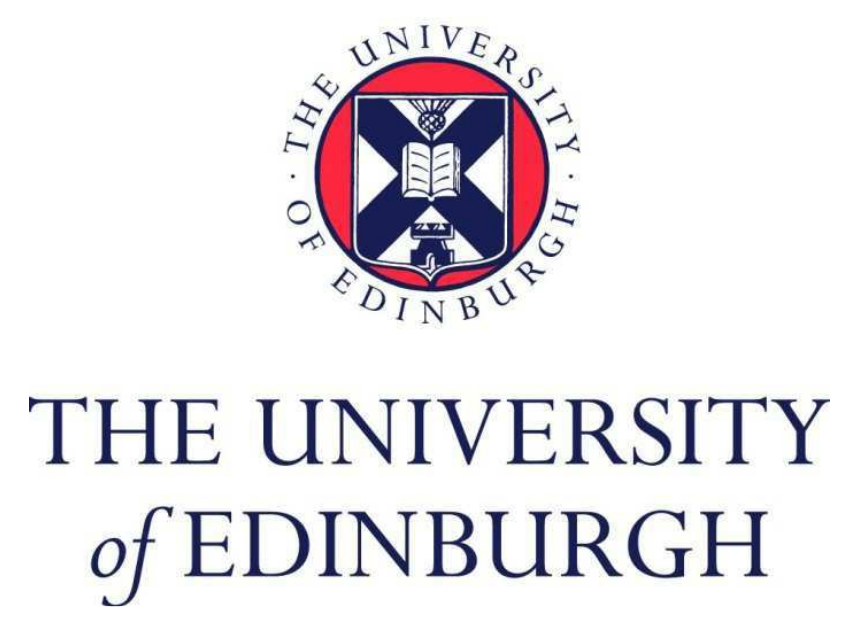

This thesis has been submitted in fulfilment of the requirements for a postgraduate degree (e.g. PhD, MPhil, DClinPsychol) at the University of Edinburgh. Please note the following terms and conditions of use:

This work is protected by copyright and other intellectual property rights, which are retained by the thesis author, unless otherwise stated.

A copy can be downloaded for personal non-commercial research or study, without prior permission or charge.

This thesis cannot be reproduced or quoted extensively from without first obtaining permission in writing from the author.

The content must not be changed in any way or sold commercially in any format or medium without the formal permission of the author.

When referring to this work, full bibliographic details including the author, title, awarding institution and date of the thesis must be given. 


\section{Validity and Variation in the Parentela Policy Network: Conflict and Cooperation between Ruling Parties and Interest Groups in Bulgaria}

Mihail Petkov

$$
\text { PhD - The University of Edinburgh - } 2015
$$




\section{Table of Contents}

Chapter 1:The Parentela Policy Network Type.........................................................

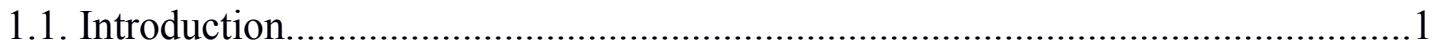

1.2. Parentela: Definition and Formation Causes.................................................. 8

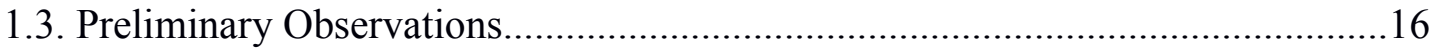

1.3.1. Traces of Party-Insider Group Network Relationships...............................17

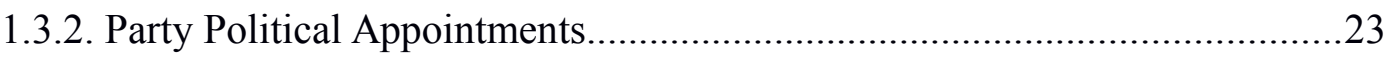

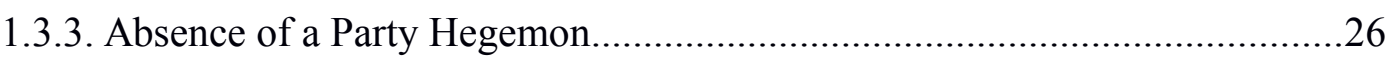

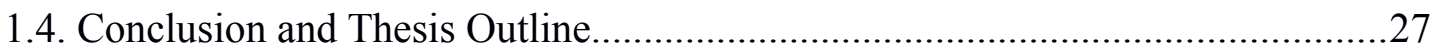

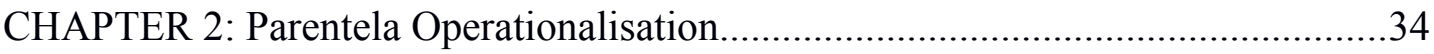

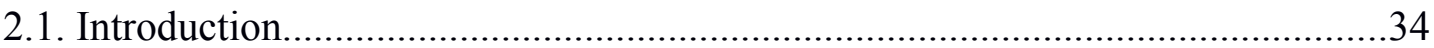

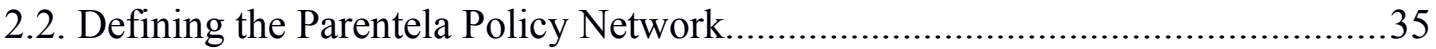

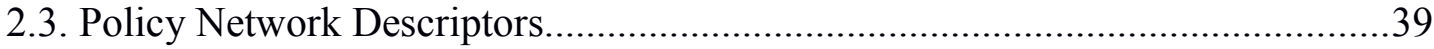

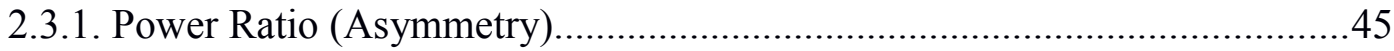

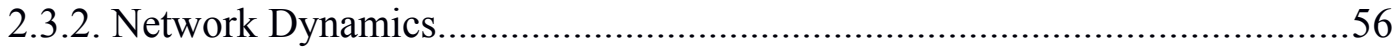

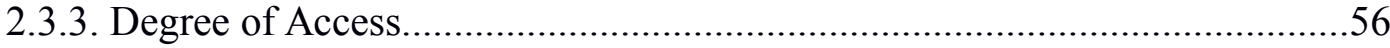

2.3.4. Primary Venue and Venue Scope..........................................................58

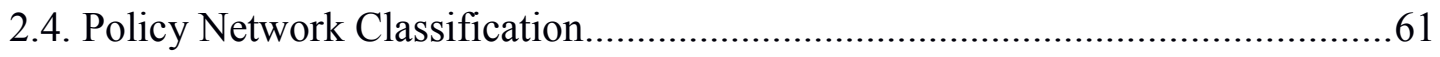

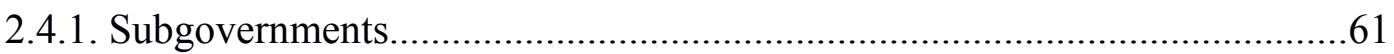

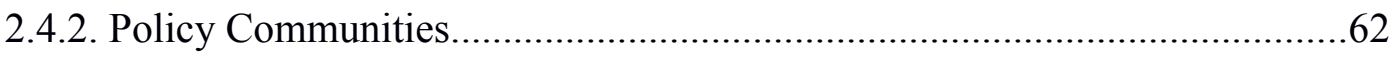

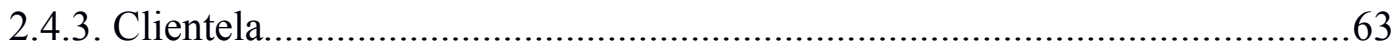

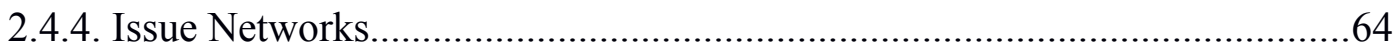


2.4.6. Policy Network Classification Using Network Descriptors

2.5. Conclusion. 66

CHAPTER 3: Elite Interviews, Systems Design and Case Studies. 68

3.1. Introduction. 68

3.2. Elite Respondent Pools Comparison. 71

3.3. Causes of Elite Respondent Reluctance and Resistance. 84

3.3.1. Insider/Outsider Positionality. 84

3.3.2. Expert Positionality. .85

3.3.3. Adversarial Positionality Types. 87

3.4. Reducing Elite Respondent Reluctance and Resistance Using an Intermediary. 91

3.4.1. Respondent Selection Stage. .94

3.4.1.1. Specific Respondent Selection......................................................... 94

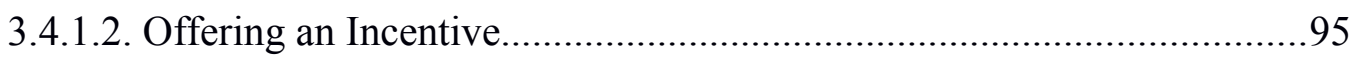

3.4.1.3. Intermediary's Respondent Identification and Researcher legitimation 96

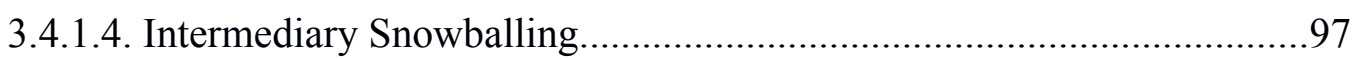

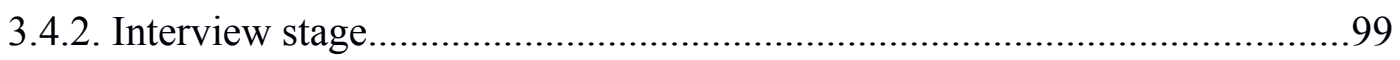

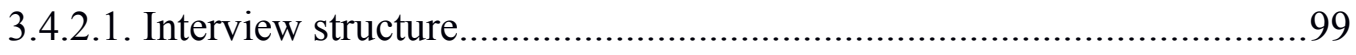

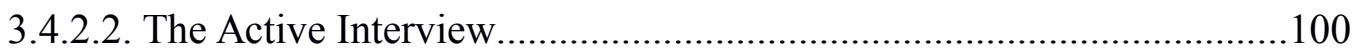

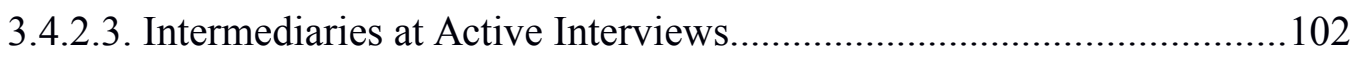

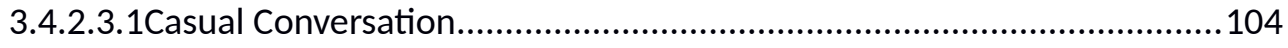

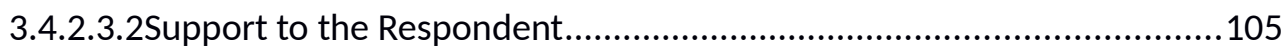

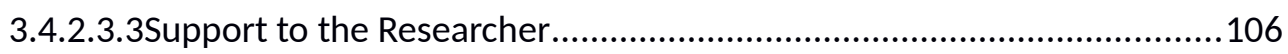

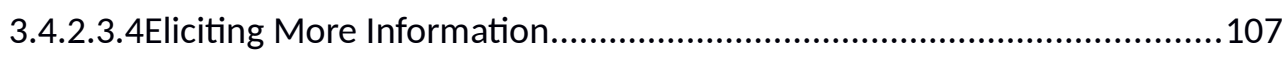

3.4.2.4. Limitations to the use of the intermediary at elite interviews...............111

3.5. Causality, Comparative Designs and Case Studies.........................................114 
CHAPTER 4: The Party in Power as a Parentela Primary Venue: The Case of National Council on Tripartite Cooperation (NCTC) .............................................118

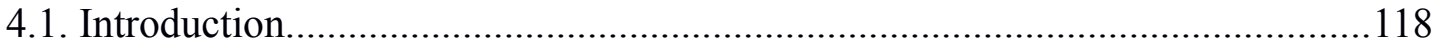

4.2. Party Intervention and the National Council for Tripartite Consultations (NCTC)

4.3. Alternative Perspectives on NCTC: Prime-Ministerial Democracy or Oligarchy 128

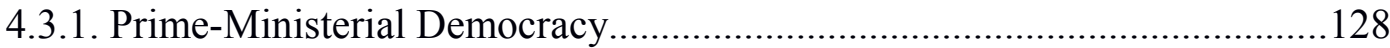

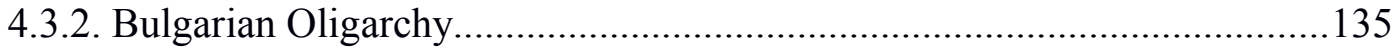

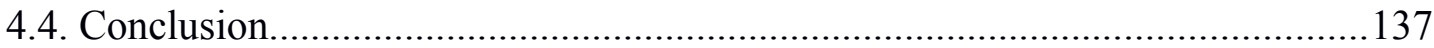

CHAPTER 5: Party Political Appointments and Venue Scope................................138

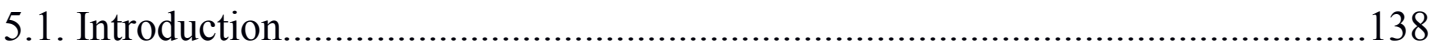

5.2. Scope of Party Political Appointments in Bulgaria..........................................141

5.3. Structure of Appointments on Central and Local Level...................................148

5.4. Explaining Party Political Appointments: Political Distrust..............................155

5.4.1. Party's Distrust of Independent Expertise...............................................158

5.4.2. Distrust of Appointees of Party Electoral Losers......................................163

5.4.3. Insider Agreements and Resource Exchange..............................................164

CHAPTER 6: Insiderness, Cooperation and Power Symmetry...............................169

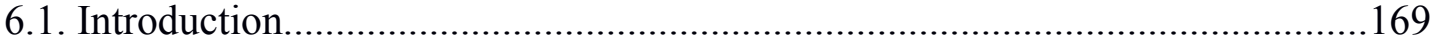

6.2. Core Insider Status, Cooperation and Power Parity........................................172

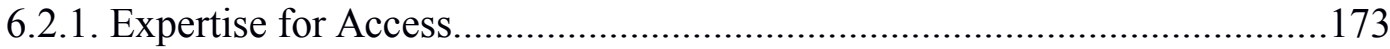

6.2.2. Voter Support and Ideological Proximity for Access................................177

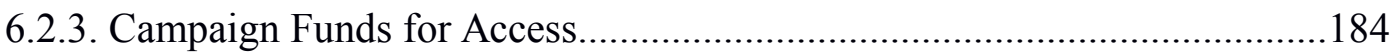

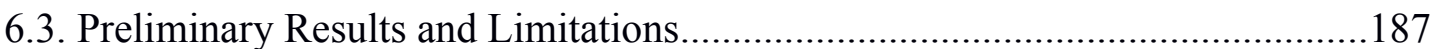


CHAPTER 7: Profiling Private Parentela Actors.................................................... 193

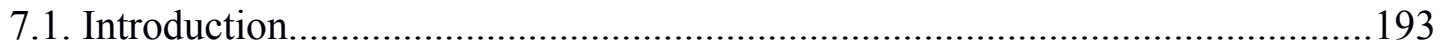

7.2. Circles of Big Business and the Parentela....................................................... 195

7.2.1. Core Insider Status, Exchange, and Party Political Appointments.............196

7.2.2. Circles and Party Political Appointments..................................................197

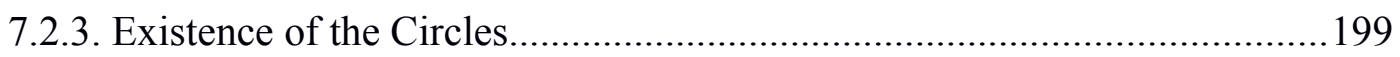

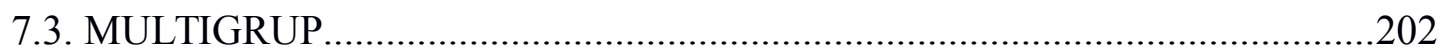

7.3.1. Multigrup and New Parentela Dynamics.................................................203

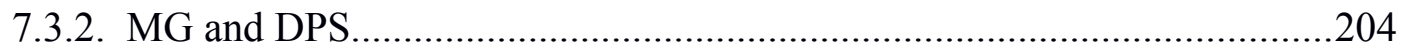

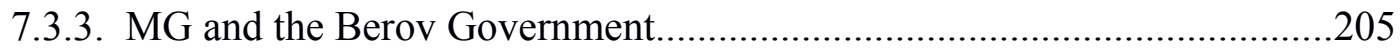

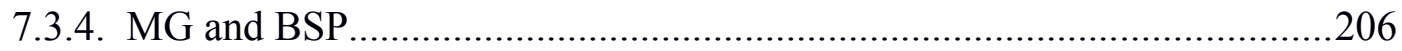

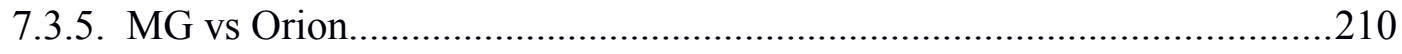

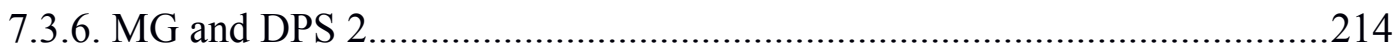

7.4. The Profile of Private Parentela Actors...........................................................216

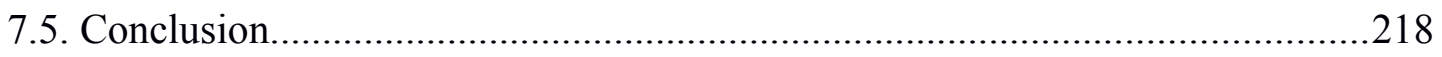

CHAPTER 8: La Palombara's Parentela: The Case of Bulgarian Law on Public

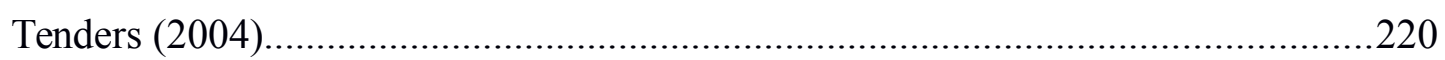

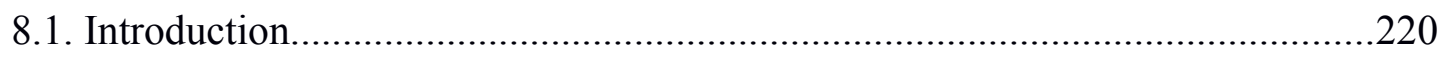

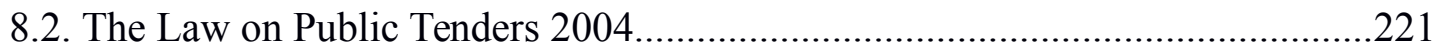

8.3. Public Tender Contractor Pre-Selection Mechanism........................................223

8.4. Scope of Contractor Pre-Selection at Public Tenders.......................................225

8.5. Party Interference in the Public Tender Committees and Contractor Pre-Selection 230

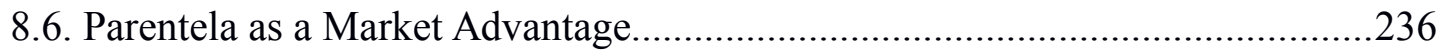

8.7. Public Tender Committees in the Construction Sector and the Parentela..........237 
CHAPTER 9: Parentela: Two Types or One?......................................................242

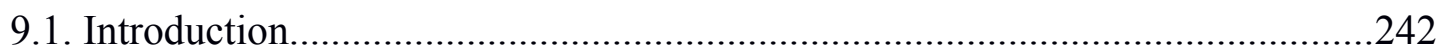

9.2. Understanding Type 2 Parentela Dynamic......................................................245

9.3. Behaviours within Type 2 Parentela Dynamics..............................................251

9.3.1. The Logic of Conversion and the Offer one Cannot Refuse.......................252

9.3.2. Insider's Direct Intervention against Outsider Market Competitors...........257

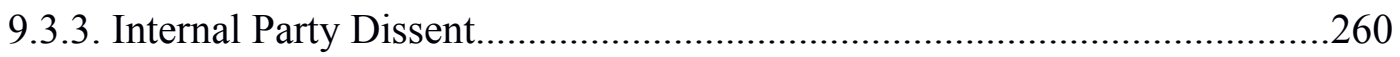

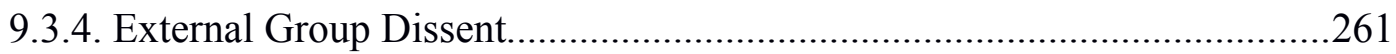

9.3.5. Type 2 Parentela Dynamics Causal Summary........................................263

9.4. Type 2 Parentela Dynamic Validity and Novelty .............................................266

9.5. Perspectives on the Extended Parentela..........................................................269

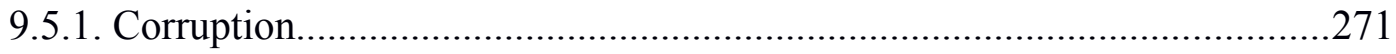

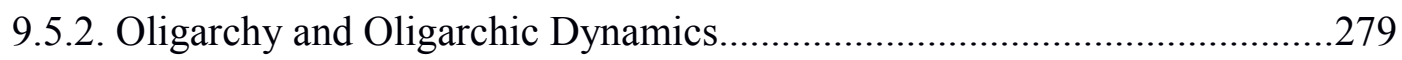

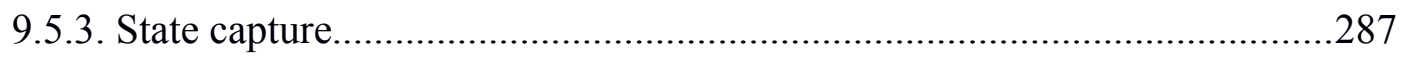

9.6. The EU as an External Variable to the Parentela..............................................291

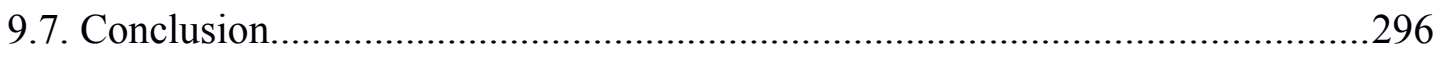

CHAPTER 10: Validity and Variation in the Parentela Policy Network..................298

10.1. La Palombara's Parentela Confirmed................................................................303

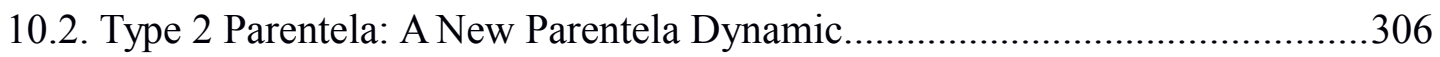

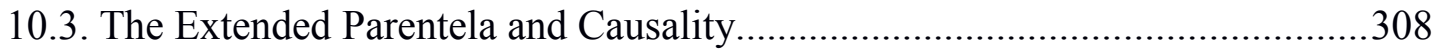

10.4. New Perspectives on the (Extended) Parentela..............................................309

10.5. Conclusion: Limitations and Future Research............................................... 312

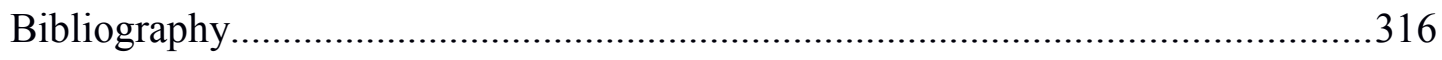




\section{List of Tables}

Table 1 Conditions (Independent Variables) associated with the Parentela as per La

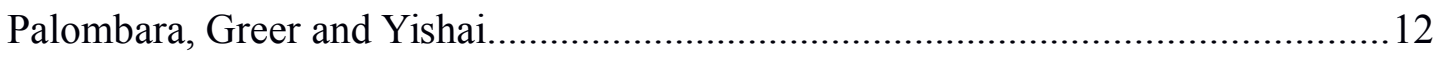

Table 2 Popular Circles in Bulgaria at the start of the project (2013)......................21

Table 3 Bulgarian Governments to-date.............................................................26

Table 4 Adaptation of Dowding's SNA indicators..................................................41

Table 5 Network Descriptors, adapted from Atkinson and Coleman (1989: 54).......46

Table 6 Network Descriptors, adapted from van Waarden (1992:50).....................47

Table 7 Network Descriptors, adapted from Jordan and Schubert (1992: 25)...........48

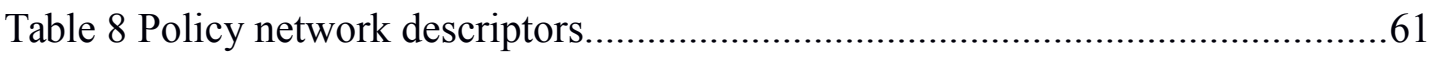

Table 9 Policy Network Classification Using Policy Network Descriptors..............66

Table 10 Interview Numbers and Respondent Pseudonyms.....................................72

Table 11 Profile of La Palombara's Respondent Pool................................................74

Table 12 Summary of La Palombara's Respondents' Backgrounds...........................76

Table 13 Conservative Respondent Pool Comparison, LaPalombara and this Study.76

Table 14 Conservative and Multipositional Comparison of Respondent Pools.........78

Table 15 Detailed profiling of the Bulgarian Respondent Pool................................79

Table 16 Conservative representation of political parties in the study......................81

Table 17 Multipositional Representation of Political Parties in this Study...............82

Table 18: Levels of PPA (Kopecky and Spirova 2011: 907)..................................141

Table 19 PPA in Ministries and agencies, (Kopecky and Spirova 2011: 908)..........142

Table 20 Policy Network Descriptors Expressed with Network Features.................188

Table 21: Table 21 Classification of Type 2 Parentela.............................................251 


\section{List of Figures}

Figure 1 Do you believe that political appointments in the state administration happen often/sometimes /never? (Spirova 2012: 60)............................................146

Figure 2 Hierarchical Structure of Party Political Appointments as permitted by the

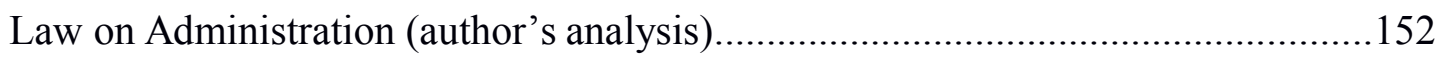

Figure 3 Appointments at Local Level.................................................................155

Figure 4 Parentela Formation Process in the LPT Case.........................................240

Figure 5 Causal Chain for Type 2 Parentela........................................................266 
To R001 and $210 i$ 


\section{Acknowledgements}

I am indebted to Andy Aitchison and Richard Parry, Francesca Batzella and Lambros Kaoullas for being patient with me re-reading the drafts and always being there with valuable advice. I am also indebted to my parents, respondents and intermediaries, without whom the study would have never materialised. 


\section{Abstract}

Policy networks is a body of literature dedicated to modelling state-civil society relationship formats. In this particular relationship, an interest group with privileged (insider) access to the party in power gains advantage in the policymaking process by utilizing party's ability to make political appointments in the civil service. The parentela (or type 1 parentela) was first discovered by Joseph La Palombara (1964) in 1960s Italy and was documented later again by Greer (1994) in 1920s-1970s Northern Ireland.

Still, there has been no parentela research since 1994, save for Yishai (1992), who argued the parentela did not exist in Israel in 1980s. It seems the concept is considered of little utility to the academic community today. At the same time, as a category of policy networks, the parentela is also susceptible to the wider criticism of Thatcher (1997) and Dowding $(1995 ; 2001)$ that the policy network literature is unable to introduce causal dynamics in its models and distinguish between network features and network independent variables. This study, therefore, addresses both criticisms by studying the party-group-civil service relationship in Bulgaria, for the period 2013-2015, using 26 elite interviews and a number of cases.

Results show that this particular policy network is still viable today. They support Yishai (1992) that hegemonic parties have no effect on parentela formation. The study demonstrates that the cooperation between ruling parties, in need of funds, and organised businesses (groups), in need of market advantage, produces the parentela. In a case study on construction tenders, the study demonstrates La Palombara's parentela, by exposing the process of how ruling parties intervene in the civil service through political appointees to ensure construction projects are granted to their party insider groups. The study also discovers a new parentela dynamic, labelled as type 2 parentela, where the party intervention extends further to the free market by affecting party insider's market competitors through prejudiced regulatory inspections that disrupt targeted businesses' operations temporarily or altogether. 


\section{Declaration}

I hereby declare that, except where otherwise indicated, this thesis is entirely my own work, and that no part of it has been submitted for any other degree or qualification.

Mihail Petkov

If Mithar Petsor 


\title{
List of Abbreviations and Acronyms
}

\author{
ABV Alternativa za Balgarsko Vazrazhdane (Alternative for Bulgarian \\ Renaissance; political party) \\ BCCI Bulgarian Chamber of Commerce and Industry \\ BIA Bulgarian Industrial Association \\ CA Catholic Action \\ CIEB Chamber of Industrialists and Employers in Bulgaria \\ DPS Dvizhenie za Prava i Svobodi (Movement for Rights and Freedoms; \\ political party) \\ LPT Law on Public Tenders (Zakon za Obshtestvenite Porachki) \\ MG Multigrup corporation \\ NCTC National Council for Tripartite Cooperation (or Natsionalen Savet za \\ Tristranno Satrudnichestvo) \\ NDSV Natsionalno Dvizhenie Simeon Vtori (National Movement Simeon the \\ Second; political party) \\ PPA Party Political AppointmentsUFU Ulster Farmers' Union
}




\section{Chapter 1: The Parentela Policy Network Type}

\subsection{Introduction}

The present research is an enquiry into the existence of a particular policy-making arrangement known in the literature as parentela type of policy network. This term is part of the policy network body of literature and stands for a particular relationship format between ruling political parties, interest groups and the civil service. The purpose of the present study, therefore, is to determine whether the relationship between these policy-making actors in Bulgaria conforms to the parentela.

The policy network literature descends from an earlier, macro debate of 1970s-1980s on the relationship format types between the state and civil society (i.e. pluralism, corporatism). By the early 1990s, researchers conceded that this relationship could be better studied if the concepts of the state and that of civil society are operationalised on a meso level of analysis (Heisler 1979: 285; Jordan 1981, 1984: 147-152; Cox 1988: 298-300; Marsh and Rhodes 1992: 3-4; Jordan and Schubert 1992: 10; Marsh 1998; Marsh and Smith 2000; Ross 1983). As a result, the state-society relationship is now studied in terms of policy networks. Again, they stand for the various relationship formats between the bureaucracy, the political party in power, the Parliament, interest groups and the media.

In his Interest Groups in Italian Politics (1964), Joseph La Palombara defines the parentela as a party-group relationship where an insider group within a party extends its policy-making access from party structures into the civil service, usually by means of political appointments. La Palombara's seminal work on Italian interest groups remains the only large-scale research that has firmly established the presence of the parentela to-date (1964: 306-349). The only two other studies explicitly devoted to the parentela are from Yishai (1992) with Israel as a case and Greer (1994) on Northern Ireland (1920s-1970s). 
Evidence of the parentela network type has not convinced the academic community. The model received some prominence nearly thirty years after publication, when it was discussed in the context of the policy networks classification debate (Atkinson and Coleman 1989: 54; Waarden 1992a: 45, 50; 1992b: 133). Nevertheless, its omission by Jordan and Schubert (1992: 25) from their network classification scheme reflects a wider lack of enthusiasm for this network type. They, however, did not exhibit the same misgiving towards La Palombara's other model, clientela (1964: 252), which he introduced in the same book where he proposed the parentela (Jordan and Schubert 1992). Yishai (1992) also questions the validity of the parentela, after failing to find supporting evidence of its existence in Israel. So far only Greer's study provides some optimism, as he demonstrated the presence of a parentela in the farmer-state relationship in Northern Ireland, although, for the much more distant 1920s-1970 period (Greer 1994). More recently, Guy Peters in his 2001 edition of "The Politics of Bureaucracy" mentions the parentela, but without providing any new evidence. Ultimately, the impression is that the concept of the parentela bears little analytical value. The purpose of the present study, therefore, is to determine whether the parentela exists, and if so, determine the causal dynamics it is involved in by applying the concept to the Bulgarian polity in 2013-2015 time period. There are two reasons for selecting Bulgaria.

First, preliminary research suggested that the Bulgarian policy-making process featured parentela-like relationships. Known publicly as circles or rings these are policy-making phenomena identified by Bulgarian media and accepted by the society at large. They denote any type of business that is in close association or cooperation with a given party in power. A pilot study suggested great similarities between those and the parentela.

Second, the parentela dynamics observed in the preliminary research above occurred in the absence of a hegemonic party in power. This relates to the parentela literature, which posits that hegemonic parties cause the parentela. This was first proposed by La Palombara (1964) and later confirmed by Greer (1994). Both of them, respectively, observed that the parentela's existence correlated with the presence of a 
hegemonic political party: Christian Democrats in 1960s Italy and the Unionist Party in Northern Ireland (1920s-1970s). With a case study on Israel, however, Yishai (1992) contradicted that purpotedly causal relationship, by showing that what was a period of Israeli politics, known as party democracy, the political parties with hegemonic features as of 1908 s did not correlate with a parentela policy network. The present thesis would support her claim that hegemonic parties do not influence the parentela formation (chapters 8,9). Results from the present study on Bulgaria (2013-2015) show that the parentela can form in the absence of hegemonic political parties.

In addition, the research project is also geared towards identification of other possible independent variables that may be of relevance in this relationship. This is a direct response to a criticism made elsewhere in the literature (chapter 2) that policy networks were more descriptive than causal, if at all. In sum, the study has two parallel objectives:

- To assess the extent to which the relationship between the party in power, interest groups and the bureaucracy in Bulgaria conforms to the parentela; AND.

- To identify any causal dynamics relevant to the parentela, particularly what causes the parentela into formation and what dissolves it?

Results demonstrate that the parentela exists in Bulgaria (chapters 3-8).It is formed in order to facilitate the exchange of resources between two policy-making actors: the ruling party and the insider interest group. Respondents indicate that political parties are in a constant need for campaign funds. At the same time, endangered yet affluent companies (or simply groups) may need an additional form of pressure against their competitors. As a result, the intersection point of the two actors marks the beginning of the parentela formation. While political parties can provide a market advantage to the given group, the latter reciprocates with donations. 
While disclosing the process of party's civil service intervention, which has only been stated but not shown in previous research (La Palombara 1964; Greer 1994), another contribution of the research is the discovery of a new parentela dynamic, labelled type 2 parentela (hence, type 1 for La Palombara's parentela). A large number of the elite respondents reported that a second form of a market advantage a party insider group could gain is by instigating a prejudiced regulatory inspection on an insider's market competitor (Chapter 9). In other words, the ruling party can use its control over the civil service agencies through political appointments to conduct regulatory inspections against firms that compete with the insider on the market. These are legal inspections from any of the agencies that regulate through sanctions the operations of a business establishment, also including all other agencies monitoring for violations in working conditions, tax and social security contributions, the environment, etc.

According to the type 2 dynamics, some inspections of the above authorities may be prejudiced and intended to disrupt the business operation of a market competitor of the party insider. The distinctive feature of those inspections is that they immediately establish offences, quickly revoke licenses of operation and initiate court proceedings or simply artificially prolong a routine inspection (which requires the temporary discontinuation of certain business activities). The end point is for the targeted business to stall operation temporarily or altogether. A variation of that is what many respondents described as the offer. Instead of direct inspections, the targeted outsider is offered a choice: to sign away $51 \%$ of their business ownership to the insider and be compensated, or face endless inspections.

The discovery of type 2 dynamics also showed that political parties alone can resort to prejudiced inspections. First, they might use such mechanisms to threaten internal dissenters or opposing interest groups. Alternatively, type 2 could be used in order to obtain more campaign funds. Here political parties make offers to select affluent outsiders: either engage in a semi-legal form of public funds machinations that will deliver benefits to both the party and the outsider or refuse the offer and face crippling inspections. 
In comparison, type 1 is a description of the cooperative relationship between the ruling party, its insider group, the civil service and how the party intervenes in the civil service. Type 2 is an add-on to these dynamics. It reveals the aggressive relationship between the parentela core (party and insider) and an outsider group. However, this also shows the different manifestation of power: while power is shared under type 1 cooperation, it is successfully applied in type 2 on outsiders without the latter being able to retaliate.

Results also suggest that a key intervening variable (enabling factor) is party's ability to make party political appointments (PPA). This adds credence to the correlation observed in earlier the literature: PPAs are present where the parentela is found (La Palombara 1964; Greer 1994), while they are absent where it is not (Yishai 1992). Greer's study of Northern Ireland, however, can be included as a case of the said correlation only if we agree that the intra-party selection of nominees from interest groups as ministers is also a form of PPAs (1994). Endorsing group's nomination as minister is somewhat different from La Palombara's intended meaning of the mid-tolow civil service echelon appointments (1964).

The present project on the parentela in Bulgaria also made inadvertent contributions to other bodies of literature. It corroborates the results of Kopecky and Spirova (2011) on PPA's far administrative reach arguing that this is the result of the prevalent distrust in the Bulgarian policy-making system. Similarly, the study argues that the policy-making network of Bulgaria's transition, has given way to the parentela, even if the latter has inherited some of its elements. Chalakov et al (2008) observed that the network mechanism employed by the communist politicoadministrative elite to convert its waning access into capital (molecule of conversion) gave way to a new network structure with unclear contours post 2001. The present study argues that this network is the parentela, which has retained only a fraction of the molecule's dynamics, namely, party's desire to convert its access to the civil service into campaign contributions, which acts as the reason why a party would cooperate with or confront affluent groups.

Furthermore, the present project demonstrates that both parentela types, coupled with parliamentary elections create dynamics of elite formation, competition and 
dissolution. The close, reiterated cooperation between a ruling party and its insider group (i.e. type 1) could be seen as an elite formation process. However, a party change following parliamentary elections and type 2 dynamics could eliminate an elite formed earlier. This instability among political parties and interest groups and creates an environment of competition among elites (chapter 9). 
This finding corroborates similar research on Bulgaria, carried out by Barnes (2007) who has made the same argument, where at each new elections Bulgarian politics are captured by a new elite in competitive fashion. Though basically both views overlap, the present study would warn against the use of capture. Results show that any advantage a group has is due to the permission and cooperation with the ruling party. As type 2 demonstrates, the party in power through its appointees in the regulatory agencies is the most powerful actor (chapter 9).

In a similar fashion, the results also overlapped with the Offe's description of some of the corruption forms in Eastern European policy-making (2004). Here, type 2 in particular was unquestionably evident in Offe's thinking. However, because Offe's level of analysis is primarily on the individual, micro level, while the parentela is on a meso level, both types are better compatible with the literature on oligarchy or transition (Barnes 2007). On oligarchy, the study also disagrees with the proposition that both parentela types are evidence of oligarchy. Their aggressive and conflictual dynamics is at odds with the notion of a stable and monolithic elite community with full access to all policy-making aspects.

Finally, the study also makes two methodological contributions. The first relates to the operationalisation of the generic term policy networks by developing a system of classification the different types. The study reviews the network categorisations prevalent in the literature (Jordan and Schubert 1992; Kenis and Schneider's 1989; Atkinson and Coleman 1989; van Waarden 1992) and promotes a new one. It promotes five qualitative indicators the combinations of whose values constitute the different policy network types. Doing so ensures comparability of the results vis-àvis other studies.

The second is the development of a new method of interviewing resistant elite respondents, where the person who facilitated the interview (the intermediary) is its third participant. This method received academic recognition with the publication of a joint-paper with L Kaoullas (Petkov and Kaoullas 2016). Essentially, intermediary's interview participation legitimised the researcher and relaxed the respondent into giving more information. 
This introductory chapter, therefore, is divided as follows: subsection 1.2 gives a quick, working definition of the parentela, to be developed more fully in chapter 2 and introduces the preliminary causal observations derived from a pilot study on the Bulgarian polity, which suggest the hypothesis that the parentela can exist without the presence of a hegemonic party. The preliminary observations are discussed in more details in section 1.3. The overview of the chapters and corresponding contributions are reviewed in the conclusion at 1.4.

\subsection{Parentela: Definition and Formation Causes}

The parentela is a relationship format between the civil service, political party and select interest group (or policy network type). In the first of the two stages to establish such a network, an interest group has to gain privileged access to the ruling political party (La Palombara 1964: 309; 331). Stage two is when the political party endorses the interests of the privileged group by securing favourable appointments in the civil service (1964: 308, 310, 311). In doing so, a group with privileged access to a political party could control an agency or parts of the civil service because it can affect the personal career of the bureaucrats (1964: 327) and/or because it can procure own appointees as chiefs of civil service agencies (1964: 326). In the words of La Palombara (1964: 327):

[...] the impact of Christian Democracy (ruling party, sic) and its parentela groups on bureaucratic recruitment, placement, and promotion evidently extends considerably beyond commanding heights and involves levels that, in theory at least, are supposed to be staffed strictly on the basis of merit and seniority.

All of the above is, of course, assuming the party in power has the right to political appointments (1964: 346). These quotations serve to illustrate what the parentela is and what it does. However, there is still the question of any formal statement of the term.

A formal definition of the term is not readily available in the literature, unfortunately. All authors, save for Peters below, seem to share the same notion of the concept, 
without formally codifying it. La Palombara (1964) in particular provides an elaborate description of the parentela, as opposed to a formal definition. The closest he goes to defining that network is with reference to the Italian Christian Democratic Party, as if the term is a phenomenon relatable only to that party, although it is quite clear that this is spoken in general (La Palombara 1964: 306, emphasis added):

[...] parentela involves a relatively close and integral relationship between certain associational interest groups, on the one hand, and the politically dominant Christian Democratic Party (D.C), on the other. It is this relationship between group and party - and not strictly between group and bureaucracy - which is of interest ot us. The generalized proposition we shall explore is that where parentela exists, and where certain other related conditions are met, interest groups that enjoy the relationship can exercises considerable influence over a bureaucracy quite apart from any consideration of clientela.

While his definition is based on the observation of DC and its relationship with interest groups, La Palombara (1964) states it in general terms and, to make it clearer, does so in contrast to the other network type he developed in parallel - the clientela. One difference between the two is in the venues, the parentela starts from the party in power, while the clientela in the civil service. He seems to suggest that groups in both relationships can overpower the bureaucracy, but it is the group from the parentela relationship that can cause a more significant impact, than its clientela counterpart. In any case, the idea is that the parentela stands for a situation where a group can gain privileged access in the civil service, following a party's intervention, but that idea has not been formally communicated in the form of a definition.

Yishai's definition of the parentela closely follows the writings of La Palombara (La Palombara 1964: 306 in Yishai 1994: 270; 1987: 210 in Yishai 1992: 271) and as such is equally descriptive. She too conveys the same idea of a group's privileged positioning in the civil service, following an equally privileged standing within the ruling party:

A parente is a member of one's family and is entitled thereby to special consideration and unique privileges. In modern politics, parentela involves a 
close relationship between certain associations and bureaucrats on the one hand, and the political dominant party on the other. The conditions for the development of a parentela relationship are the existence of a hegemonic party, one unchallenged by serious rivals, and its willingness to act on behalf of its kin groups. Parentela also requires that associations succeed in finding a place inside the party (La Palombara 1964, p. 306)

Similar to La Palombara above, however, her attempt at defining the parentela falls short of providing the necessary formality. Yishai above also seems to conflate the parentela definition and the causes for its formation. when she states that a parentela "involves a close relationship between certain associations [...] and the political dominant party" but later stating that part of "The conditions for the development of a parentela relationship are the existence of a hegemonic party". In any case, this literature-wide weakness has been dealt with elsewhere in section 2.3. The point is that Yishai's parentela explanation emphasises that it is a party-group relationship which allows the latter to exercise influence, or control over the civil service, thanks to its pre-existing insider-standing in the ruling party.

Greer on the other hand, presents a more formalised expression of the term, when promoting Peters' definition (in Greer 1994: 397):

Single dominant party or faction, and in which pressure groups must gain access and legitimacy through their attachment to that particular party rather than through their ability effectively to represent a sector of the society

Note, however, that La Palombara does not require party factions as part of the definition of the parentela. This is an important point, which is evidenced in chapter 7 and the case of Multigrup. Party insider status, therefore, means that a private group becomes an ally to an intra-party faction. All renditions, in short, share the idea that being an insider to the party in power, the respective interest group is in the position to influence the behaviour of the civil service in a way that reflects that group's interests.

Yet one clarification needs to be made. La Palombara emphasises above that influencing the bureaucracy in the interest of own party insiders could only be 
achieved through party political appointments, which, in the absence of a formal definition, has misleadingly implied that political appointments are also part of the parentela definition. It needs to be clarified that the parentela is essentially about political parties interfering or intervening (in his words) with the work of the civil service in the interest of a third actor, i.e. the party insider group. The lack of research into the parentela has given the impression that appointments are the only form of a party's interference with the civil service process to the interest of the party insider group. Another possible mechanism of a party's intervention in the interest of own insider is by legally codifying the criteria for groups' access to civil service consultations. Chapter 4 demonstrates how at certain periods in the past the ruling Bulgarian party was able to pass legislation that effectively rendered certain interest groups as ineligible to participate in civil service consultations. While evidence is insufficient to firmly state that chapter 4 is a case of a party interfering in the interest of own insider, it provides sufficient grounds to suggest that Bulgarian ruling parties are indeed in the position to do so.

Therefore, the way this study defines the term parentela is as follows: It is a cooperative relationship between a group with an insider status to the ruling party and/or its factions, and a ruling party, which is in the position to interfere in the bureaucratic consultative, or otherwise policy-making, process to its own party insider group's advantage. (On this note and to gain better perspective on the parentela, sections 2.4.1.-5 review a number of policy networks that differ from the parentela. Also, sections 8.5.-6. provide a typical case of the parentela, while 9.2. reports on the discovery of a new parentela dynamic, following the same logic party intervention in the interst of own, party insider.)

The only modification of the original parentela term would be to specify that this study sees groups in a much broader light. While previous studies have focused on the more tangible groups, i.e. formal representative organizations, the present study, as it will be seen later, applies the parentela to also include informal collections of a limited number of private actors acting as a single unit to collectively defend their shared interests through direct engagement with the party in power. This means that 
the non-political side in a parentela relationship in the Bulgarian case (2013-2015), may also include companies, oligarchs, businessmen and other relevant business actors who act as a single unit outside the channels of formal representation, i.e. through their respective trade association. As the final chapters of the thesis will reveal, this has the benefit of filling up the conceptual space of the grey borderline between policy-making and corruption. Because, it is naiive to believe or conceive of politics as necessarily fair game.

The literature on the parentela has so far put forward 5 prospective explanatory variables, only the first of which, however, has been tested more consistently. These are (in La Palombara 1964 accordingly):

Condition 1: hegemonic political party (p. 316);

Condition 2: party political control over the bureaucracy (p.322)

Condition 3: a group gaining privileged standing within the party (p. 331)

Condition 4: dispersed authority inside the state administration (p. 339)

Condition 5: willingness of the party to intervene in the work of the bureaucracy (p. 322);

Those conditions/Independent Variables have been promoted to explain the parentela in the literature, which are summarised in table 1:

\begin{tabular}{|c|c|c|c|c|}
\hline$\#$ & $\begin{array}{l}\text { Conditions/lndependent } \\
\text { Variables }\end{array}$ & $\begin{array}{c}\text { (Independent } \\
\text { Variable) } \\
\text { Type } \\
\end{array}$ & Metrics & Authors \\
\hline 1 & hegemonic party & binary & Present - Not present & $\begin{array}{l}\text { La Palombara (1964: 316) } \\
\text { Yishai (1992: 271) } \\
\text { Greer (1994: 410) }\end{array}$ \\
\hline 2 & $\begin{array}{l}\text { procure insider favourable } \\
\text { appointments }\end{array}$ & categorical & $\begin{array}{l}\text { Through party politic al } \\
\text { appointments (PPA) }\end{array}$ & $\begin{array}{c}\text { La Palombara (1964: 322) } \\
\text { Yishai (1992: } 278,282- \\
\text { 283) } \\
\text { Greer (1994: 410-411) }\end{array}$ \\
\hline \multirow{3}{*}{3} & \multirow{3}{*}{$\begin{array}{l}\text { Presence of Party Insider } \\
\text { Groups }\end{array}$} & \multirow{3}{*}{ categorical } & $\begin{array}{l}\text { through resource } \\
\text { exchange }\end{array}$ & La Palombara (1964: 318) \\
\hline & & & through party affiliation & Yishai (1992: 276-277) \\
\hline & & & $\begin{array}{l}\text { through shared ideology } \\
\text { w/ party }\end{array}$ & $\begin{array}{l}\text { La Palombara (1964: 331), } \\
\text { Greer (1994: 406, 411) }\end{array}$ \\
\hline 4 & $\begin{array}{l}\text { Dispersed authority inside } \\
\text { the Bureaucracy }\end{array}$ & binary & Present - Not present & La Palombara (1964: 339) \\
\hline 5 & $\begin{array}{l}\text { party's willingness to } \\
\text { intervene }\end{array}$ & binary & Present - Not present & La Palombara (1964: 322) \\
\hline
\end{tabular}

Table 1 Conditions (Independent Variables) associated with the Parentela as per La Palombara, Greer and Yishai 
The research of Greer (1994) and La Palombara (1964) seems to indicate that there is correlation between the parentela and the presence of a hegemonic party. Yishai's case study on Israel in the 1980 s, featured a hegemonic political party with no corresponding evidence of the parentela. This suggests that while hegemonic parties can contribute to a parentela formation, their attributed level of explanatory power may be exaggerated. The ascertainment of this relationship, therefore, is behind the present study on Bulgaria.

However, the present study does not see utility in adopting the rest of the items in table 1 as independent variables. Following Thatcher's call to segregate the descriptive from the causal policy network elements, the present study sees only item 1 , hegemonic party as sufficiently detached from the parentela in order to constitute an independent variable. The rest of La Palombara's conditions for the parentela formation (in darker shades) are seen to fit better in the description of the parentela, rather than its causes. There are a number of reasons for that.

First, it is not clear whether conditions 2 and 3 are external pre-requisites to the formation or features pertinent to the parentela. With condition 2 (political appointments) La Palombara makes it clear that a key feature of the parentela is the insider group being in the position to make nominations or utilise existing party appointments in the bureaucracy (1964: 306-316), yet the same practice of partypolitical appointments is also featured as a pre-condition for the formation of the parentela (La Palombara 1964: 322-331). Condition 3 (presence of a party insider group) has been operationalised in the present study as part of the description of the parentela, as it is still hard to conceptualise it as an external factor contributing to the parentela formation. The position here is that if a party has made steps towards granting insider status to a group or practicing political appointments then that is taken to mean here that the process of parentela has already begun. This study sees both concepts therefore as part of the definition of the parentela, as opposed to independent variables. 
Likewise, Greer (1994) too does not differentiate between external independent variables (i.e. conditions) and network features (Greer 1994: 410-411). The fact that the Unionist Party was hegemonic is not explicitly distinguished as an independent variable for parentela formation, although La Palombara (1964: 316-322) makes the point that it is a necessary precondition. It is noticeable also that the adherence to the conditions is a bit loose in his and Yishai's studies and no causal links are explicitly addressed involving the conditions above, particularly in the relationship between ruling hegemonic party and the insider group Ulster Farmers' Union (UFU). In a similar vein the operationalisation of the parentela by Yishai (1992) makes it hard to distinguish a parentela indicator (feature) from a parentela-forming condition. It seems this complaint has least relevance to her first indicator group strategies, which seems to be conceptually discrete from La Palombara's conditions (Yishai 1992: 275277).

La Palombara (1964) posits condition 4: bureaucratic segmentation as a possible independent variable but that concept is still wrought with complications. His argument seems to be that the Italian bureaucratic departments lacked cohesion, if left without immediate political control. The confusion also stems from the fact that La Palombara is uncertain whether bureaucratic authority is in the hands of lower level officials because those above are reluctant to review them, or simply that there is overall uncertainty as to who the relevant administrative authority is (La Palombara 1964: 342-343). It seems La Palombara implies that a fractured, or dispersed administrative hierarchical structure facilitates the parentela formation (as a catalyst intervening variable), it remains insufficiently clear (1964: 339). Even if that were the case, then another difficulty on operationalisation would be how to determine whether a present day Bulgarian civil service has the same feature of administrative fracture as 1960's Italy. At the same time this condition is not immediately connected in a causal relationship with parentela. Therefore, in light of this ambiguity and lack of identification of causal relationship that prospective independent variable was rejected from the study as inoperable. 
Furthermore, condition 5, "willingness of the party to intervene" suggests that even if the conditions are met, it is a subject to a personal choice of the politicians from the ruling party whether to establish a parentela. This line of thinking appears difficult to integrate in a classic cause-effect relationship because it is unknowable whether an action is product of free will or external stimuli. An independent variable based on free will reduces predictability. If we assume political parties act without constraint, on free will, then it becomes impossible to predict when they will decide to establish one. And again, even when they rationally decide to establish a parentela, that rationalisation would rather be the reflection of external stimuli rather than own choice. Still, the present study sees utility in employing this concept as part of the description or definition of the parentela. In fact, it is implicit in the practice of party political appointments and party political control over the bureaucracy, i.e. Condition 2. (A more detailed discussion on those is provided in Chapter 3.) This prospective independent variable requires more re-definition as, at present, it seems synonymous to the practice of political appointments in the civil service.

Only hegemonic party therefore has qualified to be operationalised as an independent variable. Overall, condition 1 above seems to have been most readily conceptualised by the three authors as an independent variable, while condition 2 has been conceptualised more as a parentela feature. While it is hard to say where La Palombara places the stress among conditions 1 to 5 , the presence of a hegemonic party nevertheless seems conceived most as an independent exogenous variable. Both Yishai (1992) and later Greer (1994) seem to follow suit in this interpretation. Yishai motivates her case selection of Israel on what was known at the time as the party state, hence, condition 1 (1992: 271). Accordingly, she refutes the proposition that hegemonic party correlates with the parentela. She finds that the Party Political Appointments (PPA) practice in Israel in 1980s was impossible given the Civil Service Law of 1958, which stipulates that appointment and promotion is strictly on merit and competition (Yishai 1992: 282-283). To the contrary, Greer (1994) seems to support La Palombara (1964: 410) in arguing that a hegemonic party causes the parentela. In both cases the parentela correlated with the presence of a hegemonic 
party: the Christian Democrats in Italy, and the Ulster Unionist Party in Northern Ireland.

Two main research questions, therefore, become obvious as a result of this discussion:

- Does the presence of a hegemonic party correlate (cause) the formation of a parentela, and if so, how?

- What other independent variables could explain or affect the parentela policy network?

In order to answer the above questions, the present study proposes one hypothesis based on preliminary observations and existing literature. Preliminary research indicated that the search for the parentela in the Bulgarian polity was warranted because features of the parentela, such as party insider groups and party political appointments, were identified in secondary qualitative data (e.g. citation?) and one pilot elite interview (Golemanov). In addition to that, the pilot study also warranted the inclusion of two other prospective independent variables that may have an effect on the parentela relationship, if it were to be confirmed: parliamentary elections and EU membership. The few informal interviews and secondary information, part of the pilot study, simply indicated that elections have the capacity to disrupt the relationship between the party and its insiders. The next section will review the basic results of the preliminary observations on the Bulgarian polity that motivated the study.

\subsection{Preliminary Observations}

Preliminary data both motivated the study and suggested a number of hypotheses, because the gathered information preceding the study suggested that the party-group relationship resembled the parentela. This hypothesis was derived on the basis of traces of existence of a network relationship between ruling political party and a privileged group; and the practice of PPAs. In addition, the hypothesis was advanced also because it is a commonly known fact that that Bulgarian party system by 2015 is competitive and absent of a hegemonic party, suggesting a need to revisit La Palombara's causal claims. 
At the time of considering Bulgaria as a case of the parentela, both media reports and sociological research indicated the presence of groups around ruling political parties that taken together resembled the parentela (Chalakov et al 2008; Raychev and Stoychev 2008; Haralanov in Georgieva 2005; Bakalov 2011; Lilov 2009, 2010a, 2010b; Iliev 2011; Vladimirova 2011a,b, "Budimir Kuyovich Testifies" 2008; “GERB Includes the Circle Capital” 2009; Raydovski 2007; Gyurova in Kostadinov 2008, 2011a,b; "Slavcho Hristov is assembling" 2011; Chalakov 2003; Chakarov in Siromahova 2009, 2010; "The Circle Capital” 2010). Political parties were reported to be in cooperative relationships with business owners or simply groups. The general impression Bulgarian media reports conveyed was that these were interest group types, which were comprised number of firms, acting as a single unit in an informal manner, as opposed to formally identifiable interest groups, e.g. trade association. They were portrayed to cooperate with ruling political parties (hence, privileged access to political parties, to begin with) and were also associated with certain civil service appointments. At the same time the high turnover of political parties indicated that the party political system was competitive and no dominant or hegemonic political party has been or was in existence at the start of the project. Finally, media reports were also rich on cases of party political appointments. All of the above suggested the hypothesis that the Bulgaria hosted a parentela despite the absence of a hegemonic political party.

\subsubsection{Traces of Party-Insider Group Network Relationships}

A number of Bulgarian sociologists writing on the party-civil society relationships before and after the regime change on 10th November 1989 argued that a number of political networks were in operation at that time (Chalakov et al 2008; Raychev and Stoychev 2008; Raychev 2003). The presence of such relationships in the past suggests that some form of party-group relationship may have remained to-date under different forms. Of greatest importance was the research of Chalakov et al (2008) and their sociological network molecule of conversion. Essentially, it is a network mechanism for the conversion of political power and access into economic capital, used by the retiring political elite immediately after the regime change in 
1989. The authors argue that this network type dissolved with the completion of the privatization in 2001 and with that the formation of the first fully independent business actors.

The authors trace the origin of the molecule of conversion in the civil service before the regime change in 1989. Accordingly they saw two big divisions in the civil service, i.e. the nomenclature: political and economic. The purpose of the economic branch was to operate with the economic assets of the state (e.g., through stateowned enterprises), while the political branch was to facilitate party's control over the bureaucracy and prevent the economic branch from political mobilisation given the resources under its control (Chalakov 2003: 110; Chalakov 2008: 51; Bundzhulov in Chalakov et al 2008: 234-6; Raychev and Stoychev 2008: 38-40). As a result each side of the nomenclature attempted to either exert or resist party political influence in the policy-making process through: appointments control (or cadre control) or through the informal policy-specific resource exchange, e.g. of expert or classified information, organisational control, or propaganda abilities, etc., (Chalakov 2008: 44-47; Bundzhulov 2003: 109; Raychev and Stoychev 2008: 36, 38). These exchanges, within the political nomenclature in particular, assumed the form of autonomous informal interpersonal networks, which fractured the entire socialist civil service and which had varying access to, and influence over, the policy-making process (Bundzhulov in Chalakov 2003: 110; Raychev and Stoychev 2008: 39). These networks were internally cohesive due to the exceptionally strong influence of patriarchalism, which translated itself in very strong loyalties to the family, the region, friends, select colleagues (Bundzhulov 2008: 44; 233; 236; 239). Even the formal operation of the nomenclature was impeded by these loyalties (Bundzhulov 2008: 234).

With the regime change of 1989 however, the nomenclature networks had to reform. Chalakov (2008: 45) explains that thanks to their experience in (quasi-)economic dynamics, the economic nomenclature had the technical knowledge to compete in the capitalist order than their political counterpart. However, as the latter still had an overwhelming ability to appoint and remove from office, they subjugated the 
economic nomenclature networks (Chalakov 2008: 45-48). As a result, the network members of the hitherto political nomenklatura, who temporarily retained their general policy-making positioning after the regime change as members of any of the nascent political parties, began to exploit that positioning by converting their decreasing state administration and policy-making access by privileging the businesses they acquired through the privatization process over which they exercised political control (Bundzhulov 2008: 209-210; 240-241, 249-250, 253-265, 260, 738; Chalakov 2008: 495; Hristov 2008: 63-116; Raychev and Stoychev 2008: 8, 10-13, 41-46).

Therefore, the process of conversion of political access into economic ownership and the privileging of such businesses in policy-making, is labelled by Chalakov et al as the process of conversion and the totality of actors connected in such network dynamics - molecule of conversion (Chalakov et al 2008: 258, 260; 280-281, 288289). The generic actors in such networks that facilitated the conversion were: politicians, businessmen, actors with media/PR resources and, for some time, agents from the former intelligence services (Raychev and Stoychev 2008: 83-84; Bundzhulov in Chalakov et al 2008: 258).

For example, as early as December 1991, the party-protected networks began to take control of the larger economic sectors of the economy by procuring deliberate legislative and administrative changes that relaxed the stringency of the procedures governing the state assets privatisation process (Chalakov et al 2008: 270-287; ff. 147; 295-304, 306, 309, 318-329, 341; Raychev and Stoychev 2008: 39). This process is also illustrated by the personal observation of Kostadin Chakarov - the last adviser to the Chairman of Bulgarian Communist Party comrade Todor Zhivkov regarding Andrey Lukanov, Bulgaria's first prime minister, months after the regime change (Chakarov 2010: 236-239, quotations of translations from Bulgarian will be in italics):

[...] From dawn till dusk he was visiting banks [...] editorials, firms, etc. He was lobbying for some, he was hindering others, and he 
secured credits for some, but blocked credit lines for others. [...] And all that happened behind the back of the party (BSP, sic).

The account of Chakarov exemplifies how hitherto highest ranking civil servants of the nomenclature, like Lukanov, sought to exploit their personal access to state administration resources and selectively promoted certain businesses. The implication here is that - as with the parentela - there was a form of close cooperation between the party political leader and the business actor.

As a network structure that shares features of the parentela, the molecule of conversion warrants the presence of the parentela because of its inherent party-group dynamic and the fact that sociologists are not certain of its complete dissolution. This type of politically dominated party-business relationship, as exhibited by Lukanov, Bundzhulov (2008: 210-211) argues was adopted by all governments to varying degree until the 2001 government of Simeon II Saxe-Coburg-Gotha, when a process of emancipation took place and party-controlled businesses wrested freedom from political patrons (Chalakov et al 2008: 261- 262): "[...] through delegation the emancipated breaks free from his patrons, emancipates and opposes them". Yet, Chalakov reports as of 2008 the observation that there are network formation between political parties and the now emancipated businesses, which according to him posits the question whether the molecule has ceased or whether there is a completely new network type. Although he is not explicit, his inquiry clearly implied that the new network in question was the so called in Bulgaria krag (circle) or its synonym obrach (ring) (or policy circles collectively) (in Chalakov et al. 2008: 737, 738).

The policy circles, or the circle in particular denotes a network type which is very similar to the parentela as reportedly, it represents the symbiotic relationship between the ruling political party and a privileged interest group, which usually is a single business of large proportions. The coinage of the term circle is attributed to former Prime Minister Mr Zhan Videnov who attempted to describe the proximity of certain party members to large-scale business actors as: "[...] one friendly circle among a number of people" (Iliev 2011). According to Gyurova, however, his was a 
reiteration of an earlier idea made by Andrey Lukanov arguing that certain forms of party-business cooperation no longer take the form of a holding company but have merely devolved to direct, interpersonal business partnership (Gyurova in Kostadinov 2008). Regardless, historically, every such circle has had a name given to it by the media or the public. The name "Orion" was given to the circle Mr Iliev, Mr Videnov and Ms Gyurova refer to above. Overall, similar to the parentela, the policy circles are associated with business actors with privilege access to the party in power, who are also in the position to make nominations for civil service appointment.

To give a sense of scale of the circles phenomenon, see table 2 below, where there are approximately 12 known circles in circulation in Bulgarian media as of 2013:

\begin{tabular}{|c|c|c|c|}
\hline \multirow{2}{*}{ NR } & \multicolumn{3}{|c|}{ Popular Circles in Bulgaria } \\
\cline { 2 - 4 } & English & Phonetic & Bulgarian \\
\hline 1 & Admiral & Admiral & Адмирал \\
\hline 2 & Bankya & Bankya & Банкя \\
\hline 3 & Capital & Kapital & Капитал \\
\hline 4 & Empire & Imperiya & Империя \\
\hline 5 & Global Bulgaria & $\begin{array}{c}\text { Globalna } \\
\text { Balgariya }\end{array}$ & $\begin{array}{c}\text { Глобална } \\
\text { Бьлгария }\end{array}$ \\
\hline 6 & Helios & Helios & Хелиос \\
\hline 7 & Monterey & Monterey & Монтерей \\
\hline 8 & Olympus & Olimp & Олимп \\
\hline 9 & Orion & Orion & Орион \\
\hline 10 & Sapphier-Diamond & Sapfir-Elmaz & $\begin{array}{c}\text { Сапфир- } \\
\text { Елмаз }\end{array}$ \\
\hline 11 & The Blissful & Blazhenite & Блажените \\
\hline 12 & Tomcats & Kotaratsite & Котараците \\
\hline
\end{tabular}

Table 2 Popular Circles in Bulgaria at the start of the project (2013)

Most names come from restaurants or hotels where influential members would frequently met. The numbering in table 2 above is in the alphabetical order of the English translation. The table is not exhaustive, but illustrates the breadth of the phenomenon. It was compiled using the google search engine and the search-phrase 
“кръг X” without initiating a search query, where X stands for all letters in the Cyrillic alphabet. The point of not initiating a search query is that the search engine automatically suggests a completion of the search term, based on already existing searches from other users online. The above table 2 is based on an initial search in 2013. In 2015, the engine additionally suggests the circles Lamb Heads and the Apostles.

The rings, too are synonymous to the parentela and the circles above. In 2005 Akhmed Dogan, then leader of the party DPS (Dvizhenie za Prava i Svobodi, Movement for Rights and Freedoms), introduced the term ring:

[e]very party has [...] a ring of firms... If you think that my capabilities are lesser than those of a banker then you do not have a real idea of the capabilities of a politician. In the last 15 years surely half of the businessmen who are doing above average are [doing so]... either with my support, or at least due to my smile.

In his honest addressal, Mr Dogan also conveys the same image as the circles, where any business actor's only hope for success is through close cooperation with the party in power. The quotation implies a cooperative relationship between the ruling party and a privileged business actor (or group), where the former will employ its control over the executive branch in order to facilitate the success of the latter. Both the ring and circle clearly overlap as they both represent a symbiotic relationship between the political party and a select business actor.

Bundzhulov (in Chalakov et al 2008: 731-736), however, argues that there is a distinction between the two terms, although such a distinction seems forced at this stage. He seems to draw the line between circles as symbiotic model at a central governmental level between a group and the ruling party and the ring as a likewise party-group symbiosis but on a local level, designed to give a local business a friendly push:

Between the ring of firms from the type of Orion and from the type of Olimp there is fundamental difference, because the circle Olimp is a project for taking over the entire economy or at least large parts of it [...] while the ring of firms, as Dogan says is rather a local-based formation 
[...] they (Dogan's rings, sic) are not monopolists. They are with different weight, with different intensity but they fight among themselves. The problem is that with all of these rings there is symbiosis, and there is no way for us to distinguish business and politics [...] but this is not some oligarchic circle, which commands the entire state

The distinction seems exaggerated without additional research. The notion of central vs local level arrangements seems forced. A difference based on geographical locality is meaningless, because larger business actors have offices in the municipalities, as well. For the most part, any negotiations with the ruling party will have local effects. As chapters 8 and 9 demonstrate, the administrative measures taken by party insiders to push their competitors aside are not limited geographically. A difference based on administrative locality, or that rings are in a symbiotic relationship with the local administration is also meaningless, because even then, any negotiations, as Mr Dogan, speaking as the leader of the DPS above declares, are ultimately of interest to the central party leadership. This is reinforced in a second key voter addressal in the next subsection, where he publicly states that the financing of local EU-related projects is determined politically by himself, i.e. the DPS (Dvizhenie za Prava i Svobodi) party leadership.

Ultimately, however, both terms share a great resemblance of the parentela. They depict private actors with a privileged standing within the ruling party (regardless of local or central level) and following the parentela, there is some form of mutual exchange, or cooperation. Furthermore, another overlap of the policy circles with the parentela is that political appointments are also part of these party-group dynamics. While this is a plausible assumption in this subsection, this is discussed at length in the following one, 1.3.2.

\subsubsection{Party Political Appointments}

In fact, the social scientists above are not the only ones interested in the circles. While they emphasise the party insider status of businesses the media narrative on the subject indicates the importance of party political appointments to policy circles. That is another key similarity with the parentela. The investigative journalists Lilov (2009, $2010 \mathrm{a}, \mathrm{b})$ and Bakalov (2011) indicate cases of organised businesses that seek 
to procure favourable appointments in the state administration with the help of political parties in power. For example, Lilov argues that the Bulgarian premier Borisov owes his premiership to his subservience to the circle Monterey (2009: 287). Though warning against grossly overstating their influence (2010: 230; 237), Bakalov also confirms the presence of policy circles: businesses in close symbiotic relationship with political parties in power, however, heavily relying on party's control over the state bureaucracy (2011: 120, 170-222). Similar to Monterey, the circle Capital has been reported in the media as responsible for the deposition of a close economic adviser to the premier Borisov (Paramov 2010) and also as backing a number of other possible political appointments in the state administration (Vladimirova 2011; “The Circle Capital” 2010; vsekiden.com 2009; Raydovski in Kostadinov 2007).

The rings too share a similarity with the parentela in that they clearly involve securing favourable appointments in the state administration. At a rallying event for the 2009 parliamentary elections, Mr Dogan also explains that the party control over the state administration is of utmost importance to the party in power, because it is through its control over the state administration that a political party can coerce or help businesses (Dogan 2008):

I am the instrument of power, which divides the portions of financing in the state [...] this regards the financing and the execution of your projects [under EU programmes ...] And when we want a more powerful presence in parliament, this means that we want a broader positioning [...] in the executive branch. [For example,] like her, [who] is the chief of the State Fund for Agriculture, ministers, viceministers $[. .$.

In other words, the relationship Mr Dogan describes fits the parentela. If someone wants financing for their project under an EU program, they first have to seek access to Mr Dogan, i.e. the party leadership of DPS. In turn, Mr Dogan, or the party leadership, will ensure that the respective project will receive due attention because DPS had already appointed the right person as a chief of the Fund for Agriculture. 
Implicitly, the political appointment here implies that those who seek the cooperation of DPS will have their projects taken with priority over others.

At the pilot stage, when the task was to determine whether the parentela concept might have analytical power in Bulgarian circumstances, one elite pilot interview with a former high ranking party functionary and civil servant was conducted. Its results also indicated parentela-like relationships of groups with insider access to political parties and using that as spring board to gain access to the civil service using party political appointments. The full significance of this interview is evident in the last chapters where Golemanov outlines the dynamic where every new incumbent party removes from office all appointees of the previous party and instils own. The significance of that is that it allows the new party to establish political control over all departments which could be activated in the pursuit of purely party interests that on occasion may coincide with those of groups with insider party access. It was inescapable, therefore, that the overall description of the party-group relationship found in Bulgaria, prior the study resembled the parentela.

The previous section, showed strong indications that the parentela existed in Bulgaria, in the absence of a hegemonic party. Therefore, the study hypothesises that:

- In agreement with Yishai (1992) the absence of a hegemonic party has no effect on the formation of a parentela. Stated positively, preliminary data suggests that the presence of a hegemonic party does not explain the formation of the parentela.

In addition, in order to establish other independent variables that might have an effect on the parentela, the study focuses on parliamentary elections and Bulgaria joining $E U$ because the former was indicated by the pilot study (Golemanov in particular) while the latter was a major event in Bulgarian political history. Looking at parliamentary elections is warranted also particularly in the absence of a hegemonic political party. This is discussed in section 1.3.3. 


\subsubsection{Absence of a Party Hegemon}

On $10^{\text {th }}$ November, 1989, Bulgaria changed its political regime from totalitarian socialism to capitalist democracy. Since then, the Bulgarian party political system has been competitive, i.e. absent of a hegemonic political party, evidenced by the variety of governments that have been in power by 2015 :

\begin{tabular}{|c|c|c|c|}
\hline \multirow[b]{2}{*}{ PREMIER } & \multicolumn{2}{|c|}{ TENURE } & \multirow{2}{*}{ POLITICAL PARTY } \\
\hline & FROM & $\mathrm{TO}$ & \\
\hline Andrey Lukanov & 10 November 1989 & 20 December 1990 & $\mathrm{BSP}$ \\
\hline Dimitar Popov & 20 December 1991 & 08 November 1991 & BZNS \\
\hline Philip Dimitrov & 08 November 1991 & 30 December 1992 & SDS \\
\hline Lyuben Berov & 30 December 1992 & 17 October 1994 & $\begin{array}{c}\text { Non-Party Care-taker } \\
\text { government }\end{array}$ \\
\hline Reneta Indzhova & 17 October 1994 & 25 January 1995 & $\begin{array}{c}\text { Non-Party Care-taker } \\
\text { government }\end{array}$ \\
\hline Zhan Videnov & 25 January 1995 & 13 February 1997 & $\mathrm{BSP}, \mathrm{BZNS}$ \\
\hline Stefan Sofianski & 13 February 1997 & 21 May 1997 & SDS \\
\hline Ivan Kostov & 21 May 1997 & 24 July 2001 & SDS \\
\hline $\begin{array}{c}\text { Simeon Sakskobburg- } \\
\text { Gotha }\end{array}$ & 24 July 2001 & 17 August 2005 & NDSV \\
\hline Sergei Stanishev & 17 August 2005 & 27 July 2009 & $\begin{array}{l}\text { BSP, NDSV, DPS (Tripartite } \\
\text { Coalition) }\end{array}$ \\
\hline Boyko Borisov & 27 July 2009 & 13 March 2013 & GERB \\
\hline Marin Raikov & 13 March 2013 & 29 May 2013 & $\begin{array}{c}\text { Non-Party Care-taker } \\
\text { government }\end{array}$ \\
\hline Plamen Oresharski & 29 May 2013 & 06 August 2014 & BSP,DPS \\
\hline Georgi Bliznashki & 06 August 2014 & 07 November 2014 & $\begin{array}{c}\text { Non-Party Care-taker } \\
\text { government }\end{array}$ \\
\hline Boyko Borisov & 07 November 2014 & incumbent & GERB, ABV, RB, PF \\
\hline
\end{tabular}

\begin{tabular}{|c|l|}
\hline \multicolumn{2}{|c|}{ Legend } \\
\hline ABV & Alternative for Bulgarian Enlightenment \\
\hline DPS & Movement for Rights and Freedoms \\
\hline BZNS & Bulgarian Agrarian People's Union \\
\hline GERB & Citizens for European Development of Bulgaria \\
\hline SDS & Union of Democratic Forces \\
\hline RB & Reform Bloc (splinter parties from SDS) \\
\hline BSP & Bulgarian Socialist Party \\
\hline NDSV & National Movement for Simeon the Second \\
\hline PF & Patriotic Front \\
\hline
\end{tabular}

\section{Table 3 Bulgarian Governments to-date}

Again, the table above clearly shows that the Bulgarian party system is highly competitive and absent of a hegemon. Yet, in the event that the parentela existed, it was also interesting to see as an independent variable whether and how the party 
change affected an insider group's parentela relationship with ruling political parties - if any.

\subsection{Conclusion and Thesis Outline}

The purpose of the present study is to establish whether the relationship between the civil service, interest groups and the party in power in Bulgaria conforms to the parentela policy network type. This is in response to the relative academic disuse the term seems to have fallen into. This policy network type has not been found in existence since 1960s, other than in Northern Ireland up until the 1970s (Greer 1994). At the same time, it may also have explanatory power for the Bulgarian public, because both the local phenomena known as circles or rings share great resemblance with this term. At the same time the study is also geared towards establishing the internal and external causal relationships the parentela might be involved in. More specifically, to ascertain whether the absence of hegemonic parties hampers parentela's development or there are other external factors that account for that network's emergence?

To that end the Bulgarian polity was selected on the basis of preliminary research of secondary sources and one pilot elite interview, which suggested that the parentela dynamics existed in Bulgaria. The pilot study indicated key parentela characteristics in the absence of a hegemonic party, such as insider groups and the practice of party political appointments. On the Bulgarian polity was therefore selected to further test the hypothesis that the parentela forms without the input of hegemonic political parties.

The results indicate that the parentela can exist in the absence of a hegemonic political party. Firms from the currently flagging construction sector in Bulgaria seek the cooperation of ruling parties in order to gain market advantage vis-a-vis their competition. At the same time, ruling parties seeks to exchange access to policymaking with groups who possess campaign resources. The crossing point of both actors lays the foundations of the parentela. Once the exchange is set up, it is through the political appointments that the ruling party ensures insider's market advantage. In 
the case of the construction sector in Bulgaria (Chapter 8) in particular, this translates in the preferential treatment of insider firms in the award of public tenders.

However, gaining market advantage can also be achieved more aggressively. Chapter 9 discusses at length the discovery of a new policy network dynamic, part of La Palombara's parentela. In light of that discovery, the present Bulgarian study sees La Palombara's original parentela dynamic as type 1, while this new dynamic as type 2 . So, if La Palombara's type 1 concerned the cooperative and power-balanced relationship between a party insider and the party in power (or the parente collectively), type 2 parentela is about the conflict between an outsider group (business) and the parente. This is manifested in the parente mobilising political appointees in the civil service to conduct excessive and prejudiced inspections against businesses that compete on the market with the party insiders. The same practice is also reported with regards to political parties alone, who resort to type 2 dynamics in order to extract additional campaign funds.

An important factor in both type 1 and 2, or the extended parentela (collectively), is the practice of party political appointments. In both cases, they act as an enabling factor, or an intervening variable (9.3.5). Neither parentela dynamic would be functional unless facilitated by PPAs. Nevertheless, the presence of political appointments alone does not explain any of the parentela dynamics. This intervening variable, therefore, is seen here as the most important variable for the sustenance of the parentela and if disabled, that is political appointments are prohibited, both parentela types will be greatly deterred.

In addition, two other external variables had an effect on the parentela. Parliamentary elections for example introduce an external shock to the existing parentela arrangements (chapter 7, 9.52, 9.5.3). With a new party in power insider groups have to re-negotiate their continued privileged status. This may not always be possible. As a result, some groups, like Multigrup (Chapter 7) opt for a pre-emptive strategy of establishing good relations with all relevant political parties, including the 
opposition. Though costly, this strategy minimises the risks of losing access with the change of government.

Membership in the EU is another external variable with potential effect on the parentela relationship (9.6). Many respondents spoke favourably of Bulgaria's EU membership. Overall the indication is that at present Bulgarian politicians are dependent on EU's positive review of their tenure, and will react accordingly. However, that is not enough to have a significant impact on the parentela. The results suggest that EU institutions can have a real impact only if there are coercive institutional mechanisms in place that could penalise or disable certain party political behaviour. Therefore, this is an external variable with potential effect on the partygroup relationship.

However, establishing those causal relationships is not straightforward. The main methodological challenge is to devise a common classificatory scheme of policy networks and to establish a pool of elite respondents that is comparable, if not better, than that of La Palombara's. The former objective enables comparisons across cases, and, ideally, discrete policy network types and ensures against false novelty. The development of such a classificatory scheme is elaborated in the next chapter 2 . The chapter proposes a system of classifying policy networks according to a number of features. However, it should be noted that while the classification seeks to encompass all known major policy networks to-date, a specific feature of the parentela are party political appointments.

Chapter 3 addresses the second methodological objective: to devise a comparable pool of respondents to that of La Palombara. This enables direct comparability of the results between the two studies. However, the main challenge here was to overcome posed by elite respondents who were both reluctant and resistant to conduct interviews. This challenge was met with the invitation of intermediaries. This is a new type of research participant. Their primary role is to introduce the researcher to the respondent and vouch for former's credibility. It is their involvement at interviews that secured respondents' cooperation and full participation. This 
approach to elite interviews was reported in an article published recently at Qualitative Research, July 2015 (Petkov and Kaoullas 2015).

Later chapters are dedicated to the results. Chapters 4 through 7 are dedicated to the features that constitute the parentela. Chapter 2 will define the parentela as a collection of five characteristics, the existence of which is revealed in chapters 4 to 6 inclusive. These are: cooperation, power parity, presence of a privileged group with the party in power, the party is an effective policy-venue, the party intervenes in the civil service (venue scope, chapter 2).

Chapter 4 demonstrates that the party in power provides an effective route to policy making and with that has the potential to host a parentela. It argues that if the parentela is to exist, then there has to be an indication that groups find that route to policy-making effective, which is what the chapter demonstrates. Evidence suggests that the party is more effective in comparison to the civil service.

Chapter 5 is dedicated to the practice of party political appointments. The purpose is to illustrate the breadth of that practice and show that this functional feature of the parentela there. This chapter argues that party political appointments are greatly prevalent. It reviews the research of relevant authors and corroborates it. It also provides additional legal analysis of the actual process of appointments. Its main contribution however is the argument that political appointments follow from the high level of political distrust in the policy-making process. As a result, political parties interfere in the civil service through political appointments.

Chapter 6 argues that the remainder of the parentela traits are also present in the party-group relationship: that the party provides insider access to groups; that there is cooperation between insider groups and ruling parties; and finally, that neither side seeks to overpower the other. The argument is also that while cooperation is visibly part of the process of granting insider access, that in turn implies that there is a power-balance between the two sides. Furthermore, the chapter reveals that the 
dominant mechanism under which insider status is granted is the exchange of campaign resources (group) against access to policy-making (ruling party).

Chapter 7 addresses one limitation of the research: there is absence of a clearly defined profile of the group that partners the ruling party in a parentela relationship. Earlier parentela research, e.g. of La Palombara and Greer, was clearly focused on the partnership of political parties with clearly defined monolithic representative bodies: Catholic Action (Italy) and Ulster Farmers' Union (Northern Ireland). The available data in the Bulgarian case does not indicate the presence of any such bodies which at the time of research were in a clear parentela relationship. It seems that a larger number of firms (groups) engage in a parentela, even if access tends to be exclusive. Still, despite being able to clearly pin-point a specific actor, the chapter reviews several private actor types that can engage in a parentela: oligarchs, circles (e.g. Orion from above) and single large companies such as Multigrup. That chapter also provides a brief case study of the relationship of Multigrup vis-a-vis DPS, and its conflict with the circle Orion within the Bulgarian Socialist Party (BSP), in particular. Both actors established respective parentelas within BSP at the time and vied against each other for more influence on the contents of the Law on Protection of Agricultural Workers (LPAW). That legislative draft proposed that agricultural subsidies be provided to farmers under the forms of specialised loans, which were to be distributed by a private bank and the funds for those loans, to be provided by the state-controlled Agricultural Fund. Multigrup and Orion each sponsored a bank which was close to their own economic structures and wanted to see it become the partner of the Agricultural Fund.

Chapter 8 looks at the case of the Law on Public Tenders and public tenders in the construction sector. It traces the process of parentela operation and how insider groups receive preferential treatment through ruling party's intervention in the civil service. The main argument is that the main causes for the parentela formation are groups seeking improved market standing combined with political parties searching for campaign funds. In short, chapter 8 reveals a typical case of La Palombara's parentela overlapping with its dynamics. The only differences (elaborated in 9.2, 
9.3.5 and 9.4) are that La Palombara's parentela manifests itself in non-policymaking setting and without the involvement of single, sector-wide interest groups. Instead, it is observed in the case of public tenders (or procurement contracting) encompassing the relationships between the ruling party with single, relatively big companies or single "oligarchs" who work in concert to procure own interests.

As already mentioned above, chapter 9 is dedicated to the discovery of a new parentela dynamic, which transpired from the elite interviews. Defined as type 2 parentela dynamic (or simply type 2 parentela), the chapter argues that the parentela features another relationship: between the parente and outsiders. Type 2 parentela dynamics essentially stands for the practice of prejudiced regulatory inspections whose aim is to sabotage the normal operation of a target business, using primarily, tax investigations, rescission of licenses of operation, police raids, account freezes, litigation, etc. It is part of the parentela because the dynamics originate from the same nucleus, namely, the party and its insider group, or the parente. While La Palombara focused on the relations within the parente (type 1), the newly discovered dynamics shed light on the relations outside of it. That is between the parentela core and their collective collective (political and business) rivals. In this conflict, the parente uses type 2 dynamics as an implement of opponent elimination (9.2-9.4.). For instance, the businesses that comprise a dissenting party faction or owned by a party functionary could be put up for inspection until proven guilty of misconduct. Or likewise, firms that are members of a government-opposing interest group could be subjected to the same prejudiced regulatory pressure.Finally, instead of favourable political appointments, a party insider could request that the party interferes in the administration and thus instigate prejudiced inspections. Type 2, therefore, is the result of the intersection of the interests of the party and its insider group. The party may engage in type 2 forced by the need to convert political access into business capital (extortion, 9.3.1), desire to quell internal party dissent (9.3.3) or suppres external group opposition (9.3.4). A party insider on the other hand could be motivated to engage in type 2 relations by the need to expand its market share, say in a declining market (chapters 8 and 9). 


\section{CHAPTER 2: Parentela Operationalisation}

\subsection{Introduction}

Chapter 1 introduced the concept of the parentela, defining it as type of party-group relationship, where the ruling party grants privileged (insider) access to a given interest group. Once having assumed an insider status the group could then influence the policy-making process in the civil service by utilising existing or nominating new party political appointments. The present chapter will explain how this concept is operationalised in the present study.

The most important point about the parentela is that it is a type of a policy network. This means that the definition of the parentela must not overlap either with the generic term policy network or any other policy network types. The way this is done in the present study is by developing a system of policy network classification, based on previous attempts in the literature to do so. The purpose of this categorisation is to define all policy network types following the same rules. There are policy network types have to be defined with reference to the same set of generic features that are accepted by the literature as most important when discussing the relationship between interest groups and policy-makers.

This is why, the classificatory system developed here consists of policy network descriptors. A network descriptor (or network feature) is a qualitative indicator that denotes a particular characteristic of a group's relationship with the relevant policy makers for a given policy-making location (venue, e.g. party, civil service, parliament and media). The present study utilises the following qualitative indicators or descriptors such as degree of access, power ratio, type of interaction, primary policy venue and policy venue scope. Each of these descriptors is a binary, ordinal or of multi-select type, and represents each of the five most important aspects of the relationship between an interest group and policy makers. The combination of descriptor values therefore helps both to define and differentiate individual network 
types. In developing said network typology, the chapter develops a generic policy network definition which accommodates all of the more prominent policy network types and overlaps with none of them.

The proposed policy network definition, therefore opposes the policy network definition currently employed in the literature, which specifies that a policy network is a cooperative, exchange-based relationship, because this overlaps with some of the already known network types (iron triangles) and excludes others that harbour conflict (issue networks). This is a weakness in the literature, which is also addressed in connection with the policy network classification.

The chapter is organised in the following way: Section 2.2 differentiates the generic term policy network from its categories, i.e. policy network types. Section 2.3 defines the policy network descriptors implemented in the present study. Section 2.4 applies the policy network descriptors to the policy network types (2.4.1-5), developing therefore a policy-network classification system, discussed as a whole in section 2.4.6.

\subsection{Defining the Parentela Policy Network}

There are a number of policy networks in existence, but because they have not been developed in an immediate comparison with each other, there is a degree of confusion as to the distinctiveness of each from the rest, and from the generic term policy network. The present section is dedicated to disentangling the generic concept of policy network from its categories. The next sections, 2.3 and 2.4 are dedicated to distinguishing each policy network type (category) from the others.

The literature has already acknowledged the need for a formal policy network classification. Jordan and Schubert (1992: 11-12), and van Waarden (1992) argue that policy network proliferation requires the policy network classification and the differentiation between the generic policy network and its categories (also Pappi and Henning 1998, Rhodes and Marsh 1992, Peterson 2003). 
A cursory review of some of the more prevalent policy network types and policy network definition shows that there still is a degree of insufficient definitional discreteness between: the generic term network and its purported types; and between each of the network types. Generic definitions tend to describe policy networks as cooperative, exchange-based relationships between groups and policy-makers. On the one hand this overlaps with a number of policy network types, such as policy community, iron triangle and the clientela (Ripley and Franklin 1987: 8; Jordan 1990: 319-320, 322, 324; Richardson and Jordan 1979: 98; 101-105, also Hay 1998). At the same time such a formulation makes it impossible for the policy network type issue network to classify as a policy network type, because it lacks those two features. It is described as a conflictual relationship between a large number of state and non-state actors over policy contents, and by implication, absent from exchange. Such networks could be observed at mass protests, public stunts, angry media appearances, etc. (Heclo 1978; Richardson 2000; Gais et al 1984).

Let us quickly review some of the more prominent generic policy network definitions and then observe later how they come to exclude the issue network as a policy-network type. Observe Rhodes and Marsh's adoption of Benson's definition (quoted in Rhodes and Marsh 1992: 13):

a cluster or complex of organizations connected to each other by resource dependencies and distinguished from other clusters or complexes by breaks in the structure of resource dependencies.

The definition suggests that a pre-condition for, or a constitutive feature of a policy network, is the exchange-based relationship between the public/private actors, codified above as resource dependency. Similar phraseology is also evident in Kenis and Schneider's 1989 policy network definition (in Jordan and Schubert 1992: 12):

A policy network is described by its actors, their linkages and its boundary. It includes a relatively stable set of mainly public and private corporate actors. The linkages between the actors serve as channels for communication and for the exchange of information, expertise, trust and other policy resources. The boundary of a given policy network is not in the first place determined by formal institutions but results from a 
process of mutual recognition dependent of functional relevance and structural embeddedness (1989: 14).

Note again that the stress is on the exchange network feature. Compared to one another, both network-generic definitions above stress that the public and private actors, engaged in policy negotiation, are mutually dependent on resources. The difference between the two appears in the scope of resources used in the Kenis/Schneider definition above.

There is another of the more common definitions of policy network is promoted by Borzel (1998: 254) and adopted more recently by Compston (2009: 7):

a minimal or lowest common denominator definition of a policy network, as a set of relatively stable relationships which are of non-hierarchical and interdependent nature linking a variety of actors, who share common interests with regard to a policy and who exchange resources to pursue these shared interests acknowledging that co-operation is the best way to achieve common goals.

Compared to the Benson's, and Kenis and Schneider's definitions above, hers too, suggests that a necessary prerequisite for a policy network is the exchange-based relationship. However, the difference here is that it introduces the second consitutive network-feature, cooperation. According to Borzel, not only are policy networks by definition cooperative but also exchange-based state-group relations.

Such a conflation of the policy network term with the idea of cooperation is very much due to the predominant incidence of cooperative network types and the ambiguity inherent in the policy network literature. Such a conflation of the policy network definition with cooperation and exchange has the effect of contradicting and excluding certain policy network types. In other words, the overarching term overlaps with some of its types, while excluding others from the typology. For example, as stated above, the policy network notion overlaps with the policy community/iron triangle network types. Not only is it difficult to differentiate between the two, cooperation and exchange are at the core of those networks, but it 
makes matters worse when those networks' respective definitions overlap with the term they are supposed to descend from.

Furthermore, specifying that policy networks are by definition exchange- and cooperation-based contradicts with other nown network types, such as the issue network. As it will be seen later, these are networks with conflictual dynamcs, lacking resource exchange. Given the general definition, therefore, issue networks are not a policy network type (2.4.4.). At the heart of this term is the observation that certain policies are the product of a massive social conflict played out by coalitions of actors who oppose each other. The conflict spans from the public realm to the institutions of government, including politicians, civil servants, NGO leaders, scietists, journalists, etc. The point is that this is different if not the opposite of the policy network term definition revealed above.

That is why it is necessary to distinguish a truly neutral generic policy network definition that simultaneously differentiates itself from its categories. Part of the solution, therefore, is to adopt Hanf's definition above that:

the term 'network' merely denotes $[. .$.$] that policy making includes a large$ number of public and private actors from different levels and functional areas of government and society.

But one also has to include at the very end: and their relationship formats. This addition, advocated by the present author, denotes that a policy network is essentially a relationship between groups and policy makers. Therefore, a specific relationship format is equivalent to a specific policy network type. This is an echo in agreement to Dowding's conceptualisation that 'Networks are distinguished one from another by the relations between the actors' (Dowding 1995: 152). A relationship format in turn is a specific relationship feature, e.g. conflict, cooperation, overpowerment, etc. Therefore, policy network types are about the combination of specific relationship features between groups and policy-makers. The following section is dedicated to a policy network classificatory scheme, based on the more common network descriptors (features) discussed in the literature and operationalized in this study. 


\subsection{Policy Network Descriptors}

The purpose of the present section (2.3) is to operationalise the different policynetwork types on the basis of the different features in the relationship between the group and policy-makers discussed in section 2.2. The features of the policy-making relationships are operationalised here as policy network descriptors. A network descriptor is a quantitative or qualitative indicator, which expresses a state-group relationship characteristic (feature). A policy network type is the discrete combination of descriptor values. This means that policy network classification rests on the discrete value combinations of a pre-defined set of descriptors.

There are several challenges associated with network descriptors at this stage. First is: which descriptors will serve as the basis for comparison? The literature has yet to agree on such a set (Atkinson and Coleman 1989; van Waarden 1992; Rhodes and Marsh 1992; Jordan and Schubert 1992; Adam and Kriesi 2007). Jordan is one of the first to explicitly alert for the necessity to find a commonly shared descriptors so to differentiate between types of policy networks (1990: 329; Jordan and Schubert 1992: 14-15, 18, 24; Rhodes and Marsh 1992: 191). Van Waarden (1992: 49) also complains about the insufficient effort authors exert to distinguish their allegedly novel policy network types from the pool of already existing ones.

One example of such a necessity are Wilks and Wright who introduced a new policy network type and in doing so redefined the term policy community (in Jordan 1990: 334-335). As a result, for reasons of disjointedness with pre-existing network literature and non-justified re-definition of the established terminology, Marsh and Rhodes supported Jordan above in rejecting any such claims of novelty (Marsh and Rhodes 1992: 186). Novelty claims, therefore, will be better justified and warranted in the presence of a clear policy network classification system.

The second major difficulty is whether network descriptors could be expressed quantitatively. Jordan and Schubert (1992) stress the importance of establishing network dimensions (or descriptors herein) that lend themselves to empirical scrutiny 
and operationalisation, implying quantification. More specifically, serving the Atkinson/Coleman table (p. 39) as an example, they argue if networks are defined on the grounds of highly disputable, immeasurable features, classification becomes impossible (Jordan and Schubert 1992: 18; also on quantification Borzel 1998). As a result, Jordan and Schubert (1992) seem to suggest that quantification is the way forward.

In fact, the absence of policy network quantification is seen by Dowding (1995, 2001: 93) and Thatcher (1998) as the very weakness of the policy-network literature (also Peters 1998, Marsh and Smith 2000). Both authors advocate the transposition of quantitative indicators from Sociological Network Analysis (SNA) into the policy network literature. This is a quantitative approach to studying networks in policymaking adopted by sociologists (Thatcher 1998; Dowding 1995). Borzel sees the policy network literature as divided between the Continental borderline sociological/political scientists, who adopt quantitative methods to study policy networks, and the Anglo-Saxon/British branch, based on observations on policymaking in UK, US, Holland, France, Italy, which at the time of her writing was primarily qualitative (1998). Dowding (1995; 2001), Thatcher (1998) and Borzel (1998) suggest that the British branch of the policy network literature should adopt the indicators used by the Continental branch. (Unless stated otherwise, the present study is nested in the British/Anglo-Saxon branch of the policy-network literature.)

Furthermore, in agreement with Jordan and Schubert (1992), Dowding (1995, 2001) and Thatcher (1998) argue that quantification will lead to a precise and discrete policy network classification and ability to introduce causality in the policy-making models. However, both authors are mute on the question of how far the borrowed SNA quantitative indicators would match the descriptions developed in the AngloSaxon policy network literature. The SNA indicators are conceptually removed from the observations on the UK/US/ITA policy-making which the different policy network types sought to summarise. In fact Thatcher acknowledges that the main weakness of the interorganizational (sociological) network approach (SNA, essentially) is the inconsistency with which a policy network had been defined by 
respective researchers (1998: 400-402). This means that there is an already present mismatch within the SNA literature of term's definition, types and indicators. A conversion stage is necessary where network descriptors are distilled from existing network description, and calibrated for accuracy. Without such a stage a direct transplantation of SNA indicators will not match the policy network term and related observations described earlier in the Anglo-Saxon network literature. Again, the mismatch is compounded by the fact that the Anglo-Saxon literature is itself uncertain as to what a policy network actually is (2.2).

Dowding's discussion on quantitative policy network indicators from SNA literature and his proposition to transpose those over to the British branch of policy network literature is another example of the difficulty in making such transposition(Dowding 1995: 153-158). First, the study here agrees with his conception that policy networks are about the type of relationships policy-makers enter. Following the SNA logic, therefore, Dowding expresses those relations in terms, which are very similar to what here is advocated as network descriptors, namely of members' characteristics and relations characteristics, summarised in the table (p.35) (1995: 153):

\begin{tabular}{|c|c|}
\hline Characteristics of Members & Characteristics of Relations \\
\hline Knowledge/information & Centrality \\
\hline Legitimacy & Number of Connections \\
\hline Ability to conditionally change others incentive structures & Inclusiveness \\
\hline Ability to unconditionally change others incentive structures & Rules of Interaction \\
\hline Reputation & Embeddedness \\
\hline
\end{tabular}

Table 4 Adaptation of Dowding's SNA indicators

While some SNA network characteristics such as inclusiveness and rules of interaction appear synonymous to degree of access and type of interaction (discussed below), others, such as embeddedness or centrality appear quite disjointed from the Anglo-Saxon side of the literature. Moreover, it is not immediately clear above how for instance characteristics of relations would fit the description of, say, policy community (1995: 153). 
The third difficulty associated with policy networks is causality, although still related to quantification. Thatcher (1998), Dowding $(1995,2001)$ and van Waarden (1992: 32) note that policy network analyses conflate network characteristics with the independent variables responsible for the respective policy network type. Dowding (1995; 2001) and Thatcher (1998) in particular argue that quantification will help researchers establish various causal relationships between: the network and the policy-making process; external variables and network formation; and endo-/exogenous variables and changes of network structure (Dowding 1995; Thatcher 1998: 396-398). Ultimately, according to Dowding (2001: 92-93) and Thatcher (1998) network descriptors would be integrated in a more dynamic, mathematical model, that will reflect the causality related to the ideally discrete policy network types.

However, the position in this study is that the concern with quantification, though justified, is premature. The most pressing issue is the uniform definition of policy network and its descriptors. As the section demonstrates, there is no reliable policy network definition at present and that the debate on descriptors is still ongoing. Once descriptors defining the types of policy networks are settled it would be possible to engage in quantification. Those indicators promoted by Dowding and Thatcher do not immediately fit into the existing observations of the policy networks from the Anglo-Saxon branch (as Borzel (1998) calls it), which the parentela would be part of.

The argument here is not against quantification, rather to promote debate on the development of descriptors that are theoretically in tune with the policy network types. The danger is that if indicators are immediately transferred from elsewhere, those might not reflect the description of known policy networks. The present case on the Bulgarian political system, however, does not lend itself to such an agenda. For example, the development of quantitative indicators may rely on the reviewal of a known Anglo-Saxon policy network type (say a policy community) for any possible metrics that could later be used to describe/define other policy networks. Those metrics would then have to be triangulated in a mixed-method study in a case study on a network relationship, which hypothetically resembles one of the better 
known policy network types (say, between a UK department and a sectoral trade association). If in a such a study both methods yield similar results, namely, that the described relationship qualitative and quantiatively at the end is of one and the same type (say, policy community), only then those indicators could be seen as calibrated and ready for implementation in other studies. In light of that, however, the present study is neither geared towards such a quantiative agenda, nor is it in the possession of reliable quantitative network indicators (descriptors) that have already been developed in the Anglo-Saxon branch of the literature. That is why, it is primarily qualitative. Moreover, given that the parentela appears either elusive to document or simply non-existent, the qualitative method is better suited for this inevitably exploratory study, because it allows for more and varied data to be analysed. Again, going the quantitative road in the present study would mean applying previously untested quantitative policy network indicators on a case where it is unknown whether the policy network in question exists. Any measurements, therefore, would be unreliable in the absence of pre-established indicator validity.

Let us quickly review one example of the difficulty of employing quantitative indicators and their validity. In a study on the possible existence of the parentela in 1980s Israel, Yishai (1992) employs a quantitative indicator labelled group strategy, which measures the contact frequency between an interest group and policy-makers from a given venue. However, it raises the question of how to interpret such metrics: is that a measurement of degree of access to the given venue or an indication for the existence of a venue-specific policy network, i.e. parentela in her case. Yishai (1992) takes the decreasing count of groups opting to influence through the party venue as an indication that the parentela is not in operation. In her case, Ysihai (1992) takes the position that the fewer the groups seeking contacts with the party venue, the less one can claim the parentela exists.

However, the measurments of her group strategy indicator is also consistent with another part of the literature that only a few groups are generally granted privileged standing within a certain venue states that regardless whether the venue as a whole experiences increase or decline of contacts (Maloney et al 1992;1997). This is 
particularly relevant to the party, as in the parentela studies of La Palombara (1964) and Greer (1994) identify only one group as the main partner to the party in power in Italy and Northern Ireland, respectively. Therefore, the declining access does not indicate that the parentela does not exist. As Greer's case demonstrates, a parentela can exist even when no large scale practice of party political appointments exists (1994).

Moreover, the overall decline of contacts with the party venue, therefore, means that group strategies in fact might not be even measuring access but the perception of that venue's effectiveness by the interest groups universe. The party was once a thriving venue for groups seeking access to the policy-making process, suggests barriers of entry remaind low also during her study (Yishai 1994: 277, table 2). As Yishai argues, things changed when the bulk of the policies of interest to the group universe were largely placed under the purview of the civil service, which shifted the perception that the civil service is the more effective venue (1994: 282).

In sum, the purpose of this discussion was to illustrate the inappropriateness of the quantitative approach at this stage. The qualitative approach is better suited because there is some agreement on the qualitative indicators (descriptors) which lend themselves to immediate employment in an exploratory setting. Moreover, as it will be discussed in the next chapter, the qualitative approach allows for the detection of power relationships and party-group dynamics that have not yet been discovered. But before all, quantitative or qualitative, authors have to first and foremost come to some agreement on what discrete policy networks descriptors will be used to classify policy networks.

The next sub-section will discuss the descriptors employed in this study. On the basis of the selected descriptors it classifies the better known policy networks and in doing so facilitates the effective results comparison between this study and the already existing network descriptions. Again, each descriptor is equivalent to an indicator, which represents one aspect of group's relationship with policy-makers. The descriptors discussed here are distilled from the literature. The benefit of a form of 
policy network classification is that it helps to accurately identify network relationships observed in new polities. That in turn helps with carrying out causal and comparative projects. This, however, is a point discussed in chapter 3. The present section is dedicated to how and why the network descriptors in this study are adopted from the literature.

The network descriptor selection for the purpose of a network classification was governed by a number of principles:

- Fewest practically possible descriptors;

- Descriptors also have to be applicable to largest number of known policy network descriptions;

- Maintain a meso-level focus, as per Marsh and Rhodes (1992: 1-4).

The following sub-sections (2.3.1-4) discuss the five descriptors from the literature which were adopted in the present study: power asymmetry (ratio), network dynamics, degree of access, primary venue and venue scope. It ends with the conversion of the more commonly known policy network types in discrete combinations of descriptor values.

\subsubsection{Power Ratio (Asymmetry)}

The first network descriptor relates to the power relations between the private actors (interest groups) and state policy-makers (civil servants and/or politicians) from the primary policy venue. Jordan and Schubert (1992: 18) argue that the network features that would serve as a basis for networks comparison have to be nondebatable or easy to operationalise, which is a difficult task, as exemplified in the first literature attempt at network classification produced by Atkinson and Coleman (1989). They classify networks according to two descriptors: degree of mobilization of business and state's propensity to yield to outside influence (state structure) (Atkinson and Coleman 1989: 54, table 5 below): 


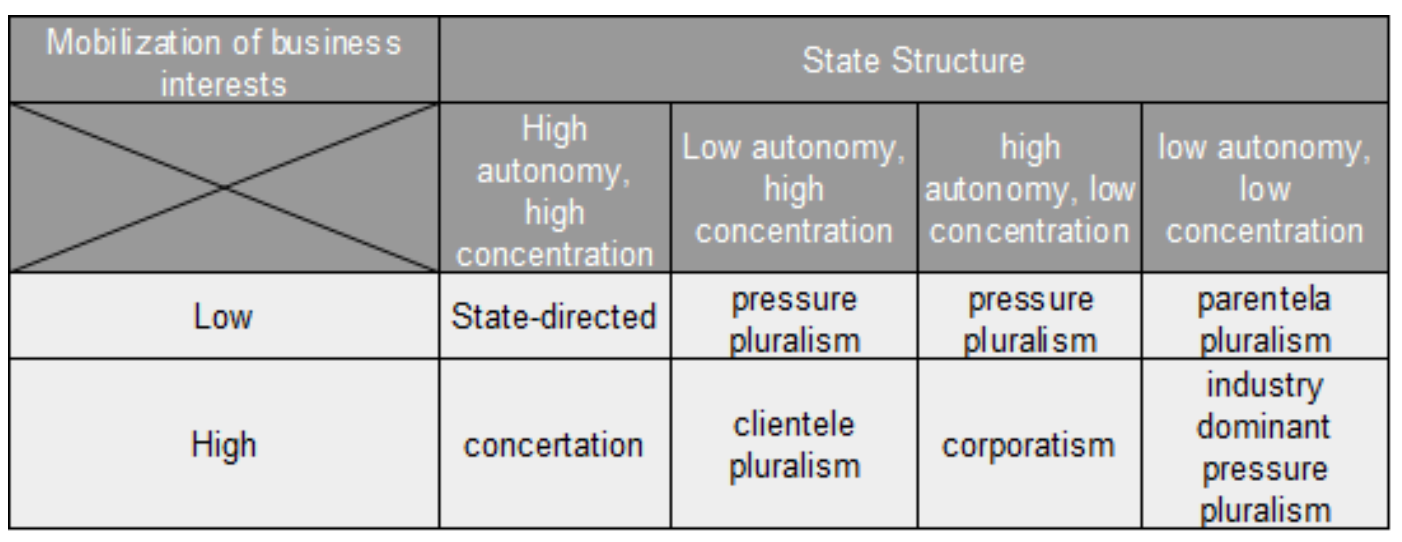

Table 5 Network Descriptors, adapted from Atkinson and Coleman (1989: 54)

Jordan and Schubert (1992) and van Waarden (1992: 32) disagree with the AtkinsonColeman classification because it does not allow for all network types to be plotted, e.g. issue networks. Van Waarden's second criticism, echoed later by Thatcher (1998), is that it is hard to distinguish between network features from exogenous variables that explain network formation and its characteristics (van Waarden 1992). In addition, the present study also sees that the Atkinson-Coleman classification is based on a macro level of analysis between the State and Groups (pluralism, vs corporatism), while policy networks operate on a meso level (Marsh and Rhodes 1992: 1-4).

Nevertheless, the Atkinson/Coleman network typology highlights a literature thread that seems to have preoccupied many attempts at policy network classification. This is namely the distribution of power among the policy network actors, or power ratio. Looking at the Atkinson/Coleman table, it plots policy networks according to the power ratio between business and the state. The same is evident in van Waarden's classification in table 6 (p47), although he includes other dimensions: 


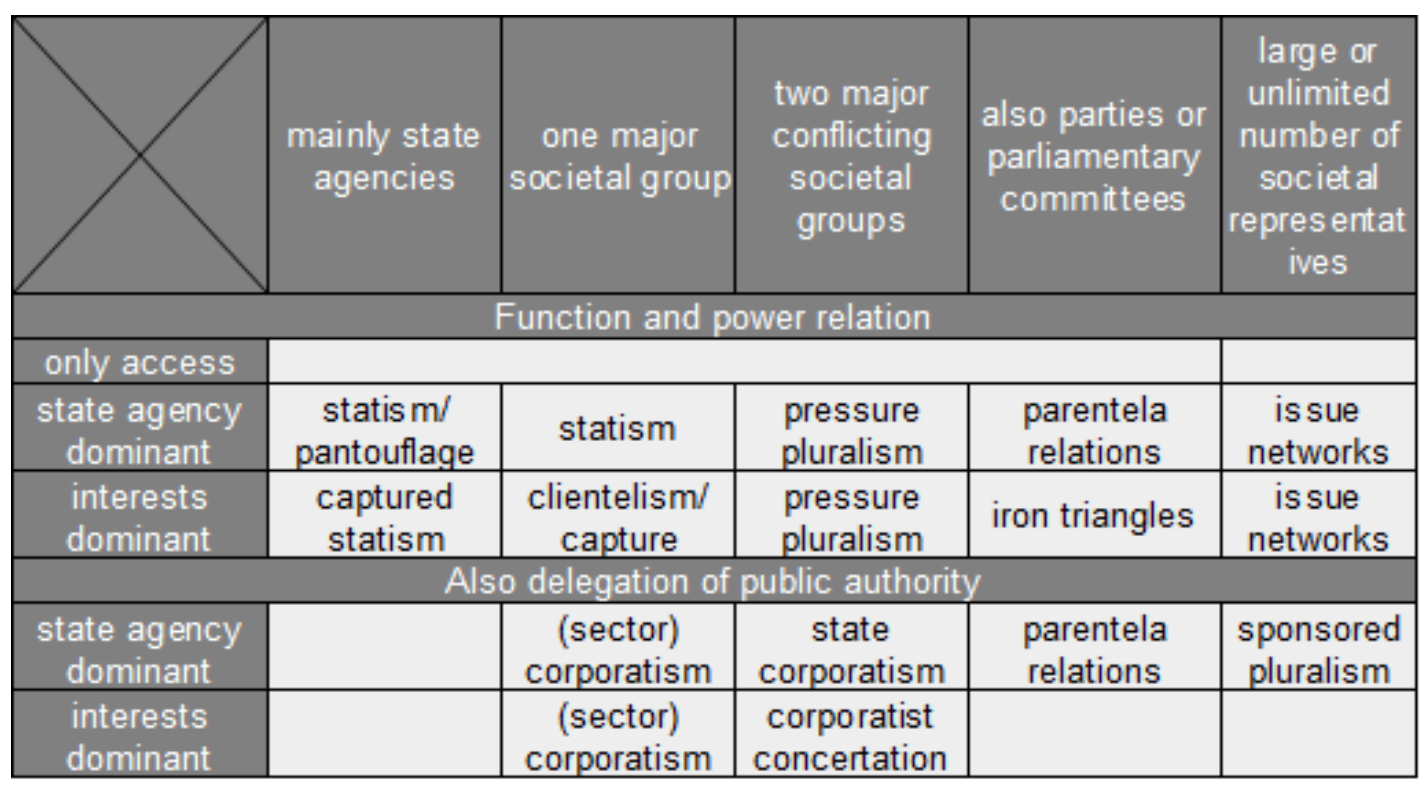

Table 6 Network Descriptors, adapted from van Waarden (1992:50)

Van Waarden's concern with power, or power ratio, is evident above in the descriptors: state agency dominant and interests dominant, and also in one major societal group and mainly state agencies. (1992: 49-50). In addition, mainly state agencies and parties or parliamentary committees are network descriptors that are also concerned with where the policy network manifests. That is to say they are concerned with the locus of the policy venue hosting the network dynamics (discussed below in 2.3.4). The descriptors one major societal group, two major conflicting societal groups and unlimited number of societal representatives above refer to the number of actors involved in the network, and with that to the degree of interest group inclusion in the policy-making process that the network provides. Finally, the descriptors number of actors and network function stand for whether the network is engaged in implementation, delegation or other policy-making stage.

However, the van Waarden classification is still susceptible to the same criticisms at the Atkinson/Coleman classification. Jordan and Schubert still highlight the inoperability of van Waarden's classification, particularly power ratio (Jordan and Schubert 1992: 12). Again, to this we should still add the level of analysis is still 
unclear, particularly with the conceptualisation of corporatism and pluralism as policy network types.

Following their emphasis on measurability, Jordan and Schubert (1992: 25) offer a classification based on descriptors kept as close to quantification as possible, and with that, entirely omitting the question of power relations. Their network classification is primarily based on number of group participants and issue scope. Observe table 7 below:

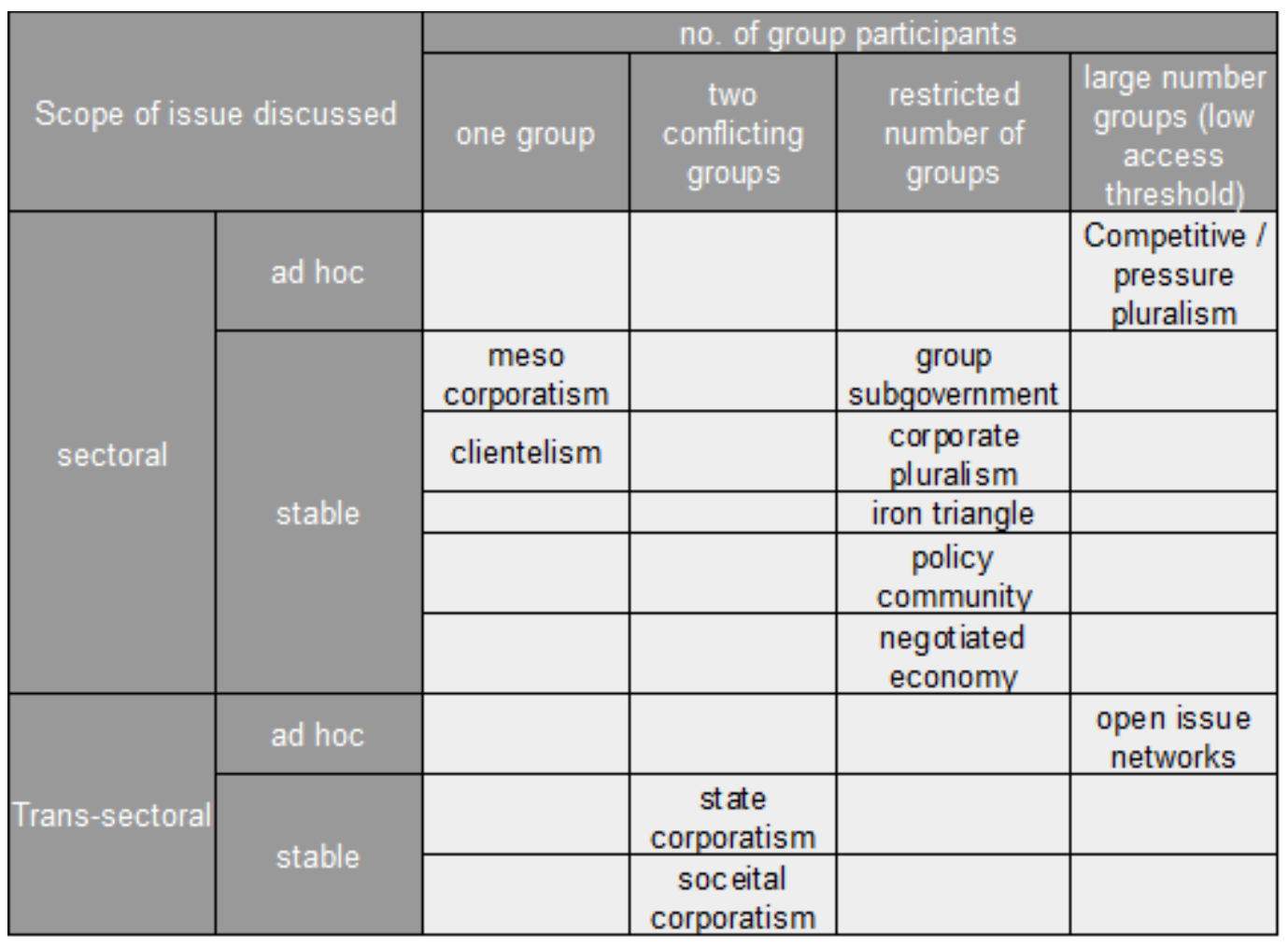

Table 7 Network Descriptors, adapted from Jordan and Schubert (1992: 25)

While the number of group participants is a clear reflection of their emphasis on quantification, issue scope is about whether the issue at hand cuts across social/economic sectors.

Jordan and Schubert object to an enquiry into the power ratio as futile in the absence of power metrics (1992: 25). However, the position here is that this descriptor is too important to be overlooked. In fact, the entire literature on policy networks, on corporatism and pluralism is concerned with the question of power asymmetry 
between public and private actors. The concern with power is obvious in the classifications of van Waarden (1992: 50) and Atkinson/Coleman's low autonomy v. high autonomy of state structure (1989: 54). Moreover, the Rhodes/Marsh model is also based on a power ratio gradient between state and group actors (Rhodes and Marsh 1992: 184). More recently, Adam and Kriesi (2007: 133-135), too, have promoted the use of that descriptor, although it is true that they, and Marsh and Rhodes (1992: 184, 199) are mute on the question of power metrics.

Again, the question of power is too important to ignore and even if future classification omits it as a descriptor, it is nevertheless adopted in the present study. Moreover, while nuanced power disparities may not be easily captured, extreme ones should be. As this study will demonstrate in chapter 9, it is possible to observe power ratio that clearly puts interest groups at a disadvantage vis-à-vis the party in power.

In light of the above, however, a point of clarification needs to be added here. In relation to the concern with the concept of power, the policy network authors above do not directly relate its use to the literature that is dedicated to debating and refining it, even if the concept is of central importance to policy networks. The uncovered concern with power above is implicit in the literature and it may give the erroneous impression that this is somehow part of the wider debate on power. However, that is not the case. The network literature (Anglo-Saxon branch as per Borzel 1998) simply states that power is part of the relationship between interest groups and venue policymakers. That is why, the following few paragraphs attempt to translate the use of power in policy-networks in the conceptual frameworks employed in the explicitly power literature. However, most notable of those are the three dimensions of power developed by Steven Lukes (1974; 2005).

The use of the term power in the policy network literature appears to primarily overlap with what Lukes has classified as first and second dimensions of power. (1974; 2005). In his three dimensions of power typology Lukes reviews and systematizes some of the most influential works on the subject of power by early 1970s. In a second edition dedicated to his typology, published 2005, he reviews and 
revises some of his analyses on the concept. For the purposes of the present discussion, however, it is not necessary to venture deep into the debate spurred by Lukes' three dimensions of power. Accordingly, this dimension is manifested when policy-political conflict is observable, with clear preferences exhibited by all sides involved in it (2005: 19):

this first, one-dimensional, view of power involves a focus on behaviour in the making of decisions on issues over which there is an observable conflict of (subjective) interests, seen as express policy preferences, revealed by political participation.

In other words, this dimensions concerns the situations where observers can indeed observe political conflict unfold, its parties and their interests. At the centre of the first dimension, however, lies a dynamic which, according to Lukes, is evident in a number of pluralist writings, most notably of Dahl, who defines the first dimension thus (in Lukes 2005: 16):

A has power over $\mathrm{B}$ to the extent that he can get $\mathrm{B}$ to do something that $\mathrm{B}$ would not otherwise do

This, in other words, could be seen as coercion. A forceful imposition of A's will onto $\mathrm{B}$, against B's interests and preferences.

Policy networks, therefore, appear to demonstrate such dynamics, although the authors discussing them have not at all made direct links to the power literature. For example, the issue network, which will be discussed later in this chapter, is a textbook example of a policy network entirely manifesting the first dimension of power. Developed by Heclo (1979), this network models policy and political conflicts waged in the open, between two (or more) clearly visible camps. Each camp comprising journalists, politicians, scientists and activists openly state their preferences through media appearances or direct protest. Ultimately, resulting legislation could quite straightforwardly be attributed to either camp. That is, there is a clear winner and an actor who has imposed their will.

There is possibly another example of a policy network whose power dynamics relates to thee first dimension of power. We have to be more cautious here, for this 
conflict does not exactly appear in context which Lukes (above) prescribes, i.e. open conflict. As already defined in the introduction, the parentela is a relationship where the parente, or the ruling party and its privileged, insider group, exert control over the civil service through the practice of party appointments of civil servants. Chapter 9, then, reveals that there is a new dynamic, part of that same parentela, which can be observed in Bulgaria, labeled type 2 parentela. Accordingly, the parente can subject their political oppoinents - the firms that are associated in an interest group that opposes party's policies or the businesses of intra-party dissenters - and the market competitors of the party insider group to prejudiced regulatory inspections. The last means that the control organs or, elsewhere, regulatory agencies of the state are mobilised by the parente to inspect the businesses of said actors and find evidence of malpractice at all cost in order to prevent them doing business. In that sense, the parente forcefully imposes its will on its various opponents to discontinue market operations at latter's clear expense.

The only difference from a clear-cut overlap between the type 2 parentela and the first dimension of power could be in that conflict is hidden in open sight. It is a very unusual situation as these inspections are publicly observable and within the law. However, what is not observable is the true motivation behind them. As respondents will argue in chapter 9, any inspection could be as lenient or stringent as the agency director sees fit, which makes it hard to determine which inspection is prejudiced. At the same time, an outsider put under such pressure is not always aware that what is happening to their business is in fact pre-mediated. One respondent will argue in chapter 9 that it is only by comparison to how inspections usually go that a given business owner can subjectively determine for themselves that they are a target. Sometimes, others will know why and can definitely tell that this is not an ordinary inspection. The bottom line is that conflict in the case of the parentela of type 2 is observable only for those involved in the dynamics, while for external observers it may remain hidden in the open, under the guise of the usual inspection of regulatory agencies. 
Lukes traces another body of works headed by Bacharch and Baratz (in Lukes 2005: 20). They responded to Dahl arguing that policy conflict need not be publicly advertised and observable for power dynamics to take place. Essentially, ability to control the political agenda, that is, to perpetually filter out undesirable discussions or policies is another example of powerfulness. In their words (Bachrach and Baratz in Lukes 2005: 20):

Power is also exercised when A devotes his energies to creating or reinforcing social and political values and institutional practices that limit the scope of the political process to public consideration of only those issues which are comparatively innocuous to $\mathrm{A}$.

As Lukes elaborates (2005: 20-22), A's power over B in the context of policy-making is limiting the political debate on issues that matter to A and continuously ignoring, i.e. non-deciding, on issues of importance to B. This is achieved through a combination of a number of practices, such as manipulation and threat of sanctions (Lukes 2005: 20-22). Thus, the conflict between A and B comes to the fore, so far as external observers are concerned, that can only be visible if the observer can ascertain the un-declared greivances of B that have not entered the political agenda (Lukes 2005: 24). All in all, the second dimension is the ability of those who benefit from the status quo to maintain it despite the pressure from any policy contestants.

In relation to policy networks, the second dimension appears at the heart of a number of network types. These are the iron triangles, policy communities and the possibly the clientela, although authors are far from explicit on the subject of second dimension of power in policy networks. The common denominator among the three networks (which will be reviewed at length later in this chapter) is that they model cooperative group-policy-maker relations. Essentially, these are relations between civil servants and groups who possess policy expertise, which is of value to the bureaucrats who are tasked with amending or advising on the amendment or drafting of new legislation. Thus, an exchange relationship forms: in exchange for their expertise, the group is more frequently consulted on a wider range of issues. The longevity of such an exchange relationship engenders trust among the participants and the continued preeminence of the insider group. Normally, such groups are sectoral (peak) associations who possess considerable social/economic representation 
and a technocratic approach to policy-making. That is why, the potential effects of drafted legislation on the respective social or economic sector are discussed with such insider groups, who need not necessarily be those potentially affected by prospective legislation. Even if potentially affected groups are consulted, however, this still does not mean their views will be necessarily endorsed. Therefore, while respective authors do not necessarily elaborate, it is not difficult to imagine that those insider groups are best positioned to keep the demands of outsiders out from the political debate.

Parenthetically, there is another author whose power conception is applicable to these three networks. To the extent insider groups are able to influence the decisions of policy-makers through reason, we can speak of influence in Russell's terms (1986). This is namely, when A is able to change the opinion of B (Russell 1986 [1938]: 1920). Again, this appears relevant to all cooperation-based network types, i.e. policy community, iron triangle, clientela and parentela.

In any case, La Palombara's parentela, too, could be provided as another example of the second dimension of power. Although the earlier three network types operate at the civil service, in a parentela relationship the control over the agenda is done through the ruling party. The dynamic is the same: a trusted insider group is in the position to filter undesired policies out by nominating new or utilising existing party political appointees who are loyal to the parente. As it will be elaborated later in the present chapter and in chapters 6 and 8, parentela insider status is also achieved following an exchange relationship, the longevity of which also renders the given group trustworthy and its insider status confirmed. In the parentela, the insider status is based on group's ability to mobilise its member-base to vote for the given party and contribute campaign funds for future elections. In exchange, the party provides the core insider access to the policy-making process, hosted by the civil service. This is achieved by the practice of party political appointments, where individuals loyal to the party and its insider are sent to work as key civil servants who have immediate discretion on draft legislation. 
Again parenthetically, on the note of campaign contributions, this and not meaning to engage in an elaborate discussion on power, one can also make a reference to another author on power, whose conception of the term is also relevant the parentela, clientela, the iron triangle and the policy community network. Again, we stated that in a parentela relationship, the driving force behind party's recognition of a group as an insider partly rests on that group's ability to provide resources to aid party's reelection: group's ability to mobilise own membership and its ability to provide campaign resources. In that sense, in a parentela relationship, a group could exert influence on the party on the basis of the resources it commands. This is what Galbraith defines as compensatory power (1983: 214):

in the modern economy, the most important expression of compensatory power is, of course, pecuniary reward - the payment of money for services rendered, which is to say for submission to the economic or personal purposes of others

In other words, economic resources are a source of power, but as the parentela reveals, in the party-group relations, this translates not only as crude campaign contributions but also as votes which the party insider group is able to mobilise. If we expand the notion of compensatory power, then expertise, too, can become one such source of power. This means that policy networks such as the iron triangle, the clientela and the policy community manifest this power-relationship. A later discussion will reveal that in those relationships, a group's insider access depends on its ability to provide expertise to the respective venue policy-makers.

Lukes (1974; 2005) also developed a third dimension of power, which concerns those groups or rather more generally actors whose conception and narrative of social reality is such that it is widely accepted despite that those groups or social strata endorsing it are in fact at a disadvantage. In essence, this is a critique to the earlier two dimensions which were primarily developed on the basis of an observable 
conflict (2005: 26). It seems Lukes takes the second dimension further than nondecision, where decisions that change the status quo are not taken because of an authority that manipulates (or otherwise influences) the policy-making process. Rather, an authority benefits from the status quo, which remains unchallenged because there is a dominant interpretation of social and political reality which is so widely accepted that disadvantaged groups proactively defend it, oblivious that they act against their own interest (Lukes 2005: 25-26). The dominant narrative may or may not be issued by the benefiting actor but it may be structurally so (Lukes 2005: 26). In his words:

Moreover, the bias of the system is not sustained simply by a series of individually chosen acts, but also, most importantly, by the socially structured and culturally patterned behaviour of groups, and practices of institutions, which may indeed be manifested by individuals' inaction.

That is to say, the third dimension of power stands for undetected injustice which is brought about the social and political structure. Again, those who are disadvantaged are unable to realise that they are such, simply because they are embedded in the structure. This is quite evident in the definition of the third dimension of power, locked in the following dynamic where (Lukes 1974; 2005: 27):

A may exercise power over B by getting him to do what he does not want to do, but he also exercises power over him by influencing, shaping or determining his very wants.

In other words, the third dimension is a situation where an unjust social order is maintained by those disadvantaged because they have been manipulated or otherwise made to believe that keeping the status quo is in their favour.

At this stage, however, no policy network types appear to have modelled any power relations that fall along the lines of the third dimension of power. It appears that it operates on a macro level, while interest groups and policy networks are social dynamics on a meso level. In any case, it remains to be seen whether any policy network type will manifest dynamics similar to the third dimension. Let us now turn to the next policy network descriptor, network dynamics. 


\subsubsection{Network Dynamics}

The second point that follows from Jordan and Schubert's classification earlier is that the network stability (stable vs ad hoc, table 7) descriptor seems to be universally accepted. It concerns whether there is conflict or cooperation between the group and policy-makers. The concern with network dynamics is evident in the Atkinson/Coleman's concertation (Atkinson and Coleman 1989: 48-49) and pressure pluralism (1989: 55) descriptors. In van Waarden (1992), Jordan and Schubert's network dynamics is addressed through the descriptors rules of conduct (1992: 35-6) and actor strategies (1992: 37-38). The concern with the extent of cooperative dynamics is also evident in Rhode/Marsh's network classification (1992: 183), and of Adam and Kriesi's type of interaction (2007: 134-5). Given the wide-spread concern of whether groups cooperate or are in conflict with respective state policy-makers it is accepted under the label network dynamics.

\subsubsection{Degree of Access}

Third, consistent with van Waarden (1992), Jordan and Schubert (1992) include the number of groups descriptor which is metrics for a group's degree of access to the policy-making process that the given venue provides. This is implied by Jordan and Schubert with their low access threshold (1992: 25). Basically, the fewer the number of group participants, the higher barriers of access there are. This is also evident in the van Waarden's table at the intersections of the descriptors state agency and interests dominant, on the one hand, and all horizontal descriptors, except parties or parliamentary committees (table 6, van Waarden 1992: 50).

However, we have to note the difficulty in employing this indicator, as in the case of Israel (Yishai 1992). However, weary of it, this situation is partly resolved by the introduction of the new indicator primary venue, discussed below. As of now, the study deems degree of access as an expression of group's extent of overcoming the barriers of entry to the respective venue it occupies. The phrase barriers to access means the extent to which a group meets the criteria for a trusted policy-making partner, who is to be regularly consulted on a wider range of matters. Each venue has 
its own criteria or requirements for access, such as resources and particular behaviour. Therefore, the extent a group meets such criteria, it receives privileged access to that venue.

That a low number of groups in a network correlates with deeper insiderness is already evident in the insider/outsider status interest group typology developed by Wyn Grant (1977; 1978), Jordan et al. (1992) and Maloney et al. (1994). In Grant's typology of interest groups, core insiders are a handful of interest groups that are frequently consulted on most policies and draft legislative proposals. Those who are less frequently consulted, usually en masse, are peripheral insiders, while those who are irregularly consulted, yet, on highly specific and technical matters are niche insiders. Finally those who are not consulted at all have an outsider status. In fact, Jordan clearly states that the policy community network type is compatible with the insider/outsider status interest group classification (Jordan et al 1992: 18, original emphasis):

Core participants (substantially the same as policy community members) are seen as important and relevant sources by policy makers

In other words, Jordan et al above state that there is a conceptual compatibility between the deeper degree of access inherent in the policy community network (Richardson and Jordan 1979: 99-100) and Wyn Grant's interest group category of insider status. Therefore, this study employs the restricted descriptor used by Jordan and Schubert (1992), but expresses it with Grant's ordinal qualitative indicator of access (core insider, peripheral insider and outsider), and applying the more intuitive label degree of access (Grant 1977, 1978 Jordan et al 1992; Maloney et al 1994).

However, it is not possible to apply Grant's typology without some adjustments. His classification of insider group types also features a prisoner and niche insider types. The prisoner insider is a type of a civil service core insider which is partly institutionalised and is financially, legally or otherwise dependent on the government, hence constrained by it (Grant 1978: 5; 2004; Maloney et al 1997: 27). The prisoner insider is excluded from this study as a possible access descriptor, because it rather stands for a new policy network type. The qualifier prisoner is also an indication of power-relationship, which suggests the group is at a power 
disadvantage. These complex dynamics render the prisoner insider a separate policy network type as opposed to a network descriptor, which is why it is excluded as such but listed in later tables as a separate policy network type.

Niche insider, too, is excluded here as a degree of access indicator. This type of group is between the civil service departments and a highly specialist interest group that only occasionally is elevated to a core insider status on policies that require exceptional expertise that generally falls outside the capabilities of sectoral interest groups. The niche insider descriptor is dropped because it would be hard to distinguish it from peripheral and core insiders. While it is possible to identify groups that are more or less frequently in contact with party policy-makers that is to distinguish between core and peripherals, the niche insider status denotes a group which has as infrequent contacts as peripheral insider and is as expertise-laden as core insiders. To distinguish niche insiders from either types one has to identify a small-scale group that is infrequently involved to consultations and only occasionally at their center. Such refined metrics are not available at present and may be particularly irrelevant for the party venue, because it does not necessarily host consultations of such scale, quality and intensity as the civil service. Therefore, including niche insiders would unnecessarily increase study's complexity, which is why it is excluded.

\subsubsection{Primary Venue and Venue Scope}

Finally, this study adopts the concept of primary venues (PVs) as a policy network location descriptor. The venue descriptor is used by van Waarden (1992: 42-50) and Atkinson and Coleman (1989: 55-59), who make locational references when comparing the different network types. Although only van Waarden distinguishes among network types based on venues this study sees a benefit in doing so for three reasons. First, it is easier to distinguish between networks with identical dynamics, such as policy community and iron triangles. Second, this descriptor grounds network analysis deeper in the meso-level. Third, the concern of where to look for a given policy network increases its tangibility or rather the validity of the observations. 
This study, therefore, proposes the descriptor primary venue, which signifies the main or first policy-venue which hosts the respective network dynamics. It is called a primary because it attracts interest groups that perceive it as an effective access point to the policy-making process. This follows from Yishai's research on the parentela in Israel in the 1980s (1992). She argues that the nature of group's demand determines group's perception of venue's effectiveness or in her words “[groups'] immediate needs shape their map of targets" (1992: 282).

She argues that the lower count of groups seeking the party route (venue) in Israel is a result of the fact that groups' demands are no longer relevant for or managed at that venue (Yishai 1992: 282). The implication therefore is that groups find it ineffective to approach the ruling party because policy-makers cannot process narrow, technical demands. The Israeli civil service has a considerable degree of economic interference, political autonomy and is designed to process groups' narrower demands (Yishai 1992: 282). Therefore, the party in power becomes less of an effective venue for many of Israel's interest groups, which is why they flock around the civil service.

La Palombara also suggests that the above perceived venue effectiveness (or primary venue) motivates groups to form the parentela. This is evident in one of his commentaries (La Palombara 1964: 315):

[Respondent's] argument suggests that if Confindustria wishes to continue to maximize its political effectiveness, it must achieve a parentela relationship to the Christian Democratic Party as well as a clientela relationship to the bureaucracy.

In other words, according to La Palombara's respondent above, going the civil service route is not enough. The Confindustria group needs to primarily establish core insider access (status) with the ruling party, i.e. establish a parentela, because that route is seen as more effective than the civil service (La Palombara 1964: 307).

Furthermore, his other insistence on party's willingness to intervene in the civil service as an independent variable (La Palombara 1964: 306-316; 322-331) 
contributing to the parentela formation, also reflects the idea that there has to be some perception among groups that the ruling party provides effective access. If political parties do not demonstrate any ability to influence the behaviour of the civil service, then groups would not perceive them as effective. While it may seem obvious that groups would opt for venues that they see as effective, evidence of party interference is important as it indicates whether the party in power could be a potential parentela host.

All of the above leads to the last network descriptor: venue scope. This multiple response indicator represents the venue-breadth of the network dynamics. Some policy networks inhabit only one policy-venue, like policy community, which is found in the civil service. Others, say, like issue networks have dynamics that involve more if not all, policy venues. This descriptor marks all relevant policymaking venues that a policy network covers. Such specification increases accuracy and ecological validity because it maintains some level of tangibility at that level of abstraction. These are concrete and observable relationships that ground analysis on a meso-level. The parentela, then, occupies the party and civil service policy venues because of the practice of party political appointments, or party intervention in the work of the civil service, more generally. The above discussion is summarised in table 8 (p. 47):

\begin{tabular}{|c|c|c|c|c|c|}
\hline $\begin{array}{l}\text { Descriptor } \\
\text { (Indicat or) }\end{array}$ & Data type & \multicolumn{4}{|c|}{ Metrics } \\
\hline $\begin{array}{l}\text { degree of } \\
\text { access }\end{array}$ & ordinal & core insider & $\begin{array}{c}\text { peripheral } \\
\text { insider }\end{array}$ & outsider & \\
\hline $\begin{array}{l}\text { network } \\
\text { dynamic }\end{array}$ & binary & cooperation & conflict & & \\
\hline power ratio & ordinal & $\begin{array}{c}\text { group less } \\
\text { powerful }\end{array}$ & parity & $\begin{array}{c}\text { group more } \\
\text { powerful }\end{array}$ & \\
\hline primary venue & categorical & party & bureaucracy & parliament & media \\
\hline $\begin{array}{l}\text { scope of } \\
\text { venues }\end{array}$ & $\begin{array}{l}\text { multiple } \\
\text { response }\end{array}$ & party & bureaucracy & parliament & media \\
\hline $\begin{array}{l}\text { group } \\
\text { strategy } \\
\text { (Yishai 1992: } \\
275 \text { ) } \\
\end{array}$ & continuous & \multicolumn{4}{|c|}{ frequency of contact with a policy venue } \\
\hline
\end{tabular}




\section{Table 8 Policy network descriptors}

The table summarises all of the adopted network descriptors in this study. The last descriptor (group strategy) is shaded because it is excluded from the present study. Also, as the descriptors are indicators as well, they are defined in the table in terms of the data type they assume, e.g. ordinal, binary, categorical or multiple response.

Next, regarding causality, the above network descriptors are envisaged as dependent variables (DV). As independent variables, the study recognises hegemonic parties, parliamentary elections, the drive for better market standing, the need for more campaign funds and EU institutions, but those are discussed at later stages of the thesis. Second, the descriptor-based expression of policy networks does not necessarily capture the totality of the dynamics part of the respective network. As the parentela discussed in 2.4.5 demonstrates, the practice of party political appointments (PPAs) appears to be peculiar to that network, which is why it is not included as a descriptor. It is not added therefore to the categorical expression of policy network types but in the functional description of what the parentela does (again discussed in 2.4.5).

\subsection{Policy Network Classification}

The purpose of this section is to classify the better known policy network types according to the network descriptors developed earlier. The present section will first review the more prominent policy networks (2.4.1-5). Sub-section 2.4.6 will then apply the network descriptors developed above to the network types and in doing so will offer a new policy-network classification.

\subsubsection{Subgovernments}

US political scientists have identified a host of synonymous policy networks, such as iron triangles, subgovernments or subsystems (to name a few) that account for the bulk of US non-politicised policy-making decisions. The more prominent of the terms are the subgovernments, which Ripley and Franklin define as: 
clusters of individuals that effectively make most of the routine decisions in a given substantive area of policy. [...] A typical subgovernment is composed of members of the House and/or Senate, members of congressional staffs, bureaucrats, and representatives of private groups and organizations interested in the policy area. (Ripley and Franklin 1987: 8)

In other words, while a policy or legislative proposal is debated by the Legislature, it is informally modified in policy networks that span across or combine both legislative committees and executive departments (elsewhere below, state administration, the Bureaucracy, the Executive or state agencies). In terms of internal dynamics, the members of these networks exhibit the shared values of cooperation, confidentiality, conflict avoidance and, if unobstructed, the relationships could prove to be resilient in the long run (Ripley and Franklin 1987: 8; Jordan 1990: 319-320, 322, 324). The network as a whole and the insider private groups have a disproportional ability to dominate policy-making over time in a given policy field. According to the authors, such networks could be dismantled by purposeful public and media exposure, by presidential inquiry or any such macro-political disruption, and by an extreme internal dissent (Ripley and Franklin 1987: 9). As far as the power ratio is concerned, authors strongly imply that there is power balance among the participants in this policy network type.

\subsubsection{Policy Communities}

In the British context, Jordan and Richardson (1979) discovered the policy community type of network, which is very similar to the subgovernments above. The main similarity lies in that insider status is given to a small number of private groups, who are frequently consulted on most of the policy matters affecting their respective industry (1979: 98-100). There is cooperation and parity of power among the actors constituting the network (Richardson and Jordan 101-105). The difference, however, seems to be in that while subgovernments involve bodies from the Legislature and the Executive, the policy community is locked in the civil service (Richardson and Jordan 1979: 74; also Maloney and Jeremy 1994; Maloney and Jordan 1997). 


\subsubsection{Clientela}

Jordan and Richardson (1979: 59) also recognise that policy communities resemble the clientela type of policy network, discovered by La Palombara (1964) in the Italian polity, the traits of which were later found in France by Suleiman (in Richardson and Jordan 1979: 56). Looking at the description of the clientela it does overlap considerably with the policy community, as far as internal dynamics are concerned, because it too is about the tight cooperation between civil service and privileged interest groups. La Palombara (1964) discusses two classes of conditions that have to be met for a clientela to come into existence. The first class of conditions related to the state administration: the agency seeks to consult regularly (La Palombara 1964: 272); the regulated groups cooperate with implementation (La Palombara 1964: 273, 275); the state agency solicits expert advice from the clientele (La Palombara 1964: 274); the relationship is based on exchange of information or commitments or some form of cooperation (La Palombara 1964: 285). The class of conditions pertinent to the interest groups consists: representation of entire sector; good reputation; expertise (La Palombara 1964: 277-8; 294; 296, respectively). None of them really seem to be a departure from the policy community description earlier.

However, the cooperative relationship and bureaucrats' personal identification with the problems of the sector they have to regulate confuses as to the power ratio inside the network. Richardson and Jordan quote La Palombara's dramatic characterisation of the Italian bureaucracy in his Introduction, where he argues that it is quite common for agencies to be under the control of organised business groups which they are supposed to regulate (1979: 55):

The Italian bureaucracy, $[\ldots]$ is correctly identified as a series of feudal holdings in which those in Italy who are theoretically empowered to make the rules are strikingly at the mercy of others whom the rules are supposed to control and regulate

According to their reading of La Palombara's clientela, his position is that the interest group overpowers the state agency. However, a more detailed reading of his work 
makes it hard to say where he stands. The purported power asymmetry in favour of the group does not seem to be endorsed by La Palombara's formal definition of the term (La Palombara 1964: 262):

when an interest group, for whatever reasons, succeeds in becoming, in the eyes of a given administrative agency, the natural expression and representative of a given social sector which, in turn, constitutes the natural target or reference point for the activity of the administrative agency.

This careful wording of the definition of the clientela, devoid of statements on power allows one to say that La Palombara (1964: 262) was personally undecided on the degree of power an interest group exerts on to the department, i.e. as Richardson and Jordan (1979) imply above. Yet, the present study sees that the toned down clientela definition might not reflect La Palombara's real position, but the dangers of publicly giving credence to such a controversial statement. It is taken here, therefore, that in a clientela the group overpowers the respective civil service department.

\subsubsection{Issue Networks}

In the late 1970s Hugh Heclo published an article which advocated the existence of the issue network policy network type (1978). Others also saw the emergence of the issue networks (Gais et al 1984; Richardson 2000) in the UK arguing that they were the antithesis of the iron triangles, subgovernments and policy communities. The issue network stands for open, competitive free-for-all access to the policy-making process by a greater number of participants. Contrary to the iron triangles, for instance, the participants in the issue network are in a high profile conflict with one another. The access threshold is low, that is, it is a network of outsider status groups as they initially do not occupy a policy-making venue, other than the Media, but make their way in through conflict. This is a notable difference from the triangles, communities or clientelas, which are situated within the Executive and in a close cooperation with its policy-makers and other groups with equally privileged access. Again, one of the most prominent debates since Heclo has been whether the iron triangles and policy communities have been substituted by the issue networks as the 
dominant policy style in the UK and US, and whether the issue and subgovernment (combined with policy community) networks are mutually exclusive (Jordan 1981; 1990: 330; 2005; Grant 2005; Richardson 2000; Maloney and Richardson 1994; Maloney and Jordan 1997; Gais et al 1984).

\subsubsection{Parentela}

The parentela is mentioned here only for completeness of the list. Its definition was discussed in Chapter 1. Again, this is a relationship where a party insider group gains privileged access in the bureaucracy, as a result of its pre-existing privileged standing within the ruling party. It may be that party factions or party leadership endorses that group as a preferred policy-making partner. The influence of the party insider group manifests when the party interferes on its behalf, and in its interest, in the work of the civil service. So far, the literature has identified party political appointments as one such form of interference, although chapter 4 later discusses civil service reforms as another. That chapter demonstrates that ruling political parties can change the eligibility criteria that groups must meet in order to enter consultations with the civil service. In doing so, a ruling party in theory can filter certain groups out from the policy-making process, while introducing new bureaucratic insiders. In any case, the following section will try to summarise the above presentation of the existing policy network types in terms of the network descriptors developed in section 2.3.

\subsubsection{Policy Network Classification Using Network Descriptors}

On the basis of all hitherto reviewed network types and descriptors, the following table 9 was constructed and adopted in the Bulgarian study: 
A few caveats need noting. First, prisoner insider is a hypothetical policy network that follows from 1) Wyn Grant's classification of insider status interest groups (Grant 1977) and 2) the present logic of policy network classifications. The question marks indicate that there is very little information available on the dynamics of that hypothetical relationship. Second, the primary venue of the subgovernment is placed on the legislature, because while the executive agencies are also involved, Ripley and Franklin (1987: 8-10) set the pivotal point of this network in the legislature. Third, table 9 allows researchers to add or remove descriptors as they see fit without changing the logic of presentation, as long as the descriptive categories are discrete (assumed), as few as possible, most relevant to existing network descriptions and maintain the meso-level focus. Fourth, it should be explicitly stated that the literature tends to express the network descriptors from the perspective of the group vis-a-vis the relevant venue policy makers. This perspective is also maintained in table 9 (p. 52) above as well.

\subsection{Conclusion}

In order to test the hypotheses from chapter 1, the parentela policy network type had to be operationalised. However, that in turn is also dependent on first operationalising the generic term policy network. The chapter argues that the operationalization of policy network definition and policy network types depend on developing a small set of meso-level categories that reflect specific characteristics of the public-private relationships that policy networks stand for. These are labelled here descriptors and stand for indicators types that represent an aspect of the grouppolicy maker relationship, looking from the perspective of the interest group. Although the descriptors adopted in the present study are qualitative, the future should see their quantification.

In any case, the present study operationalises policy networks in terms of the five qualitative descriptors: 
- Degree of Access, whether and how far a group has a privileged access to the respective policy venue

- Network Dynamics, whether there is conflict or cooperation between the group and venue policy makers

- Power Ratio, whether the group or policy-makers are more powerful or neither

- Primary Venue, which of the four main venues (Media/Public, Legislature, Civil Service and Ruling Party) is most effective (or first to be utilised) for the group involved in that policy network

- Venue Scope, the total number of relevant venues that collectively host the policy-network dynamics (more than one)

To illustrate the effectiveness of policy network classification with the above descriptors, all major policy network types, including the parentela, were also expressed using them. The next chapter will discuss the second main methodological challenge - the conduct of elite interviews and the methods used to overcome elite respondent resistance and reluctance. 


\begin{tabular}{|c|c|c|c|c|c|c|c|c|c|c|c|c|c|c|c|c|}
\hline Type of Policy & \multicolumn{16}{|c|}{ Descriptors } \\
\hline & \multicolumn{3}{|c|}{$\begin{array}{c}\text { Degree of } \\
\text { Access to PV }\end{array}$} & \multirow{2}{*}{\multicolumn{2}{|c|}{$\begin{array}{c}\text { Network } \\
\text { Dynamics }\end{array}$}} & \multirow{2}{*}{\multicolumn{3}{|c|}{ Power Ratio }} & \multirow{2}{*}{\multicolumn{4}{|c|}{$\begin{array}{c}\text { Primary Venue } \\
(\mathrm{PV})\end{array}$}} & \multirow{2}{*}{\multicolumn{4}{|c|}{ Scope of Venues }} \\
\hline & \multicolumn{2}{|c|}{ insiders } & \multirow{2}{*}{ 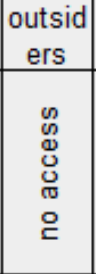 } & & & & & & & & & & & & & \\
\hline & Ð & 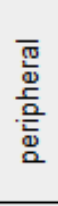 & & $\frac{\text { 은 }}{\frac{\mathrm{c}}{\mathrm{c}}}$ & 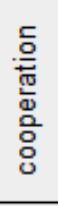 & 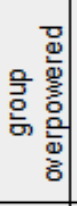 & 壳 & 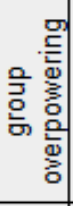 & 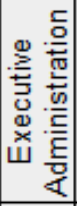 & 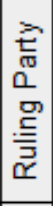 & 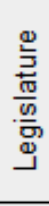 & $\begin{array}{l}\frac{0}{0} \\
3 \\
0 \\
\frac{0}{7} \\
\frac{0}{2} \\
\frac{0}{2}\end{array}$ & 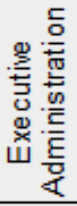 & 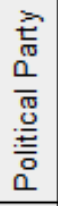 & 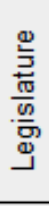 & $\begin{array}{l}\frac{0}{0} \\
\frac{0}{3} \\
0 \\
\frac{0}{0} \\
\frac{0}{2}\end{array}$ \\
\hline sub-governments & $\mathrm{X}$ & & & & $X$ & & $X$ & & & & $\mathrm{X}$ & & $\mathrm{X}$ & & $X$ & \\
\hline policy community & $\mathrm{X}$ & & & & $\mathrm{X}$ & & $X$ & & $\mathrm{x}$ & & & & $\mathrm{X}$ & & & \\
\hline prisoner insider $^{*}$ & $\mathrm{X}$ & & & $?$ & $?$ & $X$ & & & $\mathrm{x}$ & & & & $X$ & & & \\
\hline clientela & $\mathrm{X}$ & & & & $\mathrm{X}$ & & & $\mathrm{X}$ & $\mathrm{x}$ & & & & $X$ & & & \\
\hline issue network & & & $\mathrm{X}$ & $\mathrm{X}$ & & & $\mathrm{X}$ & & & & & $\mathrm{X}$ & $X$ & $\mathrm{X}$ & $\mathrm{X}$ & $\mathrm{X}$ \\
\hline Parentela & $\mathrm{X}$ & & & & $\mathrm{X}$ & & $\mathrm{X}$ & & & $X$ & & & $X$ & $\mathrm{X}$ & & \\
\hline
\end{tabular}

\section{CHAPTER 3: Elite Interviews, Systems Design and Case Studies}

\subsection{Introduction}

The present chapter discusses the research methods and the data collection process of the study. The present study consisted of two stages. At the first stage 26 elite interviews were conducted. That data provided guidance for the development of a case study that captured the parentela and its features in action, which in turn constituted the second stage. Elite interviews were a useful scanning exercise that captured so far unobserved dynamics in the policy network (parentela) literature. These new dynamics are discussed in Chapter 9, which is dedicated to a variation of La Palombara's parentela. Thanks to the in-depth elite interviews, it was possible to observe an image of the initial parentela: that of conflict between the party and core insiders versus specific outsider groups. However, the reason for the present research was designed to incorporate specific case studies is that interviews alone do not allow for the observation of a parentela as a system in operation. The approach that identified the parentela features in isolation from one another provided a segmented image of the parentela that is less reliable than presenting an actual case of it, particularly where all parentela features are observable in action. If all parentela features are evident in a political system, then a parentela must be in existence, but 
that is not the same as actually demonstrating one in operation. A case in point of an actual parentela in action will be discussed in chapter 8 .

The present chapter is focused primarily on the first research stage: the conduct of the 26 elite interviews. The intention was to replicate the backgrounds of La Palombara's pool of elite respondents (1964): civil servants, politicians and trade associations. This posed a challenge is it was necessary to develop a mechanism to compare both respondent pools in order to assess the validity of the data. If respondent backgrounds matched, then the parentela model observed in the Bulgarian respondent pool is equivalent to the parentela derived from La Palombara's elite respondent pool.

In order to address this difficulty, a counting system of respondent's policy-making embeddedness, or positionality, was developed. This term stands for the count of policy-making posts (relevant to the study) that a respondent holds or has held. These metrics help measure respondent's proximity to and embeddedness in the policymaking process. This helps compare the respondent pools and the extent to which the conclusions later are relateable (compatible) to one-another, policy-making and the overall policy network conceptual framework. The counting of a respondent's positionality points could be done multipositionally, i.e. counting the policy-makingrelevant posts a respondent has held in total, up to and including at the interview. Or conservatively, counting the single highest policy-making-relevant post held by the respondent at the time of the interview. The available data on La Palombara's methods (1964) allows only for a conservative comparison, the results of which indicate an approximate equivalence between the two respondent pools. This means that respondents from both pools came from the roughly same backgrounds and that the information they provided is relatable to the policy network framework.

The second challenge was to overcome the reluctance of most of the elite respondents. Target participants refused to be interviewed and even if some conceded to an interview, they still attempted to retain information. This challenge was overcome with the use of the intermediary. This is a relatively new research 
participant type that makes the formal introduction of the researcher to the target respondent and vouches for former's credibility (Petkov and Kaoullas 2016). The use of a small network of intermediaries helped secure interviews with some of the more reclusive political respondents. The other benefit using intermediaries came in their inclusion in actual interviews. They helped with some of the more tense respondents to calm them down and transform the interview into a discussion among equals. This improved the respondent-researcher rapport and the quality of the data released by the interviewee.

Regarding the second stage of the research process, the chapter discussess case studies (3.5.). In essence the study could be seen as a case of the parentela in Bulgaria, which comprises a number of nested case studies, each of which casts light on a different feature of the parentela or on the network as a whole. The present study could be seen as a Most Different Systems Design comparative project. It compares two quite different systems, i.e. 2010s Bulgaria to 1960s Italy, which share the same dependent variable, the parentela, but differ on the independent variable. In 1960s Italian parentela correlated with a single hegemonic party, while 2010s Bulgaria shows signs of the parentela, despite lacking a hegemonic political party. This particular absence of a pre-known cause for the possible existence of the parentela in the Bulgarian case means that the case studies have to be geared towards establishing the possible causes for the presence or absence of a parentela in the Bulgarian case. That in turn translates into the utilisation of the process tracing approach, known in the case study literature, where the researcher establishes a chain of causal dynamics that connect the effect (say, presenece of a parentela, as it will be revealed later) with its probable causes. This is discussed at more length in section 3.5 of the present chapter.

The present chapter therefore is structured as follows: section 3.2 is dedicated to the comparative scheme between the Bulgarian and Italian elite respondents. Section 3.3 reveals the causes for respondent resistance/reluctance from relevant literature. Section 3.4 then discusses the measures from the literature that were applied to this study $(3.4 .1 .1,3.4 .2 .2,3.4 .2 .1,3.4 .2 .2)$, as well as the effects of including the 
intermediary at the respondent selection $(3.4 .1 .3,3.4 .1 .4)$ and interview conduct (3.4.2.3) stages. The last section, 3.5, discusses the use of case studies in the present research.

\subsection{Elite Respondent Pools Comparison}

Before engaging in the debate on the techniques used to successfully solicit interviews from elite respondents, it has to be explained who was identified as an elite respondent. In this study, consistent with Lillecker (2003), Mikecz (2012) and Smith (2006), the lowest common denominator among all respondents is whether the person had held or was a holder of a post of authority in the policy-making process. This concern with authority is partly informed by Smith (2006) who adopts Allen's (in Smith 2006) position that it would be better to speak of power in terms of individuals possessing uncontested authority (Smith 2006: 646). This position is similar to Lillecker (2003) and Mikecz (2012) whose elite respondents were selected based on their position of political authority. For Lillecker, "Elites can be loosely defined as those with close proximity to power or policy making" (2003: 207). As for Mikecz (2012: 485), he sees elites as authority-bearing individuals who:

have been occupying powerful positions as senior government officials, chief executive officers, and senior managers in public and private organizations.

This study adopted the above conception of elite respondents and too focused on individuals who held or influenced those holding positions of authority in policymaking, coming from the three actors types that comprise the parentela: political parties, civil service (administration) and interest groups (trade associations). They were selected on the basis of the policy-making positions they held at the time of carrying the interview and/or in the past. In addition, an unanticipated respondent type was included in the study: business owners. While not immediate post holders, they were included because some of them had direct (recurring) contact with leaders and representatives of political parties in power, as well as with the administrative policy-makers. In any case, table 10 below makes a preliminary introduction of the cast of respondents: 


\begin{tabular}{|c|l|}
\hline Interview Nr. & Pseudonym \\
\hline 1 & Golemanov \\
\hline 2 & Dimitrov \\
\hline 3 & Kuzmanov \\
\hline 4 & Georgiev \\
\hline 5 & Aleksandrov \\
\hline 6 & Konstantinov \\
\hline 7 & Lyubenov \\
\hline 8 & Nikolov \\
\hline 9 & Mitrev \\
\hline 10 & Bachvarov \\
\hline 11 & Kirilov \\
\hline 12 & Petkov \\
\hline 13 & Hristov \\
\hline 14 & Valentinov \\
\hline 15 & Penchev \\
\hline 16 & Hadzhiev \\
\hline 17 & Zlatarov \\
\hline 18 & Cenov \\
\hline 19 & Gospodinov \\
\hline 20 & Donchev \\
\hline 21 & Mihailov \\
\hline 22 & Rumenov \\
\hline 23 & Stoyanov \\
\hline 24 & Dobromirov \\
\hline 25 & Petrov \\
\hline 26 & Varbanov \\
\hline & \\
\hline
\end{tabular}

Table 10 Interview Numbers and Respondent Pseudonyms

The left column indicates the chronological order in which the interviews were taken, while the right column lists the assumed names of the respondents.

In order to be able to effectively compare respondent pools it is necessary to examine and compare their backgrounds. In doing so, it will be possible to gauge the extent to which each study effectively represents each of the three actor types that constitute the parentela: Administration, Parties and (Interest) Groups. Moreover, this also enables us to assess the comparative validity of the present project to its earlier Italian counterpart. Ideally, both respondent pools will comprise the same respondent make-up and both will be fully embedded in the policy-making process.

In order to make this comparison, both respondent pools will be measured in terms of units of representativity. A unit of representativity is a respondent's career position with access to policy-making that they occupied. The difficulty in making a representativity comparison is deciding whether to take into account all policy- 
making posts a respondent has held up to and including the interview, or to take into account only the single, highest policy-making post an interviewee occiped at the time of the interview.

In the absence of details on his methods, La Palombara (1964) can only be assumed to have adopted what is defined here as a conservative representativity. This means that, what counts as an occupied post by a respondent is the highest position they occupied at the time of the interview. A multipositional representativity would then be counting all relevant post a respondent holds and/or has held in their policymaking career at the time of the interview. Posts are defined here as: any formal and informal position in political parties, state administration, interest groups and business firms that have recurringly made policy-making decisions or regularly influenced those who make them. In light of the parentela, this ideally means direct recurring interaction with a ruling party's leadership (or factions, see Chapter 7). The emphasis on informal is an acknowledgement of the observation that individual firms largely informally access to the policy-making process (Chapter 7). The emphasis on recurring is to highlight that the respondent had an insider status, as per Grant (1978) and Maloney et al (1997). Again, while the chapter argues that multipositional representativity is a more accurate mechanism for comparison of the respondent pools and a measurement of data validity, given the scant information on the background of La Palombara's respondents (1964), we can only compare both studies conservatively.

La Palombara (1964) conducted 25 interviews with respondents primarily from the three backgrounds: administrative, political and interest group. In table 11 below for the purpose of comparability, the respondents of La Palombara (1964) are represented by the same categories used to code respondents from the Bulgarian study. The Bureaucracy or State Administration is represented by the categories COM, DIR and MIN, where (COM) stands for a recurring participant or a convener of a consultative committee and (DIR) is a director of a state agency or a state-owned firm. La Palombara (1964), however, did not make any such distinctions (COM and DIR), hence the question marks. The final category is MIN and it stands for whether 
the respondent was a minister. There is one caveat, however. The MIN category could be seen as simultaneously representative of the Party and the Administration, because a minister is appointed by the party. From a strict point of view, however, and taking into account the fact that a minister deals primarily with the administration, a minister is counted as a representative of the administration.

Political parties are represented by the categories MP, LDR and ADV, which respectively stand for Members of Parliament, leaders of political parties and their respective (political cabinet) advisers. The category LDR in particular stands for a chairman of a political party, and not simply a high profile politician from a given party. These three distinctions cannot clearly be picked up from La Palombara's (1964) work, hence the question marks. Furthermore, the categories that indicate the presence of interest groups in the study are B and TA, which respectively stand for business owners and directors of Trade Associations.

Finally, La Palombara did not interview any business owners (hence empty boxes) and makes no indication of what is meant by a "leader" of a TA: an important figure or the respective director. Erring on the side of caution, this thesis assumes that a leader is a TA director or of an equal rank, although the same concession cannot reasonably be made when he refers to his respondents as "leader of a political party" (discussed in this section below). The profile of La Palombara's respondents is summarised in table 11:

Table 11 Profile of La Palombara's Respondent Pool 


\begin{tabular}{|c|c|c|c|c|c|c|c|c|c|c|c|c|}
\hline \multirow{2}{*}{$\begin{array}{c}\text { Page } \\
\text { number, } \\
\text { Interview } \\
\text { number }\end{array}$} & \multirow[b]{2}{*}{ Description } & \multicolumn{3}{|c|}{ Party } & \multicolumn{3}{|c|}{ Administration } & \multicolumn{2}{|c|}{ Groups } & \multicolumn{3}{|c|}{ Misc } \\
\hline & & MP & LDR & ADV & MIN & $\mathrm{COM}$ & DIR & TA & B & $\mathrm{J}$ & Whe & U \\
\hline 307,83 & $\begin{array}{l}\text { servant of the Ministry of Industry and } \\
\text { commerce }\end{array}$ & & & $?$ & & $?$ & $?$ & & & & & \\
\hline 309,3 & servant of the Ministry of Treasury & & & $?$ & & $?$ & $?$ & & & & & \\
\hline 318,7 & servant of the Ministry of Foreign Affairs & & & $?$ & & $?$ & $?$ & & & & & \\
\hline 328,16 & servant of the Ministry of Treasury & & & $?$ & & $?$ & $?$ & & & & & \\
\hline 344,37 & servant of Ministry of Agriculture & & & $?$ & & $?$ & $?$ & & & & & \\
\hline 326,79 & $\begin{array}{l}\text { Servant, highly placed in General } \\
\text { Accounting Office }\end{array}$ & & & & & & $?$ & & & & & \\
\hline 329,17 & $\begin{array}{l}\text { servant of the Ministry of Finance } \\
\text { Commando Generale "high placed" }\end{array}$ & & & & & & $?$ & & & & & \\
\hline 314,46 & Socialist deputy & 1 & & & & & & & & & & \\
\hline 316,40 & Leader of Christian Democratic Party & $?$ & $?$ & & & & & & & & & \\
\hline 345,4 & Leader of Christian Democratic Party & $?$ & $?$ & & & & & & & & & \\
\hline $\begin{array}{ll}337 \mathrm{fn} . \\
37,29\end{array}$ & Leader of Christian Democratic Party & $?$ & $?$ & & & & & & & & & \\
\hline 334,36 & socialist deputy & 1 & & & & & & & & & & \\
\hline 320,31 & member of the senate & 1 & & & & & & & & & & \\
\hline 311,98 & leader of Confindustria & & & & & & & 1 & & & & \\
\hline 312,30 & leader of UIL* ${ }^{*}$ & & & & & & & 1 & & & & \\
\hline 319,80 & leader of UIL & & & & & & & 1 & & & & \\
\hline 336,20 & leader of the National Civic Committee & & & & & & & 1 & & & & \\
\hline 338,35 & leader of UNURI ${ }^{*}$ & & & & & & & 1 & & & & \\
\hline 344,65 & representative of $|R|^{*}$ & & & & & & & 1 & & & & \\
\hline 309,33 & informed writer & & & & & & & & & & 1 & \\
\hline 310,81 & anonymous & & & & & & & & & & & 1 \\
\hline 310,94 & anonymous & & & & & & & & & & & 1 \\
\hline 335,59 & editor of a left-leaning periodical & & & & & & & & & 1 & & \\
\hline 337,90 & journalist & & & & & & & & & 1 & & \\
\hline 308,54 & key observer of the administrative process & & & & & & & & & & & \\
\hline \multicolumn{2}{|c|}{ TOTAL respondents per sub-category } & & 6 & & I & - & & 6 & 0 & 2 & & 3 \\
\hline \multicolumn{2}{|c|}{ TOTAL respondents } & \multicolumn{11}{|c|}{25} \\
\hline \multicolumn{13}{|l|}{ LEGEND } \\
\hline$\star$ & A trade association in Italy & & & & & & & & & & & \\
\hline MP & Member of Parliament & & & & & & & & & & & \\
\hline MIN & Minister, ex-minister & & & & & & & & & & & \\
\hline LDR & Leader of Pol. Party & & & & & & & & & & & \\
\hline $\mathrm{COM}$ & Participated in Consultative Committees & & & & & & & & & & & \\
\hline ADV & Adviser to Party $\mathrm{HQ}, \mathrm{PM}, \mathrm{MIN}$, Department & & & & & & & & & & & \\
\hline DIR & Appointed Director of a state agency/firm & & & & & & & & & & & \\
\hline TA & Director of a Trade Association & & & & & & & & & & & \\
\hline$B$ & Business Owner & & & & & & & & & & & \\
\hline J & journalist & & & & & & & & & & & \\
\hline W & writer & & & & & & & & & & & \\
\hline $\mathrm{U}$ & Unknown & & & & & & & & & & & \\
\hline
\end{tabular}

Upon closer inspection, six respondents stand out. Two people were journalists (J), one was a writer (W) and another three were unassigned a background (U). Therefore, a conservative estimate on his pool of respondents would suggest that his most reliable information must have come from 19 core (total core, below) interviews of immediate practitioners of policy-making. The quantity of his respondents could be summarised thus as in table 12 below. 


\begin{tabular}{|l|c|}
\hline \multicolumn{1}{|c|}{ ACTOR } & La Palombara \\
\cline { 2 - 2 } & $\ln 1964$ \\
\hline PARTY (Mps) & 3 \\
\hline PARTY (Leader of PP) & 3 \\
\hline PARTY (ADV) & 0 \\
\hline PARTY TOTAL & 6 \\
\hline MIN & 0 \\
\hline COM & 0 \\
\hline DIR & 0 \\
\hline ADMINISTRATION TOTAL & 7 \\
\hline GROUPS (TA director) & 5 \\
\hline GROUPS (TA rep) & 1 \\
\hline GROUPS (B) & 0 \\
\hline GROUPS TOTAL & 6 \\
\hline TOTAL CORE & 19 \\
\hline MISC (J and W) & 3 \\
\hline MISC (U) & 3 \\
\hline TOTAL MISC & 6 \\
\hline TOTAL RESPONDENTS & 25 \\
\hline
\end{tabular}

Table 12 Summary of La Palombara's Respondents'Backgrounds

Note in table 12 above that MIN, COM, DIR, ADV, B are null because La Palombara does not provide a breakdwon for such a respondent backgrounds. Let us now apply the conservative rule and compare respectively the respondent pools in table 13 below:

\begin{tabular}{|l|c|c|}
\hline \multirow{2}{*}{ ACTOR } & La Palombara & This Study \\
\cline { 2 - 3 } \multicolumn{1}{c|}{} & $\ln 1964$ & In 2013 \\
\hline PARTY (Mps) & 3 & 2 \\
\hline PARTY (Leader of PP) & 3 & 3 \\
\hline PARTY (ADV) & 0 & 1 \\
\hline PARTY TOTAL & 6 & 6 \\
\hline MIN & 0 & 1 \\
\hline COM & 0 & 0 \\
\hline DIR & 0 & 1 \\
\hline ADMINISTRATION TOTAL & 7 & 2 \\
\hline GROUPS (TA director) & 5 & 5 \\
\hline GROUPS (TA rep) & 1 & 0 \\
\hline GROUPS (B) & 0 & 4 \\
\hline GROUPS TOTAL & 6 & 9 \\
\hline TOTAL CORE & $\mathbf{1 9}$ & $\mathbf{1 7}$ \\
\hline MISC (J and W) & 3 & 0 \\
\hline MISC (U) & 3 & 0 \\
\hline TOTAL MISC & 6 & 0 \\
\hline TOTAL RESPONDENTS & $\mathbf{2 5}$ & $\mathbf{1 7}$ \\
\hline
\end{tabular}

Table 13 Conservative Respondent Pool Comparison, LaPalombara and this Study

Table 13 shows that there seems to be an imbalance in the representation of the state administration. At the time of interviews only 2 Bulgarian respondents were holders 
of an administrative post: one Minister and one agency director. Again, the main reason for that is the interview reluctance among the active staff in Bulgarian Ministries. On the other hand, interest groups seem to be better represented in the Bulgarian study. There is parity on the level of trade association directors at the time of interview of 5 in each study. To the advantage of the Bulgarian study, however, instead of La Palombara's J, W and U categories, there is an additional interest group related respondent category: business owners with access to policy-making. There also is parity in the representation of political parties with 6 in total per respondent pool. Finally, it seems that overall, the Bulgarian study is less representative conservatively than the Italian one with only 17 active postholders at the time of interview, against 25. However, this ignores the fact that La Palombara makes use of 6 respondents who are rather non-policy-making participants. Ultimately, therefore, discounting the miscellaneous (MISC) group from the Italian study, it is evident that the conservative representativity of the respondent pools is comparable, with 17 Bulgarian respondents to 19 Italian ones.

In addition, multipositional respondent description allows for the representativity of a certain time period. The variety of backgrounds in the Bulgarian study leads to high temporal representativity because respondent's careers cover almost the entire period of Bulgaria's recent democratic past since the regime change from totalitarian socialism to capitalist democracy in 1989. This adds another layer of validity particularly on those overlapping positions that are formed by respondents who have formed those positions while holding posts at different times. Let us first review table 14 below which summarises both approaches with the multipositional one on the extreme left: 


\begin{tabular}{|c|c|c|c|c|c|}
\hline \multirow[b]{2}{*}{ Respondent Background } & \multirow{2}{*}{$\begin{array}{l}\text { La Palombara } \\
\text { In } 1964\end{array}$} & \multicolumn{3}{|c|}{ Conservative Estimate } & \multirow{2}{*}{$\begin{array}{l}\text { Multipositio } \\
\text { nally }\end{array}$} \\
\hline & & $\ln 2013^{*}$ & Prior 2013 & $\begin{array}{c}\text { In + Prior } \\
2013 \text { Totals }\end{array}$ & \\
\hline MP & 3 & 2 & 1 & & 11 \\
\hline Party Leader & 3 & 3 & 2 & & 5 \\
\hline PARTY (ADV) & 0 & 1 & 0 & & 6 \\
\hline PARTY TOTAL & 6 & 6 & 3 & 9 & 22 \\
\hline MIN & 0 & 1 & 1 & & 4 \\
\hline COM & 0 & 0 & 0 & & 8 \\
\hline DIR & 0 & 1 & 4 & & 6 \\
\hline ADMINISTRATION TOTAL & 7 & 2 & 5 & 7 & 18 \\
\hline GROUPS (TA director) & 5 & 5 & 1 & & 7 \\
\hline GROUPS (TA member) & 1 & 0 & 0 & & 2 \\
\hline GROUPS (B) & 0 & 4 & 0 & & 6 \\
\hline GROUPS TOTAL & 6 & 9 & 1 & 10 & 15 \\
\hline MISC (J and W) & 3 & 0 & 0 & & 0 \\
\hline MISC (U) & 3 & 0 & 0 & & 0 \\
\hline TOTAL MISC & 6 & 0 & 0 & 0 & 0 \\
\hline TOTAL RESPONDENTS & 25 & \multicolumn{2}{|c|}{26} & + & 55 \\
\hline
\end{tabular}

Table 14 Conservative and Multipositional Comparison of Respondent Pools

It should be reminded that La Palombara (1964) does not elaborate on his respondents' background, which enforces the conservative positionality assumption that they were active single-postholders at the time of interview. A strictly conservative Italian-Bulgarian respondent pool comparison is in the categories In 2013* and In 1964, which shows some disparities in the Administration Total category and strict parity in the Party Total category. Table 14 reveals that relaxing the conservative rules increases the representativity of certain Bulgarian respondent backgrounds. In the Administration Total category, where conservative underrepresentation in the Bulgarian study is evident (with only 2 active admin respondents), a multipositional view that includes former administrative post-holders (5) totals 7. From strict parity in the Party Total category, including former postholders (Prior 2013) leads to a slight advantage of the present study in that background type. The last category Multipositionality, represents all relevant policymaking posts the Bulgarian respondents had held for that background. That, however, is only for information as no such equivalent measure is possible in relation to the Italian study. 
Table 15 below offers a full multipositional and temporal representativity breakdown of the Bulgarian respondent pool at the time of the interview, which has served as the source for the compilation of the above table 14:

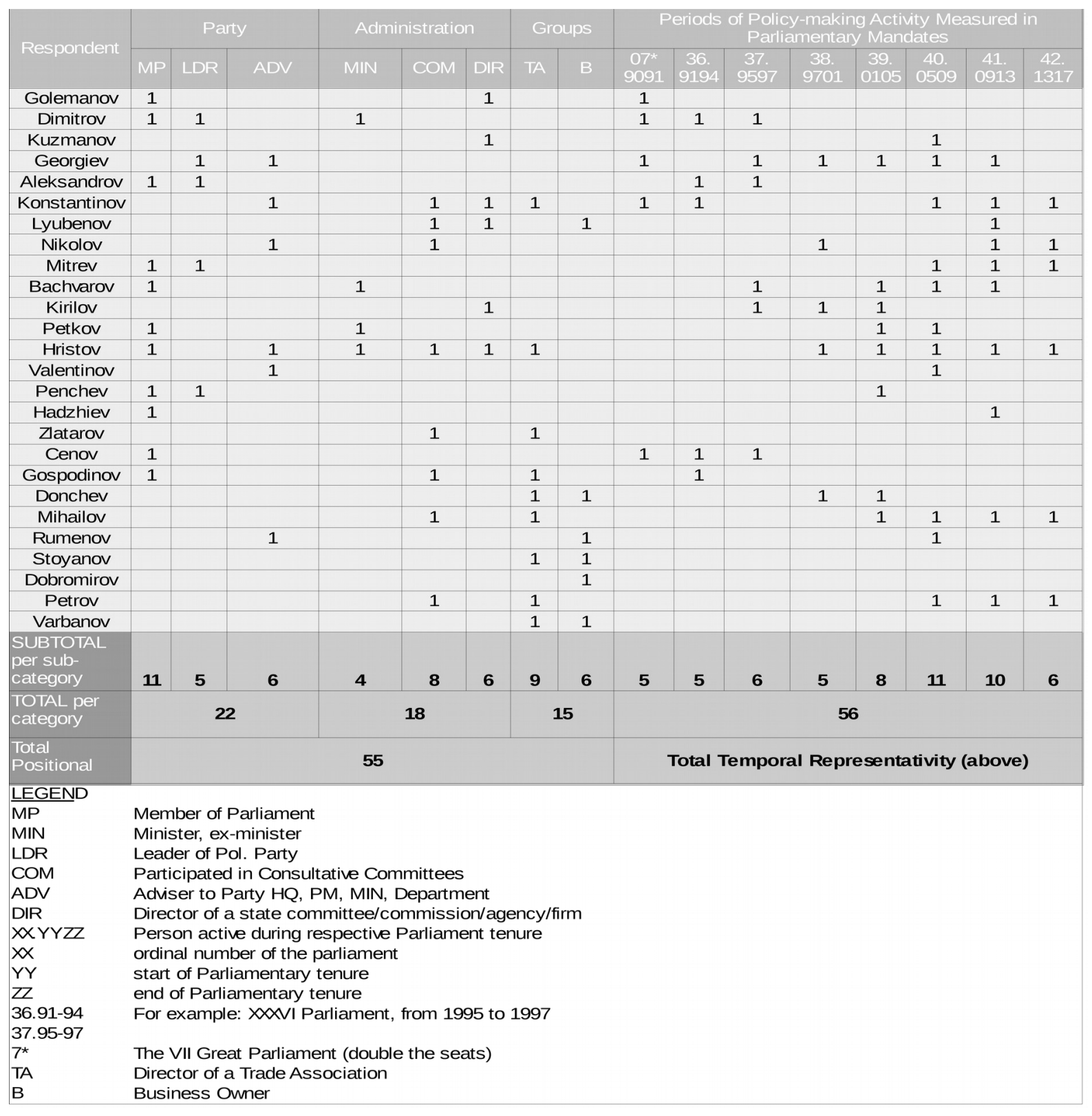

\section{Table 15 Detailed profiling of the Bulgarian Respondent Pool}

In table 15 above, the left half is dedicated to describing respondents who represent the three parentela background types, i.e. positional representativity. The right half denotes when the respondent was active holder of their posts. The time periods are measured in terms of Parliamentary sessions because given that political 
appointments are associated with the party in power, a postholder's longevity is linked to elections (chapter 5).

So, for example Hristov has been an MP, a Minister, adviser, committee chairman, agency director and a director of a trade association, with all of these positions held from $38^{\text {th }}$ to $42^{\text {nd }}$ Bulgarian parliament or from 1997 to the time of interview (and later). Table 15 is deliberately designed not to allow to match a parliamentary session to a particular post. Each position on the left bears 1 positional representativity point, while each parliamentary session covered, is marked with 1 temporal representativity point. As noted above, the right half of the table marks respective respondent's period of activity, which contributes to the representation of a certain time-frame. The table indicates that political parties tend to be a bit more represented in the study than the administration and interest groups, with 22, 18 and 15 multipositional representativity points respectively. With regards to the temporal representativity, it seems to be a bit more balanced with the period from 2009 to the time of interview in 2013 being more represented than other periods (parliaments in session), with 11 and 10 temp-representativity points respectively.

The multipositional approach is also applied in demonstrating the extent to which political parties are represented in the study. First, let us see how political parties are represented conservatively in table 16 below: 


\begin{tabular}{|c|c|c|c|c|c|c|c|c|c|c|}
\hline & $E L^{* * * *}$ & $X^{* * * *}$ & BSP & NDSV & DPS & GERB & $\begin{array}{l}\text { SDS/ } \\
\text { ODS** }\end{array}$ & VMRO & ATAKA*** & $\begin{array}{l}\text { Non- } \\
\text { political }\end{array}$ \\
\hline MP & & & 1 & & 1 & & & & & \multirow{4}{*}{8} \\
\hline Ex-MP & 1 & 1 & 3 & 1 & 1 & & 1 & & & \\
\hline Affiliated & 1 & 1 & & & & 4 & & 1 & & \\
\hline Ex-Affiliated & & & & & 1 & & & & & \\
\hline Sub-totals & 2 & 2 & 4 & 1 & 3 & 4 & 1 & 1 & 0 & 8 \\
\hline Total & \multicolumn{10}{|c|}{26} \\
\hline EL & \multirow{2}{*}{\multicolumn{10}{|c|}{ 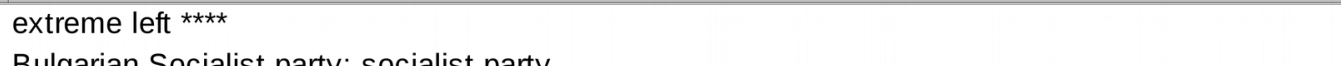 }} \\
\hline BSP & \multirow{2}{*}{\multicolumn{10}{|c|}{$\begin{array}{l}\text { National Movement for Stability and Prosperity (formerly, National Movement } \\
\text { Simeon II); }\end{array}$}} \\
\hline NDSV & & & & & & & & & & \\
\hline SDS/ ODS & \multicolumn{10}{|c|}{$\begin{array}{l}\text { Union of Democratic Forces/United Democratic Forces (briefly), center-right, now dysfunctional. } \\
\text { Dysfunctional parties with unreachable target respondents }\end{array}$} \\
\hline GERB & \multicolumn{10}{|c|}{ Citizens for European Development of Bulgaria, center-right } \\
\hline VMRO & \multicolumn{10}{|c|}{$\begin{array}{l}\text { Internal Macedonian Revolutionary Organization; patriotic party (not } \\
\text { equivalent to } \mathrm{BPI} \text { ) }\end{array}$} \\
\hline ** & \multicolumn{10}{|c|}{$\begin{array}{l}\text { Given party disintegration and exclusion from government, very small pool of potential } \\
\text { respondents was available, in a constant high barrier to access, hence, unreachable. }\end{array}$} \\
\hline $\begin{array}{l}\star \star \star \\
\star \star \star \star\end{array}$ & \multirow{2}{*}{\multicolumn{10}{|c|}{$\begin{array}{l}\text { irrelevant, the party was excluded from the study because never in } \\
\text { party names deliberately concealed to protect respondent identity }\end{array}$}} \\
\hline & & & & & & & & & & \\
\hline
\end{tabular}

\section{Table 16 Conservative representation of political parties in the study}

Some of the names of the political parties and respondent pseudonyms have been concealed. The parties are ordered from extreme left $\left(\mathrm{EL}^{* * * *}\right)$, to extreme right. It has to be noted that $\mathrm{EL}^{* * * *}$ above is a composite category of two parties. No hints are provided on purpose as to which party is X, other than it is between extreme left and the socialist left of Bulgarian Socialist Party. The table counts the party a respondent was in an active association, at the time of the interview.

However, a strict counting of MPs is an incomplete measure of political party representation. Party appointments both ministerial and administrative also allow respective individuals to speak on matters of the party, even if strictly speaking they occupy an administrative post at the time of the interview. The same goes for former administrative/ministerial appointees. Political advisers are another category of individuals who are neither MPs nor appointees, but have an insider view on the dynamics in political parties.

In order to reflect the idea that people with positions of advisers or someoen from outside political parties, too, can provide vantage point on the intra-party dynamics, 
the Affiliated lex-Affiliated categories were devised. The criteria for assigning respondents to the (ex-/)Affiliated category was whether they held a post, which is adjacent to political parties and which granted direct access to them. Therefore, if a respondent meets any one of the three conditions, they will go in the "(ex-)/ Affiliated" categories:

- If (former) MP of a different party (party nomads)

- if (former) minister (MIN)

- if (former) party leader of a coalition partner to a different party (LDR);

- if (former) an administrative appointee:

- if in a commission (COM),

- if in an agency director (DIR) or

- if in a State Owned Enterprise (DIR)

- If (former) adviser to MP or ruling party leadership (ADV).

A multipositional look on the extent political parties are represented in this study would produce table 17 below:

\begin{tabular}{|c|c|c|c|c|c|c|c|c|c|c|}
\hline & $E L^{\star * \star *}$ & $x^{* * * *}$ & BSP & NDSV & DPS & GERB & $\begin{array}{l}\text { SDSI } \\
\text { ODS** }\end{array}$ & VMRO & ATAKA*** & $\begin{array}{c}\text { Non- } \\
\text { political }\end{array}$ \\
\hline MP & & & 2 & & 1 & 1 & & & & \multirow{4}{*}{8} \\
\hline Ex-MP & & & 4 & 1 & 1 & & 1 & & & \\
\hline Affiliated & 2 & 2 & 2 & & 1 & 3 & & 1 & & \\
\hline Ex-Affiliated & 5 & & 2 & 2 & & 1 & 1 & & & \\
\hline Sub-totals & 7 & 2 & 10 & 3 & 3 & 5 & 2 & 1 & & 8 \\
\hline Total & \multicolumn{10}{|c|}{33} \\
\hline EL & \multicolumn{10}{|c|}{ 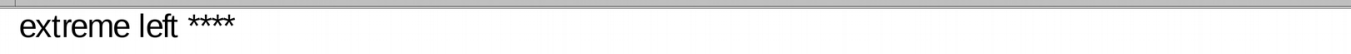 } \\
\hline BSP & \multicolumn{10}{|c|}{ Bulgarian Socialist party; socialist party } \\
\hline NDSV & \multicolumn{10}{|c|}{$\begin{array}{l}\text { National Movement for Stability and Prosperity (formerly, National Movement } \\
\text { Simeon II); }\end{array}$} \\
\hline SDS/ ODS & \multicolumn{10}{|c|}{$\begin{array}{l}\text { Union of Democratic Forces/United Democratic Forces (briefly), center-right, now dysfunctional. } \\
\text { Dysfunctional parties with unreachable target respondents }\end{array}$} \\
\hline GERB & \multirow{2}{*}{\multicolumn{10}{|c|}{$\begin{array}{l}\text { Citizens for European Development of Bulgaria, center-right } \\
\text { Internal Macedonian Revolutionary Organization; patriotic party (not } \\
\text { equivalent to BPI) }\end{array}$}} \\
\hline VMRO & & & & & & & & & & \\
\hline ** & \multicolumn{10}{|c|}{$\begin{array}{l}\text { Given party disintegration and exclusion from government, very small pool of potential } \\
\text { respondents was available, in a constant high barrier to access, hence, unreachable. }\end{array}$} \\
\hline $\begin{array}{l}\star \star \star \\
\star \star \star \star\end{array}$ & \multicolumn{10}{|c|}{$\begin{array}{l}\text { irrelevant, the party was excluded from the study because never in government } \\
\text { party names deliberately concealed to protect respondent identity }\end{array}$} \\
\hline
\end{tabular}

\section{Table 17 Multipositional Representation of Political Parties in this Study}

Note in the table above that the "non-political" column lists all respondents lacking any party political connections. Similar to earlier, the multipositional look provides a more realistic and accurate view of respondents' representativity. The seemingly 
modest conservative representation of Bulgarian political parties in the study assumes quite generous proportions when acknowledging both the flow and nuances of functionaries' interconnectedness with them, as reflected in table 17.

All of the above demonstrates that the multipositional counting system of institutional or actor type representativity is more realistic and accurate than the conservative one. However, it is not possible to tell what La Palombara's respondent selection criteria was, so comparison with his pool of respondents can happen only on conservative level. Overall, the respondents from the present study are generally comparable to those from La Palombara's, save for the group of respondents representing the civil service. Yet looking at the Bulgarian respondent pool from the multipositional perspective, then, that indicates the civil service is as represented as the other two categories (political parties and interest groups).

Moreover, the temporal representativity measure shows that the experiences forming Bulgarian respondents' perception of the policy-making process are overall balanced along the period from early 1990s to 2013, except for the 2009 to 2013 period, the end of which overlaps with the time of carrying out of the bulk of the field work. This period and the two Parliamentary Sessions it covers is twice more represented than other periods. This means that the study can be seen as a snap-shot 2013 Bulgarian politics. However, this also means we can generalise with some confidence within the 1989-2013 period. The temproal spread of the respondents shows high validity and generalisability of respondents' responses, particularly when overlapping statements were issued by different people occupying (or having occupied) different posts, at different times. After comparing the respondent pools between the present study and that of La Palombara (1964), the discussion in the following section 3.3 moves to how to convince elite respondents to given an interview and how to ensure that they provide full and trustworthy answers. 


\subsection{Causes of Elite Respondent Reluctance and Resistance}

Bulgarian elite respondents exhibited what Adler and Adler (1995) have labelled as reluctance and resistance. Key target respondents refused to be interviewed (reluctance) at all, while thers, on the other hand, did not cooperate at the interview and sought to withhold information (resistance). Many of them were also emotionally unstable, e.g. too tense, irritable, loud, or the opposite, very quiet, very brief and reclusive.

It transpired that the main cause for the above behaviour was researcher's positionality. Used in the context of elite interviews positionality refers to the idea that certain dimensions of researcher's identity could cause reluctant and resistant behaviour in the respondents. There are three major positionality types that could be distilled from the literature insider/outsider, expert and adversarial. The first relates to the extent a researcher is seen as part of the social, cultural or otherwise group the respondent belongs to. The second relates to the extent to which the respondent acknowledges the expert status of the researcher. The third relates to the extent the respondent perceives the researcher as a threat. Section 3.3.3 highlights adversarial positionality as the main cause for reluctance and resistance in this study. In doing so, it also distinguishes three subtypes of adversarial positionality, which will be discussed in more details below.

\subsubsection{Insider/Outsider Positionality}

The first type of positionality is insider/outsider and it refers to whether the researcher is perceived as part of respondent's social or cultural group. To be an insider one has to highlight any physical, social, cultural, ethnic or other identity trait in common with the respondent in order to advertise similarity with their cultural or otherwise, group (Belur, 2014: 187; Bondy, 2013: 582; Herod, 1999; MertkanOzunlu, 2007: 451-3; Mikecz, 2012; Mullings, 1999; Obasi, 2014: 65, 73; Paechter, 2013; Sabot, 1999). For example, a researcher is employing insider positionality when they seek to highlight that they, too, like their respondent are: also working class, of the same ethnic descent, of the same political views, basically anything in 
common that would make the respondent accept the researcher as "one of their own". However, practice has shown that advertising insider positionality does not guarantee rapport and may backfire (Enguix, 2014: 84; Herod, 1999: 324-5; Mikecz, 2012: 189-90; Paechter, 2013: 75-6; Sabot, 1999: 330, 332; Stephens, 2007: 206-8). Another controversy is whether it is within the powers of the researcher to define their positionality or it is conferred on them by those researched (Mullings, 1999: $346,347)$.

The present study can report that relying on insider positionality was as risky as approaching respondents from the position of an outsider. As it will be explained in section 3.4.3, for some respondents, such as Hristov, the researcher being outsider was a relief that he was disassociated from their political opponents. As for Dimitrov on the other hand, being associated with Western universities meant that the researcher was a foreign threat. Some of respondents' prejudism against the researcher support Mullings' warning above: that positionality tended to be rather a label stamped on the researcher by respondents, and not a matter of choice.

\subsubsection{Expert Positionality}

Expert positionality refers to whether the researcher acts as an expert or a layman at the interview. The ensuing power interaction at the interview usually causes the participant with an expert status to try and control the interview (McEvoy 2006: 185). Odendahl and Shaw (2001: 312) report that age-difference degrades the chances of novice researchers gaining access, which indirectly suggests that respondents interviewed by younger researchers will perceive themselves as experts and seek to dominate the interview. Seldon (1998: 11) seems to address these negative power dynamics, when warning that doctoral students' letters of introduction are unlikely to be warmly welcomed by prospective elite respondents.

The dismissive interview attitude of expert-statused elite respondents from this study is a reflection of the experience of Welch et al. (2002: 620-621) where: "On occasions elite dominance extended to directing and commenting on data collection and the analytical dimensions of the project". Many interviews also reflected the 
one-way dialogue type of power-asymmetric conflictual interviews presented by Kvale (2006: 684-685). In fact his typology is largely based on the hidden conflict over who would assume the "expert" mantle on the interview subject matter. For example, in his conflictual interview types - interviewer monopoly of interpretation, instrumental dialogue and interviewer rules the interview - the respondent dictates the meaning of the interview responses and the exact course of the interview, because they have the status of an indisputable expert (Kvale 2006: 484-485). (His manipulative dialogue seems more like a technique on dealing with resistance which will be discussed later in section 3.4.2 (Kvale 2006: 484)).

Expert positionality was a recurrent problem in nearly all elite interviews at the data collection stage of this study. This usually took the shape of Kvale's one-way dialogues, where the respondent dominated the interview by both asking questions and by using up the available time with bloated answers (2006: 484; and particularly respondents Golemanov, Kuzmanov and Aleksandrov). In many cases a respondent would reinforce their expert status by also asking the researcher questions, which in most cases were impossible to answer or were rhetoric, although it was very hard to determine either way (Kuzmanov, Konstantinov).

What a researcher could do in such situation is generally described in the expert vs ignoramus dilemma (McDowell 1998): when confronting an elite respondent, should the researcher act the expert to compensate the perceived asymmetry or act the ignoramus as someone who seeks to benefit from the wisdom of their interviewee. The views are divergent. Mullings (1999: 343), and Odendahl and Shaw (2001: 311) advocate researchers adopt an expert role. Similarly, to exude expertise seems also implicit in the research of Rivera et al. (2002: 685) who report that their expert status, equal to those of the respondents, greatly facilitated the rapport and conduct of their interviews. McDowell (1998: 2139), however, found that it was most beneficial to switch between the roles ad hoc, depending on the personality of the respondent at hand. Leech (2002: 665) however takes a more nuanced stance arguing that one should appear slightly less expert than the respondent, because the danger of the 
strictly expert approach is to appear intimidating. The experiences of this study seem to support his approach.

\subsubsection{Adversarial Positionality Types}

While it ultimately relates to whether the respondent will perceive the researcher as a threat, three sub-types of adversarial positionality could be distilled from the literature. The first and most prevalent sub-type of adversarial positionality occurs when there are two or more rival respondent groups (e.g. workers vs management, Mullings 1999 above), and the researcher is perceived by either of them as associated with the other. As a result, in what is termed here negative snowballing, being seen supportive of either camp precludes access to the other. In the case of Mullings, the mere act of helping a member of the managerial respondent group in a trivial accident was seen by the workers as a sign that the researcher had sided with management, and she admits that this closed her access to the workers (1999: 347). Similar predicament is also reported by McEvoy (2006: 185-186), who in researching opposing political camps in Northern Ireland, warns everyone entering the field against being perceived by their present respondent as a member of the opposing respondent group (e.g. pro-life respondent vs pro-choice respondent groups). For the same reason, for instance Herod (1999: 323) did not see it prudent to reveal the identity of her other target respondents at interviews. Woliver also reports that conflict among target respondents could lead to access being denied if the researcher is perceived to have favoured any of the camps in conflict by interviewing their opposition (2002: 677; also Neal and McLaughlin 2009: 694; Laurila 1997: 410).

The second type of adversarial positionality concerns the situation when the target elite respondent suspects rival elites as either sponsoring the study or in the position of taking advantage of it. For instance, Sabot was ostracised by the domestic French elites who were concerned that the information they provide will be used by their party political competition (1999: 330-332). Her breakthrough at home came only when she collaborated with a US colleague who had earlier been granted ample access by the same elite respondents that had previously avoided her (Sabot 1999: 
331). Upon reflecting on her experiences, Sabot concedes that, immersed in local politics, her respondents initially refused her access because they perceived her as associated with their political rivals (1999: 332).

For the same reasons, Mullings highlighted to her elite Jamaican executive respondents her British nationality and US academic background, and not her Jamaican descent (1999: 344). In the case of McDowell (1998: 2137) the data from interviews were also of interest to the market competition, and that brought tension in her interviews. The same could be said about Mikecz, who although had acquired reliable connections among Estonian elites, still found it necessary to highlight his Hungarian descent, as well (2012: 489-490). Overall, in an environment of competing business elites, as Herod (1999: 325) argues, in most cases a researcher has to find the "harmless" outsider identity dimension.

Given the varied sources of respondent prejudices in the Bulgarian study, it was hard to guess pre-determine what positionality to opt for. At an interview with an active minister, a third person had to convince them of researcher's disconnectedness from Bulgarian politics. However, at other occasions as described above, identifying oneself as an outsider was counterproductive. This relates to abstract adversarial positionality discussed below.

A new, third type of adversarial positionality can be the result of elites perceiving the researcher as associated with an abstract adversary. While in the previous two adversarial sub-categories it was possible to guess at least who respondent's rivals might be, that is impossible in this third respondent category. For some interviewees the perceived threat came from an either unknown or unverifiable adversary, such as but not limited to the intelligence services. It is safe to say that in this situation the respondents are concerned that the interview data would be intercepted and misused by an ill-intended someone, whom they are unable to clearly identify.

This respondent category, though unlabelled, is evident in the literature. For instance, Desmond was treated with grave suspicion by a core female elite respondent and a 
scientific staff member who were concerned that the competition might intercept interview responses (2004: 265-266). In what appears to be the most extreme case, Rivera et al. (2002: 684) were perceived by their respondents as spies, fearing the study was a cover for an espionage by Russian or foreign agencies. In their ample reference to the Denitch (1972) study, Rivera et al. (2002: 685) also appear to find traces of the same concerns with his then Yugoslavian respondents who distrusted his study's legitimacy (Denitch 1972: 153-154).

While all positionalities were experienced in some degrees, the Bulgarian study was affected primarily by abstract adversarial positionality. In many cases the respondents were prejudiced that either the intelligence services or that someone else hostile would intercept and misuse the interview data. As a result, it was impossible to generate rapport because it was impossible to demonstrate disassociation from an adversary that (probably) does not exist (e.g. that you are not a spy). The first indications of problematic positionality became apparent in the correspondence with respondent Dimitrov. That also coincidentally exemplified Goldstein's concern with the negative effects earlier researchers might have on the interviews of their colleagues with the same respondents at a later stage (Goldstein 2002: 672, endnote 2). Based on experiences with previous Bulgarian researchers, respondent Dimitrov refused to be interviewed. He feared the study would be politically exploited and ideologically biased in favour of the West, just as with the other Bulgarian PhDs studying in the West whom have interviewed him earlier.

In a similar vein, having read Dostena Lavergne's "The Experts of the Transition" (2010), respondent Lyubenov had formed the view that given its proximity to the subject of political corruption, the study was probably also financed or somehow associated with any of the US foundations in Bulgaria which Lavergne exposes in her book as serving US interests. That is why, in respondent's view, the study was deliberately seeking to establish malpractice and so be used as an instrument of political pressure by the West. Yet, it is true that the dislike of Western affiliation was not uniform. Respondents Hristov and Donchev were satisfied to find the researcher had lived the last 10 years mainly in the UK. Nevertheless, it remained that it was 
unpredictable as to how a respondent would react when hearing of a Western association. It was impossible to safely project neither domestic nor foreign identity so to elicit trust.

While Lyubenov and Dimitrov saw the abstract Western political elites behind the study, others, including some intermediaries (defined below, 3.4.), suspected the equally abstract intelligence agencies of monitoring the research project at the very least, if not controlling it outright. For example, Respondent Nikolov suddenly changed the interview venue and it was apparent that it was chosen for its remote location and noisy surroundings which would hamper any surveillance. Later, an intermediary (I2) made the occasional jokes that the researcher was doing a favour to MI5, if not working for them outright. This musing assumed more ironic contours when Dobromirov confided that in the past another Bulgarian researcher studying in the US, had been exposed as working for the CIA. Some respondents, obviously reacting on abstract adversarial fears, openly stated that the research thematics could put them and the researcher at undue personal risk (Rumenov, Mihailov, and Dobromirov). This fear was understandable, because for many respondents, their lifetime political and business adversaries were still in power and in theory could harm them.

Therefore, the tendency was for all respondents to resist employing specific names, places and dates, which was agreeable. One respondent refused to continue the interview unless the Dictaphone was switched off (Mihailov). On another occasion the mismatch between what was actually shared by respondent Stoyanov compared to the information elicited earlier through the intermediary was staggering as the respondent had pretended there had been no party-political pressure on his business. One could only guess the scale of such elite respondent information concealment. While the present section discussed reluctance and resistance as the main interview obstacles, the following one discusses the approaches taken to overcome them. 


\subsection{Reducing Elite Respondent Reluctance and Resistance Using an Intermediary}

The main solution to respondent reluctance and resistance was the involvement of a new research participant actor: the intermediary. The effectiveness of using an intermediary has already been reported to the methodological journal Qualitative Research in a collaborative paper with Lambros Kaoullas (2016). The research paper is titled "Overcoming Respondent Resistance at Elite Interviews Using an Intermediary" (Petkov and Kaoullas 2016). The present sub-section has served as a basis for the Bulgarian data and some of the argument in that article. The present sub-section argues that reluctance and resistance can be reduced with the help of intermediaries.

The literature on methodology uses a number of terms to identify the different research participants in addition to the researcher: Authors seem to inconsistently associate the research participant labels gatekeeper, informant, respondent and intermediary with the provision of contextual information, target respondent contact details, and the introduction (advocacy) of the researcher to target respondents. However, gatekeeper and intermediary labels appear to be more widely used to interchangeably denote the above functions. Healey and Rawlinson (1993: 346) see the intermediary as someone who provides an introduction to the target respondent. Herod sees gatekeepers as individuals who primarily provide contact details to target respondents (1999: 316). In addition, both Healey and Rawlinson (1993), and Herod (1999) seem to associate each respective term with the secondary ability to provide contextual information. Other authors, appear to be using the above contents, however, without consistently associating them to any of the two labels.

For instance Ostrander appears to have gatekeeper in mind when advising researchers on the benefits of using peripheral research participants who informed her of the institutional setting and of suitable target respondents and of "who to avoid" (1995: 136). Welch et al. (2002: 624) resorted to the help of respondents, who also were contextually peripheral to the respondent sample, primarily for the purpose of using their knowledge on the field context, making it hard to distinguish 
which research participant type out of the two was used. While being alone using the term sponsor, Adler and Adler (2001: 526) appear to refer to an intermediary research participant, i.e. someone who vouches for the integrity of the researcher and who makes the introduction to the target respondent: 'One function a sponsor can serve is as a referral to others in the setting, vouching for the researcher'.

Furthermore, in advising researchers to make use of additional informal research participants, Goldstein (2002: 671) oscillates between meaning a person who provides an introduction or someone who simply supplies contact details of target respondent:

DC is really a small town when it comes to politics and the more time one spends there, the more likely it is that one will make connections that can help one schedule an interview.

$\mathrm{He}$ is ambivalent whether he refers to gatekeepers or intermediaries defined above. The same ambiguity appears in Odendahl and Shaw's advice to younger researchers on gaining access (2001: 307). The authors do not make a distinction between providing contact details and making a formal introduction, when they advocate that access to target elite respondents could be facilitated by their friends or gatekeepers, i.e. the professionals who provide them with services (e.g. lawyers, accountants, etc.) (Odendahl and Shaw 2001: 307). Moreover, their use of gatekeeper and informant is inconsistent with that made by Mullings (1999) and Laurila (1997). While Mullings (1999: 338-339) and Laurila (1997: 410) make it clear that informant is synonymous to an interviewee, Odendahl and Shaw use the same in the sense of someone who provides contextual information ("Acquiring the right key informant can set the course of the research, because "Who knows whom" matters") and as someone who can be an interviewee ("gatekeepers may serve as key informants, and thus can be candidates for interviews themselves") (1999: 307).

In short, the above indicates that interview quality depends on the interview-auxiliary functions some participants perform. While labelling has been inconsistent, the literature seems to promote the terms gatekeepers and intermediaries with the cut-off difference between the two being intermediary's personal introduction of and advocacy for the researcher to the respondent. While both participant types can 
provide contextual details, the fieldwork experience in the Bulgarian parentela study supports the distinction that an intermediary is someone who vouches for the credibility of the researcher and personally introduces them to the respondent.

Conducting this research has showed that a good intermediary is best described as someone on researcher's side, helping them establish good contacts with the potential respondents and maintaining good relationship with them throughout the interview and after. An intermediary may not necessarily be a past interviewee and in the ideal case is someone who can understand the research thematics and would be willing to tactfully communicate them to target respondents. Intermediaries would possess above average knowledge of the target respondents in terms of latter's personality and career history. They are well embedded in the culture that they are able to effectively engage the target respondent in an informal setting. Therefore, they can forewarn of any culture-specific behaviour the target respondent might exhibit. The intermediaries in this research $(001 ; \mathrm{I} 1 ; \mathrm{I} 2,250 \mathrm{i}$; I3; I4) were able to secure interviews without causing any suspicion or undue distress, well-within cultural norms.

Another important attribute of the intermediaries in this study was their personal influence on target respondents. No favourable reception would have been secured, had it not been for the influence that intermediaries had on target interviewees. The source of this influence is not immediately apparent. For example I 2 simply dialled a number after another and the other side simply agreed to the interview. This may be due to respondent's respect for the intermediary, indebtedness, friendships, or simply the intermediary's authority.

However the best intermediary examples are provided by La Palombara himself in his long list of persons who helped in procuring access, such as academics, clerics, politicians and bureaucrats (La Palombara 1964: xiii-xv). For instance La Palombara (1964: xiv) notes a certain Doctor who "can open many doors" and a professor, who: seems to know everyone in Italy and passes that unique ability to lead the sometimes hapless researcher to exactly the person who can help to resolve a major field problem. 
La Palombara is clearly discussing an intermediary. The emphasis in both cases is not only on the possession of contact details but on the ability of the doctor and the professor above to procure interviews for La Palombara, i.e. they were intermediaries. The following subsections will reveal what techniques from the literature were applied at respondent selection (3.4.1) and interview stages (3.4.2). Also intended as contributions to the qualitative research literature, each subsection 3.4.1 and 3.4.2 features a sub-section dedicated to the use of intermediaries, respectively at selection (3.4.1.3 and 3.4.1.4) and interview (3.4.2.4) stages.

\subsubsection{Respondent Selection Stage}

\subsubsection{Specific Respondent Selection}

Two main techniques were attempted to decrease respondents' reluctance. The first was specific respondent selection, which stands for selecting in advance those individuals with highest propensity to be least inhibited to speak. Dean, Eichhorn and Dean (in Adler and Adler 2001: 523) have developed a typology of such respondents:

- frustrated (dissatisfied/axe-grinding),

- outsiders (those in the periphery of the policy-making process, while still having a vantage point),

- old-timers (those who are retired and cannot fear repercussions),

- outs (not involved any more but still have some information),

- neouveau statused (those who brag about their new position),

- rookies (those who are too naïve),

- subordinates and

- needy (attention seekers).

Overall, the tactics was to focus on the fringes of the political elite. Most respondents in the Bulgarian study were recruited from the outs, outsiders and old-timers. Other respondents also came from the frustrated and the needy (also discussed below).

In addition, and specific to this research, a new category could be added on the basis of the present study. These are the desperate respondents, who do not fear any repercussions or despite their fear do not care any more, because they feel they have lost everything. The difference from outsiders above is that the latter still calculate the participation risks, while the former make no such assessment as their circumstances cannot get any worse, even if an adversary finds out about the 
interview. Some of the best interviews in terms of rich data and good rapport came from that group.

\subsubsection{Offering an Incentive}

The careful respondent selection in this study went hand in hand with an incentive offering. This is a non-material benefit that the respondent perceives to gain from giving an interview. The benefit was usually in the media platform the interview provided. The fact that respondents resisted to provide full answers should not confuse as to their internal desire to talk on these issues. In most cases, it was obvious that despite the fear of repercussions there was a genuine willingness and interest in discussing interview subject matters. In that sense, the interview offered respondents the opportunity to be heard, although some found other uses as well.

In this research this was most relevant to the groups of the frustrated, the outs and the needy (above), because therapeutically they wanted to share their views. Virtually all respondents made some use of the interview to their own ends, in most cases simply venting at the political system (Kuzmanov, Konstantinov, Zlatarov, Boykov, Mihailov, Petrov, Dobromirov, Kirilov, and Donchev). Others used the opportunity to pursue a party political line (Georgiev, Aleksandrov) or criticise a specific party in particular, sometimes their own, (Kuzmanov, Georgiev, Penchev, Hadzhiev). Apart from using the interview as a media outlet, surprisingly, some respondents also used the interview as a party cadre recruitment opportunity (Aleksandrov, Georgiev and Hristov).

The "offer" to respondents above was made in the letter of introduction, as per Seldon (1998). Most of the literature on this subject focuses on the importance of letters being concise and deriving legitimacy by noting sponsoring bodies (Denitch 1972: 152-153; Zuckerman 1972: 162; Aberbach and Rockman 2002: 674). Others highlight the importance of exuding expertise by providing indication of possible questions and explanation of the study, as well as highlighting the importance of the respondent by explaining why they are so valuable to the study (Lillecker 2003: 209; Aberbach and Rockman 2002: 674; Seldon 1998: 10-12; Richards 1996: 201-202). 
However, only Seldon makes the important addition that a letter of introduction could also contain a section on the offering to the respondents, or a carrot in his parlance (1998: 11). The e-mails usually referred to statements respondents had made in public on topics that are relevant to the study and which they were invited to elaborate on. On other occasions, it was emphasised that the respondent is the sole reliable source on these topics, which is why they are invaluable. That usually had the effect of pre-determining the expert-supplicant relationship (see 3.4.2.) before the interview.

\subsubsection{Intermediary's Respondent Identification and Researcher legitimation}

The main function of the intermediary in this study was to provide an introduction to target respondents. They personally met them and verbally introduced the researcher, the study and enquired of any interview availability. This contact is unregulated by the researcher and for a period of time was a point of friction with one intermediary. There was a risk that the study or aspects of it would be misrepresented - a point already raised by Laurila (1997: 410). However, taking into account their deeper cultural embeddedness, their knowledge and personal relationship with the respondent, it was decided to leave full discretion with the intermediary. They knew best how to approach the target respondents in a way that it would not jeopardise their relationship. That is why, any confusions or additional information was to be later addressed by the letter of introduction that usually followed the initial contacts. It featured a more informative description of the study and explained in more detail why the respondent was invaluable for the study.

The secondary function of an intermediary was to provide contextual information. The literature has identified that such information could help improve: respondent selection (Lillecker 2003: 2); rapport, by knowing the host culture better (Mikecz 2012: 485-486; Welch et al. 2002: 622); and the accuracy of researchers' questions (Aberbach and Rockman 2002: 674; Gubrium and Holstein 1995: 46, 77). In addition this study used intermediaries to help identify the network of people through which a target respondent could be reached. In such situations, a good intermediary is a good 
analyst of people's interpersonal relationships in order to reach the target respondent (through other intermediaries or gatekeepers).

\subsubsection{Intermediary Snowballing}

The provision of contextual information was also useful for the purpose of snowballing. This is a method of accumulation of respondents where every last respondent becomes a gatekeeper/intermediary to the next, who is usually their colleague. Depending on the intensity of reluctance, three types of snowballing could be identified, each of them with a corresponding increase of the pressure on the target respondent to cooperate.

Reading through the literature, the first type is horizontal snowballing, detectable in studies devoid of respondent vulnerability. The way Herod used snowballing was by using gatekeepers from his local target organization to transfer him to other foreign organizations of equal standing, i.e. transfer among equals without any notification of distress involved (1999: 316). Lillecker (2003: 209), too, advocates the snowballing across equal in standing respondents, say, among former colleagues. Davies (2001: 76) snowballed to gain access further in his elite respondent pool by asking each respondent to provide access to any of their colleagues, also implying an equality of status among former and future respondents.

The second type of snowballing is vertical (downwards). This is evident in the cases where research is conducted inside organizations and where snowballing starts from the organizational top. In this snowballing type a permission of conducting research is obtained on a directorial level and then, once obtained, researchers apply the authority of this permission in persuading respondents to concede to be interviewed. Healey and Rawlinson (1993: 346) advise researchers of businesses to focus on gaining the permission of higher managers. Laurila (1997: 409-410) discusses their access as a result of top-down negotiation between the sponsoring body and representatives of the target organization. 
In the same vein, the research in other studies relied on an authority but from a different source - the sponsoring organization (Rivera et al. 2002: 684-685; Adler and Adler 2001: 526). This is also evident in the study of La Palombara (1964: ix-xv) which was conducted under the auspices of a number of US and Italian universities which negotiated access to target respondent organizations. The same is valid for the study of Denitch, who negotiated access on top organizational level between US and Yugoslavian academic and state authorities (1972). Likewise, the sponsoring organization of Welch et al. (2002: 620) negotiated access with the host respondent body.

However, horizontal respondent snowballing did not work in this study due to the high reluctance among respondents. Many of them were weary of making it known to outsiders that they had given an interview and were overall reluctant to suggest consequent respondents. For instance, while respondent Aleksandrov initially boasted knowing many people that would be suitable respondents for following interviews, only after some pressure did he later provide the number of another prospective respondent. Upon inviting respondent Konstantinov to propose follow-up interviewees, they loudly exclaimed with irritation that this was researcher's problem. The same person clarified that they would not like any of their colleagues to know they had had that interview. In agreement with Laurila (1997: 410) and Ostrander (1995: 141-142) that access was continuously negotiated, it became clear that permission to an interview did not immediately lead to agreement to provide further contacts, hence, respondent-based snowballing was hardly possible given their high reluctance.

What proved to be highly effective strategy in the Bulgarian project was a combination of horizontal and downward vertical snowballing through intermediaries. That is, each intermediary promotes the researcher to another, and also where each intermediary holds vertical downward access, to a handful of respondents, given the authority they have over them. As already explained above, while it was impossible to make direct observations on how the intermediaries did it, it seemed intermediaries had an aura of authority over the respondents, based on pre- 
existing loyalties, friendships and simply trust between them. However, it has to be acknowledged that considerable time was consumed securing an interview. On a few occasions it was necessary to approach a target respondent through two (interview with Lyubenov) or three consecutive intermediaries (interview with Bachvarov).

\subsubsection{Interview stage}

Looking at the literature on conducting interviews, two approaches were devised to reduce interview resistance. The first approach was to construct the interviews on the basis of ad hoc, open-ended questions that were formulated on the spot, with the occasional quotation of excerpts from earlier respondents (3.4.2.1). The second was to adopt the active interview style of Gubrium and Holstein (1995) (3.4.2.2) and combine that with the active participation of the respective intermediary to that respondent (3.4.2.3).

\subsubsection{Interview structure}

The first technique was to start from the general and then move to the more specific questions (prepared in advance of the intervew), which might cause greatest resistance. It is beyond the scope of this discussion to enlist all authors, but suffice it to say the idea was to save the most difficult questions for last (Lillecker 2003: 209, 210; Davies 2001: 76-77; Healey and Rawlinson 1983: 250; McEvoy 2006: 185; Woliver 2002: 677; Adler and Adler 2001: 529). In our case such questions related to several topics. The questions on circles in Bulgaria almost always caused discomfort: how they work, what were respondents' experiences in interacting with them or what were their life-time observations on the circles. The other difficult topics related to the practice of political appointments, the relationship between the party in power, and big business, and of party coercion of select businesses through the state agencies.

The approach rests on the assumption that the researcher is well aware of respondent's past in advance of the interview. Such contextual information is critical for the approach to work. Some interviews, however, were not that successful 
because it was not possible to know enough of respondent's background in advance so to ask relevant questions.

A second technique was to ask semi-structured questions on the spot which emanate from the topic at hand, as opposed to firing pre-determined ones (Davies 2001: 76; Gubrium and Holstein 1995: 76; Aberbach and Rockman 2002: 673; Odendahl and Shaw 2001: 310; Richards 1996: 202). Consistent with the literature, the benefit was that the interview flow was more natural and the transitions from one topic another fitted very well in the overall interactive and conversational framework (e.g. 3.4.2.2.). All of that was coupled with reiterated promises of anonymity of their participation, which further helped relax the interviewees (Richards 1996: 203; Davies 2001: 77).

However, the difficulty in this approach is that the conversation might alternate between topics, without necessarily finishing them. So, the researcher has to remember all unfinished topics and explore them later. Where it worked, the approach yielded great rapport and rich responses. However, it was not always possible to follow all unfinished threads, due to the answer complexity and the highly emotional respondents' disruptive behaviour.

Finally, while not specifically designed to reduce resistance and though more relevant to a debate on validity, the practice of triangulation was also useful in reducing resistance. Davies (2001: 78-9) and Richards (1996: 203) advocate juxtaposing respondents' answers to one another in order to ensure high response validity. Applying this technique had mixed results. While the most suspicious respondents would not believe the quotations of previous interviewees were genuine, citing previous respondents relaxed some participants as they heard that other equally important people had exposed themselves vulnerable by braving the subject.

\subsubsection{The Active Interview}

In trying to dampen resistance, the active interview approach was attempted in all interviews. The intention was to move away from the tense power dynamics inherent 
in classic elite interviews by developing a more conversational atmosphere among equals - akin to Gubrium and Holstein's active interview model (1995). Their position is that standard interviews that forbid intensive interaction with the respondent, lest data is contaminated, unrealistically assume that the respondent would unemotionally provide "uncontaminated" answers (Gubrium and Holstein 1995: 9). The text-book perspective therefore wrongly sees respondents as "vesselsof-answers", while in reality they can only interpret or self-reflect on their past experiences and should be seen as "vessels-of-knowledge" (Gubrium and Holstein 1995: 30). Respondents, therefore, should be induced to use their self-reflective and interpretative abilities to produce "knowledge" in an interactive event with the researcher (Gubrium and Holstein 1995: 30, 59). Validity in other words becomes about respondents constructing meaningful answers to the posed questions, based on deep self-reflection on past experiences (Gubrium and Holstein 1995: 9):

the validity of answers derives not form their correspondence to meanings held within the respondent but from their ability to convey situated experiential realities in terms that are locally comprehensible

In a way, the respondent becomes the "device" with which knowledge is produced from the social world, and through the use of questions, the researcher becomes the operator. Looking at it in another way, Gubrium and Holstein (1995) appear congruent with Berry's position that "excellent interviewers are excellent conversationalists" (2002: 679) because all authors emphasise that an interview generates more data if it is closer to a natural, lively, conversation. Therefore, excellent interviews are excellent conversations. That is why the main attempt at the interviews was to create an analytical-conversationalist atmosphere between two nearly equal participants.

This approach was useful because it moved away from the immediately factual review of past events, the details of which nearly all respondents resisted to provide. Overall, the intention was to guide interviewees to use their professional experiences in producing analytical responses in a more conversational context. Conducting the interviews in this way served as a wall behind which one could hide all the facts and 
details they were not comfortable with. For instance, asking a trade association director to evaluate the relationship between interest groups and the state administration, invited the respondent to use the totality of his experiences in dealing with the civil service and exercise discretion as to what examples to provide. In some instances, where respondents demanded a more detailed introduction to the theory behind the study, they were happy to recognise their own thinking and experiences summarised in the parentela dynamics.

In most cases, however, while the questions did indeed probe into personal past experiences, the conversationalist element was rather limited, largely due to the discrepancy in age and status with the respondent (e.g. expert positionality). The approach also rests on the assumption that the researcher is well aware in advance of the interview in order to formulate questions that more precisely tap on respondents' experiences. This contextual information is critical for the approach to work and was not always available, which reflected on the interview quality.

\subsubsection{Intermediaries at Active Interviews}

While trying to employ the active interview approach, at the same time, some interviews provided the opportunity to include the intermediary as well. The usefulness of intermediaries taking part in the elite interview reduced respondents' resistance and improved the received data. In fact, there is already some evidence that the use of intermediaries at interviews help reduce the tension between the respondent and the researcher. Probably one of the earlier documented deliberate uses of an intermediary to that end comes from Shaw (in Odendahl and Shaw 2001: 307, emphasis added):

While interviewing individuals on the topic of best practices for grantmaking research, Shaw (1997) was fortunate to have a member of a wealthy family on the advisory committee who actually joined her on the research team. This person's presence proved invaluable in establishing rapport and making the interviews less guarded. People, regardless of their status, like to converse with others with whom they feel comfortable

While it is only implied that they introduced Shaw to her later respondents, akin to employing an intermediary, she included in her later interviews an authoritative person, with good reputation whose presence at interviews reduced respondents' 
resistance. The conversational exchanges between the intermediary and the respondent are highlighted above as reducing the overall tension. To reiterate, having befriended a colleague from the US (the intermediary), Sabot used him to procure interviews with the elite respondents they both shared and who had earlier refused her any interviews (but not to him) (1999: 331).

The intermediary-based interviews in this thesis also had a strong emphasis on creating a conversation between the respondent and the intermediary because that in turn facilitated the rapport between the researcher and the respondent. While the downside of this approach was that the conversation between the intermediary and respondent could veer off, the conversation was steered in the desired direction by timely and accurate questions. Overall the sporadic involvement of the intermediary created interviews of different dynamics, where that participant assumed a distinct role of a providing balance between the researcher and the respondent. The net result was increased rapport in otherwise highly conflictual and resistant interviews, also leading to the collection of more information. With some pre-existing instruction, the intermediary asked tough questions, which the researcher could not have afforded raising otherwise (Nikolov, Dobromirov). In any case, the intermediary consistently helped reduce respondent resistance and helped uncover information respondents usually sought to conceal. In sum, involving an intermediary at the elite interviews provided the following two benefits:

1. Reducing the conflict between the respondent and the researcher:

$\circ$ by behaving as if the academic interview is a casual conversation;

○ by supporting the respondent;

- by supporting the researcher

2. Uncovering more information:

$\circ$ by provoking the disclosure of information the respondent attempted to conceal.

The study made use of intermediaries at 7 elite interviews out of 26 . The next section will illustrate the points above. Before continuing further, a quick note on the formatting of upcoming quotations is necessary:

S reSearcher;

R Respondent; 
I Intermediary;

litalics/ participant's behaviour

/italics -- X/ interjecting participant: $\mathrm{S}, \mathrm{R}$ or I;

( ) author's in-quote clarification or comment;

[...] author's edits of quoted material;

mmss a time-stamp format for emphasis, mm-minutes; ss-seconds

A to $\mathrm{Z}$ letters used to redact an actual name, activity or event

\subsection{Casual Conversation}

The first way in which the intermediary decreased respondent resistance was by taking part in the interview and by tactfully engaging the respondent. Some intermediaries attempted to provide answers or provided opinions to posed questions alongside the respondent and made the latter feel comfortable by talking directly to them for a while on unrelated topics. This was another manifestation of the active interview. The difference is that the active engagement with the respondent is made by the intermediary and serves the purpose of increasing rapport by bonding with them. The interviews with respondents Nikolov and Dobromirov for instance began and were littered throughout with friendly exchanges between the two. The interviews with Hristov and Dobromirov featured inquisitive interjections by the intermediary towards the respondent. In the context of a friendly conversation, humour was in fact welcome, as with respondent Petkov who took the liberty of the following anecdote:

R: Boyko Borisov, do you know why they hurried to sign him out from the cardiology ward, the governmental one, you know, they could not print out even one EKG slip: he snipped the band as soon as it come out.

Another similar example was the moment when respondent Nikolov deflected the topic of conversation in the direction of the future of young Bulgarians, focusing on the intermediary as the conversation partner. In this situation (and as with Dobromirov), the researcher decided to stand aside as an observer and wait a 
reasonable period of time before intervening again the conversation and redirect it to a relevant topic.

\subsection{Support to the Respondent}

Another way in which the intermediary reduced respondent's resistance was by providing emotional support to the respondent. This came in the form of spontaneous interjections in agreement with the respondent and even speaking in their defence in front of the researcher. The accumulation of such interjections created the impression that the interview was dominated by "respondent's team". The brightest example is the following critical moment for respondent Petkov:

$S:$ And what would be the effect of political appointments?

$R$ : Well, if they appoint kalinkil, the effect is bad. If for example for political reasons I appoint Y because I know he will be doing a good job, or let's not give an example with Y -I know for instance-The chief of my political cabinet, which is not part of the state administration, but the man with whom I have worked the longest in the ministry of $X$, was the husband of my first cousin. "But why did you appoint him?" /slightly raises voice/ "I trust him most, you people!" He is capable, a colleague of ours /"us" meaning intermediary and themselves/ and he is from state security, but it does not matter--

I: It does not matter, it is important that they work!

R: Iraises voice/ because I trust him! I don't want to be betrayed! (/in agreement/ Ahem. --I). Governance is a collective job. In Bulgaria, collective sports do not work, and that's including politics, if we take it as a form of collective sport. (This is true -I) Because there has to be a team! /raises voice/ and it is hard to make a team! (Yeah -I) In the team there is always someone who is better, and they refuse to play in the national team! For example, Berbatov, (llaughing/ --I) Kaziyski /inaudible/ the same is with politics!

In the quotation above, the respondent experienced discomfort from the discussion of the topic on political appointments, because they had personally made such in the course of their ministerial duties. Noticeable is the sudden interruption in their response where they seem to switch from talking about appointments in the state administration to a less confrontational terrain of appointments in their political cabinet. Emotionally escalating from the start of their response, the interviewee's

1 kalinka, kalinki (pl.) - reference to the public case of Kalina Ilieva, who was appointed chief of the State Fund for Agriculture, and who was later convicted of forging her diploma of higher education. The word kalinka also means ladybug. 
stress culminates in the enactment of a scene where they are, as if, under public criticism. They are not only raising their voice, but they make an explicit addressal to the abstract adversary "you people!" The accusative "you people" also included the researcher, because they raised the question, seemingly, on behalf of the perceived adversary (the general public).

At this confrontation, a key role is played by the intermediary who defended the respondent with "It does not matter, it is important that they work!" and supported them emotionally by uttering the minute "yes" and by laughing at the appropriate times. They sought to degrade the critical edge of the question and communicate that the respondent is right. That is to say, those gestures were intended to protect the respondent from the researcher. A similar situation, but going out of control was when respondent Lyubenov entered a short tirade against the researcher (again as a representative the abstract adversary), but there was no one to vouch for latter's reliability.

\subsection{Support to the Researcher}

An intermediary could also express support of the researcher to the effect of reducing resistance, as well. In some moments an intermediary legitimized the researcher as someone on the side of the respondent and whose behaviour was dictated by the essence of the academic literature and not by personal attempts at exposing malpractice. In relation to Mullings' concern on who has the power to define researcher's positionality, this was a clear example of a more influential participant favourably defining researcher's positionality. Example of that is the intervention of the intermediary at the very beginning of the interview with Petkov, who had immediately took control over the interview with the question:

$R: \quad$ /to S/ Any preliminary knowledge on these questions regarding Bulgaria... do you have any pre-existing knowledge, what happens in Bulgaria, how these questions are resolved?

I: Well, I apologise for interjecting, your question is very accurate! (/contemplative/ Hmm... --R) He left /Bulgaria/ at the age of 18, (Ah, you have detached a lot from, yes $-R$ ) and during all those years, already tenth year, he does not have the direct look on things. From one side this 
is good, because he is not (Yes, not burdened -R) burdened, /inaudible/ and that is why I find him that he even finds Bulgarian hard, but regardless. My point is that he is not burdened and that is why he is asking like that. /pause, all quiet/ /with concern/ By the way, he made a few interviews, he is collecting his materials so to speak, [...] In fact, /to the researcher/ you say, I interrupted...

$S$ : Yes, yes, yes ... /approvingly/

This case is an excellent example of the power asymmetry between the respondent and the researcher on the grounds of expertise and covert adversarial concerns. Already from the first seconds, the control over the interview is taken by the respondent, whose questions undermined both researcher's right to attempt such thematics and their motives in doing so. However, pleading in their defence, the intermediary stresses that the interviewer had been so detached from Bulgaria that they even found it hard to speak Bulgarian, hence impossible to be politically prejudiced against the respondent. The intermediary took the initiative to redefine the positionality of the researcher as uninformed outsider.

\subsection{Eliciting More Information}

The final benefit of involving intermediaries in elite was that they helped uncover information the respondent deliberately attempted to hide. One way to do that was to change the topic of conversation to another which was much closer to the topic of interest to the researcher (Kuzmanov). The other way was to indirectly provoke the respondent to expand on their answer. Sometimes there are opportunities for probing which the researcher might abstain from in order not to aggravate the situation, and delegate those to the intermediary, instead. At interview with Nikolov, for example, the intermediary provoked on two occasions the respondent to expand their answer:

$S:$ Ah, is it true that around Kostov was that circle, Olimp...

R: Yes, /pausel

I: /inaudible/ with them now?

$R$ : Well no, they went elsewhere, I want to tell you that they, from that circle Olimp, the only one left is -

$S: X ?$

$R: X$ is left, but he bends over to absolutely everybody, I want to tell you.

$X$ is in a very good relationship with Boyko [Borisov]. 
I: Huh?! /surprised; disbelief/

R: How else?! /confidently/

It is noticeable in the quotation above that there is a pause that follows the immediate answer "yes", which signifies that a certain hesitation had taken place, most likely how much to be shared with the researcher. As a result of the question of the intermediary, however, the respondent enriched their answer. Another example is offered in the interview with Hristov:

$S:$ And what decreases the effectiveness of these relationships, [...] what hampers business, for example, to express clearly their position before the state administration. Is there any inefficiency innate to the state administration which inhibits it?

$R$ : Well, business can very clearly declare that which is considered as a problem. For example, if they deem that the state has overused her rights with the control organs, they could say that categorically and unequivocally $[\ldots]$

I: I apologise, but do they really do that?

$R$ : Some do, others are afraid.

S: Why would they be afraid?

In this situation one could better observe the unsuccessful attempt of the respondent to conceal the conflict which exists between some business groups and state administration. Their attempt at hiding friction between interest groups and the state administration over access to the policy making process is discovered by the intermediary, which is why they intervened with "do they really do that?"

In the case of Dobromirov the concealment was not only expected but pre-empted. The way the respondent began the interview was an early sign that they would be pre-disposed to information concealment: "Your topic is so gruelling, in the sense that it is one thing to write it /pause, thinking/ it is entirely another to reflect it [in the thesis]". The intermediary to Dobromirov was briefed on where the discussion would ideally venture and twenty minutes into the interview they decided to expose the undergoing deflecting manoeuvres of the respondent and position the conversation on its right course: 
1820 I: /interrupting/ you tell him in your field how-from which moment did you begin as a main contractor with your own machinery [but ended up as] subcontractor? How did things turn around?

1833 R: /mumbling/Well, when he came...

$1835 \mathrm{I}:$ /raising voice, interrupting/WHO?

1836 R: /inaudible, mumbling/... to power...

1837 /silencel

1842 R: I simply... about this [Bulgarian] people... /brooding/

$1845 \mathrm{I}:$ /to respondent/, tell him about [the highways] how you were paid?

1850 R: Well, look now, this is not only [the highways] — it's everywhere.

In this final example above, the intermediary had clearly noticed the evasive language used hitherto by the respondent and hit the spot with the information which the respondent tried to conceal. It is clear that the respondent was particularly evasive in three ways: by resisting to answering the intermediary, by giving, though self-reflective, very general response "about this [Bulgarian] people..." and that whatever happened to him was "everywhere". Noticeable also is the silence of nearly 5 seconds (1837-1842). That signifies respondent's internal stress and most likely calculation of the risks involved in sharing the information.

After the 1850 benchmark, the respondent provided an answer, which the intermediary found unsatisfactory. What followed was a dynamic which clearly demonstrated the benefits of using an intermediary in interviews with researcherdistrusting respondents on the grounds of abstract adversarial positionality. In the enlivened conversation that follows the intermediary pushed the respondent again to tell their story (emphasis added):

2020 I: Tell him about the highway, the highways.

2022 R: Well, it's the same story (explained between 1850 and 2020), they take - /interrupting himself/ do you know what is worst, but I don't know how you will write it, because it is -2038 I: /interrupting/ He knows how to write it-2039 R: No, do not hit on (reveal? sic) this because they will come tomorrow, do you understand me? That's what I am talking about -/commotion, the three erupt talking, unintelligible/ 2051 S: My respondent yesterday warned me "for your own safety"- 
2052 R: Yes, that's it! [...] I will tell you, I have a friend, whose daughter was connected to the US, that [agency] that investigates, do you understand? They called to warn him to [make her] stop. I am simply telling you this straightforwardly. And that was recent - two years ago. /Yes, was she involved with a university? --S/ not with a university but with their intelligence services, some foundation that investigates, similar to what you are writing about but hers was even more complicated and she - directly like an investigative journalist, do you understand? Only difference is she was on a US service. And he is not young, a big director [...] and they were here directly warning him and I now think she is no longer in Bulgaria. She had begun to enter some channels /I have no [interest] -S/ /all erupt, commotion, unintelligible/ I am simply [warning you]! Because [the intermediary] brought you here. and I was not going to tell you any of this! [...] you must have a very light touch, for example, 'to walk on top of the wave', as [the intermediary] says, because [...] you have to consider all these things, as I said earlier. You simply have not had trouble as I have in my life...

It was quite clear that the respondent was influenced by the hostile presence of an abstract adversary. The commotion occurred when both the intermediary and the researcher sought to assuage the respondent that the study was not intended to expose trafficking channels or organised crime. It is unascertainable where the threat came from: Bulgarian or foreign intelligence services, organised crime or elsewhere. Still, given respondent's confession at the end (emphasised) of the interview, it testifies how an abstract adversarial positionality could be reduced and more information solicited with intermediary's active involvement and occasional interview leadership.

In sum, section 3.4.2 was devoted to the methods used to reduce elite respondents' emotional instability at interviews and their proclivity to resist divulging important information. Section 3.4.2.1 discussed some of the more basic methods used in the study, such as devising a semi-structured list of questions, with the more controversial ones coming in late in the interview, which, also would feature excerpts from previous respondents. Section 3.4.2.2.2 emphasised that the interviews 
attempted the adoption of a more relaxed style, which was far better attained when intermediaries participated (3.4.2.3.). Sections 3.4.2.3.1-4 revealed that the benefits of using intermediaries in elite interviews helped to increase rapport (that is, reduce resistance; sections 3.4.2.3.1-3) and improve data quality (3.4.2.3.4). The use of intermediaries is discussed in more detail by Petkov and Kaoullas (2016). Before discussing the use of case studies in the project later, the present section will conclude with a short expose of the drawbacks related to the use of intermediaries in dealing with elite respondents.

\subsubsection{Limitations to the use of the intermediary at elite interviews}

Despite the benefits listed above, there are some drawbacks to consider when drawing intermediaries into the fieldwork process of recruiting elite respondents. These are discussed below.

The intermediary method is best suited to researchers who already approach their project with at least one pre-existing intermediary who can facilitate both the first handful of interviewees and at least one reference to the next intermediary. This means the method is hard to replicate. A potential remedy to un-/dis-connected researchers may be to invest time to develop interpersonal connections with around the target respondent, as in Kaoullas' case (in Petkov and Kaoullas 2016). These may be anyone from a respondent's friends, family or collegial circles.

This, at the same time, is one of the drawbacks of the approach. It has the effect of adding to the time and resources to most likely already time- and resourceconstrained research projects. More time being spent on organizing and conducting interviews was also true for the present project, which is also why the rather low interview count. Ultimately, for other qualitative projects this may reflect negatively on the validity of the data if the low interview count does not reach a data-saturation point where themes consistently emerge. While this was not an issue with this research, it might as well be in future cases. 
Another challenge is the management of the added relationship with the intermediary. While the present study argues that the potential intermediary also has to be personally invested in the project, either emotionally and intellectually, a possible danger is when that person decides to exercise discretion on certain aspects of the project. It may be that, an intermediary describes the project in a way different from the way a researcher would, or they may shift the topic too far away. In short, there is the theoretical danger that the intermediary may not cooperate as the researcher would like them to.

In the present study, the points of friction with one intermediary were mostly on how the interview subject matter was to be advertised to respondents and then occasionally on how the discussion was to be steered at some interviews. In this research project, intermediary's phrasing of what the research project was about was clearly better than the researcher's proposed one, yet an intermediary who has not been briefed in advance of the aims of the interview may indeed cause undue time loss in coaxing the respondent in off-topic chats. Such was the case of some of the earlier interviews, when the idea of the role of the intermediary had not yet fully emerged. Some of the earlier interviews could have been made more efficient by more active intervention by the researcher in advance of the interview by better instructing the intermediary on the important points of the interview that need to be covered. As it turned out, some of the earlier interviews with an intermediary had too much of off-topic discussions.

Finally, a third challenge may be that the researcher is at the mercy of intermediary's interpersonal skills. Despite their best judgement a researcher may place their trust in an individual who might limit the chances of the target respondent conceding to an interview. Or, it may be that during the interview when the intermediary exercises poor judgement and with their behaviour antagonise the respondent. This is particularly relevant to cases where researchers have to undertake their study without 
pre-existing intermediaries. So, they have to trust someone who they do not know and who may not fully understand their role as an intermediary.

Distrusting the intermediary at some point, however, is not necessarily an insurmountable pitfall. With clear, simple instructions, an appropriate behaviour may be elicited from the intermediary. For example, at the last interviews of the present project, where the idea of intermediary's role had firmly taken shape, prior each interview, the intermediary was given specific instructions. They were given the key areas where to navigate the conversation to, they were told to coax the respondent, even at the expense of the researcher, they were also told to begin the conversation (interview) with a natural chat on unrelated matters, as they would normally do with the respondent on a daily basis. Finally, because instructions usually happen some time prior the interview on one occasion the researcher had the time to arrange the chairs at the table so to place the intermediary closer to the respondent than himself by putting his backpack in the empty chair between himself and the respondent. This was intended to act as the psychological protective barrier that delineated the safe space, within which were the respondent and intermediary and outwith of which was the researcher. A similar strategy could also be performed by a researcher and/or their intermediary prior an interview.

Overall, it has to be reinforced that this approach is suited to projects where respondents are reticent and/ or data is of significant value because the intermediary approach is costly. In this study, the discovery of new (sensitive) data was very important and far more difficult because the matters are controversial and carry a degree of realistic personal risk to the respondents. So naturally, they are more reluctant to participate, but the importance of what they have to say justified the considerable sacrifice of time and money in organizing and conducting the interviews. For example, this study came across the phenomenon of prejudiced regulatory inspections (chapter 9) which happened early in the field work interviews. This was apparently of grave importance to many policy-makers and businessmen, but at the same time exposed them to some personal risks, which is why many were 
reluctant to discuss. As this was an important novelty in the parentela network, it was worth exerting the extra effort in bringing intermediaries in the interviews so that this theme could be explored. This is different, from, say, when respondents are asked to comment on well-known historic events (e.g. elections) or social phenomena that already are in public circulation and the discussion of which may bring lesser personal risk.

Having covered the benefits and drawbacks from the use of intermediaries, the following section will turn to the composition and use of cases in the study, before concluding the chapter later.

\subsection{Causality, Comparative Designs and Case Studies}

The operationalisation of policy network types, or the group-venue(s) relationship as discrete combinations of descriptor values also allows for the descriptor operationalisation as dependent variables (DVs). In terms of causality, this means that we are interested in the external forces (independent variables, IVs) that affect one or many of the network descriptors. This ultimately facilitates the application of comparative case study designs.

The suitability of the comparative approach is visible in a post-hoc rationalisation, where lining up Bulgaria (2013-2015), Italy (mid-1960s), Northern Ireland (19201970) and Israel (1980s-1990s) demonstrates sufficiently odd quartet ${ }^{2}$ (in terms of time and space) of cases with which authors sought to determine the existence of the parentela. On that note, the present research design was not necessarily intended as a comparative study, although it could be seen in that light, given that Bulgaria is fairly removed from the other cases and was selected because of the absence of hegemonic parties (on the IV). However, introducing a causal relationship by defining the network descriptors as the DVs allows us to review them in retrospect as malleable to MDSD.

2 Apt expression credited to Richard Parry 
The present study in Bulgaria sees the unit of analysis as the relationship between political parties, interest groups and the bureaucracy (i.e. the constitutive parentela actors). The Bulgarian case of the parentela is a combination of elite interviews and four nested cases (Yin 2003; 2009). Elite interviews served three purposes. First, the pilot study could not identify any potential cases of the parentela. Instead, those were identified in the course of interviewing the elite respondents. Second, elite interviews allowed for a much wider view on the unit of analysis and in doing so helped identify new aspects of the parentela relationship such as group's multi-party approach, volatile insiderness, group's party faction insider access (chapter 7) and type 2 parentela (Chapter 9). Finally, elite responses were used to corroborate other data such as other reports, particularly within the context of case studies (Chapter 5, 8).

In the course of the interviews' conduct, 4 parentela-relevant cases emerged. Three of them exemplify a particular parentela feature existent in Bulgaria and one La Palombara's original parentela in action. The first is the NCTC Case (Chapter 4), which demonstrates party's ability to interfere in the workings of the civil service. The second is the Case on The Law on Administration and Party Political Appointments (Chapter 5), which demonstrates the scope of political appointments in the civil service and explains the origin of this practice. Third is the Case on Multigrup (Chapter 7), which demonstrates that groups seek to avoid losing a parentela relationship when ruling political parties change by working simultaneously with those which are in opposition. It also shows that parentela insider status fluctuates. Finally, the Case on Public Tenders (Chapter 8) demonstrates all of the original parentela's elements together at work in Bulgaria. While a process tracing element was intended in all cases, Chapter 8 is the best example of it.

An attempt was made to apply process tracing in the case studies. This is an interpretive narrative of causal stages that connect the independent with the dependent variable. In doing so, the causal chain it follows to make such a connection also reveals the intervening variables that facilitate it (Tansey 2007; Falleti 2009; Falleti 2006; Checkel 2006). Its application was attempted in all 4 
cases, in order to address the criticisms in the policy-network literature that the models lack any causal dynamics (Thatcher 1998; Dowding 1995, 2001). The approach was most effective in the Case on Public Tenders (Chapter 8). The utility of that approach depended heavily on the available documentary data. The parentela relationship is highly informal and it leaves very little documentary traces. That is why, for instance, La Palombara's establishment of the parentela is based only on respondent accounts (1964: 306-348) and Greer's claim on the parentela is based on a handful of personal letters (1994: 411-412). This meant that process tracing relied primarily on analysing the relevant legal provisions and then on interview responses, corroborated with public sources, such as news articles, scientific reports and memoirs.

\subsection{Conclusion}

The present chapter is dedicated to the two main research method approaches employed in this study: elite interviews and case studies. Sections 3.2 to 3.4 discussed the difficulties using elite interviews and the techniques employed to overcome them. Three main difficulties were observed in the use of intermediaries. First was the need to devise a mechanism for comparison between the Bulgarian and Italian respondent pools. It was necessary to ensure that the Bulgarian study featured the same number of respondents with the three parentela-constitutive professional backgrounds: politics, civil service and interest groups (trade associations, businesses). The comparison suggests that both respondent pools are very similar, with the Bulgarian pool possibly better representative of interest groups, with the inclusion of business owners. While the civil service might seem to be slightly underrepresented in the Bulgarian study, it is compensated by the fact that many of the respondents have held more than one policy-making post in the past, also including experience in the state administration.

The second and third elite interview difficulties related to respondents' reluctance to be interviewed and resistance during their conduct. The main cause for such behaviour was respondents' association of the researcher with an unknowable and unverifiable threat, or abstract adversary. While many techniques from the literature 
were applied, they also included a new research actor: the intermediary. This is someone on researcher's side who possesses excellent field-contextual information about prospective elite respondents and personally introduces the researcher them, vouching for former's credibility. The use of intermediaries at resistant elite interviews increased rapport and interviewees' response.

Finally, the chapter discussed the use of case studies in the present study and the possibility of application of a Most Different System Design comparative study. The cases formed the second stage of the data collection process. This is so, because no suitable cases were identified prior the start of the research project. Elite interviews were first used as a starting point to identify any suitable case studies. Once identified, those were analysed using the process tracing approach, on the basis of documentary evidence, news articles and legal analysis. Given the high informality of the parentela relationship, very little documents were identified to elucidate on that network type, which is why legal provisions, news articles and memoirs were used as a mean to corroborate respondent statements (and vice versa). For the same reason, some cases (Chapter 8 in particular) focused on analysis of legal procedures. The following chapters 4, 5, 6 are based on the elite interviewees and reveal the elements of the parentela in the party-group relationship in Bulgaria. 


\section{CHAPTER 4: The Party in Power as a Parentela Primary Venue: The Case of National Council on Tripartite Cooperation (NCTC)}

\subsection{Introduction}

Chapter 2 operationalized the policy network and its types in terms of 5 qualitative descriptive indicators (or descriptors), where the value of each expresses one characteristic feature of each policy network type. Therefore, policy network types are operationalized as discrete combinations of descriptor values. The descriptors, according to which policy networks are classified, were: degree of access, power ratio, type of interaction, primary venue and venue scope.

The present chapter 4 is dedicated to the primary venue descriptor. Chapter 2 defined it as a combination of two earlier ones developed independently. These are, perceived venue effectiveness (based on Yishai's group strategy (1992)) and bureaucratic intervention (La Palombara 1964). They were conflated because both of them reflected the same idea: that as far as groups are concerned, the party in power provides effective access to policy-making. Therefore, one major characteristic of the parentela is the primacy of the political party as a focal point in that network, particularly vis-à-vis the civil service, which it dominates either through direct interference by means of party political appointments (PPA) or legislative amendments. In the case of La Palombara's 1960s Italy, political parties interfered in the work of the civil service primarily through party political appointments (PPA) (1964).

However, the following case study on the National Council for Tripartite Consultations (NCTC) demonstrates that such intervention could also be done 
through legislation that regulates the eligibility criteria for participation in civil service consultations. The case demonstrates the conflict of access to the NCTC by two opposing camps: groups representing Big (Business) Enterprises (BE) versus groups that stand for Small and Medium (Business) Enterprises (SME). In the NCTC context, the former are represented by Chamber of Industrialists and Employers in Bulgaria (CIEB) and the latter by the Bulgarian Chamber of Commerce and Industry (BCCI). The immediately available data on the case only allows for the observation that any barriers of access BCCI experienced are the result of political party machinations and much less due to CIEB being a party insider group seeking to block NCTC access to its competition. In fact CIEB demonstrates the traits of a peripheral party insider: a group that has occasional contacts with venue policymakers and is in no position to bargain or negotiate with them (Maloney et al 1997).

While still highlighting that political parties interfere in the workings of the civil service, the chapter argues that the NCTC is a case of a wider phenomenon of covert of political power centralisation in the party leadership. According to another group of respondents, Bulgarian policy-making is an oligarchy, where political parties, interest groups and other private actors meet and rule together. However, as it will be explained later, this view is conceptually flawed and the fact that eventually CIEB faced becoming an outsider to NCTC along with its competition - the BCCI disproves the possibility that on this occasion, the NCTC case is an example of an oligarchy.

The above is discussed in the following order: The next section, 4.2 reveals the details of the NCTC. Each of the two competing explanations are discussed respectively in subsection 4.3.1 and 4.3.2.

\subsection{Party Intervention and the National Council for Tripartite Consultations (NCTC)}

The National Council for Tripartite Consultations (NCTC) is Bulgaria's main consultative body where business, workers and the State (civil service) meet and discuss matters of primary interest to the entire economy, e.g. minimum wage, 
standards, contracts, etc. A number of respondents commented on the competition between Big Business (BE) and Small/Medium size Business (SME) in gaining access to the Civil Service consultations and NCTC in particular. The numerous comments, triangulated with news articles and publicly available qualitative data, were collected in a case study on the National Council for Tripartite Consultations or NCTC.

At first, for many respondents NCTC was a case of the battleground between BE and SME. The dominant position among them was that SME was the victim of BE colliding with the ruling party. While that proposition has some merit, the case of NCTC is indicative of a more prominent phenomenon. This is, namely, party centralisation of power and its manifestation, party interference through party political appointments (PPA). However, on a second read, the NCTC (BE vs SME) dynamics in fact demonstrate that the party in power can strongly interfere in the civil service negotiations. Any core insider status within the civil service could be negated by party's ability to shape or at least disrupt the usual consultative process hosted by the civil service. This demonstrates its willingness to intervene in the bureaucracy and thereby its ability to perform the function of a parentela primary venue. Ultimately, this coincides with the description of the ruling party which hosts parentela relations (La Palombara 1964).

There was virtually no disagreement among respondents that the Bulgarian civil service consulted business on legislative proposals. Speaking on behalf of peak associations Petrov and R30352 confirmed that the state seeks to consult. Zlatarov and Lyubenov explained that business prefers to consult through the state administration, particularly because they would communicate with equal experts. Hence, in principle, access is easier this way. Speaking as a business owner, Respondent Stoyanov gave a positive feedback on state consultations overall arguing that while consultations could still be better, it is definitely an improvement since 2009 that civil servants invite their representative body to consultations. 
Most importantly, however, many respondents stressed that one of the consultative fora that has greatest importance for business is the NCTC. Respondent Lyubenov argued there are consultations at all levels of the civil service, the treasury, Bulgarian National Bank, including the NCTC. Respondent Hristov singled out the National Council for Tripartite Cooperation (NCTC) as the main and most important consultative body. Other respondents such as Zlatarov, Konstantinov, also highlighted the prime importance of NCTC that has for business. Respondent Zlatarov noted 50 consultative bodies where their peak ${ }^{3}$ organization, Bulgarian Chamber of Commerce and Industry (BCCI) was in frequent bureaucratic consultation, also highlighting the "supreme" NCTC.

While noting the importance of NCTC, many respondents also saw this consultative body as a contested ground between Big Business and Medium/Small Business. The Big Business vs Small and Medium Business distinction was introduced by Respondent Nikolov, where Big Business comprises monopolistic actors in the economic niche they occupy, including individual firms, corporations or individual business owners. Without any hesitation other respondents also added in the same category the so called circles (a number of firms acting informally in concert to protect their interest, Chapter 7). SMEs consists of small shop owners, producers, merchants, also including what Respondent Zlatarov termed "micro" firms of just a few people.

Nikolov was the first respondent to voice this conflict and immediately attempted to explain it, quoting two main reasons. First, the corresponding consultative body, Agency for Small and Medium Size Businesses (ASMSB), is both under resourced and incompetent to consider SME's interest. To makes things worse, ASMSB does not deal with a consolidated actor that represents SME interests as a whole, either.

Speaking on behalf of BCCI, under what Konstantinov termed unsatisfactory relations, he argued that by definition SME is left out of decisions of core importance to them, despite the fact that the civil service consults in general. In other words, 
SME only had peripheral access to policies of interest. In agreement with Nikolov, the civil service is not capable to carry out the necessary legislative consultations, or what is otherwise known in Bulgarian policy-making: the assessment of the potential effects of draft legislation on business.

Their observation was also corroborated by the state report on the development of the state administration 2014-2020, We are Working for the People: Strategy for the Development of State Administration ("Council of Ministers Accepted" 2014; Bulgarian Council of Ministers 2014). The document clearly specifies that one of the current deficiencies of the state administration and government is the turbulent production of secondary legislation that lacks any assessment of its effects on businesses (Council of Ministers 20142014: 10). In other words, this voices the argument that the civil service does not provide effective consultative venues because it inherently incapable to do so. The report concludes that the Bulgarian civil service does not carry out the necessary level of intensive consultations to determine whether any proposed legislative amendments are palatable to those potentially affected (Council of Ministers 2014: 11-12). The report attributes the deficient consultations in general, to civil servants' general disinterest in taking up the issues voiced by interest groups and much less, if at all, to the lack of material resources (Council of Ministers 2014: 12). Again, this means that SME are ineffectively consulted primarily because the administration has limited professional capacity to facilitate such consultations.

This is at odds with what Lyubenov argued. While he is correct in principle that access to policy-making is reciprocal to group's ability to provide expertise (e.g., Richardson and Jordan 1979; Grant 1977, 1978, 2001, Chapter 2), this is a minority position. Lyubenov allows that the civil service may not always be capable of conducting meaningful interest group consultations, he nevertheless stressed that any perceived group exclusion is usually due to groups' insufficient sectoral expertise. They argued that the degree of access granted to SME may also depend on the degree of competence the group bears. Although his position is correct in principle, with 
relation to assessing the effects of legislative proposals on industry, the civil service administration de facto admits that (Council of Ministers 2014: 12):

[t] he directors and civil servants [...] do not recognise this duty as primary and do not input the necessary effort to understand better the approach and logic of the effects of the [respective] legislation.

In other words, the deficient consultative access SME experience is primarily attributable to an inherent civil service disinterest in assessing the detailed effects of the policy proposals that it handles.

While consultations might be hampered by internal problems of the administration, both Nikolov and Hristov agreed that another contributing factor is the absence of a coherent representative body of SME. The ineffective group mobilisation that adds to the diminished effectiveness of consultations is also reflected in the same report (“Council of Ministers Accepted” 2014; Bulgarian Council of Ministers 2014 p. 16):

A main problem is that in given fields and policies the representatives of $N G O s$ are too numerous and the communication with them is hampered. A cause for that [among other things] is the dispute over representability among the organizations.

Speaking on behalf of the civil service, the report informs that the state administration finds it is hard to consult a sector that lacks a coherent and an agglomerated representative body. However, the report is unclear whether and to what extent that is also valid for the peak SME associations like Bulgarian Chamber of Commerce and Industry (BCCI). Evidence suggests that while it may be true that their mobilisation is difficult a single and coherent representative of SME is clearly identifiable in the face of the BCCI which is represented at more than 50 consultative organs, indicating thereby that the group is bearer of expertise (Zlatarov). Likewise, BIA is another association with a wide business base (Konstantinov).

Another, possible explanation - and the more dominant - behind SME's perceived consultative ineffectiveness could be attributable to the possibility of core insider groups trying to create barriers of entry to other groups who too compete for policymaking access. Zlatarov provided two cases indicating a disruption of the existing consultative mechanisms (NCTC). In the first case, the respondent cited the 2011 attempted amendments in the Labour Codex as evidence of BCCI being targeted for 
exclusion from the tripartite consultations because it was the only organization, part of NCTC that did not meet the new participation criteria. Zlatarov's analysis led him to suspect that their rivals, the Confederation of Industrialists and Employers in Bulgaria (CIEB) were behind it and that BCCI not meeting the legal participatory requirements for participation at NCTC was simply the necessary pre-text for their removal from consultations. As Zlatarov explains, according to the latest amendments in the Labour Codex at the time, any interest groups that received subsidies from the state were forbidden representation as independent actors at NCTC consultations. However, the internal legal analysis of BCCI concluded that it did not receive subsidies from the state, but had been paid for services that had been outsourced to them. According to Respondent Zlatarov, ultimately, that was a move by CIEB to eliminate their rival interest groups from competing for influence in the NCTC policy venue, e.g. BCCI which Zlatarov represents.

Support of this thesis provide a number of respondents who argued that it is commonplace for the more affluent businesses to split away from their sectoral organization and seek direct representation to the party in power. The explanation is that the party is seen as the more effective route to policy-making than the civil service. Respondent Nikolov was quite specific that individual Big Business actors sought the access to ruling political parties. In exchange for benefits to individual MPs or the party parliamentary groups, they received favourable legislation. That is why one could observe legislation that directly harms the interests of small and medium size businesses. But the thrust of the argument, however, was that consultations outside the ruling party are meaningless. He argued that once decision is in direct party-group negotiations its consequent consultations in parliament serve no purpose. Moreover, the position of the peak association is undermined, when such splinter large corporations express independent, and often opposing, positions in private to the party in power (e.g. the respective Trade Association).

The view that single big business owners (groups) would seek to circumvent their respective representative body and directly negotiate with the ruling party was also reflected by Kirilov. They argued that sectoral bodies that represent the interests of 
small and medium size businesses, such as BIA (Bulgarian Industrial Association) are not an effective medium of representation for Big Business. Single affluent businesses find it more effective to engage directly with ruling political parties. This observation is also made by the directorial representative of BIA, Konstantinov as well. In an overlap with the Council of Ministers report (2004) they argued that civil service does not enquire of business as to the possible effects on the economy of the legislative drafts in progress, and a reason for that is the observation those are legislative decisions taken in direct consultations between the ruling party and party insider groups. He argued that the civil service consults, but those consultations on legislation of interest to party insider firms are either sabotaged or non-existent. Similar to Nikolov above, he also implied that there specifically are more influential party-group relationship which are sustained on the mutual exchange of policymaking access against campaign resources, which is also discussed in Chapters 6, 8, 9. The interview with Hristov on Big vs Small and Medium Enterprises revealed the same observation: the party route is more effective than the civil service one, as long as the group is able to negotiate its provision of campaign resources for desired policy concessions. Hristov also added that SME were ineffective also because their interests were not expressed through a major representative body.

Zlatarov also agreed that the party route is more effective and influential. Speaking from personal experience and on a different matter, Zlatarov explained how the large corporation they personally represented sought to amend the details of a piece of legislation that directly affected it. They were very particular that the state administration would not have listened to them. Instead, they found it most effective to seek a personal endorsement from a member of the ruling party who facilitated the contact with the responsible Minister in question.

The effectiveness of the party route is also discernible in the accounts of Petrov who spoke from the perspective of an outsider sectoral organization that failed to gain party insider access, despite their numerous representations to consultations organised by each of the major parties in Bulgaria. With great discontent the respondent recounted how a particular party gradually stalled action on policy 
promises made personally to them. They concluded based on their immediate observations that it was the more affluent business actors who eventually secured effective party access.

Ultimately, a public statement from BCCI from $16^{\text {th }}$ December 2011 also identifies CIEB as the group that stands to gain from the legislative amendments (bcci.bg 2011b):

The statement from the interested in the removal of BCCI organization, $C I E B$ is an absolute insinuation that at some point in the past [...] the European Commission or any other such body had stated that BCCI was the inaccurate social partner.

The MPs Pavel Shopov (bcci.bg 2011f) and Todor Velikov (bcci.bg 2011f) clearly voiced the same concern. From the parliamentary tribune, the latter states (bcci.bg 2011f)):

You (to MPs from ruling party) are making this in service to CIEB, because these people (BCCI), deprived from their representation, will have to find it in CIEB. But who does CIEB represent at the moment in our country? -- Large capital! [...] We will deprive small and medium business from representation and we will redirect them to the larger capital which is of a doubtful origin. Why are we doing all this? In whose service? In service of someone who at the moment wants to take over the entire employment market, to stand next to the government and say: "I am the legitimate one, I want all [public tenders] to be given to me and I will dictate the status quo in this state"!

Although not spelling CIEB out, the MPs Rumen Petkov (bcci.bg 2011d) and Martin Dimitrov (bcci.bg 2011e) also confirm the parliamentary opposition's stance that BCCI are the intended group for exclusion. The gravity of BCCI's reaction and the numerous MP statements indicate that CIEB most likely were in some sort of a tacit agreement with the ruling party, although no such direct evidence could be found. However, this is an irrelevant inquiry.

The ability of the ruling party to impose criteria for participation in the NCTC consultations makes the inquiry into CIEB vs BCCI irrelevant. The ability to control who sits at NCTC means that the ruling party is the most effective route to policymaking, because it has the authority and ability to shape the NCTC. This is evidenced by respondent Zlatarov who cited the amendments in the Law of Public 
Property of Former State Workers (term for civil servants, sic) $2013^{4}$. He explained that according to those amendments, the chairmanship of all groups seeking representations at tripartite consultations (labour, business and the state) had to declare their income to assume such posts. Access to the consultations was conditional on chairpersons of the boards from all represented groups disclosing all sources of income. Zlatarov claimed firstly that this is against the spirit of the law, which was originally intended for state agencies only and not interest groups. Secondly, as a result, members of the business in the boards of their representative groups become unnecessarily vulnerable as they had to reveal personal data and thus risk becoming victims of blackmail. That position could be clearly observed expressed collectively on the website of BCCI's adversary, CIEB, where all employer associations at NCTC signed a declaration of discontinuation of participation in the tripartite consultations (CIEB 2013). The declaration highlights the anti-constitutional provision of the amendment and clearly states that the requirement of income disclosure puts groups' directorial boards at personal risk. But most importantly, it acknowledges that such barriers are also ruling party's mechanism of shaping NCTC consultations. The statement reads (CIEB 2013, emphasis added):

II.1. The members of the executive and directorial organs deem that [... requiring] data of their assets be published online, creates conditions for pressure (on them and their families), not only political but criminal as well.

As those amendments were seen by all industrial representative peak associations, their sole purpose, de facto was to facilitate party's entire control over the NCTC, because the new rules rendered them ineligible for further membership. The narrowest view on the NCTC case, immediately based on the more accessible data is that CIEB was a party insider who attempted to place barriers of entry to its competition, BCCI, to the consultations at NCTC. However, the fact that CIEB, too, eventually nearly lost its access to the NCTC suggests that CIEB had a status of a peripheral insider. Although CIEB had had some access to the ruling party, it could not eliminate its competition and remain the sole group at the NCTC. Eventually, just as with BCCI CIEB was barred access to the NCTC. In any case, establishing the 4 Law for Publicity of Assets of Individuals Assuming High State Public and other Duties in the Public and Private Sector 
CIEB-party link requires more data, particularly from relevant party political functionaries and business members from CIEB, which falls outside the scope of the present study. Yet, with regards to the parentela, whether CIEB was a party insider, is irrelevant, because the available evidence clearly indicates political parties are capable of significant bureaucratic intervention as per La Palombara (1964). That is to say, they are a primary venue and therefore to that extent fit the parentela description.

\subsection{Alternative Perspectives on NCTC: Prime- Ministerial Democracy or Oligarchy}

The available data above reports that political parties are capable of direct civil service intervention. Yet, it does not explain why, nor does it provide any wider context that would help assess the significance of these findings related the parentela. Taking a wider look on the available data on the parentela as a whole allows us to test two theories or rather propositions developed by respondent discussing parentela dynamics. These are namely that Bulgaria is a premier democracy and that it is an oligarchy. The reason why results from later chapters will be anticipated in this section is because they bear immediate explanatory power on this case and in doing so still demonstrate the fundamental importance of party's bureaucratic interference, both for the functioning of the parentela and more encompassing policy-making dynamics.

\subsubsection{Prime-Ministerial Democracy}

The case above suggests that political parties can interfere with the NCTC. But why would they do that? The quick answer is party political power centralisation. While many respondents above argued that splinter groups saw the party in power as the more effective route to policy-making, another group of respondents went much further. They argued that the ruling party was the more effective policy-making route because Bulgaria was a prime ministerial democracy, because of the powers already vested in the prime minister (i.e. party leader). According to this perspective, the practice of party political appointments (PPA) in the civil service facilitates the centralisation of power in the political party leader, also known as the prime minister. 
This perspective also explains why groups from the trade associations split away and directly negotiate with the ruling party. If power is centralised in the party leadership, it follows that the binding decisions are taken on that level and outside the confines of civil service negotiations. According to that view, civil service consultations are of low quality precisely because of the high turnover of political appointees with every change of the party in power. The civil service is staffed with political appointees who are always new to the job. They usually cannot apply their accumulated experience after a party change. Based on the data on the parentela as a whole and on the NCTC case, the premier democracy perspective appears most persuasive.

Respondent Hadzhiev argued that it is political parties who rule the state, and not elected MPs. The legal perspective on policy-making is blind to the reality that informal pacts between ruling parties and insider groups lie at the core of policymaking:

R: Actually in Bulgaria it is everywhere written down that it is a parliamentary republic and respectively the supreme law is the constitution. [However,] since 10th November 1989, the state is parliamentary republic only de jure. De facto [...] Bulgaria is ruled by miscellaneous parties. lemphasises/ It is entirely different the question who is connected with those Parties and how is this entire government done more generally.

Likewise, respondent Petkov shared the rather cynical position that power rests exclusively with the prime minister:

By the way Bulgaria is actually only formally a parliamentary republic. The parliament is a structure for psychotherapy for the Bulgarian citizens, who need to know how bad the politicians they themselves elect are.

In other words, the parliament and parliamentary consultations deflect the attention from the real locus of power. They are meaningless because it is the party leadership that dictates the decisions of elected MPs. The parliament and MPs are reduced to objects of misdirected hoi hatred of the political system.

Like Petkov, Penchev was as also cynical about the same 24 year period of transition to democracy. He argued that the party ruled the state unimpeded and the powers vested in the party in power - the premier - can also be at the disposal of the party 
insider groups. Therefore, a group can gain control over parts of the civil service, also including the judiciary, the prosecution and secret services:

$R$ After 23 years, democracy has not arrived yet. Everything is [politically] controlled in Bulgaria. And that is something which they see in Brussels. But they have given up on us and say that things in Bulgaria happen only with diktat and pressure. So [... it is all] about the control over the political system and political class through which [those groups] realise this power, [and it is] in the same way they control the judiciary, the state prosecutor and the services.

The above was probably one of the earlier statements directly attributable to the parentela. Other respondents also argued that the real power locus lies with political parties. Stoyanov ended the above positive note thus:

We have to walk more until we run away from those - how should I say it - interpersonal relationships which are not on the plane of real business

What interpersonal relationships implies above, are the direct personal contacts some business actors establish with the party in power. Respondent Stoyanov shall be revisited again in Chapter 9 elaborating on this point. Speaking as member of the directorial board, Respondent Konstantinov made the argument that the interest group they represent, BIA, too, like BCCI was an occasional outsider (peripheral insider) to decisions of core importance to its constitutive members:

[Business] does not make decisions; that would be the government. The National Council for Tripartite Cooperation [...] is a consultative organ and it does not make decisions [but] we are often witnesses of how without any consultations parameters are changed which in any case influence negatively on the business environment.

That the party is the key venue providing most effective access to policy-making is inferred from the difficulty groups experience in maintaining a long-term meaningful representation at the consultative administrative bodies. The respondent implies that key decisions are taken at the level of ruling political parties, whose governments only consult ad hoc the relevant sector-wide interest groups. Therefore, according to respondent Kirilov lobbying efforts have to target the prime minister.

However, the above perspective raises the question of how political power could be centralised. One answer is through the practice of party political appointments or PPA. Other chapters of the study are also dedicated to PPAs. Chapter 5 is entirely dedicated to the causes of PPA and the scope of this practice. Chapters 8 and 9 
feature PPAs in case studies, which exemplify how PPAs are applied in practice. However, the present section will discuss the role and effects of PPAs in the partycivil service relationship. PPAs do not only explain the centralisation argument, but also why the civil service provides ineffective consultative fora.

In the same self-evaluative report mentioned earlier, the Bulgarian civil service tries to argue that the regulatory agencies are not necessarily independent from party political interference. The report seeks to diminish party political influence by confusing the reader with convoluted phraseology (emphasis added) (Council of Ministers 2014: 21):

The lack of success of some independent regulatory agencies should not be sought in the deficit of their independence from political power (ruling party), but more in the absence of adequate mechanisms for responsibility allocation when their guaranteed independence remains unused

While the report admits to an open secret, that political parties control the civil service, it is not up to the body, which politically controls the civil service (Council of Ministers, or the government) and which also authors the report, to assess the extent of its own party political control over the regulatory agencies. The fact that such control exists and is wide-ranging is evident in the emphasis that staffing the civil service has to happen on the basis of competition and merit (see Chapter 5 dedicated specifically to the scope of PPA). Immediately following the preceding quotation, the report insists that:

[...] the practice of competition among civil service candidates for employment has to continue to be emphasised [...] and clear transparency mechanisms be also created

Such insistence gives a loud voice to the politically unpalatable point the report is trying to hide: that party political appointments are the norm. Coupled with the earlier nebulous explanations regarding party control over the civil service the latter quotation implies that PPAs are the shift gear that translates party authority down to administrative levels. In both quotations, the authors are trying to deflect our attention from two points: that the civil service regulatory agencies are politically controlled and that PPAs are the standard practice of staffing the civil service. This is a point discussed at length in Chapter 5 and amply exemplified in Chapters 8 and 9. 
However, the other important point is that in light of the above, the inefficient consultations the civil service provides are also a direct result of the PPAs. In a much later section of the same report, the authors are still very careful not to admit to PPAs, when they recommend more competition-based employment is necessary in order to improve the administrative consultative capacity. They clearly correlate employment not based on competition to civil service incompetence (Council of Ministers 2014: 31):

Another problem is connected to the avoidance of the regulations in the Law on the State Worker (civil servant), of appointment of servants without the conduct of a competition. In this way preconditions are laid out for the employment of servants who lack the necessary knowledge and skills for the assumption of respective position.

In an obvious attempt to avoid the phrase political appointments, the report discusses "appointment of servants without the conduct of a competition". The only way to appoint civil servants without competition is through party political appointments (Chapter 5). However, speaking as a former minister and a lawyer working on a case of appealing the results of a civil service competition, Petkov was largely sceptical of the effectiveness of civil service competitions as an alternative to PPAs. On the one hand, even if experts are appointed, they soon, forcefully or not, become politically different to their patrons. As for civil service competitions, those too are entangled with ruling party machinations.

Yet, the civil service report has to be commended for raising the point that the massive civil servant substitutions, following every party change, degrade the overall competence of the state administration. Other respondents were united in the view that civil service consultations are significantly hampered by PPAs (chapter 5 in more details). Respondent Kuzmanov was particularly vocal on this issue:

$R[\ldots] \quad$ [in Bulgaria] with the change of the political subject (party), there exists the exceptionally damaging practice to kick people out, including the nether echelon [of the civil service]. /To change their posts? --S/ Yes, yes... Simply the changes are to the lowest level /locally? --S/ Yes, yes. After all we talk about the [loss] of administrative experience. We talk about entering in a given rhythm, acquiescence with a heap of requirements with which one has to work and in one moment when someone has accumulated 4-5 years [of experience ...] they may 
not be the best, but they got it, nevertheless, they [had finally] got what is needed of them, what they have to do, [and] how to do it. On top of that they fight every year with our absolutely explosive dynamic, the legal and normative framework [especially when it] is written in quite nebulous terms, [...] and that is a fact! [...] You come to power -/theatrically enters the role of a politician giving orders/ "Get out!" /throws an object on the table, bottle cap? / "Here, this one, this one is good, because he is [my appointee]! [...] He will learn! What is the problem? I learned all by myself [in the past], he will do, too!" This is the principle. Consequently we fall in some situations, where we enter complete nonsense and that is on the top levels. Like "Kalinka", or the other one [...] who did not have the education, too.

The use of the term "Kalinka" above is of particular interest. Many respondents who discussed appointments gave the example of Kalina Ilieva, former director of the Fund for Agriculture in Bulgaria. She was appointed at the start of the GERB government in 2009 , her career quickly deteriorated as rumours were confirmed that she had forged her University Diploma which permitted her to assume that post (Mitev 20012). While the case is long gone, her first name was used as a term for anyone who was politically appointed (kalinka (sg.) kalinki (pl.) meaning "ladybug"). Many respondents used the term "kalinka" to express their disapproval of this practice. For example, Petkov exclaimed 'If you appoint kalinki - the effect [on the administration] will be bad'. Respondents Kirilov and Petkov, in addition to Hristov either made a clear use of the term or respondent to its use.

Based on personal experience, Dobromirov had similar observations to the respondents above. Fresh appointees need time to come to grips with the knowledgebase needed to address the needs of business groups. Respondent Varbanov equally argued:

$R: \quad$ So, the state administration in Bulgaria /self-interrupts, thinks hard, pauses/ there are no good professionals [they] are very slow [and] cannot respond to the problems in the respective [fields], whether those are industrial or [related to] construction; we confront this problem on a daily basis. [...] there is no constant long term plan for the development of the state, which every self-respecting state has: a long term plan, regardless of which party is in power. This is at least how I see things ought to be. /pauses/ and those who sometimes are appointed as directors to given [agencies] do not possess the respective intellect, [and] do not have the necessary education. 
Therefore, the common position between Varbanov, Kirilov, Petkov, Dobromirov and Kuzmanov is that the uprooting and subsequent substitution of the civil service staff with new appointees at every party change decreases the overall civil service professional capacity. For Varbanov in particular this is a result of the political parties' attitude of ignoring national interests for much more narrower and short-term party ends. In more practical terms this leads to civil servants being professionally incapable to partner or assist interest groups in legislative consultations because they lack the necessary knowledge to do so. That is why single large business groups seek to directly negotiate with the ruling party at headquarters, as opposed to through the civil service channels of representation.

Second, although the data from the study was not intended to be used in an analysis of the state of democracy in Bulgaria, it also allows furthering the premier democracy thesis above. The suppression of political dissent, both intra and extra party, could also be done through PPAs. Political parties can appoint the directors of regulatory agencies and departments which can impose sanctions on groups that the ruling party sees as an opposition. The report authored by the Council of Ministers (the government) ineffectively argues that appointments have no relation to civil service politicisation and subordination to the ruling party (present chapter). In fact, all elite respondents, including ex-ministers, from the present study are unanimous that PPAs are intended to facilitate ruling party's control over the civil service (Chapters 5, 8, 9).

Chapter 5 reveals that party control over the civil service originates from the analyses of BSP's leaders of mid 1990s with their "triangle of power". Sitting atop of the isosceles triangle, on the one hand the party leadership can dictate to its own MPs by enforcing iron-clad party discipline. Following the second isosceles line, and still sitting at the top, the party leadership controls the civil service by appointing trusted individuals as heads of departments and agencies. As chapter 5, 8 and 9 indicate, the philosophy is maintained by all political parties to-date. Party political appointments are wide-spread to this day, while MPs are marginalised and virtually no respondent addressed MPs and the parliament as of any relevance. 
The recent study has generated data that also lends itself to this power-centred analysis (chapter 9). In what would be argued as a variation of La Palombara's original parentela, chapter 9 reveals a new parentela-like dynamic, which is also based on political appointments. On the basis of responses from immediate victims of such pressure, that chapter reveals the party in power is in the position to eliminate firms and put pressure on entire trade associations. When in the position to appoint political trustees as regulatory agency directors, the party is enabled to instigate deliberate inspections against any business actors, to the effect of bankrupting them. Responses indicate that such forms of pressure are directed both at intra-party dissenters and firms whose owners take an active part in the lobbying efforts of dissenting trade associations. That is why some respondents (Chapter 9) also argued that some interest groups' leadership found it more prudent to cooperate with the ruling party, even if that is against the interests of own membership.

\subsubsection{Bulgarian Oligarchy}

Interest group leadership colliding with party leadership, however, is an argument that relates to a similar but more extreme respondent thesis that Bulgarian politics is an oligarchy (reviewed at more length in chapter 9). Including 2 former ministers and one very affluent entrepreneur, a number of respondents advocated that Bulgaria is an active oligarchy. Applying this view on the NCTC case, this means that CIEB would have sided with the ruling party. However, while it is true that fingers were pointed at CIEB, it is unclear why in the end CIEB was also excluded from the NCTC just as its rival, BCCI.

Moreover, the oligarchic thesis advanced by the respondents, seems underdeveloped. The term oligarchy implies a limited number of cooperating actors presiding unlimitedly over policy-making. However, no immediate evidence was found to support this solid view. The most one could say in support of the oligarchy argument is that the combined dynamics of the parentela and its variation do create some oligarchic dynamic (Chapters 8 and 9). What the present study on the parentela 
inadvertently demonstrates is that political power can be shared between a ruling party elite and party insiders (Chapter 9).

In its most simplistic form, the party-group dynamic allows for certain combinations of ruling parties with insider groups to dominate policy-making on issues of interest, which tend to last until next parliamentary elections are lost. Such close cooperation (Chapter 7, 8,9) gives the impression of an existing oligarchy, and that is further compounded by the fact that party insider groups seek to maintain insider access to all relevant political parties simultaneously (Chapter 7). Doing so increases group's chances of survival when hitherto party patrons lose elections and a new party comes to power - ideally one that the group would have already established insider relations while it was in opposition (Chapter 7).

In addition, and particularly on the party-party insider side of the argument, chapter 8 shows how groups supporting the status quo are awarded for their loyalty. It demonstrates the skewed process of granting public tenders to party insiders, which relies exclusively on populating the decision-making public tender committee with loyal political appointees. Up to and including the August 2014 amendments of the Law on Public Tenders, the party in power has the ability to directly determine the recipients of public tender contracts (Chapter 8).

Therefore, with regards to the NCTC case, more evidence is necessary to establish the link between NCTC and the ruling party at the time that the proposed amendments rendered BCCI as ineligible to compete. At the same time, it is also against the oligarchic thesis the fact that eventually both CIEB and BCCI found themselves outsiders from NCTC. Given the available evidence, the NCTC case is seen here more of an example of singular party's attempt at covert centralisation of political power, rather than a case of oligarchic dynamics However, either way, the most important point remains that the party in power can act as a primary venue, because the NCTC case demonstrates that the party in power is a venue that it is both seen as effective (as admitted by respondents themselves) and was shown to interfere in the civil service. 


\subsection{Conclusion}

The present chapter focused on the case of Bulgaria's National Council for Tripartite Cooperation (NCTC). This is Bulgaria's civil service top consultative body, where Big Business, Small and Medium Business, trade unions and the State (represented by civil service) discuss matters of relevance to the Bulgarian economy and labour relations. The case lends itself to three possible interpretations, all of which advance the same point: that political parties in Bulgaria are both effective policy venues and do interfere in the work of the civil service. That is to say, the party is a primary venue. At first sight, it might seem as case where Big Business attempted to exclude the representative groups of Small and Medium Enterprises. However, taking into account the totality of available data, a second and a third view transpire. The second perspective states that the NCTC is a case of party political power centralisation, or the premier democracy thesis. The third perspective is again premised on party centralisation of power, but it goes further by positing the thesis that Bulgarian politics are an oligarchy and the NCTC case is an example of that with CIEB trying to exclude BCCI from the NCTC consultations by colliding with the ruling party. However, the NCTC case does not seem to support the third perspective because there is not enough evidence to link BCCI with the ruling party at the time and because of the fact CIEB was eventually excluded on par with BCCI from the NCTC consultations. While the chapter supports the middle-ground argument of party centralisation, even if we see these second and third perspectives as extreme, the lowest common denominator among all versions remains the same: that the party in power has the capacity and willingness to intervene in the civil service (also Chapter 8 and 9). 


\section{CHAPTER 5: Party Political Appointments and Venue Scope}

\subsection{Introduction}

The purpose of this chapter is to focus on the venue scope policy network descriptor and to argue that such a party-group relationship characteristic which is pertinent to the parentela could also be observable in Bulgaria at present. The venue scope descriptor suggests that certain policy-making relationships could extend into many policy-making venues. It is the number of venues that are together involved or facilitate the respective policy network dynamics. In the parentela context, this primarily is in the shape of civil service subordination to the ruling party, through latter's ability to make party political appointments. However, that should not imply any specific dynamic, i.e. any sort of subordination, rather it is to convey the idea that the dynamics of a policy network span across a number of policy venues.

The parentela venue scope indicates that the civil service is subordinate to the party in power. Identifying then such connectedness between Bulgarian political parties and the civil service would be indicative of a parentela in Bulgaria. At this stage, the literature has identified one major form of connectedness between the party in power and the civil service: party political appointments (PPA).

On that note, Chapter 4 also demonstrated that it may be possible for the party in power to intervene in the work of the civil service through changes in the legal framework which regulates the internal processes of the civil service. In doing so, the case on the tripartite council suggested that such legislative changes could act in the interest of party insiders. And that too could be evidence of venue scope that involves the civil service and the party in power. The reason this is not discussed here is that 
this is a matter of a separate study. The case of tripartite council (chapter 4) does allow discerning whether the legislative amendments which blocked access to consultations for some groups were indeed a result of pre-existing agreements between the party and insider groups. That is why, at this stage, the study discusses links between the two venues of political parties and civil service: party political appointments.

The purpose of this chapter, therefore, is to elucidate the extent of party political appointments in Bulgaria, as a party-civil service relationship characteristic which is in common with La Palombara's parentela. The present study initially attempted to retrieve statistical data on the regularity of political appointments and possibly a correlation between a new party in power and the rate of deposed civil servants. However, as discussed in section 2 firm quantitative data could not be obtained. The study therefore looked at statistical surveys elsewhere, such as those of Kopecky and Spirova (2011) (KS 2011) and Kopecky, Mair and Spirova (2012) (KMS 2012) and compared their results to the qualitative responses from the present Bulgaria 2013 parentela project. The main contribution in this chapter, therefore, is that it adds to the explanation of the PPA causes and how they function, which KS (2011) and KMS (2012) discuss.

The responses from the present project confirm the conclusions of Kopecky and Spirova (2011) and Kopecky, Mair and Spirova (2012) on the prevalence of party political appointments in Bulgaria and on their causes, respectively. Kopecky and Spirova (2011) argue that agencies of ministries and the council of ministers (the Prime Ministerial Council or Council of Ministers, the government) are subject to wide-scale of appointments. Appointments, the authors also argue, spread, to a lesser extent, to other administrative structures, which ought to be filled strictly on merit and professionalism, such as hospital directors or principals. Data from this study confirms this spread.

KMS 2012 also argue in more general terms that PPAs are used both as a form of control and reward. While the evidence from the present project agrees with that 
argument, it nevertheless adds nuances to their argument and substance to their statistical data. First, political parties use political appointments as a form of control because they distrust any external, autonomous experts, be it from an autonomous civil service or sectoral interest groups. Parties see such independent participants as a threat, because their technocratic decisions fail to acknowledge party interests. A second form of administrative control spurred by distrust is when parties remove civil servants from office at the turn of new elections because the new incumbent distrusts the appointees of the deposed rival. Appointees of the previous party are expected to sabotage the new one. Third, also in agreement with KMS 2012, parties need political appointments in order to help maintain intra-organizational cohesion. However, the study elaborates that this use of PPAs is a form of award to party insider groups and factions. Finally, it also needs highlighting that the above practices are facilitated by the legal framework (5.2.) which enables party political appointments at central and local administrative level.

In any case, however, all of the above causes for political appointments and legal framework, that enables them, ultimately relate to the descriptor venue scope, which in the context of parentela, stands for any indications of connectedness between the party and civil service. The venue scope that the party-led policy-dynamics exhibit in Bulgaria overlaps with that of La Palombara's parentela. This is namely, that both in Bulgaria 2013 and in Italy 1964, the party in power seeks to achieve its policy or party ends by expanding its influence into civil service by party political appointments.

The chapter is divided as follows. Section 5.2 discusses the scope of party political appointments in Bulgaria statistically, by reviewing the data from KS (2011) and KMS (2012). Section 5.3 discusses the legal framework that enables political appointments, which also gives a perspective of the possible scope of such appointments, and which also overlaps with the data from KS (2011). Section 5.4 focuses on the causes for party political appointments. 


\subsection{Scope of Party Political Appointments in Bulgaria}

In order to estimate the extent of political appointments, the study initially lodged a Freedom of Information Request to the Administrative Register (http://ar2.government.bg/ras/). Among many others, this administrative structure is created by the Law on the Administration 1998 (art. 61) for the purpose of collecting information on the number of employed staff in the Bulgarian Civil Service. The request attempted to capture the extent of party political appointments by looking at the number of servants on directorial (rakovodni, ръководни) and expert (експертни) positions in any of the state agencies that were removed from office at the turn of new political parties coming to power. In this way it would have been observable how the new party in power removed the previous directorial office holders and appoints new ones. However, the request failed because the Administrative Register ignored the request.

Nevertheless, this setback had no adverse effect on this project, because the qualitative data from the present study corroborates the statistical data of Kopecky and Spirova 2011 and Kopecky, Meir and Spirova (2012). In a comparative study on political appointments in Eastern Europe for the period 2006-2008, Kopecky and Spirova (2011) develop a coefficient (index) of patronage. At the centre of their study lie Bulgaria, Czech Republic and Hungary. Their data shows medium rate of party political appointments in the three states (2011: 906-911, Table 18, p 125, Kopecky and Spirova 2011: 907):

Table 18: Levels of PPA (Kopecky and Spirova 2011: 907) 
The index values are grouped in three levels of party political appointments as follows (Table 19, p 126):

0.65 appointments occur in most institutions at all levels;

0.4 appointments occur in most institutions at top levels;

0.1 appointments are very limited and if any, at top levels.

An index of 0.42 is a measurement of a medium level of party political appointments (Kopecky and Spirova 2011: 906). Although this value places the state in the middle of a European-wide rank list of states with political appointments, the coefficient of 0.42 is a mean and that hides significant internal imbalances in favour of positions assumed on the grounds of political appointment as opposed to on merit. There still is a wide spread of political appointments both horizontally among top directorial levels of most institutions and state agencies, and, vertically, down to local and middle level in each ministry, that is also including positions far removed from party politics, such as school principals, hospitals, museums, etc. (Kopecky and Spirova 2011: 908-909), summarised and discussed in table 19 (p. 126) below.

\begin{tabular}{|c|c|}
\hline \multicolumn{2}{|c|}{ Ministries } \\
\hline Bulgaria & 0.61 \\
\hline Hungary & 0.65 \\
\hline $\begin{array}{c}\text { Czech } \\
\text { Republic }\end{array}$ & 0.67 \\
\hline \multicolumn{2}{|c|}{ NDAC } \\
\hline Bulgaria & 0.34 \\
\hline Hungary & 0.3 \\
\hline $\begin{array}{c}\text { Czech } \\
\text { Republic }\end{array}$ & 0.25 \\
\hline Executinglnstitutions \\
\hline Bulgaria & 0.32 \\
\hline Hungary & 0.34 \\
\hline $\begin{array}{c}\text { Czech } \\
\text { Republic }\end{array}$ & 0.14 \\
\hline \multicolumn{2}{|c|}{ Country } \\
\hline Bulgaria & 0.42 \\
\hline Hungary & 0.43 \\
\hline $\begin{array}{c}\text { Czech } \\
\text { Republic }\end{array}$ & 0.34 \\
\hline
\end{tabular}

Kopecky and Spirova (2011) break down PPAs in three policy venues: Ministries, Non-Departmental Agencies and Commissions (NDAC), and what the authors 
describe as executing institutions (table 19). Looking at the first category from their study, Ministries, the patronage coefficient is near 0.61, which suggest that the practice is prevalent across nearly all Ministries, including head secretaries and directors of ministerial agencies, down to civil servants on a middle level, possibly also including experts form the Ministerial Administration (Kopecky and Spirova 2011: 908-909; Kopecky, Mair and Spirova 2012: 59).

The next administrative section is the NDACs, or the "non-departmental agencies and commissions" which stand for those agencies and commissions created by and under the direct control of the Prime Minister. As the authors describe them, "These include institutions that are not part of the ministerial structures and have regulatory and consultative functions within each policy area." (Kopecky, Mair and Spirova 2012: 60). At an index value of 0.34 the level of appointments in these structures is considerably lower than in Ministries. This means that while appointments only occasionally reach the lower levels of such administration, the top levels, however, are routinely subjected to political intervention (Spirova 2012: 61; Kopecky and Spirova 2011: 909).

Last is that segment of the Bulgarian civil service that encompasses "state-owned companies, national financial institutions, the embassies and consulates, hospitals and schools, museums, and similar state-run entities.", or executing institutions (Spirova 2012: 61). Among the three states under scrutiny, Bulgaria scores second with a coefficient of 0.32 , which according to the authors indicates that (Kopecky and Spirova 2011: 909):

parties [...] uniformly appoint at the top levels of the executing institutions - to positions such as managers of state-owned companies or directors of schools [although] the overall score is driven by the extremely high level of patronage practices in the executing institutions of several of the policy areas

Despite the low score it is indeed a cause for concern because by default these structures ought to be remote from party politics and policy-making and ought to be strictly staffed by professionals, who are free from party political loyalties. These structures deliver state services, such as medical care and education, or generate revenue such as state-owned enterprises (Kopecky et al 2012: 61-62). Overall, 
Kopecky and Spirova agree with other authors that the scope of appointments in the Bulgarian civil service could in fact be wider because that could be disguised under civil service re-structuring or optimisation (Toshkov 2003 and Stanev 2005 in Spirova 2012: 62-63). The only civil service structures less prone to political interference through appointments are either those under immediate scrutiny of outsider institutions such as the EU or those which are extremely technical, such as finances (Spirova 2012: 61; Kopecky and Spirova 2011: 910-911).

In a 2012 follow up article, Spirova, Meir and Kopecky review political appointments in the Bulgarian civil service but for an earlier period between 2000 and 2005, conducted by the private polling agency MBMD (2012). The data from MBMD also indicated a high level of political appointments as of 2005. In fact, both studies combined from 2000 to 2005 (MBMD in SMK 2012) and from 2006 to 2008 (Kopecky and Spirova 2011) indicate an overall upward trend of party political appointments in Bulgaria. In the MBMD study conducted in late 2005-early 2006, asked 922 civil servants the question "Do you believe that political appointments in the state administration happen often/sometimes /never?" twice: in 2000 and in 2005. The results indicated an upward trend of political patronage. Those who believed no political appointments existed in 2000 (40\%), reduced in half by 2005 (less than $20 \%$ ). Those in 2000, who believed that there were often political appointments, rose approximately 3 times by 2005 (Figure 1 p128). Overall, if we add the MBMD results to the results from Kopecky and Spirova (2011) we could observe an upward trend of political patronage in the Bulgarian civil service from 2000 up to 2008. 


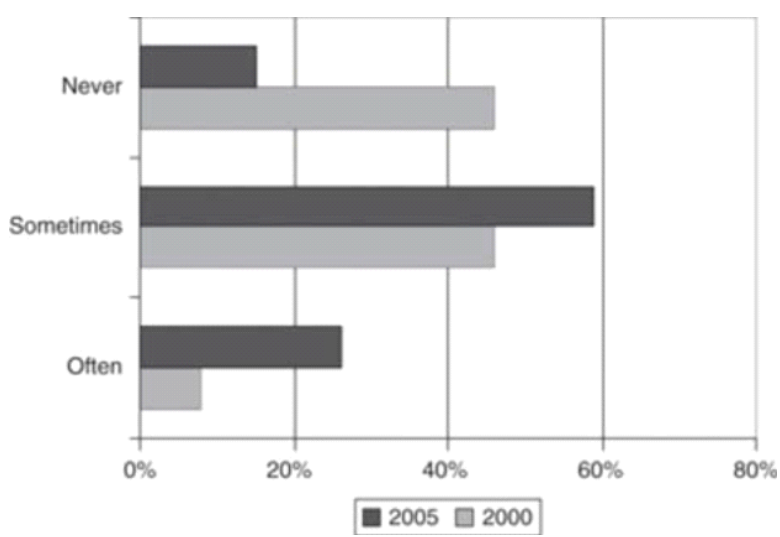

Figure 1 Do you believe that political appointments in the state administration happen often/sometimes /never? (Spirova 2012: 60)

Their results clearly demonstrate that in the Bulgarian polity hosts a high scope of political appointments. However, the data from the Kopecky and Spirova's study does not allow to ascribe deviation of political appointments vis-à-vis other European states, even if some categories may warrant concern in absolute terms, such as NDAC or executing institutions above (2011). The main point is that even at these similar levels, the scope of political appointments, particularly in the ministries remains considerable and that may prove enough for a parentela formation.

In any case, in terms of the classificatory system, the above data is enough to claim that the ruling party and civil service venues are connected by the practice of party appointments, which accommodates the parentela formation. In these circumstances, any relationship the party in power enters will extend into the civil service. The value of the descriptor venue scope, therefore, in the present study is equivalent to that of La Palombara's parentela. In fact, the evidence is stronger than that. In her attempt to describe these party-civil service relations, Spirova inadvertently describes the parentela (2012: 64-65):

As a result, a lot of the positions in the agencies that regulate the economy [including] agriculture, transport, and infrastructure were staffed with party appointees who could ensure that the important decisions were also taken with the economic interests of the political parties, or of private companies friendly to them, in mind. 
The description above identifies political appointments as the possible result of preexisting agreements between the party in power and possible insider groups. However, while the data provided by Kopecky and Spirova (2012) demonstrates that Bulgarian and Italian polities shared a key parentela feature, there is the pressing question of What is the evidence of political appointments from the present study?

Interview responses from the present study strongly corroborate the findings of Kopecky and Spirova (2011). Respondents indicated an overwhelming breadth of party political appointments to the extent that asking how far appointments spread rendered the question irrelevant. Stated with confidence, nearly every one respondent who was asked to address the topic of appointments complained on the depth of appointments down to local level. Extreme anecdotal examples included the ejection of school janitors at the turn of elections. It soon became clear other questions were more relevant, i.e. how PPAs function and what has led to the prevalence of this political practice. They are important for the study on parentela, because they provide the details of how the parentela functions, i.e. what circumstances ease its dynamics (intervening variables), and what has contributed to this particular practice (independent variables that explain the venue scope). These two broad questions of how and why, are dealt with below.

As a final note, maybe by now the discussion of Kopecky and Spirova's data has raised the question whether their methods could have been employed in the present study (2011). Their methods, however, were not used for a number of reasons. First, there is insufficient disclosure of their methods to warrant replication. They do not disclose the process of calculations that led to the division of corresponding coefficients. They also do not discuss the raw type of data: qualitative or quantitative. The authors briefly note that the Bulgarian appointments coefficient is developed on the basis of surveys/elite interviews with elite respondents, academics, media professionals, politicians and civil servants (2011: 905). That approach in particular was irreplicable in the present study because the survey questions are unknown. Moreover, it adds to the problem of access to elite respondents, which already proved to be costly in terms of time. 
Second, the above leads to the question of data validity of their methods, because only formal statistical data from the administration itself could yield the necessary validity on any data pertinent to political appointments. The question, ultimately is how the coefficient was composed: on the basis of statistical data provided by expert respondents or from some form of ordinal code quantification, e.g. as in How often do you think political appointments occur? A) Never; B) Rarely; C) Sometimes; D) Often; E) All the time? If the latter, then, that reduces some of the validity on the scope of appointments because the data is not so much statistical as it is a reflection of elite respondents' impression of the scale of the practice. The difference between that approach and the interpretive one employed in this study is the extra stage of ordinal coding, which most likely has been employed.

The composition of the categories does not fit the needs of the present study. Kopecky and Spirova's categories do not reflect the distinction between politically appointed directors and technical staff (2011). This makes it difficult to demonstrate the scope of political appointments affecting purely technical positions, as such posts are also evident in the Ministries. A more accurate civil service category composition could be developed using the Classificator of Positions in the Bulgarian civil service (Classificator 2015). The Classificator is a table provided by the Council of Ministers that defines all civil service positions in the civil service, which is directly subordinate to the prime minister (Council of Ministers) and individual Ministries. The Classificator clearly distinguishes between politically appointed and technical positions. In an ideal case scenario, a response to an FOI request that adopts the hierarchy defined in the Classificator would facilitate the more accurate construction of variables and provide a level terminological ground for any enquiries. However, this complaint is relevant to the present study on parentela in Bulgaria. It has to be recognised that the Kopecky and Spirova study is comparative and so, they had to construct categories that are relevant across a number of states (2011). The point is that their categories are inapplicable for the present research project. Section 5.3 discusses the legal provisions that enable and facilitate party political appointments 
in the civil service. Section 5.4 reviews the historical and structural causes for the political appointments.

\subsection{Structure of Appointments on Central and Local Level}

The present section argues that the prevalence of political appointments is enabled and facilitated by the provisions in the Law on the Administration 1998 (LA) and the Law on Local Self-Government and Local Administration 1991 (LLSGLA). The analysis of the legal framework that regulates political appointments is provided by the Bulgarian parentela project as another mean to complement Kopecky and Spirova's study on political appointments (2011). The early clues as to the importance of these pieces of legislation came from Kopecky, Mair and Spirova (2012: 56) who identify a handful of authors discussing the legislation that governs the conduct of the civil service, i.e. the Law on Administration 1998 (LA) and the Law on the State Servant 1999 (LSS), and the historical origins of party political appointments (Shoylekova 2004; Dimitrova 2002; Velinova, Bozhidarova and Kolcheva 2001). However, there is very little in terms of discussion on how exactly the Laws facilitate appointments, which is of importance for the present study on the parentela. Focusing on the Law on the Administration (1998) reveals the de jure connection between the party and civil service venue, as it clearly enables the ruling party to make political appointments.

Compared to the LLSGLA, the LA is the more important piece of legislation in relation to the parentela as it defines the structure of the Bulgarian state administration and demonstrates the hierarchical structure of appointments (summarised in the figures below). This is different from the Law on the State Servant 1999, which is more detailed on the procedures governing employment, publicising vacancies, and competitions for recruitment, as well as rights and responsibilities during employment. While the political appointment is itself a contract of employment, the Law on Administration 1998 codifies the authorities which have the right to offer employment without open competition, hence 
appointments. The importance of LLSGLA became evident after reviewing LA, as the former is a local mirror image of the latter, as it codifies the rights of political appointment on a local level. The legislative framework that both Laws constitute evidences that the scope of venues in the Bulgarian policy-making process may involve both the party in power and the civil service.

There are a few points worth noting before engaging with the discussion on the abovementioned laws. Bulgarian Administration is divided into central and local levels (Law on Administration 1998 article 37) (LA 1998 37). The central executive administration comprises the administration of the Council of Ministers (the government), of the Ministries, of deputy-ministers, of state commissions, as well as of the state and executive agencies, and ad hoc executive bodies created for specific tasks (LA 1998 38(1)(2)(3)). The local administration is comprised by two concentric units of administrative division: oblast (region) and within them, obshtina, (municipality) (LA 1998 38(2)). Provinces have two local executives: the oblast (regional) governor who represents the central executive locally, and elected municipality mayor (LA 199819 (3)) who represents the local executive branch. Finally, it has to be noted that usually the leader of the political party in power is the prime minister. Therefore, the entire study adopts the perspective to speak in terms of the party leader (or chairman) and less of prime minister; of party in power and less of the government or parliamentary majority.

Figure 2 (p. 134) charts the vectors of appointment in the Bulgarian civil service. The shape where an arrow starts marks the appointing body and where the arrow ends mark the politically appointed position. The main appointing bodies are the prime minister and individual ministers, denoted with blue triangles. The main and most relevant in our case appointed bodies are the agency directors or commission chairmen, which are denoted with blue rhomboids. Other less relevant to our case appointed positions are political cabinets and oblast governors, which are denoted with blue squares. In addition, there are trapezoid shapes whose purpose is to give more details on the specific articles from the Law on the Administration 1998 that govern the appointment in question. The respective articles are denoted in brackets 
"( )". The same reference system is employed throughout all elements in the figure, where relevant articles from the LA 1998 that codify the relationship are noted in brackets. Finally, every one element has a unique reference number, noted between two short dashes, e.g. "-12-“. Overall, a relationship of appointment is expressed as the collection of all shapes that lay at the start, middle and end of any given arrow, and the LA articles contained within them. 


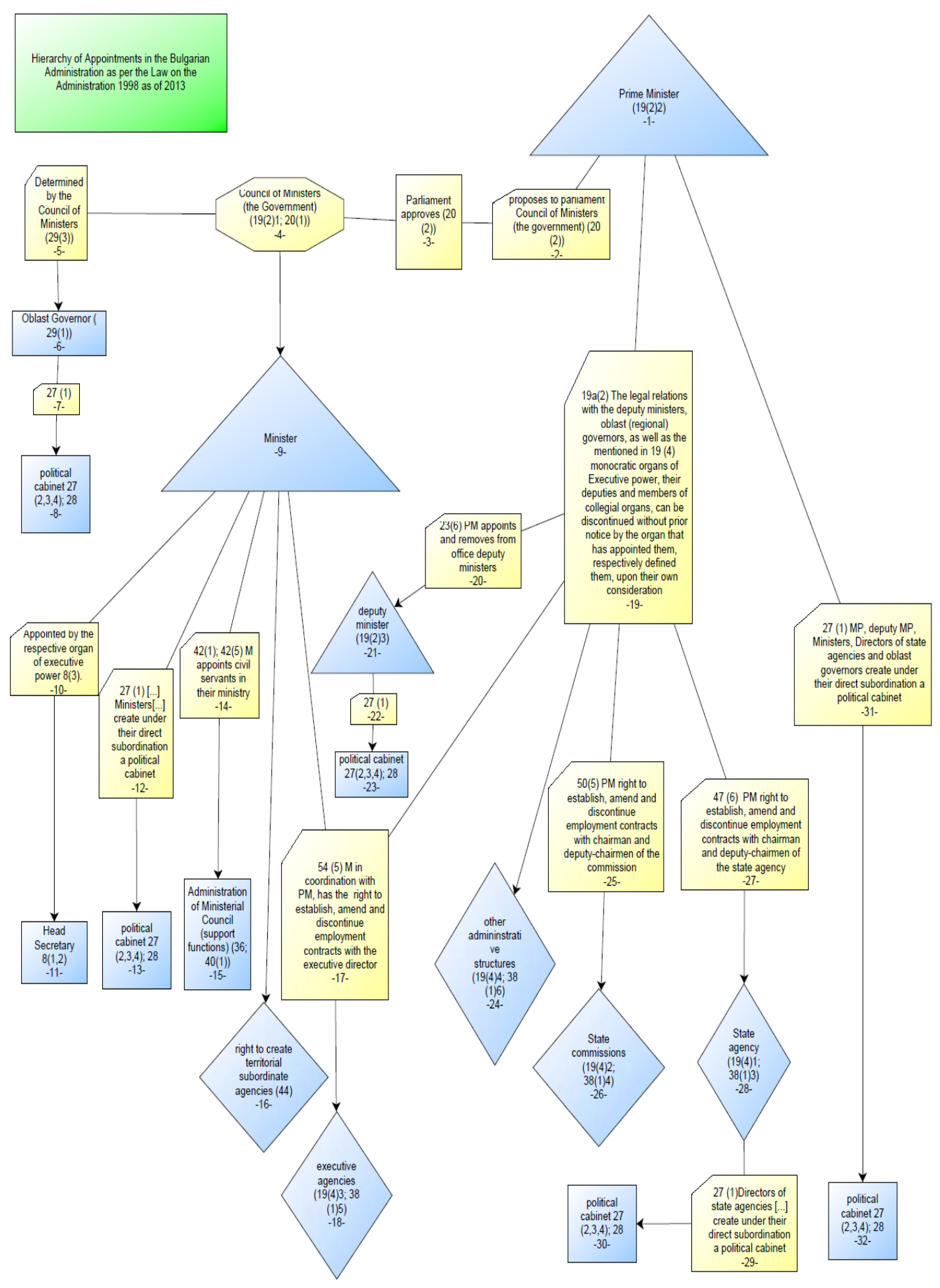

Figure 2 Hierarchical Structure of Party Political Appointments as permitted by the Law on Administration (author's analysis) 
The LA offers direct and indirect procedures available to the central party leadership (the prime minister and party functionaries equal in rank) to make party political appointments. The direct ability to make a PPA is embodied in the right of the leader of the party in power (the Prime Minister) to offer and terminate employment of directorial (top level decision-making) positions in the agencies that regulate the business and public activities in the state, and deputy-ministers. The LA is quite clear that the Prime Minister has the right to offer and terminate employment to directors in the state agencies (LA 1998 47(6), -1, 19, 27, 28-) and state commissions 50(5)) (24, 26, 28-). The former are agencies created by the Ministerial Council (the Government) ((LA 1998 47(1), -28-) in order to support the policy-making activities of the Government. The latter is a structure created to manage issues related to permits emanating from and related to legislation (LA 50(1) -26-).

The LA 1998 also specifies that the Prime Minister can offer and revoke deputyministers positions (LA 1998 23(6), -1, 19, 20, 21-). These rights are further facilitated by the provision in the LoA 1998 19a(2) which states that whoever makes the appointment, be that the party leader (Prime Minister), the Minister or the Government (the Council of Ministers), has the right to an immediate retraction of such contract (-19-). In other words, not only is the central political leadership of the party in power able to make appointments in the central executive agencies, but these are further eased by the ability to remove from office without the obligation to give notice to the respective civil servant.

The powers of the party leader to appoint do not stop there. There are indirect ways in which they can influence political appointments in the administration. These powers relate to the employment of directors of executive agencies. These are created by the Council of Ministers (LA 1998 54(1) -18-) in order to help carry out the duties of the Ministry. Here, employment and its termination are vested in the Minister with Prime Minister's coordination (LA 54(5) -17, 18-). The only positions under the direct control of a minister are the executive agencies established locally to support 
the operation of their ministry, directorates (-16-), and the staff of each ministry (40(1) -14, 15-). The law states that it is the Minister who has the sole right to offer and terminate employment in their Ministry (LA 1998 42(5) -14- ).

However, given the fact that the Minister owes their position to the party leader ( -2 , $3-)$, it is highly likely that informal coordination occurs for specific appointments of interest to the premier. This means that even those positions that do not directly fall under the powers of appointment of the prime minister could be informally subject to their influence because ministers owe their positions directly to them.

For sake of completeness, we should mention head secretaries of the central and local administration and political cabinets. The former positions stand for top level civil servants in the state administration whose duties are primarily to ensure the internal departmental cohesion and legality of all taken actions. These positions too are political appointments made by the relevant Minister (-10, 11-). As it was established above, this should not obscure the fact that due to internal party loyalty, a Minister's right to appoint does not preclude the political leadership of the party in power from influencing the nomination.

Political cabinets are committees of advisers in the office (or kabinet in Bulgarian) of each of the organs of central and local executive power: e.g. Minister (-13-), Prime Minister (-32-), Regional Governor (-6, 7, 8-), Mayor (next section). They do not have immediate duties and responsibilities with regards to the functioning of the administration, but advise their patron on political and administrative matters. It is possible, in theory that a parentela could occur at these levels, although it was only Petkov who discussed political cabinets as examples of political appointments under external nominations.

Overall, the discussion so far sought to primarily demonstrate that political appointments of directors of central (subordinate to the council of ministers) or executive (subordinate to the minister) agencies are both under the control of the political leadership of the party in power. The following subsection makes the same 
point. The party whose candidate has assumed the mayoral post has the same powers of appointment across all important positions within the civil service within the local city council. In other words, such mayoral powers of appointment facilitate the formation of a parentela on a local level. This is especially relevant to Chapter 8 which documents precisely that.

Powers of appointments vested in town mayors manifest themselves in mayor's ability to appoint their deputies and the civil service in the city council (obshtina) as permitted by the Law on Local Self-Government and Local Administration 1991 (LLSGLA). Article 39 of LLSGLA grants a mayor the power to appoint deputies. Article 43 refers to the administration of local councils, where "[t]he mayor of the obshtina appoints the secretary of the obsthina for an unlimited period of time" (43(1)). The duties of the latter are to internally organise the work of the administration of the city council. Article 44(1)3 specifies that the mayor appoints and removes deputy mayors, the chairmen of the administrative units on an obshtina budget, directors and servants in the obshtina administration. It has to be stressed that on a local level, the party a mayor represents is able to make political appointments throughout the middle and top levels of the city council administration. Figure 3 below summarise the discussion:

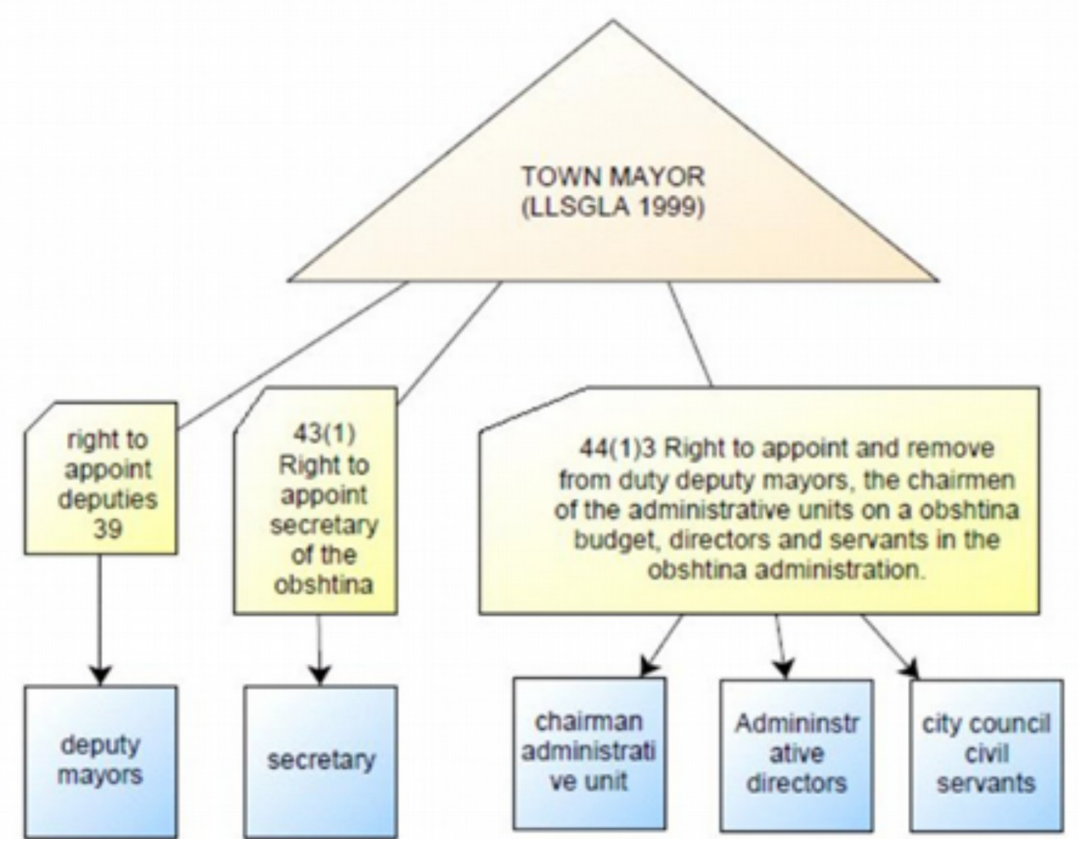

Figure 3 Appointments at Local Level 
Overall the purpose of the present section was to demonstrate that the legal provisions set out in the LA 1998 and LLSGLA 1999 laws facilitate a wide scope of party political appointments. The legislative analysis above, part of the study on the parentela in Bulgaria, also demonstrates that the central executive positions which KS 2011 identified as largely subject to political appointments are indeed so, because LA 1998 allows for the central party leadership (i.e. the prime minister) to appoint or remove directors of agencies that are either subordinate to the Council of Ministers (i.e. the government) or individual ministries. The review of LLSGLA 1991 indicates that a mayor of an obshtina has analogous powers of appointment to those of a prime minister in that the former can appoint or remove from office any director of any important city council administrative unit. Both laws demonstrate that a parentela could form locally or centrally because the party that holds executive power can influence the work of the institutionally adjacent administration through political appointments.

However, more importantly, the legal framework above clearly testifies for the connectedness of the party and civil service policy venues. In doing so it shares the same characteristic with the parentela. Being unable to contribute statistically to the debate on the scope of political appointments in Bulgaria, then, the remainder of the chapter is dedicated to contributing to the research of SK (2011) and KMS (2012) on the causes for party political appointments. However, in doing so, the following section 5.4 also provides immediate examples of how the party and the civil service could be connected, thus showing evidence of venue scope that spans from the party itself to the civil service.

\subsection{Explaining Party Political Appointments: Political Distrust}

The present section (5.4) is dedicated to discussing the various forms of distrust that ultimately lead to the use of political appointments. There are a number of authors who link the practice of political appointments is a heritage of political culture of previous authoritarian political systems. Kolcheva, Bozhidarova and Velinova (2001) 
link PPA with the heritage of Ottoman political culture and Soviet influence, both of which rested on personal allegiance to a centralized executive. The authors stress the present practice of political appointments is reminiscent of the Bulgarian civil service during its totalitarian socialist period (Kolcheva et al 2001: 3-5). Accordingly one of the main characteristics of the Bulgarian socialist civil service was the extra layer of civil servants, i.e. the political nomenklatura, which were politically appointed and were tasked to oversee the work of expert civil servants, observing thereby party policies implementation (Kolcheva et al 2001: 5-6). The same argument is also made elsewhere by Kopecky and Spirova (2011: 898-901), Raychev and Stoychev (2008), and Chalakov et al (2008).

Data from the present study tends to add credence to such historical indebtedness to previous authoritarian Bulgarian forms of government. Kuzmanov was probably the strongest supporter of the argument that the predisposition to corruptive behaviour is a residue from the times of the Ottoman Empire, where informal monetary compensations were the norm when dealing with Sultan's civil service. Similarly, Georgiev argued that "to give in order to receive", or do ut des, was the core of Bulgaria's policy-making informal mode of interaction with the central administration. Golemanov was vehement that the informal administrative dynamics employed today are direct application of the repressive style of socialist Bulgaria pre-1989. However, while many respondents had tidbit historical references to socialism, overall with the exception of Golemanov, no respondent made an explicit link between political appointments and any other preceding Bulgarian form of government.

While many respondents saw some similarities to previous times of Ottoman Empire and socialist totalitarianism, however, those do not necessarily explain political appointments. Saying that "We employ political appointments, because we have always done so", does not explain the need for such appointments. We have to look for some structural or systemic explanations. 
Overall, the present research indicates that political distrust necessitates the use of political appointments (sections 5.4.1, 5.4.2). The ruling party distrusts experts from interest groups, because their loyalty lays elsewhere and their solutions to policyproblems do not necessarily reflect the salience of party political expedience (5.4.1). Reciprocally, interest groups distrust political parties for their cadres' lack of necessary expertise to arrive at industry-efficient decisions (5.4.1). This mutual distrust manifests itself in the appointment of civil service department and agency directors, and in the question whether at all the civil service should be left autonomous from party political intervention. As a compromise, party members may promote experts from the party ranks that may combine both recognition of sectoral groups and party's trust (5.4.1). However, it is doubtful whether this alleviates distrust because as Petkov explains regardless of the loyalty the appointee may have at the start, it will always shift towards the party political patrons soon after assuming the appointment. Ultimately, as the legal framework (5.3) gives the ruling party the right to determine political appointments, the distrust towards all other non-insider actors causes them to maintain a firm hold over civil service nominations.

As a result of the same distrust, newly incumbent parties do not hesitate to sweep out their predecessor's appointees. Respondents from section 5.4.2 were unanimous that no party in power can afford to retain appointees from rival parties. The threat is that civil servants of rival political parties, acting on the commands of their former patrons, would actively seek to sabotage the new ruling government. As a result, every new election is accompanied by "sweeps" of mass replacement of "old" civil servants with new ones. These were clearly detected by Kopecky and Spirova (2011) and the negative consequences of this practice were discussed at length in the previous chapter.

Indeed there are some cases where nominations could originate outside of the immediate party in power, although effective appointment is still sanctioned by the party in power. These cases usually relate to agreements between party and insider groups, or when the party needs to appease party factions and (lesser) coalition partners (Kuzmanov, section 5.4.3). Likewise, party factions in particular may feel 
un-represented in the executive branch. At the same time, long term functionaries may also grow resentful if they do not see their contribution to the party rewarded with a prestigious post. This is a corroboration of the same argument KMS (2011) and KS (2012) make. In congruence with their findings, evidence suggests that party leadership attempts to appease intra-party factions by endorsing their nominations in order to maintain inner party cohesion (section 5.4.3). The arguments above will be elaborated in the subsections below.

\subsubsection{Party's Distrust of Independent Expertise}

The most important dimension of the PPA debate that comes up from respondents' statements is the conflict between expert and political appointments (or civil society and the ruling party, respectively). Sectoral groups distrust government's ability to lead using party political appointees, which is why they seek to resist policies particularly when those are promulgated by individuals whose professional background is remote from that sector.

This problematic is first noted by former Prime Minister Zhan Videnov (in Petev 2001) in his memoirs (in an interview format). In response, he attempted to form a government of experts, entirely supported by the respective sectors, or another of ministers entirely backed by the party and party factions. As chapter 7 will demonstrate, many of those expert appointees could have come from the structures of Multigrup, because many of the experts from the then defunct socialist civil service assumed employment there. However, Videnov regrets opting for the expert appointments route (Videnov in Petev 1998: 159-169). He admits underestimating the party-incapacitating rift of distrust between the party leadership, appointees and members of the parliamentary group, caused by the lack of support from key party factions around the leaders Lilov and Lukanov (in Petev 2001: 159-161). He reports that the party political leadership distrusted the experts in his government because their technocratic policy solutions do not necessarily conform to what party ideology dictates, nor what party leadership considers party politically expedient. 
He describes this distrustful relationship by evoking the popular image at the time: the isosceles triangle of power. In this relationship model the central party executive bureau sought to ensure its dominance over policy-making by exerting pressure on its own group of MPs and on the prime minister, who is also a member of the same bureau. This isosceles triangle reflects central party executive's distrust towards its own MPs and the expert cadres that the prime minister endorsed (appointed). The latter particularly reveals the hidden conflict over appointments in the civil service: whether they should be strictly expert and independent, or political and subservient (Videnov in Petev 1998: 173-180, 228). Ultimately, in order to prevent any such friction based on distrust, Videnov (in Petev 1998: 174) explains, other political parties such as SDS that followed his government solved this friction between the central executive bureau, the premier and MPs by concentrating party leadership into a single leader and by predominantly sending out political appointees in the state administration. The account from Videnov demonstrates that party political appointments largely reflect the tension between appointing cadres with expert qualities or such that are immediately sponsored from the party.

Other politicians, too, implicitly identify the same dilemma, also responding in similar vein: balancing between appointees with sectoral recognition and such with party sponsorship. In response to this confrontation, Respondent Hristov, a former Minister, explained that he had made consultations with interest groups in his ministry. Hristov, a minister at the time of interview, admitted to the practice of political parties seeking to ensure control over the state administration:

$R \quad I$ mean, sometimes appointed are not the necessary specialists, but people who have nothing in common with the job //inaudible/ why? Why does it happen? --S/ This is the interference of politics in the state administration, which categorically has no place there. But as much as it is not there if you look at the law, in practice it does happen. We should not lie to each other about it. I am telling you the truth of what is happening.

This statement above comes as a big political confession. This is not only another piece of evidence of the party political interference in the civil service. This is also a confirmation that party political expedience may also dictate political appointments at the expense of sectoral group. However, as far as he was personally concerned, he 
also tried to consult interest groups for possible candidates. In his words, he tried to find the "right man for the right job", implying that, he attempted to balance between party loyal and expert appointees. That is to say, while accepted nominations may come from outside the party, the appointee had to retain loyalty to the appointing political party. They overlap with Videnov above on the latter point of political control.

Hristov's policy to negotiate appointments is also reflected by Lyubenov who stated that political parties need not always have the best ideas on the table or the best party cadres to send to the administration, because those are supplied by the industry interest groups. According to him, political parties consult sectoral interest groups hoping to find mutually agreeable sectoral expert nominations. Respondent Zlatarov observed that the recent interim government of Oresharski was the product of such consultations where each appointment resulted from consultations with, and approval by, respective sectoral group. Respondent Penchev, in turn, recounted their personal involvement in the nomination and appointment of Oresharski as a prime minister. At the interview, he reached over to the drawer and took out a number of hand-written A4 sheets of paper with names on them, and gave them to the researcher for inspection. Those were the names Penchev had proposed to the leader of the party in power. All of them, he argued, were experts supported by sectoral (peak) associations. For Penchev it was of paramount importance for the BSP-DPS coalition government to gain recognition from the sectoral interest groups by promulgating their appointees in the executive branch. Whether and how far that was a successful policy remains to be seen. The important point is that the accounts of Lyubenov, Hristov and Penchev indicate that (sectoral) interest groups take advantage of the opportunity to limit party political influence over the civil service by nominating own appointees. Also, the above indicates that parties, too, are concerned with the expertise they introduce with their appointees.

However, still operating in an environment of political distrust, parties, would still largely rely on loyalists than on experts. As Petkov loudly exclaimed in defence of the appointments they had made as a former minister, "I don't want to be betrayed!" 
Petkov argued that the distinction between appointees who are expert and those which are political is meaningless. The mere act of political appointment constitutes an obligation to the one appointing. Therefore, even if pure experts are appointed, they become politically subservient immediately after their party appointment. Reflecting the same thinking, Hadzhiev intimated that lost in bargaining, political parties blur the distinction between political and expert civil service appointments. Ultimately, then, the overarching consideration when making an appointment is whether the person could be trusted.

As a result, more recently, respondents saw the administration as nothing more than an adjunct organisation to the ruling party. Respondent Nikolov was rather cynical:

$S \quad$ Political appointments in the state administration, do they help to improve the relationship between the administration and the interest groups

$R \quad[\ldots]$ the state administration de facto is one extension [...] of any one political party in power. This is very clearly and accurately said. It (the administration) is sometimes doing functions which are not inherent to it and directly services every four years the change of this or that political class (party) /pauses/ so everything which could change things in Bulgaria is turned upside down.

Note the expression above "not inherent functions". What he implies is that party political expedience governs the behaviour of the administration. The details of this experience will be revisited when introducing a 'type 2' parentela in Chapter 9. At this stage it is important to note that the state administration may be used by ruling political parties as an instrument to achieve narrow party goals (Petkov). Others, equally disgruntled respondents were also equally forward. Kuzmanov for instance stated:

$S \quad$ In the context of the relationships between the political elite in power and the economic networks, what is the role according to you of the political appointments in the state administration?

$R \quad$ Technical [...] If you are single party in power, all of the appointments are yours. If you are a coalition, you have given sectors and they are yours. Respectively you put people first whom you trust. Second, [you appoint] those whom if you tell them "Do this" they do it. [That is] to reach your given goals, and third [you appoint people] to actually get something done, 
because the system simply has to function. But this is last. And that is it.

The respondent's ordering of the reasons behind an appointment indicates that the most important consideration when making political appointments is for the party to have trust in the appointee.

Similar to Petkov, in criticising political appointments Zlatarov noted that the main ailments of the Bulgarian civil service are namely the broad party loyalist political appointments because they reduce professionalism in the service and constantly reset industry's consultative relationships with the administration (also Stoyanov, Rumenov). The importance of the latter is that relations with the civil service are essentially interpersonal and it is arduous to establish productive consultative ones with new civil servant counterparts. However, while he did not argue that political parties deliberately seek to appoint people who are unqualified, Zlatarov argued they will sacrifice good relations with sectoral interest groups and turn a blind eye on expertise in order to ensure the subservience of the administration to the executive (Kuzmanov, too). Trust, again, is the prime motivator behind political appointments.

Finally, on a basis of a statistical survey KMS (2012: 63-65) demonstrate that trust is of utmost importance when a party considers a candidate's appointment nominations. Accordingly, authors' respondents rated the three qualities an individual had to have to be successfully sent into the administration: political allegiance $90 \%$, professionalism 58.5\% and personal allegiance 58\% (KMS 2012: 66-67). Their survey confirms that first and foremost party political loyalty is the requirement for making new appointments. That in turn extends to-date the validity of Videnov's point above that political parties heavily endorse party political appointments of loyalists because they are distrustful towards any independent expertise, be that embodied in an autonomous civil service or nominations from sectoral interest groups. Political distrust however has another dimension. It is also observable in the attitude newly incumbent parties harbour towards former political party civil service appointees. This is discussed in the following section. 


\subsubsection{Distrust of Appointees of Party Electoral Losers}

Another dimension of the political distrust that causes parties to appoint relates to appointees of the political party voted out of office. As respondents Dobromirov and Kirilov explain former appointees need to be weeded out, because they will likely continue to work for their political patrons. As Kirilov and Dobromirov argue, owing to longstanding loyalties, appointees of electoral losers will seek to sabotage the new government. Respondent Kirilov highlights that the prime motive behind political appointments is the trust in the cadres that would inhabit the administrative structures, rather than any focus on professionalism. That is why cadres of former political parties have to be swept out. Trust was at the centre of Petkov's emotional and negative reaction against the question on political appointments:

S: $\quad$ And what would be the effect of political appointments?

R: $\quad$ Well, if they appoint kalinki, the effect is bad. If for example for political reasons I appoint Y because I know he will be doing a good job, or let's not give an example with $Y-I$ know for instance-The chief of my political cabinet, which is not part of the state administration, but the man with whom I have worked the longest in the ministry of $X$, was the husband of my first cousin. "But why did you appoint him?" /raises voicel "I trust him most, you people!" He is capable, a colleague of ours ('us' meaning intermediary and themselves) and he is from state intelligence services, but it does not matter--

I: $\quad$ It does not matter; it is important that they do their job!

R: $\quad$ /further raises voicel because I trust him! I don't want to be betrayed! //in agreement/ Ahem. --I/. Governance is a collective job. In Bulgaria, collective sports do not work, and that's including politics, if we take it as a form of collective sport. /This is true -I/ because there has to be a team! /further raises voice, screams? / And it is hard to make a team! /Yeah-I/ in the team there is always someone who is better, and they refuse to play in the national team! For example, Berbatov, /laughing --I/ Kaziyski /inaudible/ the same is with politics! /calms down, next topic/ (243)

It is important to note that in the excerpt above the respondent deflects a direct answer to the question on political appointments. Note that they discuss political appointments as a whole with reference to their advisers to their political cabinets (permitted and required by the Law on the Administration 1998 above). This means that while they speak with reference to political cabinets they make the same, general 
point regarding political appointments in the State Administration, avoiding getting entangled in compromising elaboration on the details of their tenure as a Minister. In short, fear of betrayal exists across the entire administration, including political cabinets. Fear of betrayal is not only on personal level but on top political level as well. However, there is one final reason for party political appointments: as a type of reward in order to maintain inner party cohesion.

\subsubsection{Insider Agreements and Resource Exchange}

Evidence suggests that political appointments could also be used not necessarily for the implementation of a specific policy but in the pursuit of specific policies of interest to the party in power, particularly as rewards to party functionaries and core insider groups. KMS argue that appointments serve as a reward to party factions (2012: 63-65). As an example KMS provide the so called "Tripartite Coalition" Government (2005-2009) where though informal, publicly discussed division of civil service positions was in place, where each of the coalition partners received positions in the proportion 3:5:8, NDSV:DPS:BSP, respectively (2012: 69-72). However that is a reiteration of an observation that Videnov makes regarding his own tenure as a prime minister (in Petev 2001: 179):

And this is what concerned me the most. [...]: to seek not so much " $a$ man for the post", but a "post for the man". Obviously, the dominant position in the party elite was that within the package of being in power we have also received mainly benefits (and not solely responsibilities), which they have yet to distribute as appointments to high places (and not distribute heavy responsibilities). I already knew then that this way of thinking is very dangerous for all of us and could put us in making thoughtless decisions regarding the cadres (appointments), which our political opponent would not have missed the opportunity to take advantage of.

For many party functionaries their loyalty to the party should be rewarded with a post in the state administration, even if they are unqualified. In any case, the point remains, political appointments are the result of political parties' distrust towards other possible policy participants, such as interest group experts.

The present study can also confirm the use of appointments as a form of appeasement or award of party's partners: insider groups or coalition partners. 
Respondent Kuzmanov narrated the story of their personal involvement in Bulgarian politics as an appointed director of a State-Owned Enterprise (SOE (or a firm)). Those are firms owned by the state and the profit they make goes to the state. Kuzmanov's mission was to bring one decrepit SOE back to its feet. Consistent with the need for politically loyal appointees' discuss above, Kuzmanov's immediate appointment, as he himself admits, was the product of his close friendship with the minister at the time, which ultimately acted as a guarantee of his loyalty to the party. However, he implied that his party leadership had other aims: the future revenues to be redirected party factions and party functionaries for the purpose of elections and intra-organizational cohesion. For a brief period at the start of his appointment, Kuzmanov worked relatively unimpeded, given their Ministerial protection and the fact they had satiated the demands of most of the actors interested or involved in this appointment and its goals. However, ultimately, due to party in-fighting Kuzmanov's political patron - the respective Minister - had to resign removing thereby all protection around Kuzmanov. Soon after his patron's withdrawal from politics, Kuzmanov was deposed as a director of the SOE he had been in charge of and which he helped to become a viable firm, and was replaced with locally more favourable appointee. These circumstances support the arguments of primacy of loyalty in making political appointments and that such appointments could also be motivated by the need to appease internal party factions.

A number of respondents also identified political appointments as a form of reward, which should be seen as nuance of the overall practice of appointment. While top level policy-makers such as Hristov, Videnov, Lyubenov and Penchev discussed appointments as a matter of negotiation between parties and sectoral interest groups, another set of respondents saw such appointments as rewards to individual businesses (firms) with party insider status. As an active politician at the time of the interview, Bachvarov clearly admitted that third actors, such as party donors sometimes had the exclusive right to have a say on the appointments. Bachvarov's emphasis was that party donors can expect many benefits from the party in power. While most of them are favourable public tender auction outcomes, some of them are favourable appointments, which could also occur locally. However, again, it has to be 
stressed that the difference in this sort of appointments is that those are subject of negotiation between the party in power and a single non-representative group (individual firm, company) with insider status.

Respondent Zlatarov too identified appointments in the local administration as forms of rewards or reciprocal benefits to party insider groups. Being particularly disgruntled he indulged on the importance of local administration to facilitate these contractual relationships between political parties and insider interest groups. However, similar to Bachvarov, Zlatarov added that ultimately decisions on local appointments tend to be determined by the central leadership (not the local) of the party that has won the mayoral seat.

Likewise on a local level, Respondent Kirilov argues that local businessmen who find their fortunes at risk may attempt to take part in politics in three ways: become party campaign donors, promote a nominee to the city council administration or businessmen themselves enter the political competition. Kirilov, however, argues that the second and third option, respectively, are most reliable for local businesses. As a result, owners promote themselves or someone they trust to directly represent them in the city council administration, e.g. as a deputy mayor or councillor. Doing so increases that business' participation chances to take part in public tenders or participation in any other major local business project. Gospodinov elaborated that direct involvement in the city council politics gives business groups the chance to ensure favourable appointments to the Public Tender Committees, which decide on the main contractor at public tenders. An exemplary case study of that situation is discussed in chapter 8 . This is so because it is the obshtina mayor who is in charge of appointing the members of the Committee that decides on the winners of public tender auctions. Stacking the committee with loyal appointees ensures favourable outcomes (discussed at length in Chapter 8).

Overall, the evidence in this section indicates that party political appointments are due to three main causes: party's distrust towards independent experts, party's distrust towards appointees of previous parties and the need to maintain intra-party 
cohesion through the distribution of favourable appointments as rewards to factions and insiders. Second, it also demonstrated with more specific examples how both political parties and civil service policy venues are connected through the practice of political appointments, which reflects another one of the parentela's features: venue scope that includes both the party and the civil service.

5.5. ConclusionThe chapter demonstrates that the party in power and the civil service venues are connected thanks to the practice of appointments in the civil service and that the venue scope of party-led dynamics involves the civil service as well. That characteristic of Bulgarian policy-making, the chapter argues, is a clear overlap with the original parentela. Political appointments are wide-spread. While the present research project was unable to generate statistical data on its breadth, the available qualitative one clearly corroborates the datasets of KS (2011) on the wide scope of political appointments. Appointments involve nearly most state agencies subordinate to the Council of Ministers and Ministries, also reaching down to local administrative posts. The present research seeks to contribute to that of KS (2011) and KMS (2012) on Bulgarian appointments arguing that there are three causes for political appointments: party-political distrust to independent experts (civil service or sectoral interest group ones), distrust appointees of former ruling parties and the need to reward intra-organizational supporters (factions and insider groups). As section 5.4 demonstrated, political parties primarily seek to enforce political appointees whom the party leadership trusts, both personally and institutionally. Yet, the need, after all, to ensure that competent individual, rather than incompetent party loyalists are appointed has torn some political leaders between nominating experts, recognised by the respective industrial sector, or individuals who are nominated by the party. In more detail, another reason why political parties would tend to monopolise appointments is to appease internal forces. Both party donors (core insider groups) and party factions need to be appeased by granting them the opportunity to make their own nomination, as a form of reward for their party support. The next chapter continues the review of party-group relations characteristics that conform to those of the parentela. Chapter 4 reviewed the primacy of the party in power in the policymaking process, i.e. primary venue. The present chapter 5 reviewed the breadth of the practice of party political appointments, which, too, overlaps with the parentela 
characteristic where the two venues - party and civil service - are connected. Chapter 6 will review the remainder of policy network descriptors that overlap with the parentela: degree of access, type of interaction and power ratio. 


\begin{tabular}{|c|c|}
\hline State & $\begin{array}{c}\text { Coefficient of } \\
\text { patronage }\end{array}$ \\
\hline UK & 0.09 \\
\hline Netherlands & 0.11 \\
\hline Denmark & 0.16 \\
\hline Iceland & 0.23 \\
\hline Norway & 0.28 \\
\hline Portugal & 0.29 \\
\hline Ireland & 0.32 \\
\hline Czech & 0.34 \\
\hline Republic & 0.4 \\
\hline Spain & 0.42 \\
\hline Bulgaria & 0.43 \\
\hline Hungary & 0.43 \\
\hline Germany & 0.47 \\
\hline Italy & 0.49 \\
\hline Austria & 0.62 \\
\hline Greece & 0.34 \\
\hline Mean & \\
\hline
\end{tabular}

\section{CHAPTER 6: Insiderness, Cooperation and Power Symmetry}

\subsection{Introduction}

The purpose of the present chapter is to reveal the remaining features of the Bulgarian party-group relationship, which match those of the parentela. These are namely: insiderness, cooperation and power symmetry. While the chapter clearly demonstrates elements in the Bulgarian party-group relations that are consistent with the parentela, the application of said descriptors indicated some degree of indiscreteness among them, thus limitations in the classificatory scheme. Nevertheless, that does not invalidate the results, but means that the study effectively employs not 3 but 1 or 2 dynamic-descriptive categories (excluding venue-based descriptors). Depending on their definitions some categories could be synonymous on a definitional level, although primarily it is their dynamics, which connect them to one another.

For example, degree of access is connected to type of cooperation. While the present chapter is formally dedicated to the descriptor degree of access, the indiscreteness of 
the concept means that the discussion of evidence on insider status is also a discussion of evidence on type of interaction. The descriptor insider status or insiderness was originally developed by Wyn Grant (1977, 1978; chapter 2), with reference to the interest group-civil service relationship in the UK. This concept was later endorsed as compatible in the state-group relationship in the policy community network by Maloney et al (1992) in their revision of Grant's insider/outsider status classification of interest groups. The concept of insider status stands for the situation where policy-makers from a certain venue recognise an interest group as a reliable partner in the policy-making process. There are four categories of that express degree of access: core, niche and peripheral insider, and outsider status (chapter 2).

However, this is where degree of access overlaps with the next descriptor: type of interaction and its value cooperation. The literature on policy communities, clientela and iron triangles (chapter 2) amply demonstrates that policy-makers provide privileged access to their venue only to those groups that cooperate with them. However, the literature has also identified that at the centre of cooperation is the exchange of policy (or political) resources. The clientela, policy community and iron triangle network types emphasise that the exchange which grants groups core insider status is expertise. To be invited to frequent consultations and become a core insider, in other words, a group has to provide policy-makers with expert position on policyrelated questions.

The other case of categorical indiscreteness relates to the power ratio and type of interaction. The concern of the relationship between these two descriptors emerged later in the study with the evidence presented in chapter 9, which suggests that political parties are able to deliberately repress companies and firms, through prejudiced inspections from the regulatory agency. Therefore, this study sees power as a type of action, as opposed to a resource that could be measured. Actors are not more or less powerful compared against a variable called power. Rather, the study sees power ratio as the act of one actor overpowering another, following the logic of Lukes' 1st dimension of power (1975). That, however, still adds to the conceptual limitations of the classificatory scheme, because if power ratio is understood as the 
1st dimension of power, then that equates it to the descriptor type of interaction. The 1st dimension of power is by definition about conflict: where A enforces its own interests on B, which are the opposite of B's, and to which B also resists unsuccessfully (Lukes 1975). In any case, however, the latter route is still preferable because it obviates quantification, hence, demonstrable in a qualitative study. In any case, the indiscreteness among some of the categories does not invalidate results but means that the three descriptors under scrutiny here share the same qualitative database.

The present chapter demonstrates that Bulgarian interest groups succeed in gaining core insider status with political parties. Without repeating the exposition in chapter 2 , core insider status suggests the highest degree of access that policy-makers can grant to a given group. The cases of La Palombara (1964) and Greer (1992) indicate that insider groups gain core insider status within the ruling party as a result of their provision of campaign resources, such as primarily, voter support. Both CA in Italy and UFU in Northern Ireland carried a considerable number of supporters, who could be mobilised to vote in favour of the respective party. Evidence from the Bulgarian case, however, suggests that groups in the possession of campaign funds can gain core insider status within political parties.

The present study demonstrates that Bulgarian parties, too, harbour parentelaconsistent dynamics vis-à-vis interest groups. Interviewees shared the observation that every political party works closely with a select group. Consistent with CA and UFU, they also indicated that the closer cooperation between political parties and their insider groups, also rested on the exchange of campaign resources against privileged access. However, the campaign resource in the Bulgarian case are campaign funds, as opposed to electoral support. Also speaking as former political candidates, the unanimous position among those respondents was that actual campaign costs are exorbitant and much of what is spent on campaigns is not reported formally. This is why these costs place the premium on campaign funds as the main resource for access through the ruling party venue. There is also some limited evidence that provision of expertise could provide some access but that is not 
any further than peripheral insider status. In any case, the fact that access, power and cooperative dynamics overlap means that the discussion on core insiderness also implies that political parties are in a power-balanced form of cooperation with their insiders (unless stated otherwise, the study assumes core insiderness).

In addition to campaign funds, ideological proximity to the party in power is also discussed as a group quality that facilitates its insider status. Although not exactly a resource, it is included primarily because of its importance in the cases of UFU and CA. Particularly in the case of Catholic Action and satellite catholic trade unions gained advantage over rival groups of equal capabilities thanks to their close ideological proximity to the Christian Democratic Party. Evidence from the Bulgarian case indicates, however, that ideology is irrelevant for political parties when determining their engagement with prospective insider groups.

The chapter is structured as follows: Section 6.2.1 reviews whether the provision of expertise as a mean to gain core insider status. The subsection argues that expertise could provide only peripheral insider status within political parties at most, if any at all. Section 6.2.2 discusses voter support and ideological proximity as factors that contribute to gaining insider status within ruling political parties in the cases of Italy and Northern Ireland. In section 6.2.3 these two group properties are applied to the Bulgarian case, arguing that none of them have any significant effect. Instead, the section argues, it is campaign funds that facilitate the provision of core insider status within political parties.

\subsection{Core Insider Status, Cooperation and Power Parity}

The literature has identified a number of ways for a group to establish core insider status. The first and most prevalent is that insiders status is granted as a result of an exchange of group's expertise against policy-makers' provision of access. This form of exchange was observed in the interaction in the US and UK executive branches between civil servants interest groups (chapter 2). Another form exchange, but this 
time to political parties, could be in the form of voter support for access. This is the dominant form of exchange that has facilitated both UFU and CA access to their respective ruling political parties. In a similar fashion, both La Palombara (1964) and Greer (1994) also discuss ideological proximity as a group feature that further facilitates insider status, although not necessarily concerned with an exchange. The Bulgarian case, however, does not show that groups gain party insider status neither on ideological proximity, expertise or the provision of electoral support. Consistent with Greer (1994) and La Palombara (1964), core insider status is provided for the exchange of a campaign resource but of different type: campaign funds (6.4).

In any case, the present section could also be read as a discussion on cooperation and power parity. The fact that political parties provide access to certain groups also carries along the implication that the relationship between the two is free from power-struggles. The introduction already warned that discussing core insider access is also a simultaneous discussion of cooperation and power parity. The section below therefore though primarily geared towards discussing core insiderness it quickly morphs into a discussion of cooperation and by implication - evidence of powerparity between the ruling party and the insider group, which is characteristic of La Palombara's parentela (1964).

\subsubsection{Expertise for Access}

The dominant perspective in the policy network literature is that privileged access, that is insider status, is conferred upon groups as a result of an exchange of resources. The form of exchange which is most widely document is that of expertise for access. This exchange has been documented particularly with reference to the structures of the civil service (clientela, iron triangles, policy community, chapter 2). Insider status, then is measured either with real numbers or with ordinal metrics. Jordan and Schubert (1992), for instance, determine that insider status is limited to two groups. Another way of measuring groups is through Grant's ordinal indicator comprising a number of categories (Grant 1977, 1978, 2000; Maloney et al 1992, 1997). First, involvement in consultations on legislation with wide reach (close to macro politics) yet with a strong technical element is core insider status. In 
circumstances where usually inconspicuous groups become leaders on almost exclusively technical issues with low public/policy implications, thus temporarily assuming core insider status, is a niche insider status. Last, those groups that tend to only respond to consultations with written statements are peripheral insider status (Grant 1977, 1978, 2000; Maloney et al 1992; 1997). In sum, typical core insiders are those groups which are frequently invited into face-to-face consultations with primarily macro, sector-wide implications, possessing a considerable degree of expertise.

In any case, however, quantitatively or not, both metrics converge around the same idea that privileged standing within the civil service depends on group's ability to provide expertise. This is so because that venue operates with that form of resource. Civil servants are tasked with revising existing legislation or drafting new one and what they need is an easier method of acquiring the necessary data and analysis. Groups who are rich on such expertise are more often consulted than others. This was clearly argued to be the case by Lyubenov, in the Bulgarian civil service. However, the question is whether such dynamics are traceable in Bulgarian parties' relations with interest groups. The original parentela model clearly expects that the party in power grants privileged access to a single (or number, if practically possible) group. The question in relation to the Bulgarian case is whether the data suggests that.

However, the question here is whether such dynamics occur in the relations between the ruling party and prospective core insider groups, because those were established with reference to the Western civil service and not to the parentela. Grant's typology of groups' degree of access seems applicable to the party-group relations, because both La Palombara (1964) and Greer (1994) make references to consultations of CA and UFU to their respective party hosts. It is also possible to discern in those cases how UFU and CA, respectively, were better represented than competing groups, that too enjoyed some access to the party in power. The only difference seems to be in the scales of consultations vis-à-vis the civil service. While consultations held by the party and civil service are not discussed in either case, the impression is that of very 
limited extent. Evidence from the Bulgarian case suggests that political parties do consult and occasionally a group could gain limited access, i.e. peripheral insider status.

The account of Petrov indicates precisely that other groups and not those with expertise are valued the most. Respondent Petrov in particular recalled occasions where he was invited to informal meetings organised by political party $\mathrm{C}$ to discuss the state of the business environment in Bulgaria, and to formal consultations organised by the Party A. In both cases respondent's policy-proposals were given ample consideration. However, in agreement with Maloney et al (1994) that access does not equal influence, Petrov's proposals did not generally materialise into legislation. Few of them were adopted and those portions of the concurrent legislation, which before stood as respondents previous lobbying victories, were rolled back to their initial state. In doing so, Petrov argued that other individual actors in fact made more effective representation and convinced the party to roll back the legislation to its previous unfavourable form. The shared position among respondents, in fact, was that expertise is irrelevant to political parties, or to the extent it is, it is still insufficient to provide a group with core insider status.

A strong indication for expertise being irrelevant to political parties is also the fact that consultations held by political parties with interest groups appear sporadic and ad hoc. Respondents Hristov (party C) and Mitrev (party A) at a given stage in their response addressed the structures designed by their own respective party used to facilitate consultations with groups. However, as respondent Lyubenov noted from his personal involvement in party-sponsored consultations the level of technical engagement at such fora is extremely low to allow groups to be persuasive. Consultations with political parties do not appear to be geared towards establishing the right policy decision on the grounds of expertise. One has to speak in a different language to politicians, who are more interested in the general, macro points, a policy covers (Lyubenov). As Lyubenov explains, political elites neither grasp the details of the policy options, nor, as Videnov argues, do party political elites trust technocrats in the civil service (see previous chapter). Lyubenov also made the 
explicit point that in the course of his advisory sessions with political leaders of party $\mathrm{C}$, the latter were unable to comprehend the details and technicalities of a given policy where civil servants would. As a result he felt that most appropriate forum for his suggestions would be the civil service consultations.

Responses from the executives from sectoral groups indicated outsider status vis-àvis political parties. Although one might respond that there is nothing wrong with that, because TAs have civil service consultations at their disposal, it is still unusual because parties nevertheless consult. That in turn suggests that those who hold highest expertise would still be consulted. However, reports indicate to the contrary. Speaking as a director of a trade association, respondent Gospodinov highlighted the resistance of the ruling political party, who apparently had been cooperating with select affluent groups from their own Trade Association, against the amendments to the Law on Public Tenders proposed by the same organization. The respondent explained that while he was in consultations with the state administration, given the unconvincing explanations on behalf of the civil servants, it became apparent that certain drafts were particularly unpalatable to the political party in power and groups with insider access to it. Similarly, respondent Konstantinov was deliberately vague as to single out the firms from the trade association he represented that had benefited economically from a closer relationship with the ruling political parties. He still pointed out that those insiders are firms with abnormal profits at times of an average economic downturn and high turnover yet very low profits (R31035). Overall, their combined positions allow for the observation that policy expertise is not a resource that would facilitate insider status with political parties.

In the same vein, speaking as a former director of another sectoral interest group, Donchev argued that party-group cooperation is driven by common interests that do not rest on improving policies but to maintain their collective long-term access to political power. Donchev complained from his relationship with the ruling party at the time. Details of his position will be reviewed in chapter 9 but it is necessary to say now that the description of the relationship of his former organization with the ruling party was antagonistic. In discussing the general party-group relationship, he 
strongly emphasised that consultations are largely contained within the civil service and that political parties in practice are trying to subvert them by only permitting servile interest groups to civil service consultations. While this was said with reference to the consultative process facilitated by the National Council on Tripartite Cooperation, this served to advance another point. According to him (and others reviewed in Chapter 9) political parties collude with a number of affluent participant and act against the interest of the wider civil society represented by interest and advocacy groups, and Trade Associations. In what he argued to be an oligarchic policy-making model in Bulgaria, expertise did not feature in the party-group relationship. It was reserved for the civil service and those groups who catered to any insider status within political parties had to provide party-relevant resources, such as campaign funds.

\subsubsection{Voter Support and Ideological Proximity for Access}

Both La Palombara (1964) and Greer (1994) make the note that the ideological proximity between CA and UFU, respectively, and their ability to provide campaign resources to the ruling party facilitated their privileged standing. La Palombara (1964) explains that in the case of the Italian parentela party insider status is granted in exchange for campaign resources: voter support or campaign funds (La Palombara 1964: 318, 331, 333, 335). Voter mobilisation in particular played an important part in Catholic Action's ability to gain insider status with the Christian Democratic Party (DC) (La Palombara 1964: 333, 335, 336). La Palombara also makes a particular note of Confindustria's attempts to gain insider status with the DC on the grounds of being able to contribute to latter's party campaigns (La Palombara 1964: 318). That is: campaign funds might facilitate access to policy-making. However, this was a vain effort for Confindustria's at the time, as such resources had already been provided by Catholic Action (CA), where in addition to being able to contribute financially, and CA also carried massive electoral support (La Palombara 1964: 318). Similarly, while Greer does not discuss the provision of any campaign funds, he too implicitly agrees with La Palombara in that the ability to provide campaign resources could facilitate party insider status (1994). Ulster Farmers' 
Union (UFU) endorsement by the Stormont government was granted primarily because UFU could muster wide popular support (Greer 1994: 406).

Particularly on ideology, La Palombara emphasises that Catholic Action and catholic trade unions in its close orbit were successful in gaining insider access also because of their ideological proximity to the Christian Democratic Party (1964). Similarly, Greer also highlights that Ulster Farmers' Union's access to the party in power was greatly facilitated by the fact that UFU shared the same ideology with the Stormont government on "parity" (Greer 1994: 406; 410; 412).

Here, it is also interesting the question of whether any of the two resources could act as the necessary and sufficient condition for a group to assume core insider status with the party in power. Ideological proximity seems neither necessary nor sufficient prerequisite for core insider status, but it can still act as a catalyst, if present. The cases of La Palombara (1964) and Greer (1994) indicate that ideological proximity could be decisive when determining the core insider among groups of similar characteristics vying for party insider status. Catholic Action and Catholic trade unions did have some closer ties with the Christian Democratic Party in 1960s Italy than others (La Palombara 1964: 310-311). Likewise although UFU did not claim representation of more than $50 \%$ of Northern Irish farmers, it still maintained its insider access in the face of splinter farmer unions, and as Greer implies, thanks to its overlap with Stormont's unionist policies (1992: 405-406).

With specific reference to Italy, the fact that there were other competing groups with insider status, means that campaign resources guarantee insider status, although, again, core insider status will be determined by ideological proximity. The UFU case seems supportive of the same argument, although more information is necessary on the UFU and other organizations. Particularly, how did the rest $50 \%$ of farmers unionise and did they have any access to the Unionist party? In any case, irrespective of their ideological proximity, both UFU and CA provided their political partners with considerable electoral support, which was the main resource of the exchange. UFU still carried at least 27000 votes (Greer 1994: 406), while CA had 
influence over the entire catholic population in Italy at the time and particularly over DC's voters (La Palombara 1964: 318). However, finally, while close ideological proximity provides core insider status only when coupled with high electoral support, ideological juxtaposition with the ruling party leads to exclusion (outsider status) irrespective of popular support (Grant 1978; 2000; Maloney et al 1992, 1994).

On ideological proximity, evidence from the Bulgarian case suggests that ideology plays no significant part in the calculations of ruling parties whether to partner with prospective groups. Although ideological proximity or its more watered down variants, such as support to the party line, may theoretically act as catalysts to a shift to core insider status, precisely ideology seems irrelevant. There is virtually no data, both as direct statements in support of that proposition, nor indirect, i.e. implicit in respondents' positions, that ideology factors in the calculations of ruling political parties whether to engage in a cooperative relationship with a given group.

No respondents addressed the argument, that access to political parties is dependent on ideological compatibility between the group and the ruling party. No evidence was found that whether groups share the ideological goals is a matter of consideration to the party in power. Instead a number of respondents emphasised on the absence of any ideological considerations in the policies of certain political parties and in appointing individuals of contrasting ideological background to their own (Georgiev, Nikolov, Cenov, Georgiev, and Bachvarov). That suggests that in their interactions with groups, too, ideology is irrelevant. Interviews gave ample space to respondents to discuss the party-group relationship, where should ideological proximity have been a factor that would have been aired.

Respondent Nikolov on several occasions argued that it is the exchange of electoral resources that counts most (also Golemanov, Gospodinov, Kuzmanov, Bachvarov, Mitrev, and Valentinov). In that context, neither Nikolov nor others saw ideology to be of any significance. Although the passage below has a second interpretation, the main and more evident one is that cooperation is on the grounds of the exchange of 
campaign resources, i.e. campaign funds. Key names of individuals are deliberately letter-coded:

S: $\quad$ And, that circle around [old party leader L], it was the so called Z, right?

R: $\quad$ Yes, /pausel

I: $\quad$ inaudible/ with them now?

R: $\quad$ Well, they went elsewhere, I want to tell you, that they from [that circle], only one is left, that one-

S: $\quad V$ ?

R: $\quad V$ is left. But $V$ bends over to absolutely everyone, I want to tell you. $V$ is in very good relationship with [the leader of party $C$ ].

S: Huh?

R: $\quad$ How else! /confidently/.

S: $\quad$ But that he worked for [L] in the past - did not that get in the way of $V^{\prime} S$ cooperation with [the leader of party $\left.C\right]$ ?

R: $\quad$ Why should that be a problem at all? He is just now working for $[D] ! ?$

I: $\quad$ [Party Leader of C] obviously does not mind, either! /laughing/

R: $\quad$ But why would [having cooperated with a different political party in the past] be of any consequence, when a bagful of money is emptied in front of [C's party leader]. And that is several times? /rhetorically/.

In the exchange above the assumption of the researcher in approaching the topic was that each political party would prefer to cooperate with ideologically similar groups or individuals. The excerpt however exemplifies that former party allegiance is irrelevant in the calculations whether to establish a relationship with a new group. In the quotation above, the businessman $\mathrm{V}$ found no difficulty in cooperating with two different governments. This indicates that the party-group relationship is not constant. While in this case the two parties in question were ideologically similar, it is hard to say whether ideological proximity has played any role, the fluidity of such party-group relations makes it implausible that ideology would provide such a strong bond.

Respondent Nikolov cited another case where the oligarch, $\mathrm{Mr} \mathrm{W}$, had contributed a significant sum to the political campaign of party A in exchange of adopting his nominee as Prime Minister H. (the making involvement of oligarchs is a theme that was echoed by a significant number of respondents, including respondents from both the entire political spectrum (Hristov, Mitrev, Valentinov, Bachvarov, Georgiev, Donchev, and Cenov)). It was an interesting fact that before their appointment as a 
prime minister, $\mathrm{H}$ had established their political career working for the ideologically opposite political parties.

At the same interview with Nikolov, the intermediary, an active functionary for party A, gave another example of a high-ranking individual within party A, who also assumed a high post in spite of a contrasting ideological past. The implicit suggestion made by the intermediary was that such party functionaries with a political past with the exact opposite parties on the ideological spectrum were the result of cooperation between party A and (usually) oligarchic party donors. Nikolov agreed.

However, given his inclinations towards party C, Nikolov could have deliberately used the opportunity to discredit party A. Respondent Cenov therefore was deliberately targeted as a former high-ranking functionary from party A, to comment on whether party A had conceded to agree to that same oligarchic nomination of Prime Minister $\mathrm{H}$. The respondent overtly supported that thesis:

S: $\quad$ Today, could it be said that there is any one circle which has entered cooperation with [party A]...

R: $\quad$ Well, that one -- [oligarch W].

S: $\quad$ I am a bit surprised, that I had not heard of him recently /deliberately acting uninformed in order to provoke the release of more information/

$R: \quad$ But why are you surprised?

I: W might not exactly be "working with [party A]", but "with" the Prime Minister $H$.

$R \quad$ /laughing/categorically! /Categorically--I/ Yes, yes, yes.

In the quotation, the surprising bit is namely that the respondent did not receive any prompts that would give away which individual the researcher had been interested in. He identified $\mathrm{W}$ as the main partner of party A without any cues. His argument above is similar to Nikolov's: it may not necessarily be the case that $\mathrm{H}$ is a prime ministerial appointment of the oligarch $\mathrm{W}$, but it might just as well be that $\mathrm{H}$ and $\mathrm{W}$ had cooperated in the past and just continued their cooperation under the new circumstances of party A's electoral victory. However, it is unlikely that their direct cooperation with $\mathrm{H}$ would have been at all possible without party HQ's acceptance and involvement. 
In addition, Cenov (also Bachvarov and Georgiev implicitly) further argued that the party A had significantly departed from its ideology and as a result found it entirely natural to be indiscriminate with the choice of groups and single actors to cooperate with on the basis of campaign resources, which in fact is illustrated with the nomination of $\mathrm{H}$. The fact that he laughed while affirming three times this argument, indicates that while seemingly correct, there is more information which he refused to discuss. The respondent further added that, based on observations and personal experience in the past, it is better to conceive of those party's politicians as businessmen, supporting the position of Respondent Nikolov and others that "politics is business".

The case of this particular appointment of $\mathrm{H}$ emerged again, at the interview with Respondent Penchev. He generously explained his life-story and involvement in the policy-making process in Bulgaria, as an active member of party B's executive bureau. The respondent made an explicit effort to ideologically differentiate himself from party A. This is important because at the end of the interview he showed the researcher a hand-written list of names of nominees for premier H's government. He confided he was personally involved in the selection process and recounted their personal telephone calls with the closest aides to leader of party A. Finally, he claimed that he personally advocated the appointment of $\mathrm{H}$ as a prime minister, but did not elaborate on any possible involvement of W.

However, it is possible to connect Penchev, $\mathrm{H}$ and $\mathrm{W}$ as they share the same ideological inclinations and also because they are united in their association with former party leader L. Cenov and respective intermediary (below) argued that $\mathrm{H}$ owed the start of his political career to $\mathrm{L}$ when $\mathrm{L}$ had been in power. Likewise, $\mathrm{W}$ owed his initial affluence to during L's tenure, as well. Finally, Penchev in fact boasted personally to the researcher of his close friendship to L, dating from before L's tenure as a prime minister, as well. However, most importantly, the above indicates in party A's engagement with $\mathrm{W}$ and endorsement of $\mathrm{H}$ were devoid of any ideological considerations because A conceded to an appointment of an individual 
from an opposite ideological background. This, too, was confirmed by someone (Penchev) who can reasonably be associated with $\mathrm{H}$, and who is also from the opposite ideological spectrum from party A.

In the same vein, respondents Aleksandrov and Georgiev identified the same ideological departure of party A from its true ideological riverbed. Both respondents extensively and avidly condemned the cooperation between party A and an oligarch $(\mathrm{X})$, resulting in the latter's monopolistic position on the market. In doing so both respondents independently criticised party A's cooperation with actors who solely focused on own self-interests. Party leaders of minor coalition partners of the same party A (Valentinov and Mitrev) voiced similar concern regarding that A's cooperation with economic actors is devoid of any consideration of any ideological compatibility, even if we bring the term down to its lowest common denominator, to mean 'common good'. That is to say, not only was the party devoid of ideological consideration as a guidance determining which groups to cooperate with but it was also devoid of any "moral compass" such as 'the common good' which would act as help determine partner suitability of aspiring insider groups.

There is only one case which approximates a situation where ideology mattered somewhat in the prospective relationship between oligarch $\mathrm{X}^{5}$ and political party $\mathrm{A}$, where ironically, it was $\mathrm{X}$ who sought ideologically compatible individuals from party A. This was particularly the case with Respondent Aleksandrov. He reported that in the distant past he had been approached by X. Through his own network of party sources respondent Aleksandrov was informed that X particularly asked for him and did indeed offer a substantial party contribution in exchange for Aleksandrov's inclusion in the party lists of MPs to be returned to parliament. The same respondent also recounted a different occasion with a different yet equally ranked big business owner, X2, who also had a particular affinity to him based on the respondent's policy position. Again, in both cases cooperation was sought on the grounds of similar understandings and attitude towards a specific policy field, which is watered down ideology, but even then this is far from sufficient to indicate any

5 This is still the same individual. Letter codes are consistent throughout the entire thesis. 
express concern with ideology and an ideological line. This was based on interpersonal sympathy and most likely having a common political opponent political party E (Aleksandrov). However, even if cooperation in those cases was sought on the grounds on common policy positions, that is less than gaining insider access based on common ideology. In conclusion, data on the Bulgarian case demonstrates that the practice of granting insider status to groups on the grounds of ideological compatibility is non-existent.

\subsubsection{Campaign Funds for Access}

The subsections so far demonstrated that neither expertise, nor group's ideological proximity have an effect on a group's core insider status. Data from the Bulgarian case indicates that it is possible for groups to establish core insider status within the ruling party under the provision of a different campaign resource than UFU and CA's voter mobilisation, namely: campaign funds. That was first exemplified by Petrov, who was fed empty promises at party A consultations, only to maintain his support until after elections when respondent's proposals were watered down by political expediency and according to Petrov in the interest of competing groups. At both seemingly consultative meetings they participated in with party $\mathrm{A}$ and $\mathrm{C}$, the consultations lacked much substance. Respondents Petrov and R31035 also implied that affluent actors had gained much better access to the respective political party, although both were also reluctant to speak with names.

Respondents are unanimous that the high costs of electoral campaigns put political parties at great dependency on campaign funds, which has become the main currency of core insider access to political parties. Although in order to combat the overdependence of political parties on campaign funds each political party is given a subsidy for the electoral campaigns, respondents who campaigned either for mayoral or MP positions report that actual costs of elections is several times higher than what is declared for reimbursement. A number of respondents from political and business background argued that the cost of political campaigns forces political parties to seek out any reasonably affluent business actors who can contribute (Golemanov, Bachvarov, Petkov, and Kuzmanov). Many used the terms oligarchs, grupirovki or 
circles to identify the private actors that parties cooperated with in order to receive the rest of the necessary funds for carrying out the campaigns. In the words of Georgiev: 'do ut des' or give in order to receive.

Groups tend to use campaign funds as the currency of core insider status. However, as already explained in the introduction, and while they may seek favourable appointments in exchange, it seems the prime good they seek in return is privileged access to public tenders. Chapter 8 documents this exchange in great detail. In the words of Gospodinov, at the one end of the bargain we have groups who possess campaign funds to cover the actual costs of the campaigns:

In Bulgaria there is an absolute merger between the party and business, between party and money, absolutely, because parties cannot function without money, and money is obtained through business and this process is not regulated. There are laws, that specify how much it could be spent [on elections] [...] Yes, but I know what the real costs are, say, for TV commercials and the sums parties declare are insulting (under-reported, sic) and ridiculous. And they declare such sums because it is on the basis of such sums that they account to the State Auditor (agency) and this is how much the law permits them. But the money they spend is 2, 3, 4 times higher. [...] I have an immediate experience in this respect because I have taken part in many campaigns.

Also speaking from personal experience in politics and political campaigns,

Respondent Petkov explains the same:

[...] We have a mutual interconnectedness between services of the state of the past, the present, and the grupirovki, which are those [actors] who make it possible for a political party to come to power. This happens in two ways. First, through the financing of a political party. It is known that elections cost a lot, [or rather] "increasingly cost more". Of course, I do not have statistics with me, but a political party which wants to leap over the 4\% barrier, if it does not have 10 million (leva), should not even attempt going to elections. And this is not a question of buying voters; it is a question of [expenses on] one serious and structured organisational work. [...] It is very naïve to believe that the members of a given party collect enough money for electoral campaigns. This could not happen because Bulgarian citizens are too poor. [...] the grupirovki have [that resource] as well as the interconnected structures with them [intelligence community], [...] so grupirovki are of importance and they are of importance for the party infrastructural organisation, financing and resourcing, so that the party can approach elections adequately.

In the same vein, Respondent Golemanov states: 
So, say you are some party; you have a state subsidy of 2.5 million leva for presidential campaigns. But you cannot do anything with those 2 million leva! Because one interview or debate on national TV costs you 200 to 300 thousand leva! Well, the minute there is between 1.5 to 2 thousand leva! That's scary! You, without you having this economic circle behind your back, the one we are talking about right now, [you cannot make it because] it actually costs you 6 million leva. After that you declare them to the State Auditor. [As for the firm,] half of that money the firm sponsoring you is accounted as New Year's calendars for 1.2 million leva, while in reality these are placards with your muzzle on them! But it is not you who pays for that!

In other words, the actual costs above that political parties declare to the authorities are covered by the party donors directly. No campaign funds, in excess to what the party receives as subsidies, is actually received by the party. To substantiate his point, Golemanov provided an example with their own mayoral political campaign:

When I decided to become a mayor [...] I went from one firm to another, [and] to those [people] with whom I was on good terms. [...] They would say, "Listen, 3 thousand leva, we can give to you!" [...] and I bought placards with that, but they did not give the money straight to me! I do not take any money!

By making this analogy, Golemanov argued that political parties need not necessarily possess the campaign funds. Those could be spent on their behalf by their sponsors. The question of actual expenses on political campaigns is intriguing but requires an independent study on its own to fully verify. Identifying such a discrepancy would require much deeper access to party functionaries and accounting documentation that is not in the public purview.

Still, some of the more prominent NGOs, such as Transparency International, who monitor elections (transparency.bg), seem to confirm respondents' concerns. In a recent report, the authors Hristova-Valtcheva and Toneva-Metodieva (2014: 16-17) argue that there are mechanisms in place to reimburse for their electoral costs with state subsidies, imbursed to parties passing a $1 \%$ threshold at parliamentary elections, however, Bulgarian parties still do not fully disclose the sources of their funding. With an index scale from 1, lowest, to 10 , highest degree of party donor financing, Bulgaria remains at about 4 (2013 Parliamentary Elections), which still means high, and very much likely, deliberate concealment of financing sources. This is clearly indicative of the fact that Bulgarian political parties could be expending more than 
what they declare to the authorities. Both the report and the results from this subsection, therefore, complement each other.

Before moving on to the next section we should remember that the above discussions on the forms of cooperation between ruling political parties are simultaneously indicative of cooperation and power parity between the two actors. All of the forms of exchange are also forms of cooperation, which in turn diminishes the direct application of power. Again, the position here is that power is an action along the lines of first dimension of power (Lukes 1975). Cooperation and power parity are strongly implied in the discussion of insider status above, primarily because they are impossible in the face of evidence, which suggests that Bulgarian parties engage in exchanges with groups that can provide campaign resources. The indiscreteness of these three categories is one of the few limitations this study demonstrates.

\subsection{Preliminary Results and Limitations}

At this stage in the study the thesis has described the parentela. Chapters 4, 5 and 6 focused on dimensions in the party-group relationship in Bulgaria, each of which followed the policy network descriptors. There is an overall match between La Palombara's parentela and the Bulgarian party-group relationship elements, which the project identified. The present chapter identified that as with parentela, political parties do endorse groups as insiders. That in turn also means that they cooperate with them in a power-neutral manner (power ratio, type of interaction and degree of access). Earlier chapters established the primacy, or rather overall importance of the ruling party as a policy venue in the policy-making process (primary venue). Still, further overlapping with the parentela, previous chapters also demonstrated that there is an intrinsic link between the party and the civil service through the wide-spread practice of party political appointments (venue scope). Ultimately, the type of partygroup relations described so far overlap with those of La Palombara's parentela (Table 20): 


\begin{tabular}{|c|c|c|c|c|c|c|c|c|c|c|c|c|c|c|c|c|}
\hline \multirow{3}{*}{$\begin{array}{c}\text { Type of Policy } \\
\text { Network }\end{array}$} & \multicolumn{16}{|c|}{ Descriptors } \\
\hline & & $\begin{array}{l}\text { egre } \\
\text { ess }\end{array}$ & $\begin{array}{l}\text { e of } \\
\text { to } \mathrm{PV}\end{array}$ & \multicolumn{2}{|c|}{$\begin{array}{c}\text { Network } \\
\text { Dynamics }\end{array}$} & \multicolumn{3}{|c|}{ Power Ratio } & \multicolumn{4}{|c|}{$\begin{array}{c}\text { Primary Venue } \\
\text { (PV) }\end{array}$} & \multicolumn{4}{|c|}{ Scope of Venues } \\
\hline & ఏ & 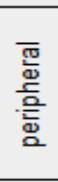 & 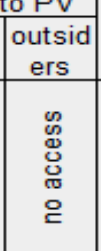 & $\frac{\text { 을 }}{\stackrel{\bar{c}}{\delta}}$ & $\begin{array}{l}\text { 듬 } \\
\frac{\pi}{\frac{\pi}{\varpi}} \\
\text { 응 }\end{array}$ & 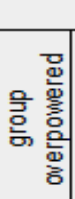 & 悹 & 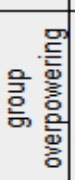 & 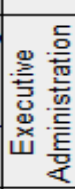 & 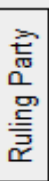 & 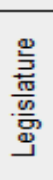 & 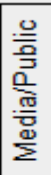 & 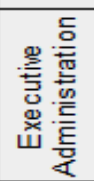 & 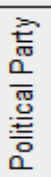 & 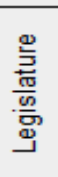 & 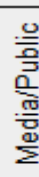 \\
\hline sub-governments & $\mathrm{X}$ & & & & $\mathrm{X}$ & & $\mathrm{X}$ & & & & $\mathrm{X}$ & & $\mathrm{X}$ & & $\mathrm{X}$ & \\
\hline policy community & $\mathrm{X}$ & & & & $\mathrm{X}$ & & $\mathrm{X}$ & & $\mathrm{x}$ & & & & $\mathrm{X}$ & & & \\
\hline prisoner insider ${ }^{*}$ & $\mathrm{X}$ & & & $?$ & $?$ & $\mathrm{X}$ & & & $x$ & & & & $\mathrm{X}$ & & & \\
\hline clientela & $\mathrm{X}$ & & & & $\mathrm{X}$ & & & $\mathrm{X}$ & $x$ & & & & $\mathrm{X}$ & & & \\
\hline issue network & & & $\mathrm{X}$ & $\mathrm{X}$ & & & $\mathrm{X}$ & & & & & $\mathrm{X}$ & $\mathrm{X}$ & $\mathrm{X}$ & $\mathrm{X}$ & $\mathrm{X}$ \\
\hline Parentela & $\mathrm{X}$ & & & & $\mathrm{X}$ & & $\mathrm{X}$ & & & $\mathrm{X}$ & & & $\mathrm{X}$ & $\mathrm{X}$ & & \\
\hline
\end{tabular}

Using the descriptors of the parentela identified in chapter 2, the study has shown that this form of network exists in the context of contemporary Bulgaria, summarised in table 20. Horizontally on top, the table lists the five network descriptors which are used to classify the policy network types. Vertically on extreme left we see the different policy network types. Note the prisoner insider is only a theoretical proposition. Every descriptor is a qualitative indicator. The descriptor degree of access is composite of a number of subordinate categories that constitute a gradient of access core, peripheral (for groups with insider status) and no access (for outsider status groups). The descriptors network dynamics and power ratio stand for whether there is conflict or cooperation, and, respectively, whether either the group or policymakers dominate each other or there is a parity. The first is represented in the binary subcategories conflict and cooperation, while the latter by the ordinal subcategories of group overpowered, parity and group overpowering. The categorical descriptor primary venue and the multiple response one scope of venues denote respectively the main venue for the given policy network and the total of all venues that the network dynamics cover. The $X$ sign denotes the active descriptor value. All descriptors from left to right up to and including primary venue can have only one value, except for scope of venues, which can have more than one values. Thus, each unique combination of descriptor values represents each of the better known policy network types to-date. 
The parentela at the bottom of table 20 (p. 170) is essentially the combination of descriptor values found by the present study based on the 26 elite interviews. Each of the shaded in dark descriptor values is discussed in chapters 4,5 and 6 . The results clearly indicate that the party-group relationship in Bulgaria at about the year 2013, revealed through the 26 elite interviews, falls within the description of La Palombara's parentela policy network (1964).

However, at this stage four limitations are apparent:

1. it is uncertain whether some categories are discrete enough

2. the parentela as a process (dynamically) is not immediately evident

3. the private actors in a parentela relationship are not immediately evident from the interviews, and

4. it remains unclear what groups want in exchange for their campaign funds.

The first limitation relates to the fact that the concepts of cooperation, power-party and core insiderness are interrelated: one implies or overlaps with another. The fact that groups are engaged in an exchange with the party in power implies they are also cooperating with it. To the extent that insider status and cooperation imply one another, this means we are measuring or describing the same phenomenon twice. First by calling it cooperation and then by calling it core insider status. Likewise, to the extent we are discussing cooperation, we are also implying power-parity. Given the state of the literature at present the study concedes that the three concepts, cooperation, core insiderness and power parity imply one-another. Thus, for instance, the present chapter on core insider access could just as well be read as evidence of both power-parity and cooperation.

However, future research might indicate that this limitation might be overstated. The questions is: Can insider status co-exist with conflict? At first sight this combination seems illogical, if not impossible. Still, it does exist in the literature, under the guise of prisoner insider groups, introduced by Wyn Grant (1978). Grant defines prisoner insider thus (1978: 5) thus:

"Prisoner groups" are those groups which find it particularly difficult to break away from an insider relationship with government either because they are dependent on government for assistance of various kind (e.g., 
loan of staff or provision of office accommodation) or because they represent parts of the public service (e.g., local authority associations or the chairmen of nationalised industries). However, such groups are not necessarily condemned to a lifetime of servitude. Desperation at lack of success by acting through the normal channels may lead them to make a risky attempt to "break out". [...] However, unless they have exceptional resources, such groups are unlikely to be able to survive "on the outside" for very long.

In other words, there are groups or near-autonomous structures of the civil service which are involved in the economy (Grant's example are the nationalised industries) whose existence depends on the resources provided by the civil service. The question then is what their relationship is with the civil service, and whether it demonstrates a seemingly impossible combination of insider status and conflict?

The quick answer is yes, Grant's definition above is a case of both conflict and insider status. Accordingly a semi-autonomous group with core insider access to relevant policies tends to be dismissed by state policy-makers, because of its resource dependence on the government. The fact that Grant gives examples with nationalised industries suggests that those seemingly impossible combinations may indeed be possible in more centralised forms of government in the border zone between public and private actors. That in turn poses the other question of how should we look at departments of the civil service, who lobby outside their immediate channels of communication. For instance, the National Assembly of Municipalities of the Republic of Bulgaria (NAMRB) is essentially an interest group of all Bulgarian municipalities who lobby both Bulgarian government and the EU institutions (projects-narmb.org).

The prisoner insider category demonstrates that seemingly impossible combinations caused by what appears indiscreteness could be resolved by looking at the fringes between the state and the free market. Another place to look for such unusual combinations could also be less than fully democratic states, where the relationships between institutions and participation of interest groups is ambiguous. After all, it should be reminded that the policy network literature rests exclusively on accounts from the UK and US, which is why studying policy networks in states at the very 
early stages of their democratization process will demonstrate unusual, i.e. conflicting, descriptor combinations.

There are three other limitations of this segmented descriptive approach. First, it did not demonstrate any consistent profile of the type of group political parties seek to engage with. Partly a limitation of the approach, partly a limitation of Bulgarian circumstances, there are no conspicuous interest group organizations of the scale of CA or UFU in Bulgaria that have clearly cooperated or otherwise engaged with Bulgarian political parties, save for the Multigrup corporation of early 1990s. That is why, chapter 8 is dedicated to profiling the type of actor who assumes core insider status with political parties. Second and in the same vein, the segmented descriptive approach does not necessarily demonstrate what exactly groups expect from their exchange with ruling political parties. This limitation is in turn dealt with in chapters 8 and 9. Finally and most crucially, the segmented approach does not demonstrate a parentela dynamics. The segmented description lacks any causal angle. This limitation, too, is dealt in chapters 8 and 9.

\subsection{Conclusion}

The present chapter revealed the last three remaining policy network descriptors: degree of access, type of cooperation and power ratio. It argued that there is evidence that Bulgarian political parties do provide certain groups with core insider status. This provision rests on a form of an exchange. The party provides access to the group, while the group provides campaign funds. This is consistent with the parentela literature because La Palombara (1964) and Greer (1994) show that campaign resources were the main resources which Catholic Action in Italy and UFU in Northern Ireland, respectively, provided in order to assume core insider status. The chapter also discussed the possible role ideological proximity between the group and the party might have. The previous two studies also highlighted that there was an ideological congruence between the insider and the ruling party. That seems to have acted as an intervening variable that catalysed the closer relations between the party and the groups. Such a variable, however, was not found in the Bulgarian case, which one would expect. In the context of the discussion on political parties and interest 
groups, respondents primarily emphasised on the role of financial donations and the fact that certain parties are open to cooperate with groups who have previously cooperated with their opponents.

The present chapter also reveals that the concepts of core insiderness, cooperation and power symmetry overlap or imply one another. First of all, establishing core insider status is on the basis of a cooperative exchange between the group and the ruling party. The presence of such cooperation in turn implies that there is power balance between the actors. The chapter reveals that while respondents do not necessarily discuss power relations, those are strictly implied by the fact that those two actors. Therefore, while the discussion of core insiderness above is essentially a discussion of cooperation, that is predicated on power symmetry between the actors. The question of power in particular will be revisited in chapter 9 .

In any case, this conceptual overlap does not invalidate results, nor makes the Bulgarian party-group description dissimilar from the accounts of La Palombara (1964). Instead it concludes that the 26 elite interviews successfully describe the features parentela policy network. The only drawbacks of this approach, and which will be discussed in later chapters are that there is no consistent image of the parentela (addressed in chapter 7); that there is no more concrete evidence of groups expecting something in return (chapter 8 ) and that the parentela features are not seen in action, as a whole (chapters 8 and 9). The next chapter addresses the question of what types of group could enter a parentela. 


\section{CHAPTER 7: Profiling Private Parentela Actors}

\subsection{Introduction}

Previous chapters demonstrated the different aspects of the party-group relationships, all of which conformed to the foundational features of the parentela. Chapter 6 , however, highlighted some weakness of the descriptor-approach. It argued that such a check-box classification and elite interviews has not yielded the identification of a single actor who is in an unequivocal parentela relationship with the party in power. The purpose of the present chapter is to address this limitation.

It argues that at present a slightly larger number than just a few core insiders inhabit a parentela policy network. These usually are number of firms who can offer campaign contributions of relevance to the party in power. Those firms usually work in an informal concert, although this does not exclude the possibility for a much larger number of individual small business owners to enter a parentela, usually, through a formal association. However, single, monolithic, publicly associated actors appear less relevant in the Bulgarian case than compared to earlier parentela cases. The Multigrup (MG) Corporation of 1990s, reviewed below, is one such example. It is a single massive private actor in a parentela policy network, comparable to Catholic Action with an equally imposing social, political and, in our case, economic presence. However, despite the attempt at profiling the private groups entering a parentela, they remain anonymous, very much along the lines of Finer's observations of the private partners to British political parties (1958).

In late 1950s Finer (1958) was one of the earliest authors to scan the UK policymaking horizon for pressure/interest groups and the lobby activity. His position on the party-group relationship closest matches the general air of obscurity evident in the Bulgarian case. He famously argued, with particular reference to the British political parties on their relationship with the anonymous empire of the myriads businesses that cooperate with them (Finer 1958: 133): 
This secrecy, this twilight of parliamentary debate envelops the Lobby in its own obscurity. Through this, above all, the lobbies become - as far as the general public is concerned - faceless, voiceless, unidentifiable' in brief, anonymous

In the appendix of his study, he lists the business and group association of all MPs at the time (Finer 1958). Likewise, this study demonstrates that unlike in Italy and Northern Ireland, the counterweight to the political parties in the parentela relationship are groups and businesses unknown and generally anonymous to the general public, whose insider status is justified on the grounds of their party electoral campaign contributions.

In addition to the above, the chapter also reveals other parentela-relevant dynamics. First, insiders' status is a state of flux, as opposed to a subscription to power. Parentela insiders have to continuously negotiate and fight for maintaining their status. Just as access does not mean influence (Maloney et al 1997) as core insider status implies, access is not a constant for the parentela insiders but a variable. This view differs somewhat from the core insider literature inherent in the policy community network types, which implies insider status is immutable (Richardson and Jordan 1979). Second, groups seek to establish parallel core insider relationships with all relevant political parties, because parliamentary elections are an external variable that could jeopardise a group's core insider status within a party. If a party loses an election, then the insider would have to re-negotiate its access with the new party in power, which is risky. Finally, a parentela can be formed around party factions and not necessarily around party headquarters. Both the MG Corporation and the circle Orion (discussed below) gained core insider access to BSP through rivalling party factions.

In the following subsection (7.2.), the chapter will discuss the so called circles of businesses as a general phenomenon and will demonstrate traces that allow us to link those formations as the private side partner parties in a parentela relationship. Section 7.3., will discuss the Multigrup Corporation as an example that most closely approximates UFU and CA: a single, visible actor with large public prominence. 
Section 7.4 discusses the possible generic profile of the private partner in a parentela network, before concluding with section 7.5.

\subsection{Circles of Big Business and the Parentela}

The Bulgarian terms krag and obrach, or collectively circles are phenomenon of Bulgarian policy-making of a network-like interaction between the party in power and privileged businesses or interest groups. The term krag was coined in 1994 by the journalists who asked the prime Minister at the time, Zhan Videnov (Democratic Left), to explain who the business circle (or group) - dubbed Orion - was and how at the time its proximity to the Bulgarian Socialist Party could be explained? In that infamous response, he stated that those were simply a circle of friends who merely did business together (chapter 1, pp. 20-21). A similar term, obrach, which also means a circle in English, was advanced in 2009 by the leader of DPS, Akhmed Dogan. He confessed in the media that he himself had helped businessmen related to his political party in their business deeds (chapter 1). Again, both terms krag and obrach are used synonymously, which is why they are collectively addressed herein as circles. The introduction of the thesis listed a number of past and present circles, which are of relevance for the Bulgarian policy-making process in Bulgaria.

The present subsection is devoted to a number of interviewees, whose responses indicate similarity between circles and the parentela. For a number of respondents circles are relationships where the ruling party provides direct access to a privileged group on the basis of a resource exchange. The exchange is usually of campaign funds against what some respondents call "protection" (Chapters 8 and 9) and Public Tenders (Chapter 8). Important element in that relationship are the party political appointments which serve either as a resource which the ruling party exchanges with the privileged group or as the infrastructure that facilitates party insider's interests. These features of a circle closely follow the outlines of a parentela. The following subsections show in more detail the match between the parentela and circle features. 


\subsubsection{Core Insider Status, Exchange, and Party Political Appointments}

Similar to the parentela, the circles host an insider-type relationship between the ruling party and a privileged group. Respondents' descriptions demonstrate that circle formation rests on the ability of a one business to assume privileged access to the party in power. In other words, this means to assume core insider status. In this case, "privilege" stands for direct access to the party in power and the ability to bargain and negotiate.

Zlatarov and Nikolov argue that circles form among groups that have already gained the privilege of direct access to the party in power. According to Nikolov, the reiteration of successful exchanges leads to solidification of the party-group relationship (higher trust and mutual reliability) implying thereby that other groups can also join so long as they prove to be constructive in that exchange. In a clear overlap with the parentela, and as it will be demonstrated in Chapter 8 , they explain that the exchange boils down to groups providing campaign funds or other favours in exchange for Public Tenders or other forms of market advantage such as but not limited to administrative protection (see also chapter 9). The protection Nikolov has in mind will be discussed at length in Chapters 8 and 9, but it suffices to say that insider groups can instigate inspections against their competition, and by implication be exempt from effective regulatory oversight.

Other respondents elaborated on the party-group exchange of resources, which is usually of campaign funds against policy-making access. Respondent Georgiev argued in his analysis on the circles that cooperation with ruling parties depends on the exchange of electoral support against benefits such as Public Tenders. He labelled this dynamic do ut des: give in order to receive. Although being sceptical of circles' existence, Petkov argued similarly that the circle narrative is indicative of a wider trend of businesses seeking to convert their capital into political resources while political parties the reverse: 
As a common phenomenon, every one [economic] structure which has a lot of money, wants to have even more money, but through political power. The reverse is also true. Every one political power (party, sic) wants to have more money and it has more money if it connects itself with the circle of business.

Likewise, Aleksandrov was particular that earlier circles were borne out of the desire of the waning nomenklatura to capitalise financially on their monopoly over access to policy-making and so to benefit from the privatization of state enterprises. In any case, this is also another overlap with the parentela's reliance on the exchange of resources.

The circle, according to Zlatarov, forms around the core insider group, which acts as a gatekeeper to the party political leadership. This means that peripheral or outsider groups that seek to engage with the ruling party and normally have close to no access to the ruling party go approach the core insiders first for two main reasons. One: the core insider has better contextual information on the party leadership and so is able to navigate the intra-party dynamics with highest chance of a positive outcome. Two: given the trust the party has to the core insider, the latter is in the position to effectively vouch for the reliability of the peripheral group.

The above, however, does not suggest the circular argument that in order to become a core insider group, a group has to be granted access by the already established core insider group. Zlatarov's argument is those businesses that lack the resources, which would otherwise make them relevant to political parties, can only gain effective access to the ruling party through an existing core insider group, that would vouch for outsider to the party in power. Therefore, according to the respondent the constellation of outsider groups or peripherals around groups with direct access to political parties in the end leads to the formation of a circle.

\subsubsection{Circles and Party Political Appointments}

The suggestion that the parentela overlaps with the image of the circles is further perpetuated by a number of respondents speaking on the importance of party political appointments in circle dynamics. This is usually within the context of the exchange- 
based relationship inherent in a circle. Respondent Bachvarov explicitly noted that party political appointments are a resource which the party exchanges with a privileged firm (core insider). Kirilov argued that the circles (obrachi originally), which Mr Akhmed Dogan referred to publicly (Chapter 1), rely on ruling party's ability to make wide-ranging political appointments in the civil service. The administrative appointments a party has already made are employed to facilitate the provision of what the party has promised to the core insider group: policy-making access and resources (e.g. Public Tenders). Additionally, specific appointments might be what a core insider expects to receive for their provision of campaign funds. Kirilov emphasised that such groups rarely have a second chance of engaging this way with political parties. Along the same lines, Hadzhiev argued that the exchanges that circles entered with political parties allowed the insider to make or to take advantage of already existing party political appointments. They too, like Kirilov highlighted that Mr Dogan was correct when publicly admitting that the importance of electoral victories lies in the scope of appointments the electoral winners can make in the civil service.

Zlatarov and Petkov strongly emphasised that political appointments are largely the result of negotiation with anonymous companies, firms or oligarchs (core insiders). Zlatarov observed that the numerous experts a party appoints is a cover for private nominations that come from the circles. Speaking as a former minister, Petkov went further arguing that the distrust which businesses might have towards political parties, also including core insiders vis-a-vis ruling party, might be so strong that business owners would rather seek to nominate themselves personally for public office. Golemanov also voiced the same argument, providing the oligarch Kovachki and his party LIDER as an example of someone following the same logic but taken to the extreme. In his distrust to political parties, Mr Kovachki in fact created his own party. In any case, Petkov argued that the practice of buying out appointments allows private groups to slowly conquer political parties and the civil service:

$R[. .$.$] In the beginning the grupirovki created their own parties but now$ things are intertwined and actually we have enough examples of grupirovki bosses seeking direct participation in politics [...]via members of parliament, via ministers //exclaims/ He himself! -I/ Yes! 
Because power is sweet! Another way is to "buy" the politicians, who would work for them. And this is precisely the connection, because this is a very complex question, because I [voted in the past] for the increase of party subsidies in order to ensure party independence /commotion, exists, interruption/.

Do note above that the respondent agrees to the notion which was voiced by the intermediary, namely, that leaders of the circles (or grupirovki) put themselves up for election. Section 7.4.4 below reveals how the vice-president of the prominent at the time Multigrup Corporation, Mr Dimitar Ivanov had the intention to set-up a political parties representing big business which would act as a coalition partner to the BSP government of 1995 .

\subsubsection{Existence of the Circles}

While there is an overlap with the parentela, respondents are divided on whether the circles exist or not. This does not have significant implications for the parentela, because the negation of circles' existence is not a negation of the practices, hence, of parentela. Respondents seem to disagree not on the above practices but on whether the alleged groups acted necessarily in concert. Some argue the image of the circles is distorted and that circles are artificially manufactured and sold by the media. For another set of respondents, the inability to clearly determine their influence is an indicator of circles' actual non-existence. Others, finally, accept the idea of the circles or at least that some business achieve direct access to ruling political parties, although some of them begrudgingly admitting that this is nearly impossible to prove (Kuzmanov, Dobromirov).

Respondent Dimitrov, being of the first group exclaimed that the circles were "media phantoms!", conspiratorial entities, perpetuated by the media. The circles were names given to a set of business actors, who among themselves probably did not hold such a collective identity, i.e. that they were a circle. As Cenov commented, the members of the alleged circle Orion, did not refer to each other as such, but were branded as such by the Media and Opposition. Other respondents, such as Georgiev argued, along the lines of Finer (1958), that the circles are anonymous. His position also overlapped with that of Finer (1958) primarily because Finer's research presents 
an atomised nature of the groups seeking party political representation. As Georgiev stated, it could be a single or a whole herd of "wild hares" that engages with the ruling party.. Respondent Petkov was of the opinion that we simply have too little information on the circles that allows us to claim that they even existed.

Kuzmanov argued that one normally hears of a circle only post factum, when it has disbanded. They argued that the fact that circles may be publicly illuminated speaks both of their ineffectiveness and mythologised influence. According to them, the circles are brought into existence by the media and a curious public, or by opposition politicians looking for fodder to compromise rivals. On the other hand, to the extent they are indeed network formations, they rather are splinter groups from the party in power, where each faction cooperates with its own core insider group (Kuzmanov).

Respondent Bachvarov was equally uncertain of their existence. He argued that the circles merely indicate that political parties tend to favouritise certain businesses. As in Maloney et al (1997), he also argued that access does not immediately translate itself into influence, and to the extent circles have any, that certainly does not suggest domination over political parties. Both Kuzmanov and Bachvarov agree that if the circles really existed, their influence would be felt, because by definition, circles dominate the party in power. (This is a position that contradicts the view in the present study, which argues that private actors have no significant power leverage over ruling political parties, discussed in chapter 9.)

The idea that their influence indicates circles' existence is also at the heart of the research of the investigative journalists Lilov (2010) and Bakalov (2010). Lilov (2010) argues the circle Monterrey, named after a restaurant in Sofia, was responsible for the successful political career of Premier Boyko Borisov (Lilov 2010). Conducting a deliberate study on the Monterrey circle, Bakalov (2011) presents the position of an elite respondent from the former Bulgarian Communist Party, who confirmed that (following Kuzmanov's line that circles are party factions) there certainly is a party faction that has contacts with businesses but their collective (faction and business') influence is grossly exaggerated (Bakalov 2011: 236-237). 
That said, there is no evidence that Monterrey was involved in the political success of Premier Boyko Borisov (Bakalov 2011). Therefore, according to Bakalov (2011: 237) since there is little evidence of their influence the solid existence of the circle Monterrey is an overstatement.

However, the tension which the uncertainty on the existence of the circles causes is best observed in the response of Stoyanov. The Respondent argues that while there is observably unusual regulatory scrutiny which stalled their operations and benefitted their market competitors, there are no immediately observable insiders. Therefore, "The circles must be there". As the intermediary to Stoyanov intimated to the researcher that rival business groups had used their access to ruling political parties and by an extension to the regulatory agencies, in order to disrupt the business operations of Stoyanov under the guise of regulatory inspections. This is a point developed at length in Chapter 9. This respondent, as well as Zlatarov, Bachvarov, Kirilov does not see the circles as a fabrication, even if circumstances surrounding them are skewed or occasionally exaggerated. The common position is that there are numerous anonymous (big) business actors, working individually or in groups, vying to assume a core status in the ruling party, on the grounds of their significance as party donors.

One explanation of the tension on the existence of the circles lies in the fact that the existence of a circle largely depends on whether the external observer will "connect the dots" between perceivably core insiders and ruling political parties, and claim $a$ circle. Consistent with the position of Cenov on Orion and Dimitrov in principle, respondent Kirilov admitted that they personally were responsible for the christening of at least two circles whose names continue to circulate in Bulgarian media. The circles therefore are a label for a number of businesses acting as a network in cooperation with the ruling party in power. The position here is that taking their effectiveness as an indicator of a circle's existence is an incorrect approach. It rests on the flawed assumption that circles are necessarily influential, that is, access automatically translates into influence. The present study adopts the view that the question whether these specific circles that we are aware of, as of now, exist is moot 
and not worthy of pursuit. What matters is the fact that on a larger scale the circle dynamics overlap considerably with those of the parentela. Therefore, even if one disproves that a certain combination of firms (dots) that is claimed to be a circle, is in fact not, this does not negate the overall parentela dynamics. For as we saw in chapters 4-6 and as we will see in chapters 8 and 9, the parentela dynamics are clearly there, outside the circles. The position here essentially is that any partyinsider group douette is a circle. However, let us now turn to a more concrete example of a parentela actor who is less anonymous and more monolithic. The case of the Multigrup corporation.

\subsection{MULTIGRUP}

The present section focuses on the Multigrup (MG) Corporation. A number of respondents provided very thorough elaboration on the importance of that actor and the accumulated data (triangulated with memoirs and news articles) indicates that it is possible to provide $\mathrm{MG}$ as an example of a single monolithic actor in a parentela relationship, probably the equivalent of CA in 1960s Italy, with its socio-political palpable presence. However, its relevance ends with the late 1990s. No such comparable, recent business actor was identified by the respondents as a possible partner to the ruling party in a parentela relationship.

The Multigrup Corporation was established in the late 1980s and its most prominent owner Iliya Pavlov owned it from the early 1990s until his assassination in 2003. Multigrup was one of Bulgaria's first and largest business holdings. It was a marketdominant actor and until the government of Ivan Kostov 1997-2001, MG was arguably the single largest economic actor in the state. Respondents Aleksandrov, Penchev, Dimitrov pointed out that MG was set up with the capital of the waning political nomenclature. Along the lines of Chalakov et al's molecule of conversion (2008), Aleksandrov and Dimitrov also observed that the origin of the corporation was the exit strategy of the retiring communist elite (including intelligence) who sought to privatise state assets in economic actors (firms, companies, banks, holdings, etc.) where the owners would be select proxies, personally loyal and 
dependent on the retiring elite (also Ganev 2001 for a more detailed overview of MG's origins).

\subsubsection{Multigrup and New Parentela Dynamics}

Overall the relationship of MG with major political parties until 2001 overlapped with the features of the parentela: an exchange-based relationship directly with the party leadership, where campaign resources are exchanged for favourable political appointments. As it will be explained below, MG secured their own ministers in three governments, of Berov in 1992, Videnov 1994 and very briefly of Simeon SaxeCoburg-Gotha 2001. The case of MG also demonstrates additional parentela-related dynamics. First, core insiders do not seek to orbit a single party, rather establish simultaneous insider contacts with all relevant parties. Here "relevant" stands for being potentially electable. The demise of the corporation began with its inability to negotiate core insider access to SDS leadership when Mr Kostov assumed the position of premier. This also shows that parliamentary elections are an external variable capable of disrupting a group's parentela relationship and that maintaining parallel core insider relationships to relevant parties is one such solution.

Second, MG shows that core insiderness can be within a party faction, and not necessarily with the party HQ itself. This is a point also made by Stoyanov. Although discussed later again, he argued that the regulatory pressure which he felt on their business was rather the work of a party faction in combination with their competition, rather than matters moved by the party headquarters. Moreover, attaching to a party faction is also risky, even if privileged access is provided, because a competition between the insiders ensues. Also demonstrating how insider status is variable, the confrontation between the circle Orion (below) and MG demonstrates how a group's insider status could evaporate if a rival party faction wins the party in-fighting.

And third, as a result of core insider status being variable, one has to distrust the dominant narrative of $\mathrm{MG}$ being a group overpowering the ruling party, because that holding had to constantly (re-)negotiate and reaffirm its status. The evidence suggests 
that MG's success with political parties rests on its ability to bargain and exchange its resources for political access. Although the question of power will be discussed in Chapter 9, it has to be noted that there is no evidence that MG could coerce political parties, as in the first dimension of power (also discussed in chapter 9). With particular reference to Ganev (2001) and Barnes (2007) who discuss with conviction that MG and Bulgarian circles, respectively, somehow forcefully dominated over political parties, any influence an external observer perceived in relation to $\mathrm{MG}$ and the circles is in fact the result of bargaining and cooperation. The MG Corporation was influential, but that was not a matter of some form of a constant connection to power but a matter of constant negotiation. In other words parentela insiderness is unstable because the venue itself is internally unstable, particularly when there are competing party factions.

\subsection{2. $\mathrm{MG}$ and DPS}

Respondent Dimitrov (speaking as a former prime minister), and Penchev (speaking as a former Member of Parliament and elite party functionary), pointed out that DPS was the first political party MG sought to establish any relationship with. Penchev testifies that in 1991, during the time of the electoral campaign for the Great Parliament, DPS was heavily under-resourced. During that time MG established excellent working relationship with DPS's leadership. In exchange for much needed resources for the set up and reach of the young party, also including benefits personally provided to the leadership of DPS, the corporation received direct personal access to the party leader. As a member of the party leadership at the time, Penchev personally met Iliya Pavlov in 1991.

Both Dimitrov and Penchev above recall MG and similar groups, that originated from the capital possessed by the political nomenclature and pre-1989 intelligence services, and which provided support for access to other political parties. In the case of MG it gave resources to several parties simultaneously (Penchev):

During this process of preparation for the Great Parliament, all of these people became service personnel for all leaders from all party centrals of all political formations [...] including SDS and BZNS, including DPS, 
parties that got in the Great Parliament. But they usually worked through the leader of the political party

Note that a stress is also put on the relationship with the political leadership. However, what ensued was a gradual formation of factions within DPS. On the one side was Penchev, on the other Mr Dogan and MG. The conflict was over the control of the nomination of MPs in the party lists as well as on the party political appointments in the civil services. Respondent Penchev noted a few key events in the lifespan of DPS that signified the true influence of MG on Mr Dogan, when many nominations both in the civil service and future MPs were made under the near-diktat of MG's representatives.

Another example of MG's influence over DPS was the vote of no confidence against the coalition partner (SDS) on 24 July 1992. Being directly involved, Respondent Penchev stated that their faction assumed the position of unconditional support towards SDS and the government of Mr Dimitrov (08 November 1991 - 30 December 1992). Instead, the position of the party leader Mr Dogan was ambivalent. This uncertainty was one of the earlier signs of external influence (Penchev). While the latter had personally negotiated the party political appointments with premier Dimitrov, in 1992, Mr Dogan personally voted against their coalition partner at the vote of no confidence. Voting in tune with the opposition and against his own MPs suggested to Penchev that there was external pressure on DPS with a view to topple Mr Dimitrov. Not much later, public pressure forced Mr Dimitrov to concede the government's resignation in a vote of confidence on 28 October 1992 which he lost as MPs from SDS voted against their own leadership. In the meantime, Penchev recalled the pressure exerted personally on them and their faction-leadership from representatives of MG to cease resisting the policies $\mathrm{MG}$ and the supporters of $\mathrm{Mr}$ Dogan promoted.

\subsection{3. $M G$ and the Berov Government}

Speaking as an immediate participant, Penchev explained that the government of $\mathrm{Mr}$ Berov, following that of Mr Dimitrov, allowed MG to procure their own nominations in the state administration. Respondents Donchev, Kuzmanov also gave precisely this 
government as an example of MG wielding an excessive power by means of party political appointments. The more glaring example of such appointments was $\mathrm{Mr}$ Stoyan Denchev who was a head secretary of the political cabinet of Lyuben Berov and at the same time vice president of Multigrup.

Ultimately, MG made use of such positioning in the government by absorbing the larger sectors of the industry (Georgiev, Penchev) through the processes of privatisation and the so called "entry-exit" economy. This means private firms (MG) would act as resource suppliers to state-owned enterprises (still an overwhelming majority in the nascent free market), that is at the "entrance". At the same time firms still under the umbrella of MG would act as exporters or distributors of the final product (Raychev and Stoychev 2008).

MG was not the only firm engaged in this practice. Other oligarchs of the rank of Iliya Pavlov also succeeded to establish a near monopolistic presence in the field they operated respectively, more or less following the same practice. Such as in the fields of heavy industry and banking: Borislav Dionisiev, Valentin Mollov Dobri Gushterov, and Borislav Dionisiev (Penchev). Collectively, those were known as the G13 and later circle Vazrazhdane (or Renaissance as per the Italian colleagues of Kirilov)(Penchev). Those were the formal representative organizations of big business owners (oligarchs with monopolistic businesses). More detailed descriptive information could be obtained from the formal communications of US Ambassadors Beyrle (2005) and Pardew (2005).

\subsection{4. $M G$ and BSP}

Following the fall of the Berov government, MG focused its attention to the next relevant party, BSP, however while still maintaining its core insider status within DPS. As Penchev recounts, after a certain satiation in capital accumulation, Multigrup, then as part of the informal G13 organization representing big business, sought the attention of BSP with the idea of a coalition government between BSP and a smaller partner, namely a party of Big Business. As the vice president of $\mathrm{MG}(\mathrm{Mr}$ Dimitar Ivanov) also reminisces in his memoirs about 1994, then the time was ripe 
for a new party political coalition between BSP and a coalition partner representing the interests of big business (the "+" in BSP+ in the quotation below, in Toshev 2004b):

In Bulgaria, VIS and SIK (single large corporations, usually associated with the "security business" and racketeering, sic) were picking up speed. There were shootings and people killed. But we were still safe from harm. Iliya Pavlov, Valentin Mollov, Ventsi Yosifov, Emil Kyulev, Dobri Gushterov were like business-gods, but everyone felt the need of a new state government. The Berov government could not offer them anything else, while at the same time it was not suitable for projects on a larger scale: oil, gas, coal, electricity, carbamide... The political class, so far as it existed, could not have made it alone... So, flicking through the newspapers on that May morning, I read that Ginyo Ganev [... will] register a new political party - the Union of Fatherland. That gave me the key to the formula, which had to be used - "BSP+", where "+" had to be a few centrist parties and citizen movements.

The leaders of big business groups in Bulgaria felt that any actions to influence political events to change the government were entirely justified and necessary. $\mathrm{Mr}$ Ivanov writes that the objective was to help a new political party get into power. While the government of Berov had been based on experts, and the cadres, as exemplified above, recruited from big business, larger and more lucrative projects could be realised with the help of a new party in power, which would be the "plus".

The "plus", it is implied, would be individuals coming directly from the offices of the single large corporations. The attempt to control the cadres of the future government as an element of the parentela is quite visible above. However, later in his memoirs, Mr Ivanov draws attention to the episode where he sought the private counsel of a handful of BSP leaders, such as Andrey Lukanov, Lyuben Gotsev and Alexander Lilov. What Mr Ivanov fails to mention is that the first and last of the list were leaders of party factions (while officer Gotsev was later pointed as the leader of the circle Monterrey, which Bakalov researched more recently). This indicates that MG was probing the attitude of the BSP factions towards big business and their own corporation for a possible form of cooperation..

In his visit to the above party functionaries, and as instructed by MG's owner Iliya Pavlov, Mr Ivanov proposed the establishment of a new political party that would 
coalesce with BSP (in Toshev 2004b). That party would be headed by Mr Ganev (from the newspaper earlier), who was in the final stages of establishing a new political party, but that party would essentially represent the interests of big business. In the presence of the then prime minister, Mr Videnov, who was summoned at that meeting between Lukanov, Gotsev and Ivanov, $\mathrm{Mr}$ Ivanov retells that he "emphasised strongly on the opportunity to attract big business in support of one post-electoral coalition with BSP." What this clearly means, according to Mr Ivanov, is that the "+" sign would be the political party expressing the interests of Big Business (in Toshev 2004b). By implication this means that that party would also be in the position to make party political appointments at the very least, if not influence the general policy of the state thus equating national interests to those of business groups with near-monopolistic market standing. All of the above, so far is a very detailed evidence of MG's attempts to establish a parentela with as many relevant parties as possible, e.g. DPS, BSP, BSP+, by exchanging electoral support against political appointments and favourable policies.

Before the electoral win of the Democratic Left (a coalition between BSP and other, smaller, parties, unrelated to MG), which brought Mr Videnov to power, there had been an earlier agreement that BSP would coalesce with the Patriotic Front of $\mathrm{Mr}$ Ganev (the MG-dominated party). As part of those agreements, Mr Ivanov reveals, there had been several consultative meetings with Videnov, where he personally nominated ministers and top civil servants (but later never realised) by writing them on a piece of paper, in an identical way the researcher was presented with a similar list by Penchev. At some of these meetings Mr Pavlov of Multigrup was also present. He offered in exchange for MG-sponsored nominations which BSP would endorse, the research and expertise capabilities of his corporation. Immediately after the Democratic Left assumed power, Mr Videnov, along with Mr Nikolay Dobrev (MP and a minister from the BSP at the time) visited the office of Mr Dimitar Ivanov, vice-CEO of MG. Mr Ivanov writes (in Toshev 2004b):

I had to personally introduce him (Mr Videnov, sic) to Mr Iliya Pavlov. Both of them came prepared and expressed respect to one another and I felt that trust had emerged between them. Iliya informed him about all projects in the business-structures of Multigrup and Zhan desired to start 
looking at each one of our analyses. [...] We created the following order - we would meet periodically in my office on different topics - depending on the analyses which came out from our structure - oil, gas, electricity, metals, banks, insurance... Iliya came to these meetings with one black leather bag, replete with business-plans, correspondence, referent literature, and after we finished our conversation he would give it to Zhan [Videnov] for "homework".

Until early 1995 the relationship between MG and BSP falls in line with what the parentela prescribes. There is trust, cooperation, as well as ministerial and by implication non-ministerial appointments discussed between MG and BSP. There is also an additional exchange element: policy-making access through appointments against expertise on draft economic policies, in addition to campaign funds. $\mathrm{Mr}$ Ivanov emphasises on the expertise $\mathrm{MG}$ was to provide (and provided) to $\mathrm{Mr}$ Videnov, although from another angle that might appear to merely be disguising MG's goals in specific sectors as policy expertise. Then again in general, it is hard to draw the line between a group's expert opinion and its toned down interests, when reading draft legislation. Finally, Mr Ivanov elsewhere (in Toshev 2004b) also shares that MG had also provided BSP's 1994 campaign with a far more considerable for those times sum of contributions.

All in all, the relationship MG established with BSP up to 1995 approximates that of the parentela. We have a group with clearly privileged direct access to the venue's central policy-makers, and in the position to bargain and negotiate with them. In addition to that, $\mathrm{MG}$ is in a cooperative, power-balanced exchange relationship, where they nominate party political appointments against campaign resources and expertise (although it is not clear whether these are MG's policy goals or MG's expert position) that they provide.

However, core insider status oscillates and is a matter of continuous re-negotiation. Although MG enjoyed close relation with BSP's leadership, it did not last long with Mr Videnov but with other party factions. Soon after the electoral victory of BSP as part of the Democratic Left, Mr Ivanov recounts bitterly that the final names of the civil service and ministerial appointees were none of those agreed with Mr Videnov 
previously. Most of them, instead, he identified, were related to the so called circle Orion.

\subsection{5. $M G$ vs Orion}

With the regime change in 1989 , not only did the state change from totalitarian socialism but from command economy to free market. This also entailed that all or nearly all hitherto State Owned Enterprises (SOEs) be privatised. While most SOEs took shape of factories and companies, there were the cooperatives, commonly known as Labour-Cooperative Agricultural Farms ${ }^{6}$ or simply cooperative farms (TKZS). They, too, were subject to privatisation. That, however, was not a straightforward process. Starting at the early 1990s, the process of transformation of ownership from collective to private meant that nearly all individuals involved in the cooperative farms would have to lose that source of income and employment. The name of the circle Orion, comes from a number of such cooperatives which after their privatisation had been re-named after stars of the same constellation.

The data on the circle Orion primarily came from an interview with Aleksandrov, who spoke both as an MP at the time and an insider to the Orion circle. That was then triangulated in an interview with Cenov, who was a close colleague to Aleksandrov, Georgiev (colleague to Aleksandrov and close observer of the early dynamics in BSP in 1990s) and news articles, primarily from the Kapital newspaper due to the ease of accessibility of articles from that period. That circle existed, even if it was still-born. On the one hand, one can identify the political and business actors, who would gain by working in concert, which signifies the existence of the circle Orion. Politically, one could identify the politicians who could potentially gain voters by promoting the policies that the cirlce stood for.

The circle Orion appears to be an attempt to merge economic profit, successful political careers and actual support to agricultural producers. Three main actors transpire. First, there is the political wing in the circle. These are Merrs Dimov and

6 Phonetically, TKZS (Trudovo-Kooperativni Zemedelski Stopanstva); ТКЗС, Трудовокооперативни земеделски стопанства 
his closest aide Orsov. The role of the former was to provide the political access to the policy-making process, while the latter to facilitate the legal technicalities. Both of them are the submitters of a number of legislative drafts intended to assist agricultural producers, most prominent of which are the Law on Protection of Agricultural Producers (LPAP draft, reference number 102.33-638 of 23rd December 1993) and the Law on Guaranteeing and Protection of Agricultural Producers (LGPAP draft, ref: 102-33-334 of 23rd June 1994).

Second, Aleksandrov explains that the personal involvement of Mr Dimov comes as a result of the plight of agricultural producers in his constituency in the Plovdiv region. During 1992, the already dysfunctional socialist cooperatives were in a process of privatisation. However, the first stages of that process entailed their liquidation, meaning all equipment sold and land coverage reorganised (Cenov). Many of the farmers, instead, wanted to retain the structure of the very same cooperatives and without any reorganisation become collective owners of the same (Cenov). The agricultural producers from the Plovdiv region were mostly affected by this new policy and found a natural expression of their interests in Mr Dimov (Cenov, Aleksandrov). As an MP at the time, Cenov reported personal involvement in the investigation into the open farmers' revolt during that time, who physically resisted the authorities coming to seize machinery and evict people from cooperatives' premises. Cenov also noted the dedication of Merrs Dimov and Orsov to redress the tension.

While the cooperatives could not be saved, one solution Mr Dimov saw was to setup a state-owned agricultural fund which would operate with moneys from the national budget and will assist agricultural producers by providing them with specific loans that are tailored to the peculiarities of farming. Aleksandrov explains that as a result of promoting this idea, the Plovdiv cooperatives freely associated in the Union of Agricultural Cooperatives (SZK) and provided some of the starting capital of the Bulgarian Agricultural and Industrial Bank (BZPB), which was to be the banking authority that would operate with the state moneys and distribute it in the form of loans to the ailing now private cooperatives. 
Essentially, at the core of this cicle lays the mutual benefits of the business and political wings in the circle Orion. While such capital would guarantee the success of the BZPB bank, the over 1000 cooperatives would provide a significant electoral boost to Mr Dimov, which is what he would gain politically, while the cooperatives potentially - gained loans on favourable terms. Merrs Mircho Spasov and his son Rumen Spasov would be the formal owners of BZPB and placing BZPB between the Agricultural Fund and the agricultural producers motivated them to take part. That would put their bank in a dominant market position because it is guaranteed fresh capital from the Agricultural Fund every year and the ability to provide better loans than their competition. As Cenov reiterated the publicly known fact, the name of the constellation Orion comes from the fact that a number of said cooperatives were owned by the Spasov family and were named after stars from the constellation. As it turned out, astronomy was their hobby.

In any case, the circle did not come into existence, because BZPB never received its license for operation. At first sight, the circle was born: the actors were in place and necessary legislation set into motion. However, the fact that the intended goals never materialised that birth was still. As Cenov and Aleksandrov reminisce, Mr Lukanov and his faction were particularly displeased when informed of the plan of Orion. As a response Mr Lukanov actively advocated the substituted Bank for Agricultural Credit (BZK) (Aleksandrov, Cenov). Cenov and Aleksandrov agreed that Mr Tilev was as a close associate to MG and Iliya Pavlov.

While the author could not establish direct evidence of ownership of BZK by MG, their association appears an indirect one. In a very succinct yet well detailed case study, Sugarev (2014) documents the details of the confrontation between Orion and their BSPB and Lukanov and the bank the latter supported, BZK, owned by Mr Tilev. The link between Tilev and Iliya Pavlov is not related to ownership but related to the unprecedented scope of non-guaranteed credits given out by BZK to numerous MG firms. This occurred in the turbulent times, immediately following the 1989 regime change, which saw plenty of misconduct, particularly in the banking sector where 
banks-owners would give out non-guaranteed loans to firms of friends and family. Sugarev (2014) reveals that the link between Mr Pavlov and BZK is through two intervening individuals: Mr Iliya Iliev and Mr Kalchev. The former is a Ruse business owner and a direct recipient of one of BZK's non-guaranteed loans in millions of leva, which were spent on the construction of an oil depot. The latter person at the time was the mayor of Ruse and former branch manager of Credit Bank, owned by Mr Pavlov. Sugarev (2014) implies that Mr Iliev was a proxy of Mr Pavlov, because Mr Kalchev was frequently recorded by the intelligence agencies phone-tapping him, to respond to Mr Pavlov with "Yes, boss!", promising on one occasion that the Ruse oil depot would be built. Indirectly, then, that gives credence to Aleksandrov's statement that Messrs Tilev and Pavlov were in close contact. However, even if the link between BZK and MG appears exaggerated, the evidence does not disprove that MG stood to gain from installing BZK as a dominant bank because its owner, Mr Tilev, would reciprocate any support to that end, which Merrs Iliev and Lukanov provided in the conflict against Orion's BZP Bank.

Evidently, both Orion and MG set up parentela relations with BSP on the basis of establishing core insider status with each of the respective factions inside. MG clearly sided with Mr Lukanov's faction, while Orion with that of Messrs Orsov and Dimov. By an extension, each of the groups had insider representation in the party in power. The only difference is that Orion's access to the civil service was not enough to put political pressure on the administration in order to defend itself. Mr Dimov was able to vouch for the credibility of the Cooperative Union before the State Prosecutor and prevent thereby the intended legal action against the Cooperative Union. Yet, he was not able to prevent the legal action taken against the BZPB (Aleksandrov). Meanwhile, Mr Lukanov proposed Mr Orsov for an intra-party inquiry to remove him from party's agricultural committee (Aleksandrov). Furthermore, the fact that Mr Rumen Spasov had drawn a loan from BZK years earlier in order to set up BZPB was exploited politically by Merrs Lukanov and Tilev to claim BZPB as incapable to return that loan, and a pretext for not granting the latter a license of operation (Aleksandrov, Cenov). 
Finally, respondent Georgiev, speaking as a well-connected opponent to BSP, with connections to BSP, commented that Orion never wielded any (significant) influence comparable to that of Multigrup. The circle's instrument of influence was intimidation based on its proximity to the Prime Minister Videnov, but not necessarily with latter's approval or knowledge. In fact Georgiev spoke in defence of Mr Videnov and for his non-association with Orion. Orion therefore had not managed to gain enough influence on the grounds of its core insider status and provided by Merrs Dimov and Orsov and in what closely resembles a parentela relationship.

At the same time MG appears to be the more effective group in exploiting its parentela relationship. Not only did it win on that occasion, but Ganev (2001) reveals in his 3 cases on Multigrup how the corporation achieved some of its goals in relation to other projects of national importance. Out of the three, the case of Topenergy is most relevant here as it follows the contours of a rather successful parentela: an insider party group which seeks to procure favourable appointments in the civil service (Topenergy was administered by the government). In short, the case is about the decision from Berov's government to establish a mediator company Topenergy - between the Russian Gazprom and the Bulgarian state for the provision of natural gas. Multigrup's plans were to appoint Mr Lukanov as the Bulgarian representative at Topenergy's directorial board. While those attempts were thwarted thanks to moves from Videnov's government and Mr Lukanov was denied that post, Multigrup still managed to gain 16.5\% of the Topenergy shares (Ganev 2011: 9-11). Given the opposition of Mr Videnov to MG and given that MG had to side with $\mathrm{Mr}$ Lukanov demonstrates the constant uncertainty of a core insider status (Ganev 2001). While Mr Lukanov succeeded to bring in MG as a stake holder in the nascent company, Topenergy, MG failed to help install him as a member of the directorial board.

\subsection{6. $M G$ and DPS 2}

As the events above unfolded in 1996, parallel to them, Multigrup attempted to maintain its core insider status by preventing their own ejection as a party insider 
from DPS. Respondent Penchev recalled the push of Multigrup to dissolve $\mathrm{Mr}$ Oktay's faction and prevent its merger with SDS in a larger political party: ODS. This historical decision for DPS was to be taken at a special party assembly in 1996. On the day of the vote, however, the faction of Mr Oktay was locked up in their hotel rooms by supporters of Mr Dogan and MG, thus being unable to attend the vote. All those loyal to the central leadership however were present and such proposals were voted down. All members of the faction of Mr Oktay were removed from all executive posts. Finally, the internal party regulations were also changed to the effect that Mr Dogan was specified as the sole unchangeable leader of the party. By eliminating internal opposition and particularly by both preventing the dissolution of DPS and solidifying the leadership position of Mr Dogan, MG succeeded in maintaining their core insider access (also Dimitrov). The above episode is an example of MG trying to maintain core insider status in parallel to two parties: DPS and BSP.

However, despite their victories $\mathrm{MG}$ entered into gradual decline with the party change and the coming of Mr Kostov to power, whose party ODS formed a majoritarian government in 1997. As a result, MG remained an outsider during the tenure of ODS. A conflict between the two gradually emerged and using their control over the state administration, ODS ejected all cadres of MG from the civil service. As a result MG had no access to the main stages of the privatisation process of state assets in Bulgaria at that time. Instead of MG or Orion, a new circle was reported to around the premier. That was Olimp, named after one of Mr Kostov's frequented restaurants. The ability to make political appointments also enabled Mr Kostov to exert regulatory pressure on the firms under the MG Holding (Aleksandrov, Kuzmanov). Mr Pavlov had become a subject of aversion and never achieved any of its earlier insider access. At that point, Mr Pavlov desperately sought any access to BSP which was in opposition, offering "PR" money to its leadership only to promote an MP he favoured. That attempt succeeded but to no avail. At the start of the government of Mr Saxe-Coburg-Gotha (National Movement Simeon II, NDSV), MG achieved some access through the G13 association representing big business, but that 
was not the same any more (Penchev). Mr Pavlov was assassinated in 2003 and with that MG discontinued active participation in policy-making as an interest group.

\subsection{The Profile of Private Parentela Actors}

The case on Multigrup and the circle Orion suggest that those who are on the private side of the network are firms with electoral or financial capabilities of relevance to the party or party factions. The count and size of those firms are irrelevant as long as they either individually (MG) or collectively (the Orion cooperatives) generate sizeable electoral resources such as campaign funds (MG) or electoral support (Orion). This is nothing different from UFU or CA, where the former is a collective of firms, while the latter is a single monolithic representative of the Catholic Church. The Orion circle in particular shows that the actual count does not matter, so long as the collective of then free-market cooperatives (represented by SZK - the Union of Agricultural Producers) provided relevant electoral resources, i.e. votes to Mr Dimov in particular and by an extension the BSP. Overall, this description is not different from the picture based on the general discussion on circles in section 7.2 where respondents were ambivalent whether insiders were a few or many but agreed that groups' influence lies in the campaign funds they exchanged for party favours.

The only new perspective is the brief discussion by a number of respondents on the role of oligarchs in the policy-making process. The description some interviewees gave on oligarchs' interaction with political parties, too, conformed to the parentela. That is why, to the above list of single large firms or a collective of many, we can also add oligarchs as an example of the private actor in a parentela network.

There is some evidence of some oligarchs trying to influence the nominations in the civil service, with Nikolov and Cenov going so far as to say that one of Bulgaria's prime minister $\mathrm{H}$ was also the result of the negotiations between the oligarch $\mathrm{W}$ and political party A. This claim is not entirely unfounded. Respondent Penchev gave the researcher a handwritten list of ministerial nominations that they compiled for one of Bulgaria's more recent governments. He explained that they personally vouched for 
the nomination of H. A link between Penchev, $\mathrm{H}$ and $\mathrm{W}$ could exist in theory because the common trait between the three is their centre-right ideological leaning, and their ties to Mr Kostov's government. Such dynamics of campaign funds for favourable nominations are clearly attributable to the parentela.

In addition, respondents Rumenov and Dobromirov also discussed $\mathrm{W}$ and their suspicious rate of winning public tenders, in exchange for campaign contributions. They discussed the oligarch Q along the same lines of exchange. The difference is that they exchanged their contributions for favours from the state administration to revoke the business license of their competition, respondent Mihailov. Although Mihailov has the interest in portraying themselves as a victim, they mentioned that at the time they also had direct representation to the coalition party to which $\mathrm{Q}$ had no access to. This means both had equal access to political parties and engage in confrontation, very much along the lines of Orion vs MG. Overall, then, to the list of private firms, or collectives thereof, we could also add individual oligarchs.

However, if the respondents from the general discussions on the subjects were unable to be specific, the image that the case on Multigrup provides is no different. The parentela, and insider status in particular, is not reserved to a single monolithic private actor, such as Multigrup or Catholic Action. Although individuals considered as oligarchs could engage in a parentela, a collective of single, small-scale firms such as with Orion and UFU is also possible. What matters most is the ability of the actors to accumulate a critical mass of party-relevant resources: campaign funds or electoral support. For those small-scale firms working together to express their interests, they usually formally associate as UFU and SZK. However, what most of the respondents from the general discussions found hard to communicate was the idea that while firms or companies acted together they did not necessarily do so in formal association with one another.

It seems that the more recent image, provided by the circles is of a larger than expected number of mid-size firms, working in an informal association with the party in power. It is hard to provide a number but it is more than what one would expect by 
looking at the cases of Northern Ireland and Italy. Respondent Nikolov spoke first of 10, then of 100 families in total, while Rumenov spoke of about 5 firms in the construction sector. We are probably looking at a slightly larger total number of privileged actors from all sectors who seek to establish a parentela with the ruling party, if we adopt Rumenov's estimate of about 5 per sector.

\subsection{Conclusion}

Following the example of La Palombara (1964) and Greer (1994), the purpose of the present chapter is to a single, tangible actor who could be involved in a parentela relationship with a ruling political party. The absence of a conspicuous actor of the scale of CA or UFU, puts a question mark over whether a parentela really exists. The Italian and Northern Irish cases clearly identify a corresponding insider actors that are easy to identify and observe. The interview approach leaves us in a situation where on the one hand respondents claim that there are party insiders, but on the other no such organization was clearly identified by them as such. The present chapter, therefore attempted to solve this issue by identifying any specific actors that have acted as party's insiders.

It argued that a large number of private firms, single companies or individual oligarchs could potentially enter a parentela relationship, as long as they accumulate the necessary level of party-relevant resources. While single actors like Multigrup are more relevant for the past, oligarchs presently are potential parentela partners. However, the main profile of a parentela is that of a slightly larger number of firms, say, 5 (Rumenov) per sector that informally work together to establish party insider status with the party in power and quite likely its party factions (Stoyanov).

In addition to that, the featured case study on Multigrup in this chapter also revealed additional parentela-relevant dynamics. First, parliamentary elections act as an external shock to the existing party-group relationship and as a result more affluent groups could seek to establish parallel core insider relations with all relevant political parties. In doing so, groups ensures to be always "in power". Second, groups can establish a parentela with a party faction. This is different from UFU or CA who 
worked straight with the party HQ. Third, insider status is variable. The case confirms the argument that access does not mean influence (Maloney et al 1997) but it also adds that access itself is not a constant. Both Orion and Multigrup in particular had to incessantly negotiate, that is fight, for their continued privileged access to BSP, with MG also in DPS.

In the next chapters 8 and 9 , the parentela will be discussed as a policy network in action. Chapter 8 will demonstrate a Bulgarian case that looks typical of La Palombara's parentela (type 1) while Chapter 9 will introduce a slightly different one (type 2), a parentela based on conflict. Both chapters will eventually distinguish between type 1 and type 2 parentela networks in order to highlight two different albeit parentela-related dynamics. 


\section{CHAPTER 8: La Palombara's Parentela: The Case of Bulgarian Law on Public Tenders (2004)}

\subsection{Introduction}

The purpose of the present chapter is to demonstrate the existence of the parentela in the Bulgarian polity. Following the research plan to find a suitable case study on the basis of elite interviewees' responses, the present study succeeded in finding a typical case of La Palombara's parentela in Bulgaria as of 2014. The parentela disclosed in the present chapter is manifested in the application of the Law on Public Tenders 2004 (LPT), with its 2014 amendments, in Bulgaria's construction sector. Essentially, the case explains the observation among respondents and the Bulgarian construction sector as a whole (discussed at length later in this chapter) that some construction firms unusually often win public tender auctions. The explanation is that this is done through a parentela relationship. However, the chapter also argues that this parentela formation is the result of the combination of two major independent variables: construction firms trying to survive in a market in decline and at the same time political parties trying to find campaign funding.

The chapter is structured as follows: Section 8.2 introduces the Law on Public Tenders 2004, up to its 2014 amendments and discusses the sector-wide position of construction firms that political parties pre-select their party insiders at construction tenders. Section 8.3 explains the mechanism of how in principle certain firms can be tacitly pre-selected as tender winners. Section 8.4 discusses the sector-wide reports that political parties pre-select favourite firms as construction tender winners. However, it is section 8.5 that explains how political parties do that Section 8.6 discusses the evidence that suggests that the major reason for groups to seek a ruling party's help to take advantage at construction tenders is the construction market decline, compounded by the fact that firms predominantly depend on public tenders 
for continued market survival. Before concluding, section 8.7 looks at the case from the perspective of the parentela and expresses its dynamics as a causal chain.

\subsection{The Law on Public Tenders 2004}

The Law on Public Tenders (LPT) was first introduced in 2004. It regulates the provision of goods and services to the public (the State) by private firms. In many cases these are large construction projects, such as highways, dams, bridges, etc., the completion of which is contracted out to private construction companies. According to LPT 2004, the process of transfer of the permission to construct is not straightforward. The civil service (the employer) ${ }^{7}$ has to organise an auction of offers submitted by prospective contractors interested in the completion of the project. Before an auction is convened, the employer (the civil service or the State) specifies a list of criteria for eligibility of participation and the criteria according to which offers will be considered for selection. Some of the criteria offers have to meet are the price range for carrying out of the announced public project and essentially any other criteria the employer deems important to ensure a quality service. Once prospective constructors are allowed to participate in the bid their offer is weighed by the employer in terms of price and quality and are considered for selection as the prime contractor for the completion of a highway section, public hospital, school, etc., is made.

A number of the respondents from the present study, short of a consensus, argued that public tenders, particularly in the construction sector, demonstrate the exchange mechanism between insider groups and the ruling party. In a recent study conducted by the Chamber of Bulgarian Constructors (KSB) and the Higher School for AgriBusiness and Regional Development (VUARR), a predominant observation of construction firm owners is that firms with direct party access tend to locally dominate the market for construction tenders (VUARR 2014). The study was carried out in the form of a survey among the construction firms in the Bulgarian construction sector in 2014. According to the report, the second (37.5\%) most

7 According to article 7 from LPT, employers of public tenders is essentially the civil service, such as ministries, agencies, local level administration. 
important difficulty that Bulgarian construction firms face is the disloyal competition, i.e. the firms that win public tenders thanks to party political interference in their favour (2014: 16-17, original emphasis):

The fact that the larger category investors are not private [...] places the larger sector before the larger problem of corruption, the dictation of foreign and/or those firms having political protection and investors, as well as disloyal competition (using non-market means to gain advantage over competition, sic). This is the position of more than one third of those participated in the questionnaire. Part of the construct [ion firms] and experts describe classical cases of eventual competition elimination with "specific" criteria, which decrease the possible competitors to a few. [9] That in turn allows for the easier arrival to cartel agreements.

The report states that a dominant position among construction firm owners is that political parties interfere in favour of party insider groups to the effect that the latter become disproportionate construction tender winners. This is worded above as corruption and "those firms having political protection" (VUARR 2014: 16). Towards the end, the quotation above also indicates that the most often used mechanism for tacit pre-selection (of party insider groups) is the careful wording of the eligibility criteria for participation at the auction. Limiting the number of eligible participants, the report concludes, leads to cartel agreements among them. Finally, the report also notes that foreign firms also exercise diktat on domestic competition, although this is not elaborated.

The VUARR report, however, has a main weakness, which is that it does not provide any evidence that links the party in power and the outcomes of the public tender auctions. The present study on Bulgarian parentela contributes to the VUARR project by showing that this is a two-stage process. First, the party appoints the members in the Public Tender Committee (PTC), which publicly announces the opening of a competition for the best construction offer of a given site and decides on the winning tenders. And second, once the PTC is staffed with party loyal appointees, they then limit the competition among firms by the careful specification of the eligibility criteria for auction participation. Ultimately, however, once both stages are complete, then we can observe a parentela formation. 
However, a large part of the above explanation rests on the understanding of what the report means by "classic cases of elimination of eventual competitors with "specific" criteria, which decrease the possible competitors to a few" (VUARR 2014:16-17). In order to understand the two-stage process, it has to be explained what those specific criteria are in relation to public tenders and why are they significant in this case. Therefore, before approaching the two-stage process, discussed in section 8.4, the chapter will discuss the question of specific criteria that limit the public tender competition.

\subsection{Public Tender Contractor Pre-Selection Mechanism}

Essentially the VUARR report above relates to the criteria that govern firms' eligibility for participation at public tenders and the consideration of their offers. Making the eligibility criteria more stringent is the prime mechanism for the covert pre-selection of intended tender winners. Of particular interest here is the second version dated 28.08.2013 (the first one being on 26.07.2013) of the Motives ${ }^{i}$ that support and explain the LPT October 2014 amendments which bear reference number $\underline{302-01-14}$ and in effect from 01.10.2014. (Unless stated otherwise, the section refers to these amendments with the phrase "the amendments to LPT".) The second version states that the LPT amendments are also motivated by the decision of the Bulgarian Commission for the Protection of Competition (CPC) $570 /$ 20.05.2010, which also lists the forms of manipulation of public tenders which LPT permitted due to its imperfection.

The CPC Decision 570/20.05.2010 classifies public tender manipulation in two categories: public (employer) and private (contractor) (CPC570/20.05.2010: paragraph 9). According to the CPC Decision employer-related forms of public tender manipulation could serve as a mechanism to pre-select party insiders. Paragraph 10 (CPC570/20.05.2010) states that the free competition of offers submitted by wannabe contractors can be inhibited by actions, inactions and legal acts that are within the legal purview of the employer, which in the LPT case is the 
civil service (discussed below). However, Paragraph 11 (CPC570/20.05.2010) directly describes how employers can pre-determine the grant of tenders to desired firms (or party insiders as this chapter argues) (emphasis added):

The public form of tender competition circumscription could be realised by the employers themselves through the introduction of discriminatory conditions and requirements on the participants at the start of public tender assignation procedure, which narrows the circle of potential contractors, creates unjustified access barriers to candidates or favouritises in advance a specific market participant. The violation of the principle of free and loyal competition is possible when some applicants are unlawfully decreed permission to enter the auction and their offers considered when in fact they should have been disqualified.

In other words, the criteria of eligibility to participate in a tender and the criteria according to which each offer will be assessed for assignation can be worded and devised in a way so as to fit a desired firm. As it will be demonstrated below, respondents from this study and that issued by the industry report a ubiquity of this practice as of 2014.

Employer-related forms of contractor pre-selection are also observable in the adjoining paper produced by the CPC to be read with decision $570^{\mathrm{ii}}$. Unfortunately, that document does not explicitly identify public (employer) forms of competition disablement leading to pre-selection of intended constructors. Instead, it features a list of circumstances that might arise at public tenders and thus be indicative of either public or private malpractice. In the list of manipulation indicators, the focus appears to be on indicators related to private forms of competition limitation, although one could still discern circumstances of employer-based forms of public tenders manipulation:

1. [...] an offer is submitted by a candidate who is publicly known to be unable to execute the tender. [...]

On this note both Rumenov and Dobromirov mentioned in their experience cases where firms with background of market operation in another sector win tenders for road constructions. 
The next indicator relates to cases where candidates do not enquire for nor include the necessary technical specification for the execution of the project:

3. One or a few of the enterprises who have submitted offers, have not required from the employer the technical specifications on the object of the tender or their offers lack such data that would normally follows to be included [...]

At first sight, this scenario is also fitting a case where private participants have agreed in advance who would win the bid (i.e. formed a cartel) and so, all save for one submit technically flawed offers. However, in cases where a firm lacking such technical specifications is selected as the main contractor that does indicate suspicion.

Point 30 offers the clearest case of public form of competition disablement:

30. Given participants regularly win the procedures for the assignation of a specific type and volume of public tenders, or procedures opened by specific employers, or in specific geographical regions often win the same participants from the market, although there is evidence of real and potential competition.

Accordingly, employer-caused pre-selection at public tenders is most visible where there is co-variation between the success rate of a given constructor and given employers, job, or region, particularly in the face of proper competition. In any case, the presence of this document and the practices outlined therein is based on the hitherto experience with public tenders in Bulgaria. Now that it is explained how specifying the criteria for participation at public auctions can limit the number of participants, the following section 8.4 demonstrates how political parties are still in the position to employ this practice, with the October 2014 LPT amendments, through the Public Tender Committees.

\subsection{Scope of Contractor Pre-Selection at Public Tenders}

Based on the personal experiences of the respondents in the VUARR (2014: 76-104) study, the VUARR report demonstrates that the prime (if not the only) source of manipulation of the public tenders lies with public bodies that skew the criteria for 
participation so to narrow the competitors down to the intended ones. Commissioned by the Bulgarian Construction Chamber, the VUARR report is representative of the construction sector in Bulgaria, with about 350 surveys featuring open and closeended questions (VUARR 2014: 5-11). While the report does not feature a technical discussion on any statistical representativity measurements, given the target audience, certainly the overlap of its qualitative data with this study's results mutually reinforces the reliability of both studies. The VUARR study reveals that construction company owners mostly complain that administrative bodies that organise construction tender auctions skew the selection criteria in the interest of party insiders. VUARR respondents make no relationship identification between the employer and the contractor, but between the political party and the contractor, via the public body organising the tenders.

The results of the VUARR study are a clear testament of the unimpeded practice of pre-selection of party political insiders entirely according to the logic of public forms of competition manipulation at public tenders, specified in paragraph 11 of the CPC decision CPC570/20.05.2010 discussed above. The responses are too voluminous for proper analysis but a few quotations succinctly summarise the above. For example, some respondent state:

Sometimes it happens so that the conditions are so specific to one firm that the only thing missing in the [selection] criteria is its name. (VUARR 2014: 104)

The construction sector is hostage to politicians. (VUARR 2014: 77)

Real market competition is shifted aside by the fight for maximal proximity to party political tenders. (VUARR 2014: 104)

The created proximity between politics and the construction sector limits free competition. (VUARR 2014: 104)

There is an accelerated liquidation of small construction firms through LPT and more specifically the introduced criterion of "economically most suitable offer-technical offer". The options are: remaining of a small number of big firms that dictate on the market. Which ones would they be depends not on their technological and technical or cadre capabilities, but on whether their owner is in close relations with the ruling political party. (VUARR 2014: 101)

Overall, however, the question of the public forms of manipulation of public tenders is largely evaded in the conclusion of the report above. It is surprising, then, how the report does not discuss at any considerable length the practice of administrative 
(public) pre-selection of party insiders, particularly in the presence of such an abundance of responses from construction work owners, who claim on the basis of their experience, that the selection criteria public tender committees is skewed so to fit only the profile of the intended (party insider) firm.

Given the available data within the VUARR 2014 report, its conclusion quoted earlier (8.2) is imprecise because corruption, disloyal competition and party political protection are equivalent to the notion that in far too many cases the auction winners are also the informal party insiders. The VUARR respondents note the keyword corruption, but nowhere do they associate that with any forms of private manipulation of public tenders. To the extent the competition is affected by the actions of private firms, which is what may appear to be referred to as disloyal competition, VUARR respondents associate that with the practice of main contractors not paying what is due to the sub-contractors in the hierarchy of project contractors. There is virtually nothing in the respondent interview excerpts in the VUARR (2014) report that indicates construction firms complained from cartels, which is along the logic of private forms of manipulation (CPC 570/20.05.2010). As for cartels and foreign firms, there is virtually no mentioning of those in the interview responses summary in the Annex to the report (VUARR 2014: 76-104). That is to say, the argument that VUARR respondent firms also complain from cartels and other foreign firms is unfounded, as no such references could be found in the Annex of respondent quotations. Therefore, the use of disloyal competition, corruption and foreign firms misleads from the main problem: party political interference with the principle of competition with public tenders. In addition, the gentle mismatch between the responses and their interpretation suggests that the authors of the report had engaged in some degree of auto-censorship.

In unison with the VUARR (2014) respondents, those from the present study on parentela are overwhelming in their identification of political parties as the source of public tenders malformation. There is no deviation here from the view that political parties attempt to pre-select party insiders at public tenders in order to reciprocate for latter's earlier campaign contributions. A considerable number of respondents argued 
ruling parties are in the position to control the decisions of PTCs. The difference was in the nuances of the argument. Two active policy-makers at the time of interview, respondent Hadzhiev and Gospodinov, explained that insiders expect public tenders or appointments in the state administration in return for their campaign resources. The idea that public tenders are exchanged for access is at the heart of Gospodinov's position:

$R: \quad$ So, we start from here (inability of parties to meet the actual costs, sic) and we finish with the sources. Sources [of financing] are clear: the business [for parties], the big Public Tenders [for business]. We (on behalf of industrial sector) are trying to win Public Tenders. At present this is the only source of income for business. When there were big foreign investors in the recent past, there was not such a high level of pressure, but now, things are serious. So, parties, coming to power, there is nothing for free. Once you have taken the money, you have to give it back. And this is done through state power (government).

Respondent Bachvarov directly admitted that party political donors approach parties with the intention to exchange that for public tenders and appointments:

$R \quad$ So, the business groups in Bulgaria take part in the entire chain of conduct of politics in this state. From one angle, business participates as early as the formation of the branches of power, which is at the electoral campaign, through sponsorship of various political powers, and in another way - in the formation of the future government. Very often specific ministerial and high positioned civil servants are appointed under the influence of business structures. And third, they (business) participate in the process of real politics, which is primarily through the distribution of public tenders, where every business structure attempts to tear as big a share (contract, sic) as they can for themselves.

As the respondent elaborated further, business groups see campaigns as a form of investment. If the party becomes incumbent, then the group should expect public tender in return. Respondent Gospodinov, spoke with particular reference to the entire construction sector:

R: $\quad$ Our aim is to try and decrease subjectivism (i.e. administrative pre-selection of intended tender winner, sic) to minimum. We tried in various ways. One was through the direct introduction of the German legislation [... or] with very simple things, such as everything to be uploaded online on the day of opening of the offers. However, we were met with a stark resistance, because there is a manipulation between the process of announcing the criteria and the process of the opening of the offers. So, the process of opening of the technical criteria [for the job] lasts until the offers are opened. There is a gap of 2 to 3 weeks between 
these two processes, when manipulation could be done, such as crosschecking the prices in the offers.

$S \quad$ You mentioned some resistance...

$R \quad$ The resistance comes from the administration which does not want to make the procedures public--

$S \quad$ Why?

$R \quad$ laughs/ because for the reasons I have just told you. So that the ability to manipulate the end result remains. This is done through transparent envelopes and all other ways, nearly criminal. I am telling you like this but there are colleagues claim for such cases.

SIt is curious for me, how is it that the administration is doing that on own initiative or under influence from elsewhere

$R W e l l$, here things are intertwined. The administration says that the European rules allow it, which is a manipulation and a lie. Here is the connectedness between the administration and the people who rule at the moment and the entire politics is towards directing [the outcome of] public tenders. Overall, the general solution to this problem is transparency, internet transparency and every step of the process be announced publicly. There is no single impediment for that to be achieved. [...] but it is not happening [...] they are voted in the committees but do not enter into effect.

The contribution of the present parentela study to the respondents' position VUARR (2014), that public tender committees pre-select party insider firms, is in that the statements come from respondents who at the time of interviews were active politicians and civil servant experts. The respondents from the parentela study only add to the validity of those from the VUARR (2014) report.

In any case a detailed comparison of the answers between the respondents is hardly necessary. Respondents Donchev, Kirilov, Bachvarov, Gospodinov, Zlatarov, Rumenov, Dobromirov, Varbanov, and Petrov spoke with particular reference to public tenders in relation to insider groups securing insider access as a result of an exchange with ruling political parties. Arguably the more important statement is from Donchev who argued that the law is deliberately imprecise so as to allow party insiders and the party itself to be able to tilt the outcome of public tenders in favour of party insiders. This is also another confirmation of the argument that the core weakness as of 01.10.2014 is party interference. Speaking as a director of a peak construction association prior 01.10.2014, Gospodinov stated that LPT's 
imperfections allowed for party appointed experts took part in the PTCs decisions, however, without elaborating what the process is.

However, another missing link in the analysis of this case is that between the political party and the actual application of the mechanism of pre-selecting the tender winner. The presence of discriminatory criteria that leaves only one suitable competitor at public tenders does not alone constitute a party political intervention, for the selection of competitors for public tenders does not directly connect to political parties. Even if there is a uniform choir of voices in the VUARR report (2014) saying "party political interference", the actual link is still missing. Neither the CPC Decision mentioned above, nor the VUARR 2014, nor the respondents from the present study elaborate how political parties pre-select the party insider firms at public tenders. They provide no evidence linking the malformation of the participation criteria for public tenders with political parties. The following section will address namely that: how political parties intervene administratively in order to covertly pre-select the party insider firm as the winner of public tender auctions.

\subsection{Party Interference in the Public Tender Committees and Contractor Pre-Selection}

Political parties could pre-select party insider firms at public tender auctions by shaping the membership of the administrative body that decides the winning tenders: the Public Tender Committee (PTC). These committees are specified in art 34(1) from the LPT and they are established by the state employer, i.e. the civil service. Overall, the members of the PTCs have to administer the conduct of public tenders: from the formal announcement of the prospective auction to the final selection of the winning bid, and the maintenance of necessary legal or administrative communication with third bodies, such as trade associations, EU institutions, and ministries.

The controversy around the PTCs is about who will sit as their members, because those who do define the criteria for participation and assessment of the offers made 
by prospective constructors. The parentela forms when the PTCs are predominantly staffed with party political appointees, because those are in the position to pre-select the party insider auction participant. While the October 2014 amendments provide for non-political experts to sit at such committees, the legal provisions are in fact permissive of the continued political appointments practice. First, there is no obligation on part of the employer to staff PTCs with external experts, and second, there are no criteria to assess the professional capacity of those experts, appointed by the employer to sit at the PTCs. This means that specifying that the Agency on Public Tenders has to maintain a list of experts does not necessarily limit political interference because determining who counts as an expert in the eyes of the politically appointed civil service is a matter of party political convenience and not a matter of rules and licenses confirming that those individuals truly are experts. Staffing a PTC with political appointees therefore allows insider pre-selection through targeted definition of the participation and "winning tender" criteria to fit the profile of the party insider participant, i.e. public form of tender manipulation described above. All of this ultimately relates back to the VUARR 2014 report above which posited that a major impediment to the public tender auctions execution is the party interference in favour of certain firms. The present section explains how this is done.

Let us delve in the evidence. A recent report by Bulgaria's intelligence agency DANS, presented by Mr Kalin Krastev concerning oblast ${ }^{8}$ Shumen, states that the careful selection of the members of the PTC facilitates the tacit contractor preselection. In his summary to the public (Shumenska Zarya, (40/12420)/27.02.2015, p2) he confirms that the main mechanism of pre-selecting an intended contractor offer is through the malformation of the criteria for participation and the criteria for assessing offer feasibility. However, he also notes that this is the result of political parties influencing the work of the PTC, which sets the criteria for eligibility and main contractor selection. In his words (emphasis added):

Interconnectedness exists between the employer, contractor and subcontractors where in many cases; the servants on a governmental post

8 Oblast is the largest regional unit, which consists of smaller units called obshtina (sg; -ni, pl.). 
exert influence on the selection of specific constructor or consortium.

[...]

A defining factor is that the committees are convened by servants of the respective administration which are directly subordinate to and find themselves in hierarchical dependence on persons holding governmental posts.

The DANS report then clearly corresponds to one of the main complaints stated in the VUARR report above, that political parties interfere in the market for construction work in the interest of party insiders. The DANS report above explains this to be the result of parties shaping the staff and decisions of PTCs.

This argument, however, becomes increasingly more tentative as we move further away from 2014. The time-period the DANS report and the VUARR (2014) interview responses refer to is the status quo before the $1^{\text {st }}$ October 2014 amendments of LPT. The Motives behind the LPT October 2014 amendments also state that a common complaint among groups (those had sent written statements in response to the consultations) was that there previously had been a strong political interference in the work of the civil service tasked to carry out the public tenders (LPT Motives 2013a: 3; LPT Motives 2013b: 3). This further suggests that the conclusions from the DANS report above are more pertinent to the time-frame before the October 2014 amendments.

Yet, the generalizability of the DANS 2015 report might extend past the October 2014 benchmark. Political parties are still able to interfere in the work of the PTC even with the LPT (리-01-14) amendments, which came in effect in October 2014. The first version of the motives to the LPT changes openly recognises that a major objective of the proposed amendments is to sever a party's interference in the work of the PTCs (2013a: 18-19, section IV.2.3). Surprisingly, the section IV.2.3 is entirely missing form the second version (28.08.2013). This sudden omission indicates either a surprising lack of confidence in the effectiveness of the intended measures to curb party influence or possibly an attempt to hide that conflict. The latter is namely about who will sit at the PTCs: experts sent from sectoral peak associations or experts appointed by party political civil service appointees. 
In his written statement on the LPT $\underline{302-01-14}$ amendments, Docent Doctor Gancho Popov (Popov written statement, 2013, reference 167/27.09.2013) argues that ultimately the party is still in the position to pre-determine the outcome of PTC decisions. Popov's critique is that facilitated by a chain of political appointments, the absence of obligation on employers to use experts from the list of external experts (nominated by trade associations) in the PTC allows the administration to continue to use civil servants who are political appointees when preparing for public tender procedures and who in turn will design the assessment and participation criteria in a way that will fit the profile of the party insider firm (section 8.3) (Popov 2013: 1-3). Another factor that enables the use of politically appointed civil servants is that LPT does not specify the criteria that determines who is qualified as an expert to sit at the PTC. Therefore, state-appointed experts are an extension of the party in power. This is entirely consistent with former minister Petkov's position earlier that any individual, regardless of the expertise they hold is never free from the party that has appointed them. Popov argues therefore that politically appointed civil servants will always seek ways to recruit experts from the rank and file of the state administration, when public tenders have to be organised. This is facilitated by the absence of any provisions in the LPT, which enforce objective criteria for any expert appointments. As it stands, experts sponsored by the civil service are left to the discretion of civil service directors to determine their expert status $(2013: 2)$.

He rests his critique on the interplay of articles 8(7) and 20(1) of the LPT October 2014 amendments, although for completeness, one also has to add the importance of articles 34, 19(2)8, 20(1) from LPT and 19(1-4) from Law on Administration. Article 19(1) from LPT clearly states that the director of the agency that regulates public tenders is a political appointee: 'the Agency on Public Tenders (APT) is directed and represented by an executive director, who is appointed by the Minister of the Economy, Energy and Tourism.' This demonstrates the party-civil service link. The party-public tender link is evident in article 19(2)8 which states that it is the politically appointed executive director who has to maintain a general list of external experts: 
[T] he Executive Director of the agency creates, maintains and updates a list of external experts for participation in the preparation and conduct of procedures for granting of public tenders

In addition, article 20(1)1 regulates where experts could be recruited from: the trade association of relevant expertise to the tender, the civil service and any individuals who consider themselves as experts in the respective field of the tender auction:

The list according to art. 19(2)8 includes persons who have professional competence, connected with the [...] public tender, and: 1. are nominated by professional associations and organizations from the respective sector or from bodies according to art. 19(2-4) from the Law on the Administration, with a notice of their professional competence, or 2. Individually have submitted such a claim [...]

In other words, the APT director is a party appointee, who in turn can make political appointments of experts. Those experts are then used to formulate the specifications public tender offers have to meet in order to be allowed to compete and be considered at the auction. Article 8(7) of LPT states that prospective employers have to include experts in the execution and assessment of public tenders, where if they do not have any such experts at their disposal, they can call external ones:

In preparing for the procedure of granting a public tender, employers are obliged to provide for the preparation of technical specifications, the methods of assessment of offers in the documentation for tender participation [...] at least one expert who has professional competence connected with the tender object. When the employer does not have at their disposal [civil] servants, who can meet the professional competence requirements, then he provides external experts from the list specified in [19(2)8]

The crux of the matter is essentially here. According to Popov, the law implies that it is up to prospective employers to determine whether they have or not the necessary experts to carry out the public tener (2013: 1-3). In Popov's parlance, these are appointed experts (2013: 1-3):

If the employers have an interest not to observe the suggestions in art. 8(7), [they can appoint] a convenient for them expert, [who] will establish criteria which will only be met by the desired public tender candidate. [...] We are left [to depend on] those who will nominate the experts to forego their own personal interests and to demonstrate righteousness in carrying out their mission.

In other words political appointments in the civil service facilitate the covert selection of the party insiders at public tenders. In the absence of any formally stipulated criteria for assessing one's level of expertise, there is nothing to prevent a 
prospective employer to appoint his subordinates as "experts" in the preparation and execution of public tenders. Ultimately, because of being dependent on those who have appointed them, those tasked to oversee and select the winning tender will develop such criteria for tender participation and bid assessment, which will narrow the outcome more or less to the only one participant (firm), as desired by the party bosses.

The only clarification one could make to the above is to add that this dynamic materialises in the Public Tender Committee (PTC) which is the actual body of experts and servants that presides over tender auctions and selects the winning tenders. Article 34(1) states that 'The employer appoints a committee in order to conduct the public tender.' Articles 34(2-3) also specify that the membership of the PTC has to be at least 50\% manned by experts and if those are not available, those should be recruited as per article 19(2)8. And it is exactly here where Popov's dynamics above take place. Employers convening a PTC determine whether they have the necessary experts amongs their staff to carry out the public tender, without having any obligation on include external experts. In other words, a party's ability to interfere in the work of PTCs allows it to pre-select desired groups as main contractors. This means that articles 20(1), 19(2)8 from LPT (October 2014) and articles 19(1-4) from the Law on Administration allow the party in power to control the membership of the PTCs by first appointing the head of the central or local executive structure and then by specifically allowing the same political appointees to make their own appointments to staff the PTCs.

Despite the critical tone above, there are a few points that need to be aired. First, article 20 from LPT above is a step in the right direction. LPT versions until 01.07.2014 deliberately or not overlooked the forms of extra-administrative, citizen control over the work of the committee, which alone is a positive development. The LPT (October 2014) version of article 20 is re-instated. In fact, earlier versions of the law did not address the problems posed by selecting the members of PT committees, nor did they always feature an article 20. This is the other formal acknowledgement, next to the first versions of the Motives to LPT (2013a), Popov and Mr Krastev, that 
party political influence on public tender outcomes manifests itself in the PTC decisions. It also has to be conceded that even despite their best intentions political parties may not always find the proper experts to staff the PTCs. The provisions, in fact, generously assume that there is an ample reserve of relevant experts outside the civil service, who are ready to staff the myriads of PTCs on the double. While the question in this section has been how political parties intervene in the interest of party insiders, the following section 8.6 discusses why groups seek to do that.

\subsection{Parentela as a Market Advantage}

Evidence suggests that all groups who have gained insider status have done so in order to ensure a better economic standing for themselves. Many respondents from the present study reported increasing difficulties staying afloat in a market that is now in decline. The chairman of the Chamber of Bulgarian Constructors, $\mathrm{Mr}$ Svetoslav Glosov, announced on 23.03 .2015 that $80 \%$ of the work undertaken by firms rests on public tenders (2013). This means that, Bulgarian construction work firms remain dependent on financing sources that are subject to party political control, given the PTCs above. Respondent Donchev noted that the financial crisis since 2008 has left many firms with a choice: announce bankruptcy or seek the cooperation of ruling political parties. In fact, the number one impediment in the sector, reported by construction work firms in the VUARR 2014 report, is the bad economic state of the market. This means, firms as of 2014 report significant economic and financial difficulties (VUARR 2014: 14).

Therefore, this section argues that this forces firms to make a choice of existence on the brink of collapse or to fight for party favours. The evidence is that firms choose the latter. In a zero-sum game, party outsiders have two options: to go bankrupt or further seek closer cooperation with the party in power, reinforcing thereby this vicious circle. The answer of Respondents Kirilov and Dobromirov in particular reveal the gradual concentration of resources in party insiders at the expense of the rest of the market participants, whereas per Dobromirov:

$R[\ldots]$ they hold everything, particularly the public tenders. I am working 99\% public tenders and the percentage of independent investors in 
Bulgaria is very, very small compared to six, seven years ago, when private firms were booming. But this is no more. And they used to build resorts by the sea [...] but this is dead now. [...] And the relationship with the ruling party, it is all based on the public tenders. [...] But what happened with us, the small fry in the sector, is that the larger sites are given to a defined circle of firms. That is it. These are around the party political power. There have always been such circles but earlier there was [an unwritten principle that], "we should leave some tenders for the others". Give or take, nearly every one observed this thing, but during the mandate of the previous government, there were no such considerations. [Tenders to the tune of] one and a half billion (leva?) were spread among ten firms. That is it. These are some strange public tenders. [...] Then, I also gave up participating when I saw those firms at the auctions.

This is remarkably close to the position of a respondent from the VUARR 2014 study, that 'Real market competition is shifted aside by the fight for maximal proximity to party political tenders.' (VUARR 2014: 104). The sections so far have described the process of party political intervention in the work of civil service public tender committees and how that helps predetermine party insider groups to receive public tenders. The following section, 8.7 , however, will operationalise this description in as a causal parentela model.

\subsection{Public Tender Committees in the Construction Sector and the Parentela}

The present case of Bulgaria's Law on Public Tenders 2004 (LPT) demonstrates that groups' prime motivation in seeking a parentela relationship is to oust the competition. The economic downturn in the construction sector has forced groups to seek party political cooperation in order to improve their own market standing. This means: small-scale businesses seek party political protection in order to survive; midsize businesses to gain advantage against the competition, while big business, to maintain a monopolistic market standing. Businesses from all shapes and sizes,

9но по-рано имаше едно такова, тва за нашите да има, ама и да има за другите също да работят, горе-долу всички се съобразяваха с тва нещо, 
therefore, attempt to survive at the expense of the competition through an exchange with political parties.

At the same time, political parties use the ambiguities of LPT to honour their side of the exchange relationship. In the case of construction sector LPT 2004, provision of access to the insider takes the form of the political party interference in the work of the Public Tender Committee that decides which contractor companies will be granted the given public tender. As the case demonstrates, the party insider groups ${ }^{10}$ tend to win far more tenders than their competition. This is possible because the party interferes in the work of the PTC through political appointments and deliberate ambiguities in the LPT 2004. A party's prime motivation to cooperate with insider groups is to secure funds for future campaigns. A secondary motivation is also observable, though a bit less pronounced, stems from the logic of molecule of conversion. Better observable in chapter 9, parties could also be motivated to cooperate with insiders with a view of converting the policy-making access that they provide into economic capital for the setup of party-controlled businesses.

Following the process tracing approach, however, it is clear that this relationship is not that straightforward. The parentela forms gradually, as opposed to in a single strike. Its formation happens on a number of causal stages, or causal chains. Taken together, these stages reveal a chain of dependent (DV) and independent variables (IV), as well as intervening variables (IntV), which are responsible for the parentela formation in the market for construction public tenders. Figure 4 (p221) summarises the chain of causal relationships that collectively constitute a parentela. Figure 4 also uses the following abbreviations and numbers:

$$
\begin{array}{ll}
\text { IV } & \text { Independent Variable } \\
\text { IntV } & \text { Intervening Variable } \\
\text { DV } & \text { Dependent Variable }
\end{array}
$$

(1-9) a reference number to a box from the diagram

Also note in the diagram below that because the process is a chain of causal relationships, some DVs are also IVs because they in turn exert an effect on 10 Any firm or a collection of firms, that may belong to an oligarch, involved formally or informally in policy-making are seen as groups 
consequent variables, e.g. elements 5 and 7 from the diagram. In the commentary that follows figure 4, a reference system is used, where each variable is referred to its respective location box in the diagram, denoted with "(variable type, box number)", e.g. $(\mathrm{IV}, 3)$.

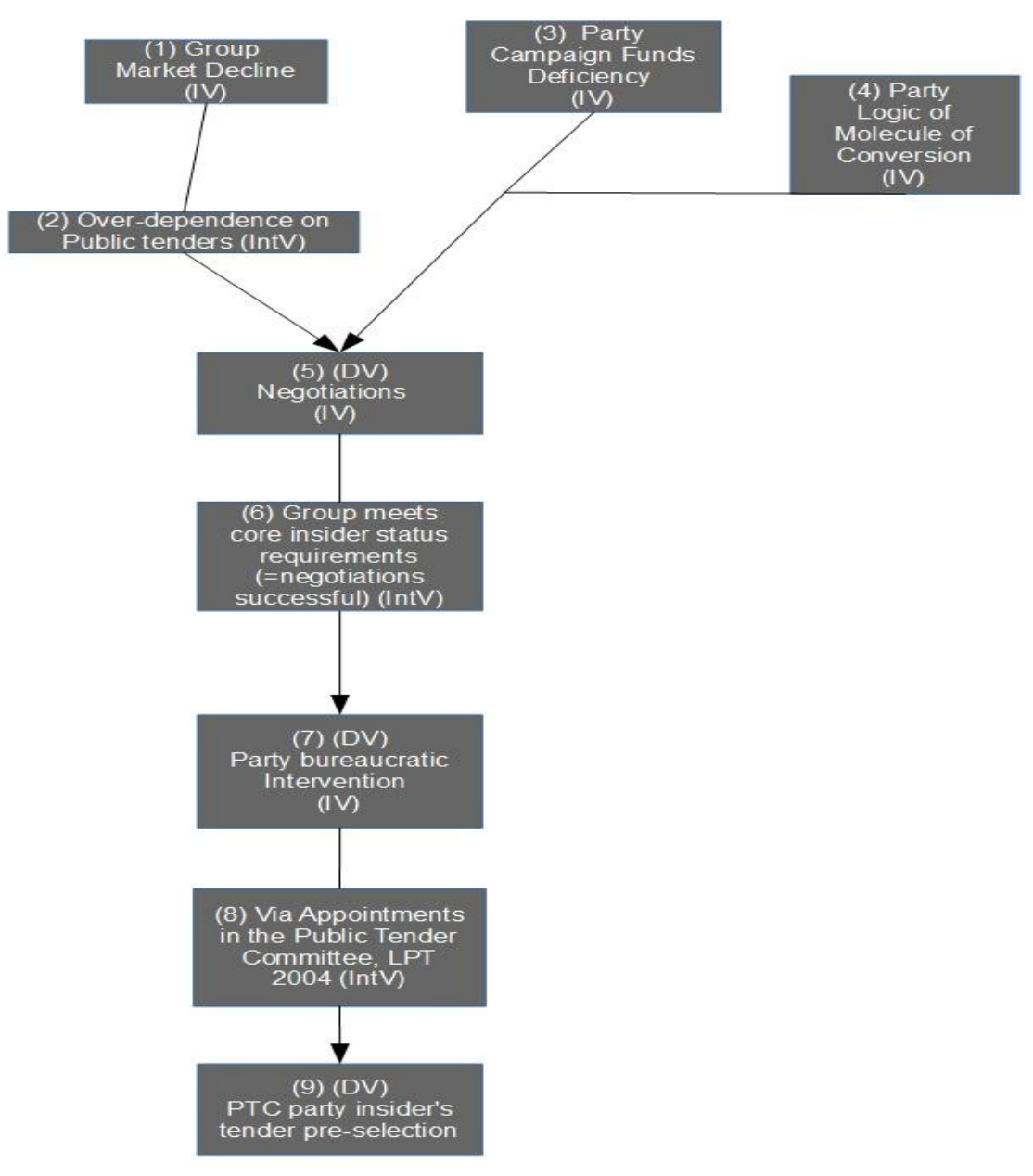

Figure 4 Parentela Formation Process in the LPT Case

A declining construction work market (IV, box number 1 in Figure 4) forces firms (groups) to seek negotiations (DV, 5) with the ruling party, with a view to improve their market standing. This is compounded by the fact that construction firms are heavily dependent on public tenders (IntV, 2). Simultaneously, a ruling political 
party's campaign fund deficiency (IV, 3) also causes it to seek out groups in order to exchange its access to policy making against campaign funds. Though much less pronounced, another reason why ruling parties also seek out groups for negotiations is the logic of the molecule of conversion (IV, 4), where party's access to policymaking is converted to business capital at party's disposal for the purpose of sustainable source of funds. This is more clearly visible in chapter 9. Both sets of Independent and Intervening Variables (1-4, Figure 4) above ultimately lead to an episode of party-group negotiations (DV, 5). Facilitated by group's qualities to assume insider status (IntV, 6 (also Chapter 6)), the successful negotiations (IV, 5) force the party to meet her side of the bargain, hence party intervention in the civil service (DV, 7). This intervention is not an end in itself (IV, 7) but leads to interference in the work of the Public Tender Committee (PTC) (DV, 9), whose task is to impartially decide which public tender offer will win the contract. In other words, facilitated by the ability to make party loyal political appointments in the PTC $(\mathrm{IntV}, 8)$, the party engineers the selection of the offer submitted by the party insider group (DV, 9).

In essence and except for the very first IVs (market decline and campaign funds), all of the above causal relationships and intervening variables reflect the characteristics of the parentela. Cooperative network dynamics: this is evident in fact that there is a form of exchange between the group and the party, which is locked in elements 5, 6 and 9. Balanced power ratio: this is implied by the fact that the party in power reciprocates a favour to the insider group (element 9). Group insider status is expressed by elements 5 and 6 , where a group is given access to directly negotiate with the ruling party, and as a result of the group meeting the requirements for being an insider group (element 6) the party seeks to reciprocate. Party primary venue is evident in the group first seeking to enter direct negotiations with the ruling party (5), and then have its interests met following party's bureaucratic intervention $(7,8,9)$. The fact that the ruling party intervenes in the work of the civil service, or the Public Tender Committee, to be precise, indicates that the party-group relationship spans from the party into the civil service. The significance of the Public Tender Committees is that they are part of the civil service structure and they decide the 
winders of construction tender auctions. The case demonstrates that through the use of political appointees facilitated by the Law on Public Tenders $2004(7,8)$ the party in power is capable of interfering in the work of the PTC, thus informally predetermining the party insider group as the winner of a given construction tender (9).

\subsection{Conclusion}

The purpose of the present chapter was to demonstrate a typical case of the parentela, which follows La Palombara's original description of the relationship. The case demonstrates the parentela with the controversy of who staffs the Public Tender Committees. First, according to the Law on Public Tenders, employers have to appoint experts to PTCs with expertise in the field of the public tender. If the employer organising the public tender is unable to find any from the list of intrainstitutional experts that they are obliged to maintain, those have to be recruited from the relevant sectoral peak association or from self-nominated individuals as experts. The crux of the matter is that an employer will never find themselves in the position to run out of experts simply because, in the absence of a clear criteria that specifies who counts as an expert, they can sign in anyone in the list of experts for PTC appointment. In doing so, party appointed experts specify the offer characteristics so that they match the profile of the desired, party insider, firm. This form of bureaucratic interference is at the heart of the parentela in the case of construction public tenders in this chapter. The following chapter will reveal a broader parentelarelated dynamics, also including additional set of dependent and independent variables. 


\section{CHAPTER 9: Parentela: Two Types or One?}

\subsection{Introduction}

Chapter 9 reveals a new party-group dynamic, which is similar to La Palombara's original parentela, described in chapter 8 . While this dynamic resembles a policy network, it is better conceived as an add-on to La Palombara's parentela. Essentially, a number of respondents reported that the party and its insider, or parente, in La Palombara's parlance, engage in confrontation with party outsider groups. Similar to La Palombara's original parentela, or type 1, for short, interviewees argued that political parties engaged in what they described as prejudiced regulatory inspections. These are forms of regulatory agency investigations of businesses, whose purpose is to incapacitate targeted businesses under the guise of regular inspection, which, say, the Fiscal Officers or Health and Safety inspectors would usually carry out.

So, facilitated by political appointments, regulatory agencies would target the market competitors of the party insiders with the intention to incapacitate their business operations. This is simply a mechanism available to a party insider group to deal with its market competition. Such prejudiced inspections, respondents claim, were also used by political parties. For example, the business enterprises that constitute certain interest groups that oppose certain governmental policies could be targets of such inspections. Internal party dissenters, too, could be brought back in line with such coercion, if those have own businesses. A third use of prejudiced inspections, according to some, was simply extortion of some of the more lucrative businesses. Some respondents argued that extra campaign funds could be generated when the party approaches suitable candidates and offers them the opportunity to collaborate in a public tender. In that case, we would observe a public tender of the kind described already in chapter 8 . If the approached business entity refuses the offer, they are punished with prejudiced inspections. It is this practice that is at the heart of type 2 dynamics. 
The main questions, then, are (1) whether the observed dynamic is essentially a new, discrete network and (2) to what extent does it relate to policy-making at all? On the first question, type 2 is best seen as an additional dynamic within and part of the parentela policy network framework. At the core of both types lay the same partyinsider core, the parente (in La Palombara's parlance). The dynamic which the initial parentela concept referred to was within the parente. Given the present research, however, we are now able to observe one additional dynamic, between the parente and outsiders. The addition of this new, second dynamic does not change the overall concept (La Palombara's parentela) but merely expands it. Both types concern a form of party interference in the work of the civil service. However, the only difference is that the party in a type 1 interferes in the civil service in order to extract legislative and policy benefits, or to provide deeper access to its party insider group. For example, the party can appoint a nominee of the insider group, or pressure its own bureaucratic appointees to heed the interests of its insider. In type 2, however, while the party also intervenes in the bureaucracy in the interest of its insider, such interference takes the shape of aggressive elimination of a pre-selected outsider businesses through what respondents described as prejudiced regulatory inspections.

On that last note, it then appears that this dynamic is unrelated to policy-making, and by an extension, to policy networks. While type 2 was reported as a mechanism of party insiders to parry their market competition, a number of respondents cast regulatory coercion in policy-making light. The party in power in particular can resort to this practice in order to pressure into submission policy dissenters. Interest groups that adamantly oppose a ruling party's (government's) policy can be coerced informally through prejudiced inspections. Likewise, internal party dissenters or otherwise opponents could be dealt with by targeting their businesses with prejudiced inspections. All in all, type 2 dynamics can potentially be used in the policy-making context, which means that this concept fills up the conceptual space between policymaking and political malpractice. 
Respondents indicate three main causes for type 2 parentela. First, and common to type 1 in chapter 8 , is insider's need for a better market standing or to beat the competition. That was first manifested in Chapter 8, where insiders sought to dominate construction tenders. However, interviewees reveal that this could be done by making one-sided offers to outsiders (an insider's market competitors) of, say, buying out their businesses. Alternatively, facilitated by political appointments, the third option is to directly interfere in their business operations through prejudiced regulatory inspections.

The second and third causes for type 2 dynamics relate to political parties. Given the need for funds (for campaigns or otherwise), they too resort by making similar offers to lucrative outsider businesses (groups), and they, too, may be coupled with the threat of prejudiced regulatory inspections, thanks to practice of political appointments. Finally, type 2 could follow from party's attempts at coercing dissenting internal party members or external interest groups. Those who oppose party's policies, depending on the gravity of disagreement, may be pressured into submission through incessant regulatory inspections.

Following the establishment of type 2, the present chapter also discusses the implication of both dynamics for Bulgarian democracy. While at first sight the extended parentela types of behaviour (type 1 and 2) appear to be cases of corruption, the available evidence suggests that these dynamics are part of the informal structure of the Bulgarian polity. The chapter looks at both dynamics from micro, meso and macro perspective. On a micro perspective, both dynamics appear as forms of corruption, while on a meso-level they appear as processes that lead to social and economic imbalances. Then on a macro level both dynamics appear to constitute an oligarchy. However, that is not entirely correct. There is no evidence of a single, stable elite minority that has usurped all policy-making. Instead, we have a number of competitive elites who occasionally are able to dominate policy-making some of the times but ultimately, given elections and prejudiced regulatory inspections, are in a constant state of instability and unable to consolidate an 
oligarchy. Therefore, both parentela dynamics together share oligarchic-like features but do not constitute an oligarchic community.

In order to discuss the above, the chapter will precede as follows. Section 9.2 will describe and define the second parentela dynamic. Section 9.3 will discuss the causes for type 2 in more details. Section 9.4 will discuss the validity of the findings. Section 9.5 will discuss the implications for Bulgarian democracy. Section 9.6. will discuss the possibility of an influence coming from the EU instiutions, before concluding in section 9.7 .

\subsection{Understanding Type 2 Parentela Dynamic}

Type 2 parentela dynamic (also type 2 parentela, or simply type 2 ) could be better understood when compared to La Palombara's original parentela dynamic, or simply, type 1 . In order to make such a comparison, the discovered type 2 dynamic in this section is "converted" or explained in terms of a policy network, employing the network descriptors developed earlier in the thesis. The comparison reveals great similarities between type 2 and type 1, which indicate that type 2 is best classified as an add-on dynamic, which is part of La Palombara's parentela policy network. This new dynamic fills up the conceptual space between the original parentela relations and political malpractice, without constituting a new discrete network type. If La Palombara's parentela focused on the relations between the party and a privileged group (insider), type 2 parentela (dynamics) focuses on the relations between an outsider with the party and its insider group combined (i.e. the parente).

The existence of a second dynamic was first detected in the answers of two of the earlier respondents in the study: Golemanov and Kuzmanov. Quite remarkably their mutually independent thinking was identical in distinguishing between types 1 and 2 dynamics. They accept that parliamentary elections act as an external shock to the existing party-groups relationships. But more importantly and similar to Chapter 8 , they revealed that insiders could gain better market standing in three ways. The first one is by dominating public tender decisions, which was reviewed in Chapter 8 . 
Second, an insider could further gain market advantage by absorbing its competition through what appears to be prejudiced regulatory inspections. On the surface these are inspections of market regulatory agencies, some of which in reality are used as a "weapon" of incapacitation of the party insider's market competitors. Such dynamic also often comes into place in the context of what some respondents called an offer of cooperation. The offer is an informal communication either from the party, the party insider or both, which requests the targeted firm (outsider group) to discontinue its market operations against some form of compensation - usually to transfer firm's ownership to the party insider. Refusals to such an offer are met with deleterious inspections by the regulatory agencies, which are mobilised by the parente. Such prejudiced investigations are a convenient instrument to eliminate business actors because they within the law and immediately require the investigated business to stall all business transactions. In a turbulent market, halting operations for a long time means that a firm would irreversibly lose its market share and risks insolvency.

Quite curiously the views of both respondents on the party-interest group relations in Bulgaria overlapped with the initial, type 1, parentela dynamic of La Palombara. Respondent Golemanov argued that Bulgarian elections are an opportunity for the formation of a new close party-group relationship. Using the Bulgarian circles as the epitome of these dynamics, he argued that ruling parties are the natural center of gravity for many individual business players who are eager take advantage of their possible privileged intra-party standing. Vice-versa, political parties are equally open for such possibilities, as long as there is a mutual benefit. The deal between the two is while the party provides some form of market advantage to the given business actor (the insider), the latter would give something in return.

Moreover, further along the lines of parentela, Golemanov argued that it is part of the party-insider deal that the latter nominates their own, trusted proteges for appointment by the party as key civil servants or vice-ministers. In his view, at the heart of politics lays the battle for appointments:

S: $\quad$ So, you have...

$R: \quad$ linterrupts/ a battle for that appointment [...]. Say, lenacting theatrically/ "If Mr. X gets appointed, I will be fine, and my firm will be 
fine! If not, there is a chance they will "draw the knife on me". For example, the construction of highways. The most tolerated firm in our region is Hidrostroi! Hidrostroi, if you notice, in the presence of Avtomagistrali Cherno More - who possess immeasurable resources, Patno Stroitelstvo Shumen, and the firm BAS - the three of them are from Shumen [and are out], while Hidrostroi is from Varna. Second, the entire winter [road] maintenance is from Hidrostroi. Here is one example of one firm being tolerated.

Golemanov essentially describes type 1 parentela from Chapter 8 . He identifies Hidrostroi as the local insider firm known for its staggering track record of wining local construction tenders. But that is thanks to their ability to negotiate access with a sequence of ruling political parties on a local level. This is nothing different from those economic network members who successfully orient themselves to every new political network in power, as per Kuzmanov. All in all, both respondents so far describe the features of type 1.

However, not only do both respondents converge on the classical parentela dynamics, but they also converge on an additional dynamic that emanates from the parente. Both respondents indicated the existence a new, conflictual dynamic between the party (plus insider) and an outsider group. For example, Golemanov concluded his elaboration on Bulgarian politics with the suggestion that such a dynamic is rooted in the party-insider parentela core:

But to establish this circle of [privileged] firms, you need to remove the competition and to create monopoly. /You mean to eliminate the other circles --S/ Precisely! Well, not exactly, but to parry them. To parry them! Hence, battle for political power. You use state power for personal interests $[\ldots]$

The respondent's hesitation on the meaning of remove the competition implies some form of pressure on third actors, i.e. the market competition of the party insider group. Note, however, that in his statement on political appointments of insider group nominees that the mentality of those groups vying for party insiderness, if the competition is lost, they will "draw the knife on me", implying the losing, party outsiders, might suffer as a result. What is actually meant behind this veiled expression of the seeking political correctness Golemanov is revealed by Kuzmanov. He too stated earlier that somehow the ruling party and its insiders, or in his parlance, the political networks are in the position to overpower the economic ones 
(emphasised string above). Kuzmanov states that while the common state of affairs between insider groups and ruling political parties is that of an exchange (9.3.1), parallel to that, there are more conflictual dynamics that might befall outsider groups who refuse to cooperate with an expanding political network in power, i.e. the offer of cooperation of the party or its insiders $(9.3 .1,9.3 .4)$ :

$R[\ldots] \quad H o w e v e r$, there are some who have said, "I will not pay them any more" and naturally that is bad for them. In the frame of a few years they (parties, sic) can [purposefully] destroy his business using legal means. [...] What you observe now is precisely that. While the previous [political parties] have given preferences to some businesses and the latter pay back, [... a] t present, they are destroying businesses. Say, you have business which is "of interest" and they make you an offer [...] to which you tell them to go to hell. After that strange legal things begin to happen to your business until a point where you cannot function any longer. You then either sell out or go bankrupt.

$S: \quad$ Who makes the offer?

R: $\quad$ You can never go back and identify the chain of individuals and say: "Here, that one made the offer and he is connected to that one". Everyone knows that those men are connected lemphasises/, but this is impossible to prove. If after all by accident someone decides to prove said relationships, [they will] get fired.

This dynamic is essentially what Golemanov stated earlier that as soon as a new party goes to power and as soon as it recognises its insider group, the latter begins to expand its market presence. This offer is simply a peaceful attempt by the party insider to expand its market shares, namely, by forcing the competition to sell its business to him.

Towards the end of the excerpt above the interview becomes quite cryptic with regards to the nature of the offer. As section 9.3.1 will demonstrate, the offer is an informal request made by a party insider onto an outsider business owner to transfer ownership of the firm to the insider (Varbanov) or some other form of market elimination. If the offer is made solely by the party in power, it could be an offer to ensure that the target outsider is granted a public tender, in exchange for redirecting some of the public moneys paid for the tender project to the party (Rumenov, Dobromirov). As Kuzmanov however emphasises, the offer comes from the locus of the party in power (Kuzmanov):

S: $\quad$ Is the origin of the offer political? [...] 
R: $\quad$ Entirely political. I am telling you again: We have had periods as with the government of Berov, or that of Videnov, if you will, when the economic actors pursued their interest /unintelligible/ [but] they were interested only to take for themselves. They were disinterested in the politicians. However, there is another scenario [...] where the politicians exert powerful pressure on business one way or another - the whole is motivated politically. And I am saying again, how could you explain [seeing] a struggling businessmen rush to enter politics?

$S: \quad$ To protect their business?

R: $\quad$ And to expand it [...] therefore it follows that the political network dominates over the economic one.

According to him, while in the past business groups may have been in a more favourable power position vis-a-vis ruling parties, this is no longer the case. Political parties and their insiders today are in the position to eliminate businesses through the use of prejudiced regulatory inspections. This is the label given to the practice of elimination of businesses under the guise of a common regulatory agency inspection, when in fact, the ulterior objective is to sabotage the business in the interest of the party insider. While Golemanov only implies that the ruling party and its insiders can harm the political and market opponents of the parente, Kuzmanov is more explicit and states that this is through litigation and inspections.

This is the essence part of type 2 parentela dynamics: it is the conflictual relationship between the combined party and insider on the one hand (parente), and an outsider group, on the other. In terms of policy network classification, type 2, however, is not a new policy network type but an extension of the existing parentela (type 1). What is tentatively labeled type 2 is essentially the same party-insider core of La Palombara's type 1, which is why it is the same network. However, prejudiced regulatory inspections (the essence of type 2) add new dimension to the parentela relations: the parente and outsiders.. Yet, in order to better analyze it in comparison the parentela, type 2 parentela dynamics can be expressed as a policy network. Thus, in terms of, network dynamics and power ratio, therefore, this is a conflictual network where the policy-making side, i.e. the parente, overpowers the outsider groups. The ability to make appointments in the civil service allows the political appointor the ability to mobilise the entire regulatory and security state apparatus against select groups or individual businesses. Section 9.3 exemplifies the inability of targeted groups to 
resist the State. As the minister at the time of interview, Hristov, argued - no actor is stronger than the state, so long as the latter has full control over its agencies. The dynamics inherent to type 2 parentela are described in Table 21 below:

\begin{tabular}{|c|c|c|c|c|c|c|c|c|c|c|c|c|c|c|c|c|}
\hline \multirow{4}{*}{$\begin{array}{l}\text { Type of Policy } \\
\text { Network }\end{array}$} & \multicolumn{16}{|c|}{ Descriptors } \\
\hline & \multicolumn{3}{|c|}{$\begin{array}{c}\text { Degree of } \\
\text { Access to PV }\end{array}$} & \multirow{2}{*}{\multicolumn{2}{|c|}{$\begin{array}{c}\text { Network } \\
\text { Dynamics }\end{array}$}} & \multirow{2}{*}{\multicolumn{3}{|c|}{ Power Ratio }} & \multirow{2}{*}{\multicolumn{4}{|c|}{$\begin{array}{c}\text { Primary Venue } \\
\text { (PV) }\end{array}$}} & \multirow{2}{*}{\multicolumn{4}{|c|}{ Scope of Venues }} \\
\hline & \multicolumn{2}{|c|}{ insiders } & \multirow{2}{*}{ 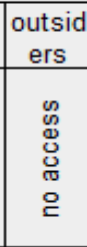 } & & & & & & & & & & & & & \\
\hline & ڤั & 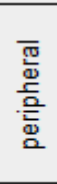 & & $\frac{\underline{\underline{U}}}{\mathrm{C}}$ & 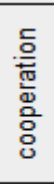 & 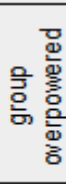 & 屁 & 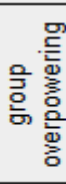 & 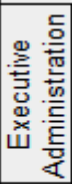 & 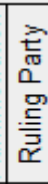 & 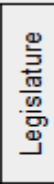 & 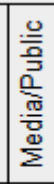 & 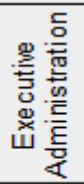 & 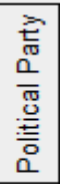 & 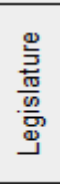 & 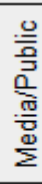 \\
\hline sub-governments & $\mathrm{X}$ & & & & $\mathrm{X}$ & & $\mathrm{X}$ & & & & $\mathrm{X}$ & & $\mathrm{X}$ & & $\mathrm{X}$ & \\
\hline policy community & $\mathrm{X}$ & & & & $\mathrm{X}$ & & $\mathrm{X}$ & & $\mathrm{x}$ & & & & $\mathrm{X}$ & & & \\
\hline prisoner insider ${ }^{*}$ & $\mathrm{X}$ & & & $?$ & ? & $\mathrm{X}$ & & & $\mathrm{x}$ & & & & $\mathrm{X}$ & & & \\
\hline clientela & $\mathrm{X}$ & & & & $\mathrm{X}$ & & & $\mathrm{X}$ & $\mathrm{x}$ & & & & $\mathrm{X}$ & & & \\
\hline issue network & & & $\mathrm{X}$ & $\mathrm{X}$ & & & $\mathrm{X}$ & & & & & $\mathrm{X}$ & $\mathrm{X}$ & $\mathrm{X}$ & $\mathrm{X}$ & $\mathrm{X}$ \\
\hline Parentela & $\mathrm{X}$ & & & & $\mathrm{X}$ & & $\mathrm{X}$ & & & $\mathrm{X}$ & & & $\mathrm{X}$ & $\mathrm{X}$ & & \\
\hline Type 2 Parentela & & & $\mathrm{X}$ & $\mathrm{X}$ & & $\mathrm{X}$ & & & & $\mathrm{X}$ & & & $\mathrm{X}$ & $\mathrm{X}$ & & \\
\hline
\end{tabular}

Table 21: Table 21 Classification of Type 2 Parentela

Again, sharing the same core of participants with La Palombara's parentela, the table above raises the question of whether to classify type 2 parentela as a genuinely new network type or as an adjunct to the parentela established by La Palombara (1964)? The chapter leans towards the latter. La Palombara focuses on the dynamics within the parente, i.e. between the party and its insiders. Type 2 on the other hand focuses on parente's relations with outsiders. Therefore, type 2 is an extension or an add-on to La Palombara's original parentela policy network dynamics. It describes the aggressive dynamics between La Palombara's parente and select outsiders but does not constitute a new policy network in itself. That type 2 is not a discrete network is evident by expressing type 2 in terms of the network descriptors.

The purpose in this section was to elucidate the new concept before discussing it in causal terms in section 9.3, where four independent variables will be reviewed as explanations for the emergence of type 2 parentela dynamic. 


\subsection{Behaviours within Type 2 Parentela Dynamics}

Section 9.3 explains why political parties and/or insiders enter a conflictual relationship with outsider groups, i.e. type 2 parentela dynamics. There are three reasons for that. Party insiders engage in type 2 to gain a better market advantage, which manifests in three forms. First, this is by monopolising public tenders, which was already discussed in Chapter 8. The second form is by making insider's competitors (outsiders) a highly disagreeable offer of cooperation, which ultimately drives them out of business in the long term (9.3.1). Third, such an offer is usually combined with the third form of gaining market advantage - the threat of prejudiced administrative inspection, which can also be employed irrespective of the offer (9.3.4).

The offer is interesting because it is also an instrument of the ruling party to put pressure on outsider groups primarily as a result of the logic of conversion (9.3.1). This appears to be a residual dynamic from the disintegration of Chalakov et al's (2008) molecule of conversion - a sociological network in early 2000s. The logic of conversion stands for party's informal generation of additional funds, some of which could be used for campaign purposes. Political parties, too, like their insiders, offer one-sided public tender bargains to outsiders, where the latter is guaranteed a public tender in exchange for giving back some of the moneys dedicated to public project's completion. Outsiders too can be threatened by the party with direct regulatory inspections, crippling their businesses, if they refuse to cooperate. Furthermore, the needs to suppress internal dissent (9.3.2) and to quell external group policy oppositions (9.3.3) are the other two reasons why a party would engage in type 2 with outsiders.

All in all, section 9.3 explains type 2 and what leads to the situation where regulatory agency inspections are used as an implement of repression both by the party and its insiders. Again and though ultimately legal, the purpose of inspections is to disable the business operations of the targeted firm (outsider) mainly by rescission of any licenses of operation or formally identifying administrative offenses that are then 
used as grounds to take immediate legal action. These dynamics, labeled here prejudiced regulatory inspections are at the centre of attention in type 2 parentela and section 9.3 .

\subsubsection{The Logic of Conversion and the Offer one Cannot Refuse}

Figure 4 in Chapter 8 addressed the work of Chalakov et al (2008) and their sociological network molecule of conversion. Their model was discussed in sections 1.4.1 and 1.4.2. The main idea behind that network was that many individual policymakers from the ruling political parties, during Bulgaria's transition to full free market economy, sought to convert their access to policy-making in economic capital. A similar idea of conversion is already present in the Western literature on policy-networks stressing on the exchange nature of the policy-network participants, including civil servants (2.2). However, Bulgarian sociologists emphasise that the conversion they observed was geared not so much towards exchange of policyresources, which will help with policy-drafting and -implementation, e.g. expertise (in policy community). The purpose of the exchange was to set up party-subservient businesses, which the retiring nomenklatura and sponsoring political party(ies) would benefit from long term.

While this study cannot provide firm evidence of the existence of the molecule of conversion, it can certainly identify similar logic of conversion in respondents' description of political parties' behaviour. Kuzmanov argued that groups seek political parties in order to improve their market standing, but at the same times parties, too, proactively approached groups to find ways to monetise their control of the policy-making process. Similar is the position of Golemanov when he used the phrase "feeding rack" which describes firms as subordinate and highly dependent on political parties for their benefits and whom they "later pay back", or in other words reciprocate with electoral contributions. On that occasion, Golemanov also implied some form of party enrichment, separate from campaign funds-related exchange. Kirilov stated that at the turn of election, hitherto insiders might be superseded particularly by firms owned or under the control (somehow) of active politicians. 
This directly overlaps with the molecule: a business owned by active party functionaries.

In fact, Petrov's account provides closest evidence of the molecule. The respondent described a situation in the timber sector, where the local administrative units, acting as monitors and regulators of timber extraction and sales, legally assumed the powers to act as timber market participants, as well. Following the practice of political appointments and the fact that those state/private entities were controlled by the party in power, Petrov suggested that the market revenues could be used for any party purposes, including campaign financing. Therefore, while the network of the molecule does not exist, the thinking which created it still does. The evidence above demonstrates that parties seek to convert policy access into economic capital for party needs, part of which could be to finance political campaigns.

And finally, it is this logic of conversion that partially explains the conflictual relationship between the party and outsiders. Motivated by the need to convert their policy resources into capital, political parties can be proactive in some cases by initiating negotiations with individual outsider companies, whom they make an offer. Respondents stated that the offer is usually an assurance that the invited outsider will win a public contract, however against splitting with the party a fraction of the moneys dedicated to the execution of the public tender project. This is what many respondents described as the offer you cannot refuse. Kuzmanov, Rumenov and Dobromirov argued for the existence of such offers and their purpose, so far as the party is concerned, is to generate funds by forcing a suitable group into cooperation, usually by influencing the outcomes of public tenders. On other occasions, such offers came from party insider groups, who presented the outsider with two options: transfer their assets or company ownership to them against some monetary compensation. The motivation of the insider group in the latter case is the same as in chapter 8: to improve its market standing by buying out its competition (discussed thoroughly 9.3.2). 
However, in in any case, an outsider's refusal to the offer of the party or its insiders leads to a conflictual relationship with the ruling party as the control centre of regulatory agencies, i.e. type 2 dynamic. A refusal of any such offer is followed by regulatory inspections, whose purpose is, to be blunt, to drive the targeted outsider out of business. Dobromirov stated with relief the fact that they had worked at a loss for the past 5-6 years which saved them from being approached with any offers. Rumenov, however, was not that lucky. Operating at a net profit of millions of leva, Rumenov was approached by an envoy of the ruling political parties who directly offered him the opportunity to win a fuel sector tender (which was pending public announcement) against giving back a fraction of the state budget dedicated to tender's execution. That would have been party's fee for doing this favour to Rumenov. As a result of respondent's refusal, he subsequently had to undergo a sudden barrage of inspections. Given its importance, the account of Rumenov is quoted at length in order to demonstrate its authenticity (party's offer of exchange is emphasised below):

$R \quad$ But I can tell you what happened exactly lyes $-S /$ if you are interested more specifically /yes, yes, yes $-S /$. What happened when the new party came to power/rhetorically/? So, a representative of a given party central attended the firm and introduced himself and said "We have reviewed your firm as a suitable economic subject over which we can put an umbrella and calculating the economic interests, there are benefits for the respective party as well." That is. Those were party $B$ and A. And now, what happens when you decline, /rhetorically/, as I did. My question was "This party configuration at present, how long is it going to rule: until New Year, until May, the whole mandate?" [the reply was] "However long we can last, as far as we can make it." And I said, "Fine, but my firm is 20 years old and so far I have not had such attacks to participate in the circumvention of the law, crudely put, contraband and such things. I have not had such problems and I do not intend to." $[\ldots]$

$S \quad$ It is interesting for me when that representative came, what did he have in mind by saying "an umbrella"?

RThis means the securing of exclusive access to public tenders. In Bulgaria there is no stock exchange market for public tenders. It is fictitious. You just go shopping there. You go in and say, the Ministry of Internal Affairs (police) is seeking to purchase fuel for [some] prisons or whatever, and they tell you for instance that "The respective contract is 5 million leva [and] if following the market prices, you will win 100 thousand leva. However, we will increase the price for delivery with $20 \%$ and you will give $40 \%$ of the total profits back to us, and if you agree. 
you will take the tender". This is what was meant: $20 \%$ for the plavers, $20 \%$ for the party coffers. This is only half of the story. The participation - whatever it is - in the Public Tenders /self-interrupts/ even now with my partner, my son, /inaudiblel there is a new tender coming up tomorrow on the stock exchange market for public tenders. It is about the delivery of fuel to army airplanes for 6 million leva [but] with the stern warning [against me]: "Careful what you are doing. Make sure you are not seen here because heads will fall”.

In short, with the change of government, the respondent was approached by a representative of the ruling political parties at the time with the offer to become a core insider and be privileged in the competition for public tenders in the fuel sector. In this offer, what they have to do in return is give back to the ruling party a fraction of the budget they will receive to carry out the tender. In the case of Rumenov, as far as the party is concerned, the proposal for targeted grant of public tenders provides it with the opportunity for additional sources of finances. In this party offer, the price for the completion of the project is artificially increased with $40 \%$. However, while the costs to the prospective target contractor will remain the same, they will have to give $40 \%$ of the total budget that they will receive back. These $40 \%$ will be split between the party central and those who facilitated the deal.

The quotation above (253-254) also corroborates the dynamics outlined in the case of LPT (chapter 8 ) because it provides evidence of the link between party bureaucratic intervention and the outcome of public tenders. It also shows the importance of new elections as an external shock to pre-existing parentela relations (as per sections 7.3). However, the emphasis here is that the party initiates the negotiations and that a refusal to cooperate leads to repercussions, i.e. type 2 dynamic. Rumenov was barred from taking part in fuel-related public tenders with the direct threat that "heads will fall". On that point, he continues (emphasis added):

$R \quad$ They have organised against me, as soon as I declined, those [men] organised all of that against me. I was now a bit late for the interview because of the commission at the State Reserve is investigating me for a second day now. [...] Now on Monday, the state transport inspectorate (STI) will come because I have 15 trucks and the STI decided to check the itineraries [...] and whatever you can think of, despite the fact I have never been caught in an offense, neither me or my drivers, that relate to the Laws on State Automobile Inspection, the Movement on the Roads or on the Transportation of Dangerous Cargoes, but all possible instances (agencies) were sent, to show me that "Since 
you are not one of us, you are against us." [...] Ever since then, all possible state regulatory agencies - all lemphasises/ - such as the agency on the environmental protection, on labour protection, fire brigade, customs, labour inspectorate, auto-transport inspectorate, [agency on] emergencies and natural disasters, everything that you - the State Reserve lexclaims/ - think of. Total inspections, all day long! With the sole aim to justify the issuance of an Act of Misconduct - whatever it is: overt, covert or whatever. This is the situation in Bulgaria at the moment. [...] [According to] the Law on Excise and State Storage, with three such Acts of Misconduct one is in danger of being suggested for the rescission of hitherto granted license of operation. So, the excise department of Sofia Customs is holding me constantly with two such Acts (of Misconduct, sic) which I fight successfully in court, but in their place new ones grow like mushrooms for all sort of absurd reasons entirely devoid from fiscal considerations, that is, not because I evade taxes.

In short, the respondent above explains that the number of agencies that were sent to inspect his businesses is in an avid response to him refusing to engage with the party in power in biasing the outcome of fuel tenders in his favour for mutual gain. The message is simple: either with us or against us.

Dobromirov also confirms the practice of parties pro-actively offering select groups an insider type of exchange. Just as with Rumenov, he also expressed the common position of his construction peers that it was those "intelligent men" who made visits on behalf of political parties. According to Dobromirov, political parties and their insiders usually study a firm (outsider) for overall profitability before an offer is made. If it is declined, the targeted group can only expect vociferous inspections from all regulatory agencies, particularly tax and police. In these unusually strict inspections, civil servants look for all sorts of minor or major offenses which almost always lead to court cases or license revocations. Sudden police raids for illegal software are just the beginning.

Similar to the offer made by the party in power, Varbanov reported being made an offer by a party insider group also working in the field of construction. In his case the offer acted as a condition to participate at a construction tender of a section from a highway. If Varbanov wanted to win the tender, he would then have had to sign off half of his firm away to the insiders. While he did not report any repercussions on their business as a result of that, he strongly agreed with the argument in principle 
that state agencies are used by political parties and their insiders to destabilise the outsider businesses with a view of absorbing them.

The accounts of Varbanov and Rumenov on an offer made by party insiders is similar to the accounts of another respondent set, who without being offered anything, saw themselves as the victims of regulatory inspections coming from well-connected party insiders. They are discussed in section 9.3.2 below.

\subsubsection{Insider's Direct Intervention against Outsider Market Competitors}

The third form of insiders' drive for better market positioning which explains type 2 parentela dynamics comes from respondents who claim to be victims of their wellconnected competition to oust them from the market through severe regulatory inspections. The director of a trade association, Petrov and their co-director (denoted R2) deserve special attention. Congruent with Donchev, they argued that all amendments in the standards and licensees can be used by party insiders as a mechanism to beat the competition. According to this view a party insider gains advantage over the competition by using their access to the party and civil service to influence a change of licenses and standards, so that only the insider group meets the new standards, hoping the competition that finds it hard to adapt exits the market (also a position advanced by Donchev).

However, more importantly, in addition to being sectoral representatives, they were also owners of timber companies. They explained that with the change of government, unusual regulatory activity began in their sector around 2005 until the point their firms were put under continuous and stringent tax inspections. Very much like Rumenov, Petrov and his colleague noted that despite their best attempts to cooperate with the regulator, the latter remained adamant and determined to precede with litigation. However, eight years prior to the interview, the court cases are still ongoing with no verdict and with crucial documentation on the case, the respondents argue, deliberately hidden from them. At the time of interview, they were looking into suing the Bulgarian state in Strasbourg. They argued that the absence of firm 
evidence of wrongdoing against them indicated that the inspections were ill-intended to oust them from the timber market.

Mihailov also argued that his only competitor, oligarch Q, was behind some of the regulatory investigations against his business. Unfortunately, that particular respondent was adamant that recording be stopped, save for eight minutes. From the little he shared the mechanism used in Q's attempts to beat him was to use his access to the regulatory agencies in order to rescind Mihailov's license of operation. (On that note, Kirilov also commented that this is one tool from the instrumentation on how to eliminate undesirable business actors.) However, after the change of government, Q in turn became the subject of regulatory pressure, with arrests and police raids, as a result of a personal quarrel with the new government (Mihailov). Independently from Mihailov and each other, Kirilov and Kuzmanov shared the view that said police activity related to $\mathrm{Q}$ was devoid of any legal wrongdoing of his, but was politically motivated as a form of personal retribution. Note that Rumenov argued that police raids and arrests are the first line of pressure against a business that has lost favour with the ruling party. The accounts of Mihailov demonstrate two points raised earlier. First, that the civil service could be used to take a hit at one's market competition. And second, that the civil service is also used to deal with policy and political opponents. (And possibly a third point, namely, that insider access is fluid and that a party change can make one insider into an outsider)

Respondent Hadzhiev, too, argued that the use of regulatory agencies against certain businesses were in fact a sign of conflict between the party insider and outsider businesses. He argued instead that not police raids but that the main weapon is tax investigations. Along the same lines, respondent Stoyanov argued that the undue regulatory investigations did not necessarily originate from the party. He disbelieved his own importance stressing his very strong suspicion that his competitors use their access to the regulatory agencies provided by a faction within the ruling party to instigate tax investigations against them.. In conclusion, possibly Nikolov provided the best summary of the type 2 parentela dynamics and the variety of mechanisms 
used to pressure outsiders, akin to racketeering (timestamps are provided to accentuate on the four second silence of the respondent at 5703):

$5651 \quad R \quad$ /repeats to himself/ "Otherwise how could they destroy you?" They don't give you any tenders, they close your markets, they send you control organs (regulatory agencies, sic) -

5703 /Respondent becomes silent/

$5707 \quad R \quad$ You stop him from everywhere.

$5714 \quad S \quad$ How can they take your markets away from you?

$5717 \quad R \quad[\ldots]$ when they send a Financial Revision team to you and, say, when they claim that you owe them 10 million Euros or Leva, whatever it is. This kills. This is deadly. [Because, g]ood luck trying to prove in court in the next four years that you actually do not owe that money, and you will prove it indeed but you would be done for. In practice you lose your market share because you cannot sell, as [during litigation period] your bank accounts would be frozen, [and] there would be a thorough description of your storages, machines and so on, and this is how you go bankrupt.

$5752 \quad S \quad I S$ it possible to survive in the market without having to cooperate with the parties.

$5803 R \quad$ Possibly there are many people who win their bread honestly and succeed to support small and middle size enterprises. [...] but in principle, they are so few that in a city like [the one we are currently in] these are no more than 20-30 firms.

$5827 \quad S \quad$ Some of the previous respondents used the term "racket" on part of the state. I do not understand this. What would they have in mind with "racket on part of the state", and that is why I asked that (previous) question.

$5844 R \quad$ /repeats, annoyed?/ "racket on part of the state" /unintelligible/ Someone comes in here and registers that - say they came from the fire brigade - and they tell you: "The fuel tank is improperly fitted, your liquid gas tank is too close to the road, etc." But the fact that they had earlier given you the license and permission to sell fuel is of no relevance at all, because in the end they order you to stop all sales. You then are forced to relocate down the road but the costs to do that would be prohibitive. If you try to figure out the weak spot of a business in this way, you will always find something.

Nikolov clearly demonstrated hesitation whether and how far to disclose, evident at the 5703 timestamp. Nevertheless, he took a decision to share some information, even though he couched it in as neutral phraseology as possible, expressed in terms of a model and dynamics. The statement of Nikolov describes the type 2 parentela dynamics in its totality and is what is taken here to represent the core dynamic of 
type 2. It is the deliberate use of inspections from the regulatory agencies to either drive a business competitor out from the market or pressure them into party political submission using prejudiced regulatory inspections. The statement also combines the rest of the elements of the parentela that have been implicit in the reviewed respondents' statements so far. These are namely political appointments and close party-group cooperation.

\subsubsection{Internal Party Dissent}

Another explanation for the type 2 and its conflictual party-group relationship is its use as an instrument for retribution against party dissenters or intra-party opposition. Respondent Golemanov spoke from personal experience. He intimated he sought to speak their mind on numerous occasions in front of the local city council meetings, however, outside the party hard line dictated by the party headquarters. While also having a business and a few years spent in intra-party friction the respondent was subjected to ruthless tax investigations. Speaking in agreement on the use of the state administration as a tool of repression against internal party dissent, Kirilov gave an example a more recent example with a different political party:

$R \quad$ It is like the seduced and the abandoned and those abandoned from [party S] are doing tricks one against the other. That is, until yesterday you had been in the group of the anointed ones [of those who] had been crushing businesses, and taking it away from others, and that you had intimidated their children is of no concern to you because you are on the side of the victor! And you do not notice this, you only smile. But in one moment, however, they make the lists [of parliamentary candidates] and you are kicked out. And then you say, "OK fine, but what we had been doing to the others until yesterday will be done unto me tomorrow, because I am no longer close to the premier. I have now become equal to the rest. I am no longer part of the strong, of the good and righteous"

In other words, crushing businesses, or purposefully pressuring business with investigation, can be used against dissenting party members. It should be noted that the statement sounds exaggerated somewhat with the claim that business is "taken it away from others". Nevertheless, the statement bears the mark of intra-party repercussions under the guise of regulatory inspections geared towards eliminating businesses out of the market. 


\subsubsection{External Group Dissent}

Another form of using type 2 dynamics as a result of the need to punish relates to those outsider businesses that are members of business-representative interest groups who oppose the policy of the party in power. Respondent Hristov hinted that not always do professional representative bodies voice the grievances of their members at the civil service forums. They rather begrudgingly admitted that some groups refrain from voicing their problems for fear of repercussions. Respondent Donchev was adamant stating the same argument. According to him, there is a reverse pressure from the ruling party back on interest groups:

$S \quad$ In the context of the state administration and interest groups, does the state administration provide a more effective access to the policy-making process than the direct contacts with the ruling party? $R[\ldots]$ the representation of business in its standard forms is to some degree well structured, [yet] it is empty from any contents. That is, a huge part of the business organizations are also captured and they are not independent in what they say [...] because they are connected to the ruling parties in one way or another and with ruling politicians, or even if they are not directly connected they are highly considerate lof ruling party's position]. In the moment in which they are considerate not with the interests of their members but with what the Power (government) wants, they are not authentic representatives of business' interests. [As a result], to a great extent the classical tripartite dialogue suffers because business managed to create/self-interrupting/ I mean I am personally dealing with this project 7-8 years, there was a lot of authentic and strong representation [but] later after a line of a series of attacks that business organization was practically diffused and broken.

$S \quad$ What were the attacks?

RAll sorts, against the director, attacks on the members /Media attacks? --S/ Media, tax investigations, the whole arsenal. From the means of pressure /pause, self-interruption/[from] the beginning of Transition [the intention] was exactly that, to have fake participants from the civil society, fake NGOs, fake representatives of Labour, syndicates, fake business representatives, fake media. Everyone who took part in the debate had to seem independent, but in fact they had be controlled from one and the same centre.

According to Donchev in other words, interest groups have two options: to brace for a parentela type 2 conflict or appease the government on legislation that they disagree on. At the same time, the emphasised thread in the quotation above indicates that another strategy of the ruling party is to reciprocally appease the dissident interest group's leadership by offering them privileged deals. This is not stated 
directly but it is a probable implication given the practice of making offers one cannot refuse.

As if to deliberately support the position of Donchev, Rumenov stated at the start of his interview that he deliberately refused membership in the Gas and Petroleum Association because he felt it did not protect his interests, but those of the colluded interest groups and party leaderships. Rumenov was particularly disgruntled:

$R \quad$ My business, this is the gas and petroleum association, these are selected/self-interrupting/not all of us are members in these things, traders and players in this business. Well, there, the party in power and the legislative structures select who to be a member in this interest group (responded used the term interest groups, sic). Discussing the legislative changes with the group and other normative and sub-normative (primary and secondary legislation, sic) a hidden interest is pursued of a lobbying group. Everything in Bulgaria is subjugated to that. [...] So, in the trade associations, only those directors are elected who are convenient to the respective parties in power. And from there on, they play together. Noone explained, for instance, where businesses would find money for the increase of the minimum salary [...]

The position of Rumenov also reveals the two options interest groups' leadership face when dealing with the party in power. First, either collude with the party leadership and allow to be seduced (as per Kirilov), or, second, try to oppose the policies you disagree to and be put under tremendous amount of pressure public and private, as per Donchev. Respondent Nikolov, too, advanced the same discontentment from the work of Trade Associations, arguing that they collided with political parties into a "select society". Also, the role of such groups was to facilitate the party to stay in power. Of course, the present study is only able to register these relationships as opposed to assess their scope. However, what transpires is that party's ability to appoint in the civil service is to use it as a tool of repression against groups, both inside and outside party structures. Moreover, this is true for all political parties. No respondent made an explicit identification nor claim that this peculiar use of regulatory inspections belonged to a specific political party. 


\subsubsection{Type 2 Parentela Dynamics Causal Summary}

In conclusion, let us review figure 5 (p. 264) below, which summarises the causal relationships above in visual form, similar to the approach in Chapter 8. In figure 5, the elements pertinent to type 1 parentela, outlined in Chapter 8 are in gray, while the elements relevant to type 2 are in blue. Elements (1), (3 and 4) are shaded in blue and gray to signify that they are relevant for both causal models. Note that campaign funds (3) are part of the logic of conversion (4) because it is hard to discern the two.

Type 2 is used as a policy tool of retribution against any outsider interest groups that disagree with ruling party's policies (9.3.4) or internal dissenters (9.3.3) and a mechanism used by party insider groups to limit market competition, either by absorption through the offer (9.3.1) or by its forceful disruption through inspections (9.3.2.). Particularly on the offer, if that act is done solely by the party in power, it acts as a mechanism to generate additional funds for party needs (9.3.1). Each of these scenarios is summarised in figure 5 (p. 248).

Ruling political parties alone can enter a conflictual relationship (10b) with an outsider group for four reasons: to generate party funds in general or for political campaigns, but following the logic of conversion, nonetheless $(4,3)$, and to suppress external or internal policy dissent $(11,12$, respectively). Motivated by the need to increase party funds (IV, 4 and 3), a political party could target an outsider group and make a forceful offer (5a, DV). The outsider is offered to be granted a public tender against giving some of the budget dedicated to its completion back to the ruling party (5a). If the group agrees ( $\operatorname{IntV}, 6 a)$ it becomes an insider $(\operatorname{IntV}, 6 a)$ and a type 1 parentela dynamic is engaged (DV, 9a). Similar to the process outlined in Chapter 8 , the party intervenes in the civil service (IV, 7a) and facilitated by political appointments ( $\operatorname{IntV}, 8 \mathrm{a})$, secures a favourable outcome of the public tender to the insider group (DV, 9a). If the offer is declined ( $I n t V, 6 b)$, then, a type 2 relationship dynamic ensues. The outsider status is confirmed ( $\mathrm{IntV}, 6 \mathrm{~b})$ and the ruling party 
resorts to an administrative intervention (IV, 7b) facilitated by political appointments $(\mathrm{IntV}, 8 \mathrm{~b})$. The end result is inspections of the regulatory agencies against the outsider until their business incapacitation (DV, 10b).

At the same time, type 2 has a policy-implication as well. It is an instrument of coercion of dissenters inside (IV, 12) or outside the party $(\mathrm{IV}, 11)$. In both cases the chain is the same. The party intervenes (IV, 7b) in the bureaucratic via political appointments ( $\mathrm{IntV}, 8 \mathrm{~b})$ and uses the regulatory agencies to scrutinise the firms associated with the dissenting interest group or party functionaries, to the point of their market incapacitation (10b).

Type 2 dynamics could be seen from the perspective of the party insider group, as well. Identical to type 1 , motivated by the need for a better market standing (IV, 1), a group could seek to negotiate access to the ruling party in power (DV, 5). If that group meets the requirements for insiderness $(\operatorname{IntV}, 6)$, it can request its desire for market advantage manifests in requesting privileges at public tenders (DV, 9), i.e. type 1 parentela as per Chapter 8 . This is the mildest form of gaining market advantage. The second and more aggressive form of market advantage is making an offer, as the party could do (above). In this case, it is the insider group who makes the offer to the unsuspecting outsider ( $\operatorname{IntV}, 5 \mathrm{a})$ : to transfer ownership of the firm to the insider, or something else that limits outsider's market competition abilities, against some form of compensation, which in most responses has been, privileged access to public tenders (Intv, 5a). Acceptance of the terms leads to a type 1 parentela relations (6a, 7a, 8a, 9a). Refusal to those terms leads (IntV, 6b) to the third and most aggressive form of gaining market advantage: deliberate regulatory inspections, or type 2 relations dynamics. In this case, the insider group uses its access to the regulatory agencies, via party's approval (DV, 7b) and political appointments (IntV, $8 b)$, to instigate inspections against the outsider to the point of latter's market exit (DV, 10b). 


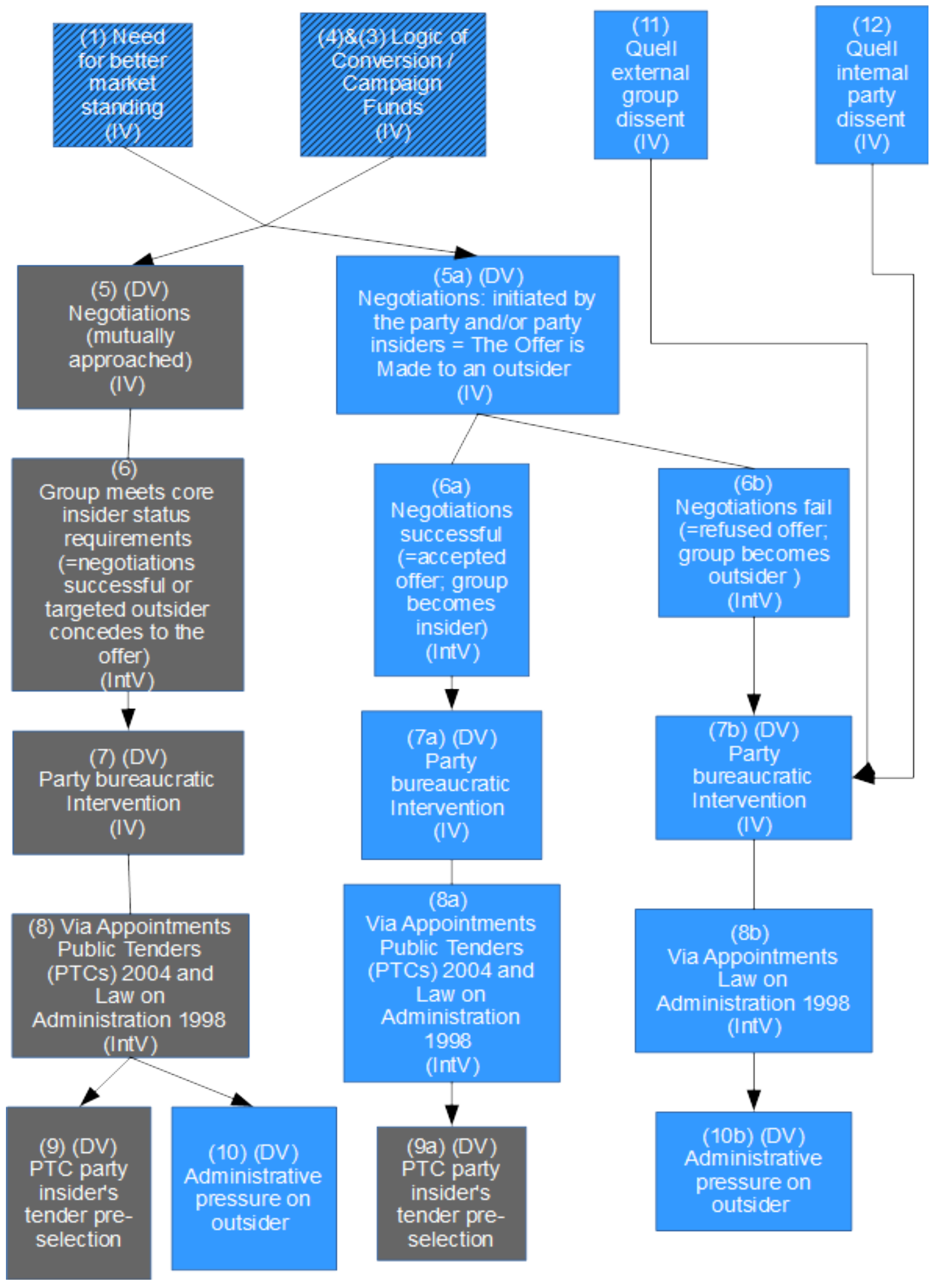

Figure 5 Causal Chain for Type 2 Parentela 
The present section discussed the evidence towards the causes of type 2 parentela dynamics. The next section will briefly discuss the validity of the claims above.

\subsection{Type 2 Parentela Dynamic Validity and Novelty}

While there is no direct documentary evidence that shows purposefulness of said regulatory investigations, the statements in this study are overwhelming that there are occasions where clearly the inspections are deliberate with the prejudice to establish malpractice. Zlatarov noted that there is nothing inherently illegal in the longevity or intensity of regulatory inspections, but confirmed that they indeed can be based on ill-intent. Those can be short, prolonged, frequent or rare, but all of them ultimately legal, although one could tell when they are the target. Respondent Stoyanov made a distinction between regular and prejudiced inspections:

$R \quad$ Unfortunately I would say yes, [but] I could prove that with
great difficulty, because you cannot prove it. Rather, the feeling is in the
way things are handled, in general, because our firm has never been
connected to any one political party. We are very particular on this - to
be disjointed from any party and to do our job as we should and pay our
taxes and everything would be OK. [...] But what we have as a gut
feeling in some moments is - how to put it - more pressure than it is
normal, regarding inspections on the firm. This imminently creates the
feeling that you are not desired in a given situation. Simply, you are not
desired, which cannot be proven but it is. For example, a tax inspection
lasting 8 months is simply too much! This is unusully much!

True, the respondent speaks of feelings, but what they and others mean to say is that at some point there is heightened regulatory activity which is different from the routine one. Respondent Rumenov noted that while usually the teams of inspectors are of 3 and give an announcement prior to the inspections, they are now more, more thorough and prolific in the offenses - founded or not - that they register.

In any case, a list of indicators of type 2 could be devised, based on the more often cited forms of pressure by all respondents (Golemanov, Kirilov, Rumenov, Dobromirov, Stoyanov, Hadzhiev, Kuzmanov, Nikolov, Donchev, Varbanov, Konstantinov, Mihailov, Petrov, Cenov): 
- unusual frequency and persistence of the regulatory investigations (inspections)

- inspectors appear to be determined to find an offense

- court charges appear based on vague, insufficient evidence

- simultaneous inspections from regulatory agencies with numerous minor offenses

- sudden inspections

- the inspection immediately leads to a situation of danger from license rescission or court charges

- active resistance of regulatory agency to help resolve matters

Nearly all of the respondents reported tax investigations and police raids in particular as the first wave of inspections. Overall, this study accepts the validity of the finding because the respondents shared the same indicators of undue regulatory pressure and their views sufficiently well converged around the four causes for type 2 dynamics (above). Moreover, validity is added by the clear distinction between type 1 and 2 dynamics offered by respondents Golemanov and Kuzmanov in section 9.2. Following the discussion on type 2 and its origins, the following section 9.5 discusses the implication of both network types on Bulgarian democracy.

In any case, the novelty associated with type 2 is in expanding of our understanding of the dynamics that the initial parentela could engage in. It does not claim that the novelty lies in the finding a new policy network, that is discrete from the so far known types. The novelty is in discovering another dynamic, part of La Palombara's parentela framework, which also involves a new type of actor: private firms. Sections 9 to 9.3 reviewed the details of the new dynamics. However, the sections did not emphasise on the fact that the group actors are not necessarily formal trade associations, but firms. The other novelty is that the parentela, along with its additional dynamic is also applicable to private actors (firms) who seek direct engagement with the ruling party.

That is to say, the term group is more inclusive than initially conceived by La Palombara. This conceptual stretching is necessary in order to reflect the observation that individual businessmen, firms or oligarchs seeking policy-making participation engage with political parties outside formalised channels of consultations. Yet, this 
inclusion does not contradict the logic of dynamics of the original parentela. The study shows that the parentela dynamics is also observable with actors who are not formal interest groups, but behave as such.

Chapter 8 demonstrated that type 1 parentela dynamics are at play at public procurement contracts, where both the party and its insider group stand to gain from monopolising and skewing the awards of public tenders. Likewise, chapter 9 demonstrated that parentela dynamics could be used by the insider group as an extramarket mean to beat its competition. The party, on the other hand, can use its access to regulatory agencies to coerce individual firms into cooperation, again in the form of shaping public procurement outcomes (the offer you cannot refuse).

Furthermore, the inclusion of such informal actors, also situates the parentela in a range of dynamics that lie between policy-making and what an external observer might define as corruption. The research reveals that the same parentela set-up of relationships between, the party, its insider group and the bureaucracy has dual use ranging from strict policy-making to less ethical (yet within the law) forms of machinations, which nevertheless are part of political life.

Therefore, a question emerges as to the extent to which types 1 and 2 parentela dynamics described here are in fact description of corruption. In essence the present study extends the boundaries of the concept by elucidating on parentela dynamics in the periphery of policy-making. The parentela dynamics described here should not be taken to negate that the expanded parentela model is removed from policy-making. A number of respondents in chapter 9 discussed prejudiced inspections as an instrument available to the ruling party to suppress internal and external policy-making dissent. In this context, it should also be noted that chapter 4 revealed that a similar instrument is party's ability to amend or introduce laws that shape policyconsultations hosted by the civil service. In this way, the party is able to filter in and out favoured and not-so-favoured groups and also suppress dissent. Both of these observations add support to the argument that even the more aggressive parentela dynamics revealed in this study can bear policy-making relevance. Therefore, a more 
general contribution of the present research is that it reveals a less naiive picture of text-book policy-making.

In the same context of legality and ethics, political appointments are a key feature that, too, can be seen in both policy-making and corruptive light. Such views, however, are valid only in cases where appointee nominations are selected in the absence of a discussion with (sectoral) interest groups or the public. Political appointments themselves are democratically founded when nominations are subject to public discussion.

Therefore, we can look at the initial parentela dynamics, revealed by La Palombara (1964) or type 1 in combination of the type 2 dynamics (revealed above) as an extended parentela policy network model. And this extended parentela (types 1 and 2 together) is what parties make of it. It is a neutral model and whether it is seen in policy-making or corruptive light, depends on political parties. It is within the hands of political parties who have the power to make political appointments (and legislatively control access to executive consultations) whether to exploit that for narrow party (or personal) needs. Political parties are in the position to decide what to do with the powers vested in them. They may still make political appointments following public consultations, or silently slip the right man in the right place. They may use their control over the bureaucracy for a faster policy implementation or consultations as opposed to targeting specific groups or companies through inspections. However, regardless whichever path they take, such behaviour still falls within the framework of the parentela both the original dynamics and its added type 2 dynamics. However, let us review the above concerns on the relationship between the extended parentela and corruption as well as the more general implications of this amended network model in section 9.5 below.

\subsection{Perspectives on the Extended Parentela}

The extended model begs the question of how are we to understand it and what are its implications of its existence for policy-making? The answer to these questions relies on the level of analysis we will employ. As the introductory chapter explained, 
policy networks analysis operates on the meso level and its purpose is to generate enough data so that we can generalise on the macro political level. Rresults so far suggest that the extended parentela could be used for both policy-making and activities which could be best described only as realist power-politics on a meso level. In the present section, we will, therefore, look at the extended parentela from a micro and macro perspectives. The reason for that is these, hopefully, will allow us to better understand the concept by looking at it from different angles.

Seen from a micro level, the extended parentela appears to reflect dynamics of corruption (9.5.1). This is not necessarily straightforward because it largely depends how corruption is defined. Yet, this does not mean that La Palombara's parentela, for instance, is evidence of corruption or about corruption. As it will be reinforced, the parentela and extended parentela can be used for both policy-making and realist power politics on a meso level. In any case, Offe's corruption definition below appears to directly match the corruptive dynamics between bureaucrats and individual businesses who seek to expand their market shares by hitting, so to speak, their competition with prejudiced inspections.

Looking at the extended parentela from a macro level, in turn, reveals dynamic that approximates oligarchy and oligarchic policy-making (9.5.2). Both type 1 and type 2 parentela dynamics could be see as processes of resource accumulation and elite formation, with the potential of solidification into an oligarchic community. However, a closer look suggests that thanks to routine elections which have produced (as of 2013-2015) effective party changes, the elites that tend to form around each political party have been in a perpetual conflict. Thus, based again on the same type 1 and 2 dynamics, each elite has the opportunity to retaliate at its competitors, once their party comes to power. Still, it is not quite clear whether informal groups manage to always switch to winning parties or are locked in a relationship with one, but either way, parliamentary elections provide the opportunity for such adjustment and it well may be that some groups do not have the capacity to switch their cooperation to the next, winning political party. The bottom line is that the extended 
parentela contains dynamics that help elites to both agglomerate and be crushed later by their opponents.

It is in this context of oligarchic dynamics that emerges the question of state capture (9.5.3). Seen from a macro perspective one may observe a preeminence of a single company, oligarch or a group of such. There may be news reports of close contacts between the ruling parties and some disclosed (say, thanks to investigative journalism) big business owners. Such business actors may subsequently be observed to have a boost in their profits and market shares, etc, and as a result of all this, many observers would be tempted to say that this is a case of state capture. This notion, explored below (9.5.3), implies that somehow the ruling party has been overpowered and those informal groups dominate it. In turn, the present study critiques this notion, arguing that as ruling political parties have direct control over the state regulatory and security agencies of the state, via direct appointments, it is not possible for any single or group of private actors to coerce (overpower) a ruling party.

Overall, looking at the extended parentela, as implemented in the Bulgarian polity, it reveals various levels and scope of social, political and economic injustice or corruption. However, as we go higher the levels of analysis, even if we begin from corruption, the fact that it is imbued in the political system both on meso and macro level, suggest that the extended parentela is a phenomenon of much larger proportions. We no longer speak of certain business owners bribing the local firedepartment to do an extra inspection on his competitors. The extended parentela model depicts a democratically unjust political system which generates oligarchic dynamics. Let us delve in the details of this picture by looking at corruption immediately below (9.5.1).

\subsubsection{Corruption}

Let us first consider the extended parentela as an example of corruption. Clearly, rigging public tenders and exploiting regulatory agencies as a weapon against select 
businesses is most disagreeable. But is this corruption? An answer to this question may be hard to provide depending on the definition of corruption one employs. If the term is limited to forms of malpractice legally defined in the law, then the above practices are not evidence of corruption, simply because they are within the law. If the definition of corruption, however, is more general and steps outside the legally defined forms of malpractice and misuse, then it may cover practices as those summarised in the extended parentela but at the same time it runs the risk of stretching too far, including thereby socially and the politically unjust yet legal practices. cover practices from a social and political. Pluralist democracies may inevitably appear as unjust simply because the policy process and simply politics generate solutions that never satisfy all interested actors fully. That is why a very clear and specific definition of corruption is of paramount importance because not all of them capture the extended parentela.

This inquiry, however, begs one clarification. The parentela or the extended parentela, if one adds type 2 , is an abstract map or model of relations between a set of actors who have access to policy making. The concept itself was not originally developed with corruption in mind. However, in light of the evidence presented so far, the same set of relations could be used for activities that are morally and socially unacceptable. Therefore, it has to be reminded (again) that the extended parentela is a set of relations that could be employed in policy-making and outside of it. The question, then is to what extend the extended parentela dynamics outside policymaking are evidence of corruption?

Certainly, even a cursory look in the corruption literature would provide us with definitions which may cover the extended parentela dynamics, particularly exhibited in chapters 8 and 9 (as opposed to in La Palombara's work (1964)). The only complaint, however, one could have is that some of the well-established definitions rest on the notions of social and political injustice, which inflate the concept of corruption too much into activities and policy conditions, which are in line with democratic pluralism but can wrongly be branded as corrupt. Let us demonstrate this thinking with a few definitions. 
On the subject of corruption in Eastern Europe, Kostadinova has made one of the most in-depth quantitative studies in the field (2014) and is certainly worthy of special attention. At the start of her monograph she reviews some of the definitions which have achieved literature-wide validity. One definition she provides is that of Warren (in Kostadinova 2012: 6), namely, that corruption is "the inappropriate use of common power and authority for purposes of individual or group gain at common expense". The definition suggests that corruption is when political power and authority, vested in active policy-makers is misused so that certain goods are taken away from the majority and transferred to a select minority, be that an individual or a group (however defined).

In short, the emphasis is on the inappropriate use of power and the subsequent socially unjust and potentially illegal transfer of resources from the many to the select few. This can be seen in the dynamics in Chapter 8. In fact, that chapter implicitly argues that public tenders in Bulgaria for the most part subjected to the illegal act defined juridically as public form of public tender manipulation (see chapter 8). Essentially, opportunities for economic development of the state are stolen away and resources unduly concentrated in a small number of firms when public tender committees are politically controlled to ensure that the winning tender proposal is made by the party insider. Likewise, the far more pronounced abuse of public power in the interest of a third actor (party insider) is evident in chapter 9 with the prejudiced regulatory inspections. As respondents reported regulatory inspections aimed at driving a firm out of business are primarily an act of extortion by legal means.

In fact, Kostadinova summarizes that the common denominator among most corruption definitions is the notion of some form of misuse of the authority provided by a public policy-making post-holder (2012: 7). Thus, she adopts the minimalistic definition of corruptions as the "misuse of public office for private gain" (2012: 7). This formulation would not necessarily change the rendition on the extended parentela dynamics. The difference between the two definitions is simply that the 
latter is a succinct re-statement of the former, e.g. instead of /inappropriate use/, we have the explicit misuse.

Stated in those general terms the definitions on corruption demonstrate a certain vulnerability when one attempts to put boundaries on the scope of practices classifiable as corrupt. In trying to determine the scope of the definitions reveals that they encompass either too few or too many practices. Essentially, the one who determines what is inappropriate or misuse of power, also determines the scope of corruption. Therefore, the scope of practices constituting corruption would be narrower, if left to the strict legal formalism of courts, than if approached, socially, i.e. by political observers or researchers. That is why, it is debatable whether seemingly political and policy-making injustice or disadvantage is form of corruption or not. For example, it is debatable whether the evidence provided in the present study enough to demonstrate that said dynamics are form of corruption, perpetrated by public officials under the diktat of the ruling party? Likewise, it is doubtful whether the evidence in chapter 9 on the misuse of regulatory agencies would suffice in court to qualify as a case of corruption. It is true that in particular the public tenders overlap with the dynamics of wrongdoing in legal texts (KZK decision, chapter 8), but those still require the rendering of a legal authority to formalise them as corruption. If the definitions of corruption, therefore rest on legal authorities for their validity, then, it appears that this would include much less social dynamics as corrupt.

At the other extreme, if corruption is left to policy-making observers and researchers, then we run the risk of allowing too many political practices to be defined as corrupt. The corruption definitions above reflect the popular and naive idea that, if left on autopilot, or somehow, on their own, pluralist democracies will produce socially and politically just policy decisions, that equally satisfy all groups and actors with vested interest in them. Such a formulation may cause an undue expansion of the concept of corruption because what is seen as socially unfair is left to external observers, if those are tasked to determine what is an unfair redistribution of wealth, and whether the gains of some interest groups make in the course of the policy-making process 
are a case of corruption? Again, the second important part of the definition of corruption above was that the policy-decisions unfairly redistribute resources from the majority to the minority. While this is true and with that the extended parentela is clearly a case of corruption, it is also true that there is private gain at common expense in contemporary pluralist democracies, as well. The concern, in other words is, that if the corruption definition is stated by a policy observer in terms of social and political injustice, then not only the extended parentela practices are also a case of corruption, but so are other practices and policies that are the product of the democratic process as it is today.

Western pluralist thought of early and mid 20th century made a series of observations centering on the fact that given the unequal distribution of resources among groups, at least some of the time, there are small number of (interest) groups which dominate a certain policy (or legislative) field at the expense of others (Jordan 1990). This is point is further reinforced in the study of Gilens and Page (2014, below) who confirmed that access to US policy-making process is very difficult given the dominance of insider interest groups. In what appears to be the endspiel of the pluralism-corporatism debate, in a literature review Jordan argues that corporatism was constructed on the misunderstanding of pluralism, namely, that the latter is a state-group model of power-balance among groups and the state. In fact, pluralism is a realist viewpoint that acknowledges that well-within democratic dynamics some groups dominate over others in the same policy field, at least some of the time (Jordan1 1990). Essentially, some groups succeed in positioning themselves better than others thanks to better organizational resources or clientelistic relations with policy-makers (Jordan 1990). This means that most of the policy output of interest of said dominant groups will directly benefit them at the expense of others.

That is to say, policy-outcomes in pluralist polities do not necessarily benefit all sectors equally and these skewed policy-outcomes are part of the democratic policymaking. Transplanting policy-making in societies hitherto unacquainted with democracy and interest group participation, therefore, are startled by this feature and domestic observers too readily attribute corruption to any policy outcomes that they 
personally feel on the losing side and where the same observers can identify other groups as the policy winners. This is clearly evident in the text-book criticism against perception-based corruption indicators, namely, that those are not reliable as what is perceived as corruption by questionnaire respondents is very broad, and may simply reflect their emotional response that goes along with their disagreement with domestic politics, on which they might be on the losing side and also which may not necessarily be informed from immediate observation of corruption. Therefore, this study argues that such perceivably unjust dynamics of wealth concentration by the few at the expense of the many are part of the democratic structure at present. However, it becomes harder to distinguish them from corruption, as soon as those defining the term corruption attempt to include the perceivably and arguably unjust aspects of pluralist political systems.

A similar point is advanced by Sajo, who argues that any corruption inquiry in the region of Eastern Europe has to distinguish clientelistic policy-making - an unhealthy, but not necessarily undemocratic practice either and criminality (2002: 2$3)$. In his view policy-making using political protection mechanics (clientelism) does not automatically qualify it as criminal or corrupt (2002: 3). Evidently, his thinking too is informed by the idea that democratic systems may still harbour unfair or unjust dynamics that do not immediately qualify as corrupt. He is vague as to whether Eastern European democratic polities are legitimate, as a result of the mixture of corruption, clientelism and democracy, but he advances the term clientelist corruption as the label of the structure of Eastern European polities:

[clientelist corruption is] a form of structural corruption, which should be distinguished from discrete individual acts of corruption. [...] In Eastern Europe, clientelism - in interaction with various forms and levels of corruption - is becoming a stable form of social organization (Sajo 2002: 3).

While certainly his interesting line of thinking requires an elaboration, more importantly for the purpose of the present discussion, the quotation above reflects the difficulty in drawing a line between corrupt conduct and political injustice in the democratic policy-making process. 
We, therefore are in need of a more precise definition of corruption. In order to achieve that it is necessary to delineate the legally criminal dimension from the socially unjust one. Sajo clearly makes the call for specification of the breaking of what rules constitutes corruption (2002: 26). On that note, Gambetta (2002) responds by specifying various categories of corruption. Holmes on the other hand offers a rather specific definition, which seems to answer the call for higher terminological precision, particularly on the need to distinguish the illegal from the socially unjust (point 4 below):

1. [corruption] is carried out by an individual or group of individuals occupying a public office; 2 . the public office must be one of responsibility and authority; 3 . the official must commit the act at least in part because of personal interest' 4 . the official must be aware that their actions or non-actions either are or might be considered illegal or improper.

Yet, even in this case, policy-making practices that are the result of pluralist (see Jordan above) dynamics are likely to be rendered, due to the improper actions of public office holders, i.e. through lobbying. The notion of improper actions is also a matter of interpretation, particularly if it is a sensitive, disgruntled public who has that authority to determine whether what is improper.

A far better definition of corruption. However, instead of muddying the waters further, the present study will turn to any definitions that seem to match the above requirements. In his discussion of a number of corruption types, as well as their effects on social trust and democracy (2004: 77-100), he defines political corruption as the "exchange of official decisions for some payment", or a bribe for policy decisions (Offe 2004: 78). He defines bribe, as a payment or promise of payment in cash or in kind (Offe 2004: 78). Corruption is political if one of the interacting sides is either an elected official or civil servant (Offe 2004: 78). He classifies political corruption in four categories (Offe 2004: 81-83). In the first type, corruption is a bribe in exchange for civil servants' permission for the continued sale of illicit goods (e.g. of arms, alcohol). The second corruption type is receiving favourable administrative decisions, and privileged provision of otherwise free state services 
(e.g. driver's license issuance) in exchange for a bribe. The third one, seems to overlap with the previous two. It is a bribe in exchange for regulatory leniency or provision of services, not normally unavailable to any actor, such as favourable policy decisions or policy non-decisions. The last corruption type is political extortion - when those civil service structures with the powers to impose sanctions proactively solicit a bribe in exchange for not sanctioning a given business in the absence of any obvious offenses.

Corruption type 2 in particular is relevant to both parentela types. This is the case of bribing officials in exchange for specific favours. As such, Offe exemplifies with public tenders - which relates to type 1 parentela (chapter 8 ). However, he continues that this corruption type 2 also includes that favours "can also involve the purchasing of relative advantage, such as bribing an official into harassing one's competitor through inspections" (Offe 2004: 82, original emphasis). In other words, to add to Offe's examples, a form of corruption is also when bribing officials with a view of gaining market advantage by instigating regulatory inspections. This is a surprising match to type 2 dynamics, which revealed that party insiders (or the party alone) can instigate deliberate inspections against outsider businesses. The emphasis, however, is on private actors establishing direct contacts with civil servants, outside the party in power. In our case, in contrast, this appears to be negotiated at a higher, party, level. We will return to the level of analysis later.

His corruption type 4, where civil servants (including their elected superiors) extort businesses to own advantage (or - as it is in our case - in the advantage of the party insider, which does not change matters much) is a close match to type 2 . The description respondents give to "the offer" is inescapably close to that of extortion. Respondents Kuzmanov, Varbanov, Rumenov, and Dobromirov revealed a practice of "visitations" from party officials who solicit funds. It was later revealed that such refusals were usually followed by some form of regulatory retribution through increased inspections. It is precisely those forms of retributions that closely overlap to Offe's corruption type 4. 
However, while his conception of corruption overlaps with the extended parentela dynamics, his level of analysis makes his rendition of corruption slightly incompatible with the description of the parentela. The parentela is a meso-level concept, while his corruption analysis is on a micro level: that of street-level bureaucrats. Offe's focus is on the interpersonal level between a firm (a businessman) and single bureaucrats working in an agency, while the parentela networks is about interaction between a policy-making actor (a group) interacting with parties, agencies and institutions of government, which is on a meso level. We are, therefore, in the position to implement Sajo's approach of looking at the system the blend between democratic and not-so-democratic practices as a whole, on a macro level. Bringing all known circles or possible parentela relationships to-date (Kotaratsite, Admiral, Olimp, etc), taking into account the regular political appointments and civil service sweeps, the regular emergence of some form of circles or individual players who seek parties' attention suggest that at a macro level, these iterations are the informal system of government which approximates an oligarchy. At the macro level, the political system demonstrates oligarchic dynamics, although the oligarchy itself has not settled yet. Let us elaborate the macro perspective on the extended parentela in the following section, 9.5.2.

\subsubsection{Oligarchy and Oligarchic Dynamics}

In the previous section 9.5.1, we interpreted the extended parentela from the micro level of analysis. Looking at the parentela from the meso level, however, is unnecessary as that has served as the basis of analysis throughout the study. We can only briefly state at this stage, that looking at the extended parentela from the meso level of analysis, the network facilitates both policy-making and power-political dynamics. That network could be used as a mean to procure policies but also as mean to fight off market or policy dissenters (9.2).

In this section, however, we are now looking at the extended parentela from the highest, macro level of analysis. This section argues that seen from that level, the extended parentela approximates an oligarchic dynamics, as opposed to a full 
oligarchic rule or community. In other words, while there is no actual oligarchy at present, the extended parentela reveals oligarchic dynamics. They both help create and destroy prospective oligarchic elites.

The question then is, what is meant by an oligarchy and how does it relate to parentela dynamic types 1 and 2? First of all, there does not appear to be a consistent use of the term in the literature on oligarchy, nor does the notion of oligarchy lends itself easily to a strict definition (Leach 2005: 315-316; Winters and Page 2009: 732). A number authors on Russian and US oligarchy, however, share the common denominator that an oligarchy is the policy-making arrangement, where policymaking discretion is disproportionately vested in a limited number of extremely rich individuals (and/or their representatives), who are not representative of the wider democratic polity (Barker 2013: 559-561; Winters and Page 2009; Zudin 2000; Shlapentokh 2004; Fishkin and Forbath 2014; Shinar 2015; Jacobs 2010; Barguinsky 2009; Nonini 2005). An additional feature of oligarchy that transpires from the use of the term by the same authors is that it correlates with both economic and political inequality (particularly in Winters and Page 2009 and the authors writing on oligarchy in Russia). Second, an interesting and important clarification is provided by Leach (2005) who insists that an oligarchic rule is characterised by informal exertion of non-public, i.e. illegitimate power (manipulation and coercion) (2005: $322-324,329)$. In her words oligarchy is a 'particular distribution of illegitimate power that has become entrenched over time' (Leach 2005: 316).

Finally, the literature on oligarchy implies a sense of oligarchic community, which is more easily discernible in the Russian strand of the debate, because the main actors (oligarchs) are clearly identifiable (see above). This is also implied in Gilens and Page's hypotheses-testing based on the US policy-network literature branch with the categories of biased pluralism and majoritarian pluralism (2014: 7-8). Given the similarity between iron triangles (US) and policy communities (UK) policy network types (chapter 2), these authors convey the sense of a community. Being explicit with their focus on oligarchic elite in the States, Page and Winters (2009) imply the existence of an oligarchic community by suggesting that most affluent $10 \%$ of the 
population, or the elite, are also the most powerful. Evidence of that are not only the power indices which Page and Winters (2009: 735, 736) develop but the foreign and fiscal policies which in turn are dominated by elites who benefit from an interventionist and inegalitarian policies, respectively (2009: 738-740).

A cursory look at previous chapters allows for the proposition that both parentela dynamic types are a manifestation of oligarchy. First, in terms of affluent actors who dominate policy-making process, this was discussed in chapters 6, 7 and 8. Chapter 6 argued that the core prerequisite for access to Bulgarian political parties are campaign contributions, which implied that only affluent private actors could provide them. Chapter 7 was more specific as it focused on the Multigrup Corporation of the 1990s and rings and circles as examples of affluent actors with dominant policymaking positioning, who are not representative of a specific economic sector or social stratum. Chapter 8 in turn could be seen as a more recent case of oligarchic control over the distribution of construction tenders, leading to the undue concentration of resources to a limited number of firms - insiders to the ruling party. Most crucially, however, both parentela dynamics (chapters 8 and 9) demonstrate how a dominant oligarchic elite exercises illegitimate power (as per Leach 2005 above) in two ways: to unjustly accumulate resources (chapter 8) and to coerce into submission any outsiders (either unsuspecting market competitors or, as chapter 9 implies, immediate rivals). As chapter 8 demonstrated, such concentration of public tenders has the effect of exacerbating a declining market, and by implication, income inequalities already present in the construction market, which spur and motivate the parentela dynamics.

Finally, a primordial oligarchic identity is evident in the retributive behaviour of the party in power and/or insiders when their offer of cooperation is rejected. As Stoyanov interpreted their "message", their modus operandi is "You are either with us or against us". This mentality of "us" (insiders, oligarchy) vs "them" (outsiders, rivals), coupled with the cooperation between the party and insider groups may be indicative of something of a community. Moreover, the need for self-preservation by 
means of administrative retribution also speaks for some form of shared selfawareness.

In fact, the circles, extremely affluent individuals (oligarchs), individual companies, politicians and appointed civil servants (chapters 6 to 9) appear to be the exact collective image claimed by some of La Palombara's respondents as an oligarchy that he confronted in his study (1964: 314). While he is dismissive that the parentela could relate to the notion of oligarchy, this study finds it impossible to ignore it as the contours of the extended parentela and oligarchy roughly overlap. Ironically, the surprising re-emergence of the oligarchy debate in the two remote cases of Bulgaria 2014 and Italy 1964 adds some credence to the oligarchic argument in both of them.

There is other, more concrete evidence for the existence of an oligarchy, found in the answers of a number of respondents. Respondents Nikolov, Donchev, Rumenov, Kirilov, Golemanov, and Petkov argued openly for the presence of an integrated economic, political and administrative elite that ruled over time. Nikolov explained there are a number of families in Bulgaria (at first 10 but then said 100) that effectively participate in policy-making through all political parties. The same respondent also expressed the view of a select community, which envelopes both policy-makers, but more importantly the leaders of the trade associations, trade unions or basically the interest groups that make up the civil society. He, Donchev, Dobromirov and Stoyanov also made the observation that group representation is on many cases fictitious, because the leadership abandons group's rank and file in exchange of membership in that select community, i.e. it colludes with the regulator. Stoyanov was adamant that there is collusion between sectoral group representative leadership and political parties. That is the reason why he refused to participate in the Gas and Petrol Trade Association. Dobromirov spoke of the handful of privileged firms in the construction sector that concentrated majority of construction tenders. According to Kirilov party functionaries, e.g. politicians assuming posts of deputy ministers and above, are also part of that community of the privileged. He explained that a number of leaked wire-tapped recordings of the meeting of Bulgaria's head prosecutor Kokinov, the Agriculture Minister Miroslav Naydenov at the residence of 
Premier Boyko Borisov were evidence that those who are no longer in that privileged community are ready to defend themselves if repression, implying type 2 relations, would be focused on them. Furthermore, respondent Golemanov referred to political parties and their connections to big business and the intelligence community as a more or less coherent entity, namely, mafia. Other respondents also conveyed the image of community with their use of the term mafia when describing the partyinsider group relations (Dimitrov, Georgiev, Mihailov, and Petrov). Finally, as with the policy community network, the fact that trust is the key ingredient in the circle formation, as per Zlatarov, is another indicator that it is possible to suggest that there is, albeit vague, a sense of community in the party-group cooperation.

The above responses seem compelling as they are consistent in their emphasis of collusion between sectoral group leadership and policy-makers. However, there is the question whether the argued collusion is the product of misperception on necessary compromises sectoral group leadership might have had to make in order to push forward legislation. Then again, we must not forget that dissident groups are in a disadvantage, given the prospect of type 2 relations. That in turn could act as a stick to collude. In any case, there is another question that could discourage us from the purely stagnat view of the extended parentela as a case of oligarchy. A closer look reveals a much more compatitive and aggressive dynamic among elites, than the term suggest.

In other words, how much of the above really fits the term oligarchy? The similarities between both parentela dynamics on the one hand and the oligarchic features on the other, however, cannot be stretched so far as to say that there is a complete overlap between the two. A fundamental assumption behind the notion of oligarchy is the presence of a single community of very limited participants with internal cohesion (cooperation) that presides over all political matters, as opposed to ad hoc arrangement, set up on select matters only. Looking closely into the two parentela dynamics, they do not sufficiently well resemble an oligarchy. 
If we take type 1 party-group cooperative arrangements as the nucleus of oligarchy, then they do not fit the requirement of stability and longevity implied in the standard understanding of oligarchy above. Due to elections, access is always temporary and usually until the end of present party's tenure. The party change causes shocks in the parentela relations and introduces systematic instability in what at first sight looks like an oligarchy. As a result, insiders may fail to renegotiate access and risk being targeted as outsiders in a type 2 dynamics, when not associated with a political party. The high turnover of circles co-varying with the change of governments indicates that new elites are constantly generated and that they are in fierce competition among themselves, which is contrary to the idea of an oligarchy, where single coherent elite dominates policy-making long term. This was also exemplified in part by Multigrup in chapter 7, where the corporation had to continuously renegotiate access to all relevant political parties until its demise when ODS took power in 1997, denied it any policy-making access and put it under the pressure of regulatory inspections.

Moreover, most of the major (publicly known) oligarchs from the early days of Bulgaria's initial capital accumulation have been assassinated, e.g. Kyulev, Mollov, Iliya Pavlov and their representative organization G13 disbanded. Major political parties, too, if we take them as partaking in the oligarchic parentela, such as SDS and NDSV, have collapsed very quickly soon after the end of their tenure, or are in decline, such as GERB who was forced to make a large coalition with three other partners (ABV, RB, NFSB) in 2014. At present, there is absence of a single major political party or identifiable group of the scales of UFU, Catholic Action or Multigrup that clearly is a long-term oligarchic partner to all political parties. Obviously oligarchs Q and O have survived, with Q in particular with numerous court cases. The wider majority, evidenced by the effervescent circles and the inability to identify a large company of the scales of Multigrup as a stable partner to a number of governments indicates the long term unstable existence of private groups (firms, companies) that could partner political parties. In other words, there is no evidence of a select community of politicians, bureaucrats and groups that conforms to the oligarchic ideal of an informal, durable and internally stable clique that rules long term, as Nikolov mentioned "families". They may well be single 
players who have individually survived in the long term, just as there are oligarchs who have survived the early days of capital accumulation, e.g. O and Q. But these overall are not actors engaged in long term cooperation among themselves and political parties. Instead, they are engaged in a perpetual confrontation with all and any parties and oligarchs in a free-for-all setting. Therefore, the longevity of a single oligarchic actor is not necessarily indicative of a presence of a corresponding community.

The argument here is that there is only oligarchic dynamics, and not a fully-fledged oligarchic community. Despite the primordial identity or self-awareness of "us", the evidence so far does not confirm the presence of stable or (c)overt oligarchic structures, as oligarchy definition above implies. The conflict and instability brought by type 2 parentela dynamics and parliamentary elections means no such stable community can exist. Elections give an opportunity for new groups to assume insider status, while type 2 dynamics provide the same the chance to hit at their competitors (i.e. former insider groups).

To the extent an oligarchy exists, it is in the informally institutionalised practice of type 1 and type 2 dynamics. The dynamics of the extended parentela have oligarchiclike features but do not constitute an oligarchy. True, type 1 could facilitate the emergence of an elite clique that dominates, say, public tenders, but the pressure brought by parliamentary elections and the prospect of becoming a victim of type 2 pressure have the potential to eliminate that elite in the long term. The closest Bulgarian policy-making is to an oligarchy are the type 1 dynamics, but not anywhere close to an actual oligarchic entity whose elite members think and act as one, for there is none. Instead, there is a free-for-all competition among elites that are recurringly disbanded and brought into living.

The proposition that the dynamics of the Bulgarian polity have oligarchic characteristics, short of complete oligarchy is also shared by others, particularly Barnes in his analysis on Bulgaria's transition to capitalist democracy (2007). Barnes' thesis is that Bulgaria is a case of Equilibrium of Competitive Capture (ECC). This is 
a concept that seeks to rectify PRE or Partial-Reform Equilibrium. PRE is a proposition that instead of quickly introducing a fully functioning competitive market economy, those elites who introduce and stand to gain most from the freemarket reforms (or first-round winners) find it more profitable to stall them in a middle state of incomplete market liberalisation (Barnes 2007: 72). PRE theory hypothesises two main outcomes of marketization efforts: full marketization or capture by "first round-winners".

Barnes argues that PRE made two incorrect assumptions (2007: 72). First, that there are only two outcomes of the liberalisation process (above). Second, that there are only two relevant actor types: first time winners and the public. He, respectively, argues that a third outcome is what he called Equilibrium of Competitive Capture" (ECC) and that a third actor type could be other prospective captors, other than "first winners". With regards to his ECC theory, he argues that it then represents a state of perpetual indetermination where there is a competition among a number of prospective captors who change with new elections. In this sense, the state is neither fully captured, nor ever immune to it. In order to exemplify his thesis, Barnes reviews the relationships of all major Bulgarian governments with what here was explained to be circles, such as Olimp, Orion and Multigrup, among others (2007: 73-93).

The argument that type 1 and 2 characterise oligarchic-like dynamics greatly overlaps with Barnes' ECC model above. Similar to the analysis in section 9.5.2 he argues that "first-time winners" are not a monolithic entity but a collection of competing elites and that the Bulgarian case demonstrates how the state is sequentially captured by them. Similar to section 9.2 and 9.5.2, he also argues that elections are the mechanism that puts a stress on hitherto captors and their links to political power and they are a vehicle for a change of captors (Barnes 2007: 73). In remarkable similarity to section 7.3 , he too argues that the best strategy of the circles or captors in his parlance is to establish simultaneous contacts with all political parties (Barnes 2007: 74). Ultimately, 'Instead of an end to capture, therefore, the more likely medium-term result is generalised corruption without a dominant group' 
(Barnes 2007: 73). This is again an overlap with the discussion so far on the relationship between oligarchy, corruption and the parentela. The oligarchic community image of both parentela dynamics rests precisely on that new elections give chance of new or former outsider groups to become insiders. What he sees as elites overlaps with the use of that concept here, in terms of ruling political parties and insider businesses. Essentially, his unit of analysis is identical to that in this study: ruling political parties and businesses (groups) with party insider status. Despite these similarities, however, this studies would disagree with Barnes on one major point: state capture.

\subsubsection{State Capture}

While the overlap of the results from both studies adds to the validity of the image advanced here, namely, that the parentela dynamics of both types are demonstrative of oligarchic dynamics, both studies disagree on the idea of state capture. Essentially, Barnes (2007) and Ganev (2001) earlier imply that this party dynamic is the result of private groups overpowering and somewhat incorporating political parties. We would oppose this view, arguing that the oligarchic dynamics Barnes' and the present study speak of are the product of the cooperation between ruling parties and affluent groups (rich individuals, corporations, etc).

Barnes' insistence on capture is overstated because it wrongly assumes that private actors are in the position to overpower political parties (2007). Not only is the term capture not formally defined in his study, and that of Ganev (2001) whose line of research he continues, but the reader is led to believe that those who conduct such capture somehow assume a position of diktat vis-à-vis political parties. If that were the case, then, Barnes' cases lack any explanation of how private groups have come to overpower the ruling party.

Chapter 7 demonstrated that the Multigrup Corporation gained access as a result of close cooperation with $\mathrm{Mr}$ Lukanov's faction and even through bribery (Aleksandrov) but ultimately on the grounds of the exchange of resources for favourable appointments. So far as power is concerned, chapters 5 on political 
appointments and 9 on type 2 clearly indicate that coercion is in the hands of political parties, because political appointments in the regulatory agencies enable them to exert selective repression against parente's rivals through regulatory inspections. Neither Barnes (2007) nor Ganev (2001), who exclusively focused on Multigrup, demonstrate the process through which Multigrup overpowered, or rather, coerced any political parties. Instead, the observation that Multigrup benefited in some way from its insider status is taken as an indicator that the corporation is also somehow more powerful than the respective political parties but that was an underlying assumption. In his detailed research that adds clarity to what normally are very nebulous chain of events, Ganev lists a number of cases where Multigrup has taken advantage of state assets in what often are less than legal means (2001). Yet, as with Barnes (2007), his analysis is nowhere concerned with the process of how Multigrup arrived at the position to exploit state assets, with political parties acting as their gatekeepers. We do not see the interaction between Multi and political parties that ultimately enabled the former to exploit said resources. That this was the result of overpowering, takeover or usurpation of some form is taken for granted.

The present parentela study instead shows that this can only be with the cooperation and permission of the ruling party. Ganev's (2001) and Barnes' (2007) idea of oligarchy based on state capture can only happen with party's permission and abetment. This study reveals that private actors cannot exert the coercion which the term capture implies. Chapter 7 clearly shows that whatever access Multigrup had was on the basis of patient cooperation and exchange of party-relevant resources, as opposed to coercion, which point (in principle) was demonstrated again in chapters 6, 8 and 9. Again, prejudiced inspections are the power instrument for coercion available to political parties and to which no defense or reciprocal response has been devised by outsider groups. A number of respondents, such as the active minister at the time Petkov, and the active agency director Nikolov argued that no private actor, including oligarchs or corporations like Multigrup could overpower the state, precisely because of the state regulatory agencies. Therefore, the dominance, perceivably, of any single actor or a circle can only occur with party's knowledge and permission, if not outright cooperation. 
The argument here is that the state capture literature is only partially correct in positing that some elites take over the state apparatus. It seems both Ganev (2001) and Barnes (2007) miss the importance of political parties as a single, independent policy-making actor, along interest groups and civil servants. The present research demonstrates that political parties are independent actors in their own right. They are an actor with own interests and depending on the country, with unique properties visa-vis civil servants and groups, such as legitimate access to executive and legislative power. The (near) absence of ideological concerns by political parties, as reported by respondents, means that they are independent organizational, policy-making organisms whose main concern is long-term survival.

By incorporating the party in the analysis the study develops a more nuanced and accurate picture of state-group dynamics. We can observe that the party acts as a gatekeeper to legitimate legislative and executive power and it is only through interaction with that actor that an interest group (formal or not) can protect its interests. This, however, holds more value when the ruling party is able to interfere in the workings of the civil service. All three studies confirming the parentela in Northern Ireland, Italy and Bulgaria demonstrate that the preeminence of a single (formal or informal) interest group is the result of its productive cooperation with the ruling party. And this is the controversial point, because the state capture view would have us believe that a group's preeminence is the product of that group's coercion of the ruling party. Yet, that is not the case. We have yet to observe an interest group being in the position to force its demands on the ruling party, or in the parlance of this study, a situation where there is conflict between a core insider and a ruling party.

This research shows that Multi's positioning within the policy-making process is the result of cooperation with certain party factions, more or less following a path of least resistance. This has to be highlighted and contrasted against the notion promoted by Barnes and Ganev that private interests, or informal groups with immediate market benefits in mind, are in the position to forcefully push their way 
among policy-makers. The present research contradicts this view. It showed that Multi sought the cooperation of factions within BSP, DPS, SDS (or UDF) and sought to establish other parties. Its success was variable. With BSP, cooperation was secured with the leading party faction, on the other hand, there was full cooperation between Pavlov and the DPS leadership. Finally, no progress was made in the project of a new political party and SDS. In short, Multi sought to establish positive, cooperative relationships wherever they could, and then convert its access to market benefits only as a result of a bargain as an insider group vis-a-vis the ruling party (faction).

The present section discussed the extended parentela, as seen from the micro and macro levels of analysis. In a sense, this section traced the element of injustice part of the extended parentela on three different levels. While on a micro level we can perceive the extended parentela as form of corruption, that view gradually blurs into meso and macro forms of social injustice. As we already saw in sections 9.2, and chapter 8 , it is quite difficult to argue that there is corruption, primarily because the practices outlined therein are within the law. Thus, as we go higher in the analytical levels, the extend parentela assumes the shapes of (grave) social injustice, in the form of resource (public tenders) and power (party appointments) accumulation. Ultimately, we can perceive of the extended parentela as of set of oligarchic dynamics which both give birth and suppress oligarchic elites. It is on this note and in this context discussed briefly in section 9.5.3 that aspiring elites can assume such privileged status only with ruling party's informal endorsement. The claims of state capture in the context of elite or oligarchic formation are exaggerated, as parties have direct control over regulatory agencies and the security apparatus. Therefore, so far as elites and oligarchic community formation is concerned, entry to those can only be granted by the ruling party so far as it enters mutually beneficial cooperation with the private entity.

However, let us now turn to the following section which discusses another prospective external variable that might have an effect on the parentela formation: the EU. 


\subsection{The EU as an External Variable to the Parentela}

Chapters 7 and 9 argued that elections act as independent variables that cause shocks on the parentela relations. However, the study also sought to find evidence in support of the hypothesis that Bulgaria joining EU has had an effect on the parentela arrangement types. The pursuit of this angle was both necessary and interesting. However, given the Bulgarian policy-making focus in the respondent selection, many of the interviewees lacked the knowledge to engage with the topic of the EU on a technical level. In light of the public tenders as a case of type 1 parentela dynamics (chapter 8), therefore, it was not possible to engage, for example, with EU's influence on them, save for a few respondents. At the same time, the wealth of relevant EU legislation that regulates the process of carrying public tenders with EU moneys suggested this is a line of research for a future project. For the most part, respondents felt to prioritise in favour of other issues and look at EU's potential for affecting policy-making from a more general perspective.

Respondents were asked to comment on the effects on Bulgarian policy-making had as a result of joining EU (Kuzmanov, Nikolov, Kirilov, Hadzhiev, Rumenov, Stoyanov, Dobromirov, Zlatarov, and Petrov). Overall the responses were positive. Interviewees saw Bulgaria's EU membership as having some ameliorating effects on the type 1 relationship as long as EU institutions were aware. They noted Bulgarian politicians are afraid of EU's opinion on their mandate. Naming and shaming works, although only to a degree. Probably most notable response came from Donchev who argued EU institutions at present lack mechanisms of coercion. He argued that EU institutions must have a mechanism of intervention in order for the conflictual partygroup relationship (type 2 dynamics), for example, to be contained. A pair of respondents, however, were conflicted. While they generally agreed that EU has some suppressing effect on any political misconduct (Stoyanov and Kirilov), Kirilov also added that structural funds and any other EU-related funding, also acted as a catalyst to any political misconduct. 
Public tenders, partly funded by the EU, in other words, were seen by some respondents (Kirilov and Donchev) as an opportunity that motivates political parties to engage in type 1 dynamics. Dobromirov elaborated that the cost of road construction in Bulgaria, which is partly funded by the EU is also prone to the same type of offer described by Rumenov earlier (9.3.1). The former respondent stressed in most cases the main contractor is not the firm doing the actual work: those would be the sub-contractors, who would be paid by the main contractor. Following the logic of the offer and cooperation described by Rumenov (9.3.1), Dobromirov explained first that in the context of road construction the insider too has to repay back the ruling party for being positioned as such. However, because they still have to maintain their profits, the higher party's demand for a repayment, the larger the sum the insider will retain from sub-contractors' profits. In this chain reaction, the subcontractors in turn find themselves forced to decrease their costs, which usually leads to paying the workforce less and using cheapest possible materials. Kirilov (and less directly Donchev, Varbanov) in particular stressed that it is due to this chain reaction that the overall infrastructural (road) quality in Bulgaria is poor.

It is at this point where future research is necessary to determine the effectiveness of EU institutions affecting such dynamics and at what point of the parentela relationship. It has to answer the question whether the EU institutions could intervene at the party-group relationship building or at the stage of tender's construction process and how. Most respondents were not able to tackle those technical questions, save for arguably Donchev, Dobromirov and Kirilov above, whose responses indicated that more EU intervention is both welcome and necessary. The rest of them speaking on the subject, discussed EU's influence on Bulgarian politics in more different, yet, interesting light.

Overall, respondents saw the Bulgarian/EU relations from the perspective of the Cold War divide, they couched those in terms of Bulgaria - the civilizational laggard, trying to catch-up with the morally superior West (Dimitrov, Georgiev, Mihailov, Kirilov, Dobromirov, Rumenov and intermediary). Respondents had the general selfperception of a second class, Eastern European citizen. This, however, was a result 
both of assuming either real or imagined share of the responsibility for the current state of political, economic and social crisis in the state, and trying to keep a realistic look on the status quo. This is best displayed in the complex position one respondent had towards the EU, and who was also disappointed that Western companies refused to participate in Bulgarian trade associations. He felt as if for foreigners, Bulgarians were not worthy of such interaction: "They look upon us as aboriginals, and in fact we are aboriginals, but that is the point: [the West] to engage [with us] in a civilizational exchange". Others still welcomed the EU but retained the East/West bitterness arguing that Bulgaria was seen by the West as someone who refuses to learn new and better ways of doing democratic politics and truly free market economy: partly because old habits die hard and partly because the EU lacks the patience to teach (Kirilov, Dobromirov). Bulgaria was seen by Kuzmanov as the opposite image of the West: where kleptocratic injustices were the norm. In fact, he regretted putting the State Owned Enterprise formerly vested in him back on its feet and showing to his disbelieving workers that a normal life-style is possible (Kuzmanov), i.e. with regular salaries, job security and bright life prospects. In his words that acted as a cruel joke on them once he was deposed and they were gradually laid off and, as he put it, thrown back into reality.

In a similar but more extreme form of self-criticism than Mihailov, Kirilov relayed what he claimed to be the dominant insider policy-making attitude towards the EU. He argued that the Bulgarian parente sees the EU as a source of income that could be taken advantage of in the spirit of realpolitik. Therefore, it would be unpatriotic of any Bulgarian whistle-blower, journalist or researcher to embarrass Bulgaria by demonstrating any form of misappropriation and misconduct with EU funds found in Bulgaria. ${ }^{11}$ Therefore, through this rhetoric, the dominant policy-makers seek to 11 Such perspective, in turn, raises the question of the role of the present research and whether its critical stance on some party-group dynamics is an act of embarrassment to the state. Yet, the position here is that, such catharsis is necessary, because staying quiet would be a silent condoning of the social and political injustice and undue concentration of financial resources, and worst of all, political power in the hands of the few who happen to be insiders at the time. (Although early to tell, the continued political apathy may lead to a situation of a single party system in Bulgaria, with the gradual dissolution of BSP and Bulgarian Left, leaving GERB as the only relevant player.) 
suppress anyone to speaks out against misconduct, particularly in the public tenders. This is by falsely claiming that misappropriation is for the common good of Bulgaria, whereas evidence is clear that this is a mechanism of resource centralisation in the party insiders and the party (chapter 8, 9; 9.5.2).

Yet, in complete contrast to Mihailov, there were others who, though still thinking in terms of East and West, did not see the Occident as necessarily morally elevated. This was completely understandable for two left-leaning respondents both of whom accused the West for teaching the earliest Bulgarian capitalist class immediately after the regime change on how to engage in market speculation and generally to economic and political misconduct in the new, democratic setting. Both of them saw the West (the EU) as the political centre that exploited marginalised Bulgaria (that particular point was also aired by Mihailov).

However, speaking as a professional in construction, Rumenov inadvertently contradicted Mihailov's argument that there is a civilizational exchange. Rumenov's position was it was wrong to assume that there was anything inherently morally elevated about the West. Rumenov discussed his time working for German Autobahn construction firms whose owners negotiated their bidding strategies at German public tenders at coffee shops. Likewise, Austrian and Greek highway construction firms exercised what was widely known strategy in the industry to register a firm de jure without having a physical office (or assets) so that when the firm is purposefully bankrupted, it would not pay its subcontractors and nothing to taken away from it (for there are no assets to take). He also shared how Occidental firms demanded a fee from any sub-contractor candidates in the city's construction projects. ${ }^{12}$ In fact, he argued that as soon as Western companies became involved in the political-economic dynamics in Bulgaria, they very quickly learned all underhand market moves, peculiar to Bulgaria and practice by Bulgarian firms alike. Rumenov argued that people are the same everywhere, and it is the strictness with which punishments are administered that matters. He also gave example with Sunny Beach resort in Bulgaria, which is almost entirely dominated by Western tourists. He argued that

12 Deliberately concealed which firms operating on what projects and where. 
their uncivil behaviour there is the result of young Western people feeling no constraints and restrictions on them, as they normally would do back home. He also gave an example with himself: he never thought twice before handing out a 20 leva banknote to the police officer for inner-city speeding, while that could not happen in Germany because for fear of the authorities there. Rules and their strict implementation is what matters and what makes the difference between Bulgaria and the West. ${ }^{13}$

In conclusion, respondents indicated that EU institutions had some constraining effect on a party's behaviour through "naming and shaming". Some respondents indicated a demand for more direct form of EU intervention that either wrests control from certain administrative duties carried out by the Bulgarian civil service or implements a more evident penalty system carried out by EU institutions. Nevertheless, a more detailed and reliable answer should come from further research. Respondents' technical competence did not extend to EU public tenders, which became relevant at the latter stages of the research, while the relevant EU legislation itself fell outside the scope of the present research agenda.

Instead majority of respondents speaking on this subject felt it were more pressing to share their personal attitudes towards the EU. Bulgarian policy-makers, speaking as retired or in the periphery of concurrent policy-making offered a range of views. Still thinking in terms of the Cold War divide, only a few of them blamed the West for the present troubles in Bulgaria. Others saw the EU as source of enlightenment and possibly an entity that could teach Bulgarian policy-makers of new and better conduct. Others, did not see anything intrinsically good or bad about the EU, because a just and rich society rests on the fairness of the rules and their application.

13 The legitimacy of this respondent is that he is a $10+$ year experience in the construction business, and who spoke in the presence of his lawyer, which means he would otherwise have not shared any of this. 


\subsection{Conclusion}

The present chapter reveals that there is a new parentela dynamic, which is similar to that originally described by La Palombara in his seminal work (1964). The new parentela dynamic is labeled type 2 parentela. It is similar to La Palombara's original parentela in that it involves the same actors (the party in power and its insider group), the same venues (party and civil service) but it is highly conflictual. The main difference lays in type 2 is a mechanism of coercion used by the party in power and/or party insider group. The position here, therefore, is that it is an add-on to La Palombara's initial parentela concept. While La Palombara's type 1 parentela dynamics focuses describes the relations between the party and the group it favours, type 2 parentela relations focus on the parente and outsiders. La Palombara's type 1 dynamic describes the cooperative relationship between the party and its insider group(s), which results in party's intervention in the civil service for mutual gain. Type 2 dynamic describes the conflictual relationship between the party and an outsider groups, which results in party's intervention in the civil service to eliminate them as political and/or market opponents (if done on behalf of the party insider). Intervention in both cases is facilitated by party political appointments, which allow the appointors to dominate any policies of interest or agencies of the civil service.

There are a number of reasons for that conflictual behaviour. First, it follows from an insider's drive to improve their market standing and is manifested in three ways. First, insiders beat the competition by dominating a fund-distributive policy-sector, such as the construction tenders discussed in chapter 8 . However, second, the present chapter demonstrates that insiders could neutralise their competition through making a one-sided offer of cooperation towards outsider groups, which largely eliminates them as market competition. This offer is usually coupled with the third mechanism to gain market advantage, the threat of regulatory inspections as a legal mean to fully disable any business activity. Options two and three are the new elements, part of type 2 but related to type 1 because they are an extension of the party-insider cooperation and former's ability to make political appointments in the civil service. 
As far as political parties are concerned, they engage in type 2 dynamics for a number of reasons. First, as mentioned already, they are motivated by the need for campaign funds (logic of conversion). As a result, and similar to their insiders, they too make the same types of offer to select outsiders, also coupling that with the threat of prejudiced regulatory inspections, unless the group concedes to participate in the kind of cooperation described in chapter 8. However, the greatest departure from type 1 is that parties also resort to targeted regulatory inspections as a policyimplementation mechanism: to suppress internal party dissent and outside interest group opposition. The inspections themselves are characterised by unusual determination of the officers to establish malpractice at all costs. This is usually manifested with sudden, determined and large-scale regulatory inspections, compared to what a business owner would perceive as a normal, regular practice. They feature but are not limited to police raids and prolonged tax investigations. Ultimately, the tell-tale element of a prejudiced inspection is regulator's insistence on litigation against the select firm (outsider) or on the revocation of its licenses on the grounds of insufficient and unfounded evidence. The objective is to paralyse outsider's business activities through long term litigation or rescission of their licenses for operation. The point is not so much to reach a verdict against the outsider, but to stall their business activities enough so that they lose their customers and market share, in favour of the party insider groups.

The existence of both parentela dynamics in turn raises the question of the implications for democracy in Bulgaria. This chapter argues that types 1 and 2 combined demonstrate oligarchic-like dynamics. If oligarchy is seen as a single, monolithic community (or elites, for lack of a better term) of limited members who collectively dominate all policy-making in a state, then no such evidence exists. To the contrary, there is competition among elites who are only able to partially dominate policy-making, in most cases until next elections. 


\section{CHAPTER 10: Validity and Variation in the Parentela Policy Network}

The present study shows the continued relevance and importance of the parentela policy-network, which was originally developed by Joseph La Palombara, who in 1960s modeled the relations between the Italian Christian Democratic party (DC) and its party insider group, Catholic Action. At the core of this party-insider group cooperation is the exchange of electoral and ideological support offered by the group, against privileged access to the policy-making process, via civil service appointments, offered by the party. Unlike other similar relationship formats, or policy-networks (Anglo-Saxon branch, as per Borzel 1998), in this policy network type, the party and its insider, or parente, subordinate the bureaucracy to their interests. A pivotal feature of the parentela, therefore, is the ability of the party to control the civil service using party political appointments. That is to say, where domestic legislation allows it, the parentela primarily rests on the ability of the ruling political party to appoint civil servants in the executive administration (Ministries, regulatory agencies, etc). The direct appointment or utilization of existing appointees ensures that the parente has full control over policy-drafting and consultations hosted by the civil service.

The only other researcher who has observed the parentela is Greer (1994), in his study on the relations between the Unionist Party of Northern Ireland (the Stormont government) and the Ulster Farmers' Union (UFU) for the period from 1920s to 1970s. In the same fashion as Catholic Action, and also facilitated by shared ideology, UFU negotiated insider access to the Unionist party by primarily advertising the electoral support that it could exert in favour of the Stormont government. Thus, a number of agricultural ministers originated from the ranks and file of the UFU. 
These distant studies on the parentela prompted two research questions, which motivated the study: First, implicitly, does the parentela still exist? Essentially, is it still a viable concept and can we observe similar relationships today and if so, what if anything - has changed? It is, in fact, staggering to see that so little research has been done on such an interesting a concept.

Secondly, a more explicitly discussed question in the literature is: what causes the parentela? From the limited research there is, two camps appear. La Palombara (1964) and Greer (1994) argue that hegemonic parties cause the parentela network. Yishai (1992) on the other hand contradicted such a causal link in her case on 1980s Israel, where the existence of hegemonic political parties did not correspond with a parentela. While some of the controversy also rests on clarifying what hegemonic party actually is, Yishai's case does cast doubt on hegemonic parties as the single cause for the parentela. Given her study, it also appears that the presence of political appointments is somehow related to parentela's formation, as it co-varies with the cases where the parentela is present.

In order to answer these implicit and explicit questions, the present study focused on Bulgaria as a possible case of the parentela. Preexisting news and investigative journalist reports indicated not only close party-group cooperation, but such parentela elements as political appointees nominated by insider groups. One particularly telling sign of the parentela was the recurring reports on the Bulgarian circles: informal groupings of a handful of firms, companies and/or oligarchs who act in concert to defend some collective interests. These circles are a metaphor used by critical Bulgarian media and public used to refer to any such suspicious partygroup interactions. Whenever a party is suspected to have close informal relations with a given business or group of businesses, then that is called a circle. To distinguish among different circles, however, the almost ritualistic practice dictates that each circle be given a name which usually is the venue where said partybusiness meetings take place, e.g. the hotel-restaurants Olimp, Admiral or Monterrey, hence respectively, the circles Olimp, Admiral and Monterrey. At the start of the study and to-date, Bulgarian media is replete with references to the circles, where the 
dawn of each one corresponds with a party change. This regularity at the time suggested a systemic phenomenon, which given the reports of political appointees nominated by said circles indicated that parentela-like dynamics were taking place.

The present study on the parentela in Bulgaria made a series of discoveries in trying to answer those questions. First of all, La Palombara's parentela relations still exist and what is new here, they can occupy non-policy-making space, between formal policy-making and political malpractice. Chapters 4 to 6 inclusive demonstrated the presence of each of the parentela elements. Chapter 4 in particular showed that, potentially, a party's control over the civil service and bureaucratic intervention in the interest of its own insider group need not be locked to mere political appointments. It could be done through administrative reforms. As chapter 4 showed, the legislative re-definition of the eligibility criteria for access to civil service policy consultations enables the ruling party to filter in and out (un-)desired groups. Though a small addition to the original parentela dynamics, this finding shows that party's intervention (and bureaucratic control) can be executed through administrative reforms in parallel to political appointments. We now see that party's arsenal of control is wider.

Chapter 8 , then, presented the parentela in a clearly non-policy-making light, with the case study on the legally permissible subversion of public tender (procurement contracts) procedure in the interest of own party insider groups (firms). That case revealed how by exploiting political appointees, the party can steer the decisions of Public Tender Committees to select the "right" procurement contestant, i.e. the party insider group. The applicability to non-policy-making contexts was further observed in chapter 9 with the prejudiced regulatory inspections. Again, (outsider) opponents to the party and/or its insider are dealt with under the guise of regular inspections by the regulatory agencies. The targeted firm is simply subjected to excessively timeconsuming (for the targeted business) inspection, court proceedings and license rescission with the sole ulterior purpose of disable their market participation. This is a new context of the parentela. This shows that the parentela relations have dual-use: 
for actual policy-making and realist power politics among political and economic actors.

Type 1 and type 2 parentela dynamics combined, i.e. the extended parentela, allow us to look at that network from a micro and particularly macro perspective. From a micro perspective, the extended parentela does contain corruptive practices. These, however, when zoomed out analytically to a macro perspective take the shape of oligarchic dynamics. As chapter 7 demonstrates, groups seek continuously to assume insider status within any (potentially) ruling political practice, but due to parliamentary elections, such insider status is never permanent and always at risk. Therefore, an oligarchy does not exist as of yet, but only oligarchic dynamics. And an important detail of this big picture is the fact that groups (say, oligarchs, affluent corporations, etc.) can only assume prominence economically and politically thanks to party's benevolence. As chapter 9 discussed, the politicization of the civil service through political appointments means that the regulatory and security agencies are under party's control, which together act as an instrument of coercion. Therefore, it is only with the cooperation with the ruling party that, say, a prospective market oligarch can assume such status. This data now allows us to see the parentela nested in micro, meso and most importantly, macro relations. The furthest analytical level allows us to generalise on the character of an entire polity (which was the intention behind the macro debate on pluralism and corporatism that necessitated a meso level of analysis), namely, that Bulgaria harbours oligarchic dynamics and that it is not an oligarchic polity so far as parliamentary elections provide a clear party change. We can now observe the relationship between the concept, oligarchy and hegemonic parties, for if a hegemonic party emerges and persists in the presence of parentela dynamics, then (hypothetically) a clear oligarchic community (in addition to dynamics) will emerge. Finally, on that same note of oligarchy, the parentela dynamics demonstrate that the notion of state capture wrongly ignores political parties, who should be seen as independent actors in possession of certain resources (political access, legislative and agenda control) which they are ready to trade. As chapters 7 and 9 indicate, given party's ability to mobilise the security and regulatory agencies, private actors are incapable to overpower a ruling party but only negotiate 
with her. And it is the fruits of such successful negotiations that the insider status of such a group could be wrongly perceived as the result of some ability to overpower, that is, coerce the ruling party. Political parties show propensity to intimidate sectoral interest groups and collude with individual large business actors, and facilitated by the parentela dynamics engage in oligarchic dynamics. On the note of actors, the data here is clear that parentela relations need not be locked to formally associated private actors as in a trade associations. Instead, a parentela relationship is also open to firms, oligarchs, corporations, etc, who can come together and defend their interests in negotiations with the ruling party as a single unit. All of this is a new and enriched perspective on the parentela, which more or less continues the oligarchy-parentela debate which La Palombara initiated and culled immediately (1964: 314-315).

In addition to all of the above, the study also made some considerable methodological advances particularly in the ability to procure and conduct interviews with elite respondents, overcoming, thereby their reluctance and resistance (Petkov and Kaoullas 2016). Moreover, it operationalised the parentela and other policy networks in a classificatory system aimed at improving comparison and aiding causality. On that note, the study also moves further the literature on policy-networks and the parentela, also because it discussed the possible causes for the extended parentela. In this instance of the (extended) parentela, we can say that hegemonic parties had no effect in its formation, rather party's insatiable need for campaign funds, a market participant's need for better market standing and (related to that) is the overall decline of an economic sector (which forces market participants to seek political protection and assistance). Again, the study uncovered more dynamics that are endogenous (type 2 dynamics) and exogenous (economic decline, campaign funds).

Finally, let us now review the above findings: section 10.1 will review the case on La Palombara's parentela in Bulgaria, 10.2 will discuss type 2 parentela dynamics, 10.3. restates the causes for the parentela, while 10.4 will look at the extended parentela from a macro perspective, before concluding with section 10.5 on the limitations and new directions for research. 


\subsection{La Palombara's Parentela Confirmed}

The findings here not only confirm the existence of La Palombara's parentela, but they also reveal a new, add-on parentela dynamic in a political context, which occupies the conceptual space between policy-making and political malpractice. Let us first review the evidence concerning the parentela. Back in chapter 2 policy networks were operationalised in terms of five categories (descriptors) as seen from the perspective of the interest group: degree of access, type of interaction, power ratio, starting or primary venue and venue scope. The parentela, therefore, is a policy network which is formed around the ruling party (primary venue: party). It is a relationship model, where the ruling party cooperates (type of interaction: cooperation) with a privileged or insider interest group (degree of access: core insider). In its original form, neither the party nor the insider seeks or is able to overpower the other (power ratio: parity). Finally, in La Palombara's parentela, the party insider extends its access and influence into the civil service by nominating new or utilising existing party political appointments (venue scope: party and civil service). Finally, the demonstration of the existence of all of said descriptors, therefore, marks, or rather indirectly detects, the existence of the parentela.

The 26 elite interviews were unequivocal that La Palombara's parentela exists in the Bulgarian political context. Chapters 4,5 and 6, looked for the 5 descriptors in the present-day (as of 2013-2015). The results discussed therein clearly indicate the existence of La Palombara's parentela. Bulgarian political parties have a considerable influence over the civil service, which attracts groups as the most influential policymaking venue, although the access threshold is considerable. Respondents conceded that while engaging with the ruling party was the most effective policy-venue, gaining access is considerably difficult as it is group's ability to provide effective campaign support (funds) that determines whether it will have an opportunity to engage with the ruling party. This is nothing new compared previous parentela studies, where UFU and Catholic Action owed their insider status largely to their ability to assist their party partner with electoral support (voters and campaign funds (chapter 6)). Similar to the original parentela, chapter 5 demonstrated that party political appointments are a regular practice, which continues to be the main 
instrument for civil service control and subsequent interference into. The data is clear that a ruling party change is accompanied by a near-ritualistic sweep of the cadres appointed earlier by the electoral party loser, substituted later by those of the new incumbent. Ultimately, this indicated that these two venues are connected, as per the parentela model.

Chapter six discussed the rest of the parentela elements which exist in the Bulgarian party-group relationship: core insider status, power parity and cooperation. Respondents unanimously argued for Bulgarian political parties' dependence on campaign funds was provided by nebulous actors. It is not clear whether the resort to extra-funding is due to exorbitant costs, which the public is unprepared to accept with the legislation regulating state subsidies for political parties, i.e. by increasing such subsidies. Or alternatively, it might be that the reliance on an insider's campaign contribution is the result of the thinking that party competition might be doing it anyways, so why abstain? Either way, respondents painted a primarily cooperative and power-balanced picture when it came to party-insider group interaction, which is based on the mutual exchange of resources. Against the access to policy-making through the civil service, which the party offers, it receives campaign funds.

All in all, the elite respondent interviews revealed all of the parentela features. As with La Palombara's study, a comparable respondent pool of elite respondents was enough to discover his parentela dynamics in the Bulgarian policy-making context. However, it did so by isolating each of the descriptors on their own. Chapters 4 to 6 inclusive essentially were sort of a detection of the parentela as opposed to immediate observation. Through the elite interviews the separate existence of each of parentela's descriptors was affirmed, without however observing that network in action. The rest of the chapters therefore attempted to provide a more direct observation of that network as a whole, active system. In doing so, the study made the discovery of new parentela actors and dynamics, which cast the question, whether and to what extent the parentela as a whole is a policy-making network or a set of actors and relations more pertinent to political malpractice, such as corruption or oligarchic policy-making. 
First of all, one new dynamic, which clearly conforms to the parentela, is the use of "administrative reforms" as a mechanism to filter in and out (un-)desired interest groups from consultations hosted by the civil service. Administrative reforms as a pre-text for mass appointments was in fact mentioned by one of La Palombara's respondents (1964: 328-329). The case study in Chapter 4, however, shows administrative reforms in a new light. They enable the party to rearrange bureaucratic consultations in a way that determines the insider group that the civil service will consult. Insufficient data prevents us from determining whether chapter 4 is indeed a case of the ruling party instilling a sectoral group as a civil service insider, following civil service reforms. Yet it is certainly indicative that it has such capabilities. The case rather demonstrates an episode where the ruling party flexes its muscles to intimidate thereby any policy dissenting groups. The case reveals how legislating deliberately exclusive eligibility criteria rendered a number of (peak) sectoral groups ineligible to take part in civil service consultations.

Another discovery concerned the nature of the insider partner to the ruling party. Elaborated in chapter 7, the Bulgarian data suggests that the parentela need not be a relationship between the party and a single, monolithic and formally associated group. Instead, the parentela observed in this study brought together firms, companies or oligarchs who acted together as a single unit in the defense of what they saw as their collective interests among them. This is at odds somewhat with existing policy-making literature, which has only discussed the relations between policy-makers and formal interest groups in a strictly policy-making setting.

This point brings us to the third and final novelty in the observed parentela dynamic in the Bulgarian case compared to its Italian counterpart. The Bulgarian case demonstrates the original parentela in a different in a different, non-policy-making context. As Chapter 8 revealed, the parentela can manifest itself when the party interferes in the process of auctioning public procurement contract. These results suggest therefore that the parentela as a model is applicable to non-policy-making 
settings. That is, the same relationship format could be used for non-policy-making ends, in parallel to policy-making ones.

\subsection{Type 2 Parentela: A New Parentela Dynamic}

An important example of the parentela in non-policy-making is the new dynamic, which the present study discovered and tentatively labeled type 2 parentela. As chapter 9 revealed, and also facilitated by bureaucratic political appointments, the misuse of regulatory agencies demonstrates that a party insider and the ruling party, or the parente in La Palombara's parlance, can aggressively suppress the business operations of outsider or intra-party policy dissenters or outsider market competitors (of the party insider). This is essentially the core of this new, aggressive type 2 parentela dynamic: the use of prejudiced regulatory inspections, where under the guise of a regular inspection, the ulterior objective is to disable the business operations of the targeted firm by registering offenses, lodging court cases or rescinding licenses.

Chapter 9 was dedicated to a number of individuals who came out and argued that the state regulatory agencies can be used by the party in power to pressure, what was implied, unsuspecting businesses through prejudiced inspections. This means that by making the right political appointments the party can control the work of those state agencies that ensure businesses have all the necessary licenses to operate and that the latter do not break any laws in doing so. Ultimately, respondents argued, certain businesses are deliberately targeted for inspection with the intention to find evidence of malpractice which would stall or discontinue their operation.

The party instigates prejudiced inspections for two reasons: to extort outsider firms for campaign funds and to intimidate policy dissenters. Both of these rationales are evident in earlier chapters. For example, going back to chapter 4, it demonstrated how administrative reforms that imposed unattainable criteria or disagreeable rules for consultative eligibility were party's way of expulsing dissenting groups from the policy-making. Prejudiced inspections, then, is the second such instrument. In that case the party targets those firms that are part of the formal association, which stands 
in the way of ruling party's (i.e. government's) intended policies. That is why, it is in this sense that type 2 parentela has policy-making relevance. Its dynamics could be used by the ruling party to eliminate any intra- or extra-party opposition to its own policies.

Furthermore, respondents also gave voice to what they dubbed the offer you cannot refuse. This was their way of saying that type 2 parentela dynamic could be used for extortion. There were a number of personal accounts where the respondents were visited by party envoys with an offer: to take part in a pre-determined public tender or be subjected to prejudiced inspections. Chapter 8 suggested that forcing the Public Tender Committees to select the tender bid by the party insider is her way of reciprocating for the campaign funds provided earlier by that group. Respondents in chapter 9, however, went further and accused ruling political parties of proactively looking for firms with whom to engage in the subversion of procurement procedures. Accordingly, the party would put pressure on the Public Tender Committee to artificially inflate the projected costs for project's completion. Then, the difference between the delivered moneys for the project's completion and the actual cost is syphoned back to the party headquarters. Speaking as immediate victims and observers, respondents argued that one cannot refuse this offer, for if they do, their business will be subjected to prejudiced inspection to the point of bankruptcy, i.e. type 2 parentela.

Furthermore, prejudiced inspections are a convenient way for the party insider to deal with its market competition. Another prominent view among respondents was that deliberate inspections were made in order to disable select business which acted as direct competitors to the party insider's. It is not through loyal competition that certain actors assume larger market share, but by literally eliminating them, through legal and continuous inspection dragging them thereby in endless court battles. These in essence, are the contexts of application of this new parentela dynamic, labeled tentatively type 2 parentela. 


\subsection{The Extended Parentela and Causality}

With the discovery of type 2 parentela dynamics we have extended the model to include another dynamic, one that fills up the conceptual space between policymaking and political malpractice. If type 1 parentela is a relationship arm that connects the ruling party with an insider group into a parente, then type 2 is a relationship arm that extends from the parente to engage outsiders. The next question that we need to deal with therefore is what causes the extended parentela (both types 1 and 2 combined together)?

The study identifies the interplay of a number of variables that explain the extended parentela (i.e. meaning both parentela types 1 and 2 as part of a single framework) as a whole. These are: sectoral economic decline (IV1) and political parties' incessant need for campaign funds (IV2). Both, however, are facilitated by parties' ability to control the civil service (Intervening Variable). Sectoral decline can spur type 1 parentela relations. As chapter 8 demonstrated, firms from the declining construction sector in Bulgaria increasingly sought closer relations with the ruling party either on a local or central level. In doing so they attempt to secure procurement contracts for themselves by engaging cooperatively with the ruling party. The cooperation is in the form of exchange, where against electoral support that the firm (or firms) provide, the party will exploit its nominees in the procurement nominees to skew the public tender specifications so as to fit the profile of the party insider firm.

However, sectoral decline, can also be seen as causing the type 2 extended dynamics. As respondents argued, firms who want to improve their market standing - not excluding declining sector - may attempt to neutralise their competition forcefully. This means that instead of procurement contracts, a party insider may request a party bureaucratic intervention that was labeled earlier as prejudiced regulatory inspections. By this we mean the (otherwise legal) inspections by the state regulatory authority (agency) which has the ulterior objective to incapacitate the targeted business. Again, it is not possible to tell with precision whether a sectoral decline will lead to type 1 or 2 dynamics, but that certainly acts as an external stimulus to the overall parentela activation. 
However, we should not lose sight of the crucial question of where hegemonic parties are in all of this? The answer is nowhere. None of the described dynamics related to the Bulgarian case of the parentela is at all connected to any hegemonic political parties. Historically, there have been none, as of 2013-2015. It is safe to say, therefore, that hegemonic parties in this case have had no effect on the parentela formation, because the latter is observed in operation in the absence of any hegemonic political parties.

In this causal relationship, what transpires as a very important element, however, are political appointments acting as an intervening variable. Neither type 1 nor type 2 parentela dynamics can function properly without political appointments. The study argues that political appointments enable the parentela, but the combined forces of campaign funds deficiency (logic of conversion) and economic sectoral decline (or the more general, need for market advantage) cause the parentela. Of course, as Greer's case demonstrates, the parentela can still function without immediate political appointments, i.e. by nominating ministers and other top-ranking government executives from the party insider, but the breadth of the parentela in that case is much more contained (1994). Nowhere does he discuss a wide-spread appointments of UFU nominees in the Northern Irish civil service of the scale described by La Palombara (1964) (Greer 1994). In the Israeli case, the absence of political appointments (due to Law restrictions) corresponded with the absence of the parentela (Yishai 1992). That is to say, party political appointments facilitate the parentela formation and the inability to perform them, greatly stalls its development and reach across the executive branch. It remains to be tested in the future, therefore, whether in other appointments-rich polities one could observe the parentela.

\subsection{New Perspectives on the (Extended) Parentela}

The collected data so far allows us to say more on the extended parentela (types 1 and 2 combined). It assumes different shapes when seen from different levels of analysis. From a micro level, as chapter 9 demonstrated, type 2 very closely overlaps with Offe's definition of corruption. Looking at the parentela on a meso-level one 
could see that it is a set of relations that are hard to determine whether they fall within corruption, policy-making or political injustice.

However, the emphasis in chapter 9 was on the macro level of analysis on the extended parentela. As mentioned in the introduction, the study on policy networks is the consequence of the earlier failed attempt to analyse the state-civil society relationships directly from a macro-level. The results of the present study, however, allow us to "climb" bottom-up analytically and engage on a macro level of analysis with the extended parentela. Accordingly, the Bulgarian polity, albeit a democracy, features oligarchic dynamics. While there is no single, coherent oligarchic community which presides over policy-making, there certainly are dynamics that both help create and eliminate elites, which to the general political observer may appear as an oligarchy. Both type 1 and 2 can be used to establish and maintain a concert of public and private actors (i.e. civil servants, politicians, interest group leadership, single businesses and/or oligarchs) who dominate policy-making, i.e. an elite. The dynamics revealed in chapter 8 can be seen as a process of such elite formation and resource accumulation. The elite forms around some of the party leadership (factions) and some of the business community. As chapter 7 revealed in the case of Multigrup, party insiders are not necessarily welcomed by the entire party rank and file. Nevertheless, a party faction and its favourite group help each other, as was the case in public tenders their pre-determination.

An incumbent elite can then solidify and expand its power (i.e. market shares, loyal appointees in the executive, favourable legislation) not only monopolising public tenders but by also "attacking" the elites that had formed during the tenure of the previously incumbent party, through type 2 dynamics. If we look at type 1 , we can see that it, too, can produce negative effects for the rivals of the incumbent parente. By gradually monopolising the most lucrative public tenders, an incumbent elite in fact prevents resources flowing into its rivals (former incumbents). However, a parente can resort to type 2 as another instrument against rival elites. Instead of silently dominating the outcomes of public tenders, party (faction) insiders can request that the businesses of their market competitors be subjected to prejudiced 
regulatory inspections with a view of incapacitating them. That is why, taken together both parentela types, formally established in this study, create only an oligarchic dynamics, as opposed to oligarchic community. Any new elite that forms around the cooperation with the parente, and in doing so by developing some primordial sense of collective identity, ultimately has very little time to mature as an oligarchy because parliamentary elections introduce a party change and with that a change within the relations of said elites.

An important factor that affects extended parentela, therefore, are the parliamentary elections which produce governments of different political parties. What dethrones an incumbent elite, then, are the democratic parliamentary elections which have the realistic chance of producing government of different political parties. In the presence of an extended parentela, a party system which is free from hegemonic political parties prevents the formation of an oligarchy. Elections have the potential to change ruling political parties and with that sever access to the civil service of their adjacent insider groups. This means there is not enough time for an elite to mature into an oligarchy. The fear of the party losing next elections forces groups to maintain good relations with all parties with potential to be in power (ideally, see chapter 7 on Multigrup). However, as resources to do so may not be enough, party insiders of today may find themselves outsiders tomorrow. At the same time, remaining in cooperation with one party might make others see that group as a rival as well, thus long-term cooperation with one party may preclude its access to others.

Essentially parliamentary elections maintain the competition among elites. These complex and highly volatile extended parentela dynamics are reset every time an effective party change takes place. With a party change come new elites or old ones are returned and so begins another round of conflict against other rival elites (old and new) following the logic of the extended parentela. That is why, Bulgaria is a democracy which harbors oligarchic dynamics as opposed to community.

However, all of this depends on the assumption that the party system is capable of producing genuinely different governments. It can only be hypothesised at this stage 
that extended parentela dynamics, coupled with elections that produce all-party coalitions or hegemonic political parties in power, will produce a stable and coherent oligarchic community. The inability to substitute the incumbent political party due to lack of alternatives (hegemonic) or due to consociational policy style means, that each of the party insiders would also have to seek compromises with their counterparts. Ultimately, this will have the effect of dampening competition and solidify a common identity, or sense of community entitled to rule.

And it is these controversial links of parentela's relationship with oligarchy that beg the question whether it is for ethical reasons that La Palombara had censored himself from pursuing when he completely dismissed the idea that there might be some connection between his parentela and oligarchy (1964: 314-315). This is quite understandable, given the danger of readers confusing the parentela for a synonym of oligarchy (or corruption). Given the close overlap between the observations in this and La Palombara's studies, it is surprising that respondents on the Italian parentela were silent on the behaviour of politically controlled state regulatory and inspection organs. It is this silence that makes La Palombara's narrative suspicious of possibly withholding data. If not, then it would mean that the parentela relationships have evolved in time, incorporating thereby new dynamics, which in the end make it unethical to close our eyes for the possible relationship between this network type and oligarchy.

\subsection{Conclusion: Limitations and Future Research}

The Bulgarian study on the parentela is subject to a number of limitations due to the difficulty in navigating the Bulgarian political landscape, brought about by the rampant social and political distrust and suspicion. The study rests on the accounts of 26 elite interviews. Despite the fact that it selected a diverse pool of individuals who had formed their views at different times and policy-making positions, a larger respondent pool would surely have solidified study's validity. Another limitation of the study was the failed Freedom of Information Request on the rate and scale of civil service appointments in election years. That has deprived us from up-to-date information on the scale of political appointments across time. Another limitation 
was the difficulty in receiving access. While the respondent pool is overall reliable and valid, the distrust towards the researcher considerably disabled access raw data from respondents.

One item in particular, however, proved hard to address effectively: to give specific examples of a private, formally organized actor who cooperates with the ruling party. Instead, their presence, in an informal form at that, is stated indirectly - based on the accounts of the losing businesses (chapter 8). Yet, on the other hand, specifying exact firms and individuals as the private partners in a parentela, might also be interpreted as a formal accusation of illegal practices, particularly when one views the parentela as evidence of corruption. That would be unacceptable, as the present study aims to cause as little effect on the observed actors and their relationships as possible.

In any case, future research projects on the parentela have to do better in gaining access in obtaining interviews, and more importantly, documentary evidence, which appears to be scant in light of previous parentela studies. Neither Greer (1994), nor La Palombara (1964) rest their cases on abundant documentary evidence, which is largely because this relationship leaves very little of that. It is hard to imagine why a party would keep a documentary track of the otherwise informal bargaining on the nomination made by its insider group or firm.

It is also interesting to see whether there are parentela relations in Western polities with high levels of political appointments. Kopecki and Spirova (chapter 5) revealed high levels of political appointments in Germany, for example. In fact, Bulgaria was a mid-ranking state on political appointments. The question is whether other states with high degree of political appointments host parentela relations and if so, is that a combination of causes, such as the need for campaign funds and declining economic sector that are responsible. This, in other words, would corroborate the findings in the present research.

Chapter 4 revealed that certain administrative reforms can potentially be used in the interest of party insiders, but more generally, showed that administrative reforms are 
another mechanism of party's control over the bureaucracy (in parallel to appointments). The significance of this finding is that in theory, the parentela can exist without any party political appointments. Instead, the advantage of a party insider would be served by re-defining the eligibility criteria for civil service policy consultations in a way that would give that group an insider status in the civil service, in parallel to that in the ruling party. The question is, can we observe any such dynamics more closely either in Bulgaria or elsewhere? And more generally, can we observe cases of a party's control over a bureaucracy without party political appointments, i.e. by more indirect means? How else can a party control the bureaucracy in own interest, or that of its insider group, without political appointments and administrative reforms? Addressing these questions in the future would hopefully help us better understand the role and utility of political parties in future democratic development.

On that note and section 9.5.3 where it argues that private state capture can only occur with a party's facilitation and cooperation there comes the research or policy question of the benefit of political parties. Following section it appears political parties are an unnecessary intermediary elite that colludes with or coerces the business one, which it is supposed to regulate. Therefore, the question is whether democratic polities can do without political parties and elections rest on candidates nominated by the myriads interest groups? Would candidates whose origin of nomination is publicly evident make resulting policies more transparent? Would that provide the much needed direct popular participation in policy-making?

Chapter 2 on the operationalisation of the parentela developed a classificatory scheme of policy networks. It would be interesting to see whether we can observe unusual descriptor combinations in polities which are border-line democracies. For example, the prisoner insider appears as an impossible combination of a group with insider access, yet, which is highly suppressed by policy-makers. Maybe such descriptor combinations exist in nascent or near-democratic polities. Another highly important methodological avenue for further research is whether we can quantify the Anglo-Saxon branch of policy networks, following Dowding's original idea, yet 
mindful against the blind transposition of quantitative indicators used for other models in other disciplines. Finally and more generally, it is interesting to see whether the parentela harbours other, new dynamics and how the model relates to oligarchy.

In any case, the present study not only confirms the continued validity of the parentela model, but it discovered variations of the same, i.e. type 2. It remains to be seen whether any of these relationships are also relevant to outside political systems, particularly EU institutions and states with high level of political appointments. The study also shows the parentela under different magnification, which reveals its borderline with concepts such as corruption and oligarchy, which in turn opens further avenues of research on how it relates to either of them. We should also not lose sight of the fact that while hegemonic political parties have no effect on the parentela formation, they relate to the same concept when studying its relationship with oligarchy.

A bit more than 50 years after its discovery, La Palombara's parentela still exists. Moreover, it has shown other new dynamics, which have been either deliberately withheld or never existed in the past. In any case, the model is still relevant and new aspects of its internal and external dynamics were added. Ultimately, the study has shown that the parentela has been under-researched and it deserves more credit than its silent omission from the academic debate. 


\section{Bibliography}

Adler, P. \& Adler, P. (2001). The Reluctant Respondent. In: Gubrium, J. \& Holstein,

J. (Eds.). Handbook of Interview Research. Thousand Oaks: Sage. 515-535.

Administrative Registry, Retrieved from: http://ar2.government.bg/ras/

Another Deputy Minister connected with the Skull was Appointed [Назначиха още

един зам.-министьр свързан с Черепа] (2013, July 23). Bivol [Биволь].

Retrieved from $\underline{\text { https://bivol.bg/botev-cherepa.html }}$

Aoslund, Anders. (2014). Oligarchs, Corruption, and European Integration. Journal of Democracy, 25 (3), 64-73.

Atkinson, M. M. \& Coleman, W. D. (1989). Strong States Weak States: Sectoral

Policy Networks in Advanced Capitalist Economies. British Journal of

Political Science, 19:1, 47- 67.

Barker, D. W. M. (2013). Oligarchy or Elite Democracy? Aristotle and Modern

Representative Government. New Political Science, 35 (4), 547-566.

Barnes, A. (2007). Extricating the State: The Move to Competitive Capture in Post-

Communist Bulgaria, Europe-Asia Studies, 59(1), 71-95.

Bakalov, Ivan (2011). In the Shadow of Borisov [В Сянката на Борисов]. Sofia: E-

Press.

BCCI (Bulgarian Chamber of Commerce and Industry). (2011a, December 15).

Transcripts of Parliamentary Debates. Retrieved from

http://www.bcci.bg/bulgarian/parliament/

BCCI (Bulgarian Chamber of Commerce and Industry). (2011b, December 16),

BCCI Press Release, Retrieved from http://www.bcci.bg/news/2613.

BCCI (Bulgarian Chamber of Commerce and Industry). (2011c, December 15).

BCCI Press Release. Retrieved from http://www.bcci.bg/news/2578.

BCCI (Bulgarian Chamber of Commerce and Industry). (2011d, December 15).

Parliamentary Debates Transcripts, \#236. Retrieved from

http://www.bcci.bg/bulgarian/parliament/236.doc

BCCI (Bulgarian Chamber of Commerce and Industry). (2011e, December 15).

Parliamentary Debates Transcripts, \#237. Retrieved from

http://www.bcci.bg/bulgarian/parliament/237.doc

BCCI (Bulgarian Chamber of Commerce and Industry). (2011f, December 15).

Parliamentary Debates Transcripts, \#238. Retrieved from http://www.bcci.bg/bulgarian/parliament/238.doc 
Belur, J. (2014). Status, gender and geography: power negotiations in police research. Qualitative Research, 14(2): 184-200. DOI: $10.1177 / 1468794112468474$.

Berry, J.M. (2002). Validity and Reliability Issues in Elite Interviewing. PS: Political Science and Politics, 35 (4), 679-682.

Beyrle, John. (2005a). Top Bulgarian Money Launderer Shot Dead in Sofia.

Telegram, 05SOFIA1847_a; Retrieved from:

https://wikileaks.org/plusd/cables/05SOFIA1847_a.html

Bondy, C. (2013). How did I get here? The social process of accessing field sites.

Qualitative Research, 13(5): 578-595. DOI: 10.1177/1468794112442524.

Borzel, T. (1998). Organising Babylon: On the Different Conceptions of Policy Networks. Public Administration, 76, 253-273.

Braguinsky, S. (2009). Postcommunist Oligarchs in Russia: Quantitative Analysis. Journal of Law and Economics, 52 (2), 307-349.

Budimir Kuyovich Testifies in Court in Kazanlak [Будимир Куйович свидетелства пред съда в Казанлък]. (2008, January 15). BGNES, Retrieved from http://www.vesti.bg/novini/liuben-gocev-predstavi-pred-zhurnalisti-krygamonterej-1148242.

Bulgarian Council of Ministers of Bulgaria. (2014) We Are Working for the People: Strategy for Development of the State Administration [Работим за хората: Стратегия за развитие на държавната администрация], Retrieved from http://www.strategy.bg/PublicConsultations/View.aspx?lang=bg-

BG\&Id=1152

Chakarov, Kostadin. (2010). The Onslaught of the Democrats [Hашествието на демократите]. Sofia: Trud.

Chalakov, Ivan. (2003) 'Socialism as a Society of Networks and the Problem of Economic Development' [Социализмът като общество на мрежите и проблемът с икономическото развитие], Sociological Problems [Социологически проблеми], 1(2), 2003, 106-130.

Chalakov, I., Bundzhulov, A., Hristov, I., Deyanova, L., Nikolova, N., Deyanov, D., Mitev, Slavenkov, B., T., Simeonov, O., Chipev, Pl., Stoynev, V., \& Felisi, St. (2008). The Networks of Transition - What Actually Happened in Bulgaria after 1989? Sofia: East-West [Чалъков, Ив., Бунджулов, А., Христов, И., Деянова, Л., Николова, Н., Деянов, Д., Митев, Т., Славенков, Б., Симеонов, О., Чипев, П., Стойнев, В., Фелиси, Ст. (2008). Мрежите на 
прехода - Какво се случи всъщност в България след 1989. София: ИзтокЗапад].

Checkel, J. T. (2006). Tracing Causal Mechanisms. International Studies Review, 8(2): 362-370. doi:10.1111/j.1468-2486.2006.00598_2.x

CIEB (Chamber of Industrialists and Employers in Bulgaria), (2013, February 4), Declaration From the Representatives Organizations on a State Level For Their Discontinuation of Participation in NCTC (National Council for Tripartite Cooperation) [ДЕКЛАРАЦИЯ ОТ ПРЕДСТАВИТЕЛНИТЕ ОРГАНИЗАЦИИ НА РАБОТОДАТЕЛИТЕ НА НАЦИОНАЛНО РАВНИЩЕ ЗА ПРЕКРАТЯВАНЕ УЧАСТИЕТО ИМ В НСТС], KRIB, Retrieved from: http://krib.bg/bg/positions/Deklaracia-ot-predstavitelniteorganizacii-na-rabotodatelite/

Classificator of Positions in the Bulgarian Civil Service. (2012). Decree of Ministerial Council Nr. 129 of 26.06.2012. (Last updated with State Gazette [Дьржавен Вестник] issue 64 of 21.08.2015). Retrieved from http://www.lex.bg/bg/laws/ldoc/2135799910

Compston, H. (2009). Policy Networks and Policy Change: Putting Policy Network

Theory to the Test. Basingstoke: Palgrave-Macmillan.

Council of Ministers Accepted a Strategy for the Development of the Civil Service [Министерски Съвет прие Стратегия за Развитие на Администрацията]. (2014, March 5). BGNES, Retrieved from http://www.vesti.bg/bulgaria/politika/ms-prie-strategiia-za-razvitie-naadministraciiata-6006775

Council of Ministers. (2013, August 28). Motives Justifying the Law on Amendment and Addition of the Law on Public Tenders. [Мотиви към Закона за изменение и допълнение на Закона за Обществените поръчки]. Retrieved from: http://www.government.bg/fce/001/0211/files/Motivi zid zop.doc MD5 Checksum: 086b84a5356d0b68af8c2894cbd7e54b

Council of Ministers. (2013, July 26). Motives Justifying the Law on Amendment and Addition of the Law on Public Tenders. [Мотиви към законопроект за изменение и допълнение на Закона за обществени поръчки]. Retrieved from: http://ksb.bg/images/stories/zid zop motivi\%20(2).pdf MD5 checksum: 6fb9e07c446df148a7333961bfb3bc57

Cox, A. (1988). The Old and New Testaments of Corporatism: Is it a Political Form or a Method of Policy-making?. Political Studies, 36, 294-308. 
CPC (Commission for Protection of Competition). (2010). List of Circumstances, whose Presence Arouses Suspicion for Auction Manipulations. [Списък на обстоятелства, наличието на които обуславя съмнение за тръжни манипулации]. (СРC Decision $\mathrm{Nr} 570$ of 20.05.2010). Retrieved from: http://www.cpc.bg/storage/file/CPC\%20Check\%20list\%20Bid-rigging $\%$ 20final.doc MD5 checksum: 407ddeb0a8e244a585c89a005d5cf736

CPC (Commission for Protection of Competition). (2010). Guidance Towards Resistance against Auction Manipulations in the Procedures of Granting Public Tenders. [Насоки за противодействие срещу тръжните манипулации в процедурите за възлагане на обществени поръчки]. (Legal aid to be read in connection with CPC 570/20.05.2010). Retrieved from: www.cpc.bg\%2Fstorage $\% 2$ Ffile $\% 2$ FCPC $\% 2520$ Guidelines $\% 2520$ Bidrigging\%2520final.doc MD5 checksum: 2c3399221024edccd69017ceca198577

Davies, P. H. J. (2001). Spies as Informants: Triangulation and the Interpretation of Elite Interview Data in the Study of the Intelligence and Security Services, Politics, 21(1), 73-80.

Denitch, B. (1972). Elite Interviewing and Social Structure: An Example from Yugoslavia. The Public Opinion Quarterly, 36 (2): 143-158.

Desmond, M. (2004). Methodological Challenges Posed in Studying an Elite in the Field. Area 36 (3): 262-269.

Dogan, Akhmed, (2005, June 26), Mediapool, Retrieved from: http://www.mediapool.bg/show/?storyid=106410.

Dogan, Akhmed, (2009), TV Broadcast, Retrieved From: https://www.youtube.com/watch?v=CsPS15PKwxM

Dowding, K. (2001). There Must Be End to Confusion, Political Studies, 49, 89-105. Dowding, K. (1995). Model or Metaphor: A Critical review of the Policy Network Approach. Political Studies, 43, 136-158.

Enguix, B. (2014). Negotiating the field: rethinking ethnographic authority, experience and the frontiers of research. Qualitative Research, 14(1): 79-94. DOI: $10.1177 / 1468794112465635$.

Falleti, T. (2006). Theory-Guided Process-Tracing in Comparative Politics: Something Old, Something New. APSA-CP Vol 17, No. 1., 9-13.

Falleti, T. \& Lynch, J. (2009). Context and Causal Mechanisms in Political Analysis. Comparative Political Studies, 42 (9), 1143-1166.

Fishkin and 
Gais, T. L., Mark A. Paterson, Jack L. Walker (1984). Interest Groups, Iron Triangles and Representative Institutions in American National Government. British Journal of Political Science, 14(2), 161-185.

Galbraith, J. K. (1983) Power and Organization., in Lukes, S. (ed.) (1986) Power. New York: NYUP.

Ganev, V. (2001). The Dorian Gray Effect: Winners as State Breakers in Postcommunism, Communist and Postcommunist Studies, 34, 1-25.

Georgieva, Svetlana. (2005, October 31). Haralan Aleksandrov: The Murder of Kyulev is a Blow against the Elite of Transition [Харалан Александров: Убийството на Кюлев е Удар Срещу Елита на Прехода]. Dnevnik, Retrieved from

http://www.dnevnik.bg/intervju/2005/10/31/96385 haralan_aleksandrov_ubii stvoto na kjulev e u dar/

GERB Includes the Circle Capital in Power [ГЕРБ Вкарва във Властта Кръга

"Капитал"]. (2009, July 9). Retrieved from http://www.vsekiden.com/54385/\%D0\%B3\%D0\%B5\%D1\%80\%D0\%B1-

\%D0\%B2\%D0\%BA\%D0\%B0\%D1\%80\%D0\%B2\%D0\%B0-

\%D0\%B2\%D1\%8A\%D0\%B2-\%D0\%B2\%D0\%BB

\%D0\%B0\%D1\%81\%D1\%82\%D1\%82\%D0\%B0-\%D0\%BA

\%D1\%80\%D1\%8A\%D0\%B3\%D0\%B0-\%E2\%80\%9C\%D0\%BA

$\% \mathrm{D} 0 \% \mathrm{~B} 0 \% \mathrm{D} 0 \% \mathrm{BF} \% \mathrm{D} 0 \% \mathrm{~B} 8 \% \mathrm{D} 1 \% 82 \% \mathrm{D} 0 \% \mathrm{~B} 0 /$

Gilens, M., \& Page, B. I. (2014). Testing Theories of American Politics: Elites, Interest Groups, and Average Citizens. Perspectives on Politics, 12, 564-581. Goldstein, K. (2002). Getting in the Door: Sampling and Completing Elite Interviews. Politics, 35(4): 669-672.

Grant, W. Insider Groups and Outsider Groups. ECPR Joint Sessions, Berlin University of Warwick, 1977.

Grant, W. Insider Groups, Outsider Groups and Interest Group Strategies in Britain. University of Warwick Working Papers, No1, 1978.

Grant, W. (2004). Pressure Politics: The Changing World of Pressure Groups. Parliamentary Affairs, 57(2), 408- 419.

Grazhdanska, Svilena. (2015, March 23). The Fourth Round Table on Modernization of Public Tenders has Begun [Започна четвъртата крьгла маса за модернизация на обществените поръчки], Vestnik Stroitel. Retrieved from: 
http://vestnikstroitel.bg/news/105818 zapochna-chetvrtata-krgla-masa-za-

modernizaciya-za-obschestvenite-porchki/

Gubrium, J. \& Holstein, J. (1995). The Active Interview. Qualitative Research

Methods, 37. Thousand Oaks: Sage.

Gubrium, J., \& Holstein, J. (2001). Handbook of Interview research Context and

Method. Thousand Oaks: Sage.

Hay, C. (1998). The Tangled Webs We Weave, in Marsh, David (Eds.) (1998).

Comparing Policy Networks. Buckingham: Open University Press.

Healey, M. J. \& Rawlinson MB. (1993). Interviewing Business Owners and

managers: a Review of Methods and Techniques. Geoforum, 24 (3): 339-355.

Heclo, H. (1978). Issue networks and the executive establishment, in A. King (Ed.).

The New American Political System. Washington, DC: American Enterprise Inc.

Heisler, M. (1979). Corporate Pluralism Revisited: Where is the theory?.

Scandinavian Political Studies, 2(3), 277-297.

Herod, A. (1999). Reflections on Interviewing Foreign Elites: Praxis, Positionality,

Validity, and the Cult of the Insider. Geoforum, 30 (4): 313-327.

Hristova-Valcheva, K. \& Toneva-Metodiava. L. (2014). Lobbying in Bulgaria:

Interests, Influence, Politics. Sofia: Transparency International.

Iliev, Petkan (2011, December 22). The Business Has Hypocritically Demanded:

Economy without Friendship Circles [Бизнесът поиска лицемерно:

Икономика без приятелски кръгове!], Retrieved from http://frognews.bg/? news $=41395$.

Jordan, G. (1981). Iron Triangles, Woolly Corporatism and Elastic Nets: Images of the Policy Process. Journal of Public Policy, 1(1), 95-123.

Jordan, G. (1984). 'Pluralistic Corporatism and Corporate Pluralism', Scandinavian Political Studies, 7:3, 137-153.

Jordan, G. (1990). Sub-Governments, Policy Communities and Networks: Refilling the Old Bottles, Journal of Theoretical Politics, 2(3), 319-338.

Jordan, G., William Maloney \& Andrew McLaughlin, (1992). Insiders, Outsiders and

Political Access?. British Interest Group Project, 8, Aberdeen: University of Aberdeen.

Jordan, G. \& Klaus, S. (1992). A Preliminary Ordering of Policy Networks. European Journal of Political Research, 21, 7-27.

Jordan, G. (2005). Bringing Communities Back In? A Comment on Grant. British Journal of Politics and International Relations, 7, 317-321.

Jordan, G., \& Schubert, K. (1992). A Preliminary Ordering of Policy Network Labels. European Journal of Political Research, 21(1), 7 -27. 
Kopecky, P. \& Spirova, M. (2011). 'Job for the boys?' Patterns of Party Patronage in Post-Communist Europe', West European Politics, 34(5), 897-921.

Kostadinov, Slavey (2008, October 14), The Adviser of Zhan Videnov - Nevena Gyurova: Rumen Spasov Even Robbed his Brother Lachezar with 15 Million [Съветничката на Жан Виденов - Невена Гюрова: Румен Спасов ограби дори брат си Лъчезар с 15 милиона. Blitz, Retrieved from http://www.blitz.bg/article/7420.

Kostadinov, S. (2011a, June 16). Nevena Gyurova: Lukanov Very Much Liked to Finish off the One on the Ground [Невена Гюрова: Луканов много обичаше да бие падналия], Blitz, http://www.blitz.bg/news/article/112273.

Kostadinov, S. (2011b, June 11). Nevena Gyurova: Had Zhan Published the White Book, History Would Have Been Different [Невена Гюрова: Ако Жан бе публикувал бялата книга, историята щеше да е друга]. Blitz, Retrieved from http://www.blitz.bg/news/article/110150.

Kostadinov, S. (2007, June 6). Krasimir Raydovski: Mircho the Gipsy Keeps the Elite in Check with a Pornvideoteque [Красимир Райдовски: Мирчо Циганина държи елита в шах с порновидеотека]. Blitz, Retrieved from http://www.blitz.bg/article/3587

Kvale, S. (2006). Dominance through Interviews. Qualitative Inquiry, 12(3): 480500.

Laurila, J. (1997). Promoting Research Access and Informant Rapport in corporate Settings: Notes from Research on a Crisis Company. Scandinavian Journal of Management, 13(4), 407-418.

Lavergne, D. (2010). The Experts of Transition [Експертите на Прехода]. Sofia: Iztok-Zapad. Original publication as a $\mathrm{PhD}$ thèses: Anguelova-Lavergne, $\mathrm{D}$ and Gossiaux J-F (2008) La 'main invisible' de la transition: think tanks et transition démocratique en Bulgarie après 1989. PhD Thèses, École des hautes études en sciences sociales, France.

Law on the Administration [Закон за Администрацията] (1998). (Last amended with State Gazette issue 27 of 25.03.2014). Retrieved from http://www.lex.bg/bg/laws/ldoc/2134443520

Law on Amendment and Addition of the Law on Public Tenders. (2014). Amendment ref 302-01-14 / 29.08.2013, in effect of 01.07.2014. Retrieved from: http://www.ksb.bg/images/NOVO1/ZOP/ZOP-11/ZOP 13 05 2014.pdf MD5 Checksum: db144c9d696f9a992085d3fc2e898337 
Law on Guaranteeing and Protection of Agricultural Producers (draft) [Законопроект за Гарантиране и Закрила на Земеделските Производители]. (1994). (Reference Number 102-33-334 of 23rd June 1994).

Law on Local Self-Government and Local Administration. [Закон за местното самоуправление и местната администрация]. (Last amended State Gazette 53 of 27.06.2014) Retrieved from: http://lex.bg/bg/laws/ldoc/2132580865

Law on Protection of Agricultural (draft) [Законопроект за Закрила на земеделските производители]. (1993). (Rreference Number 102.33-638 of 23rd December 1993).

Law for Publicity of Assets of Individuals Assuming High State Public and other Duties in the Public and Private Sector [Закон за публичност на имуществото на лица, заемащи висши държавни, обществени и други длъжности в публичния и частен сектор] (In effect with State Gazette issue 17 from $\quad$ 06.03.2015). Retrieved from

http://www.lex.bg/mobile/ldoc/2134920704

Law on the State Servant [Закон за Дьржавния служител]. (1998). (Last amended State Gazette issue 54 of 17.08.2015). Retrieved from http://lex.bg/laws/ldoc/2134673408

Leach, D. K. (2005). The Iron Law of What Again? Conceptualizing Oligarchy across Organizational Forms. Sociological Theory, 23 (3), 312-337.

Leech B. L. (2002). Asking Questions: Techniques for Semistructured Interviews. PS: Political Science and Politics. 35(4): 665-668.

Lillecker, D.G. (2003). Interviewing the Political Elite: Navigating a Potential Minefield. Politics, 23: 207-214.

Lilov, G. (2009). The Secret Project Boyko Borisov [Тайният Проект Бойко Борисов]. Sofia: Kaylas [Кайлас].

Lilov, G. (2010a). The Secrets of the Big Players [Тайните на Големите Играчи]. (Volume 1). Sofia: Kaylas.

Lilov, G. (2010b). The Secrets of the Big Players. (Volume 2). Sofia: Kailas.

Lukes, S. (1974). Power a Radical View ( $1^{\text {st }}$ ed). Studies in Sociology. British Sociological Association. Basingstoke: Macmillan..

Lukes. S. (2005). Power a Radical View ( $2^{\text {nd }}$ ed). British Sociological Association. Basingstoke: Palgrave Macmillan 
McDowell, L. (1998). Elites in the City of London. Environment and Planning, A (30): 2133-2146.

McEvoy, J. (2006). Elite Interviewing in a Divided Society: Lessons from Northern Ireland. Politics, 26 (3): 184-191.

Maloney, W. and Richardson, J. (1994). Water policy-making in England and Wales:

Policy communities under pressure. Environmental Politics, 3(4), 110-138.

Maloney, W. \& Jordan, G. (1997). Accounting for Subgovernments: Explaining the

Persistence of Policy Communities. Administration \& Society, 29(5), 557583.

Marsh, D. \& R. A. W. Rhodes (Eds.) (1992). Policy Networks in British Government. Oxford: Oxford University Press.

Marsh, D. (Eds.). (1998). Comparing Policy Networks. Buckingham: Open University Press.

Marsh, D. \& Rhodes, R. A. W. (1992). Policy Network in British Politics: A Critique of Existing Approaches, in Marsh, David and R. A. W. Rhodes (Eds.) (1992). Policy Networks in British Government. Oxford: Oxford University Press.

Marsh, D. \& Smith, M. (2000). 'Understanding Policy Networks: towards a Dialectical approach', Political Studies, v. 48, 4-21.

Martin, R. (1983). Pluralism and the New Corporatism, Political Studies, 31, 86-102. Mertkan-Ozünlü, S. (2007). Reflexive Accounts about Qualitative Interviewing within the Context of Educational Policy in North Cyprus. Qualitative Research, 7(4): 447-459.

DOI: $10.1177 / 1468794107082301$.

Mikecz, R. (2012). Interviewing Elites: Addressing Methodological Issues. Qualitative Inquiry, 18(6): 482-493.

Mitov, B. (2012, June 4). 'Kalina Ilieva Admitted to Third Class Degree and Got Away 3 Years in Prison [Калина Илиева се призна за среднист и се отьрва с 3 години условно], Mediapool, Retrieved from http://www.mediapool.bg/kalina-ilieva-se-prizna-za-srednist-i-se-otarva-s-3godini-uslovno-news193631.html.

Mullings, B. (1999). Insider or Outsider, Both or Neither: Some Dilemmas of Interviewing in a Cross-Cultural Setting. Geoforum. 30(4): 337-350.

Neal S. \& McLaughlin, E. (2009). Researching Up? Interviews, Emotionality and Policy-Making Elites. Journal of Social Policy, 38 (4): 689-707.

Nonini, D. M. (2005). Making the Case for Kleptocratic Oligarchy (as the Dominant Form of Rule in the United States). Social Analysis: The International Journal of Social and Cultural Practice, 49 (1), 177-189. 
Obasi, C. (2014). Negotiating the insider/outsider continua: a Black female hearing perspective on research with Deaf women and Black women. Qualitative Research, 14(1): 61-78. DOI: 10.1177/1468794112465632.

Odendahl, T. \& Shaw A. M. (2001). Interviewing Elites. In: Gubrium, J and Holstein J (Eds.) Handbook of Interview Research: Context and Method. Sage: Thousand Oaks, 299-316.

Offe, C. (2004). Political Corruption: Conceptual and Practical Issues. In Kornai, J. \& Rose-Ackerman, S. (Eds.) Building a Trustworthy State in Post-Socialist Transition. Basingstoke: Palgrave Macmillan.

Ostrander, S. A. (1995). Surely you're Not in This Just to Be Helpful: Access, Rapport, and Interviews in Three Studies of Elites. In Imber, J. B. (Eds.) Studying Elites Using Qualitative Methods. (3ed). Sage: Thousand Oaks, 133-150.

Paechter, C. (2013). Researching sensitive issues online: implications of a hybrid insider/outsider position in a retrospective ethnographic study. Qualitative Research, 13(1): 71-86. DOI: 10.1177/1468794112446107.

Pappi, F. U. \& Henning, C. (1998). Policy Networks: More than metaphor?. Journal of Theoretical Politics, 10(4), 553-575.

Pardew, James. (2005b). (U) Bulgarian Organized Crime (C-CN5-00054). Telegram, 05SOFIA1207 a, Retrieved from: https://wikileaks.org/plusd/cables/05SOFIA1207_a.html

Peters, G., (1998). Policy Networks: Myth, Metaphor and Reality. In Marsh, D. (Eds.). Comparing Policy Networks. Buckingham: Open University Press.

Peterson, J. (2003). Policy Networks, Political Science Series, v. 90. Vienna: Institute for Advance Studies.

Petev, N. (1998). Beyond the Political Theater through the View of Zhan Videnov. [Отвъд политическия театър през погледа на Жан Виденов]. Sofia: Hristo Botev.

Petkov, M. P. \& Kaoullas, L. G. (2015). Overcoming Respondent Resistance at Elite Interviews, Qualitative Research, 18 July 2015, Retrieved from http://qrj.sagepub.com/content/early/2015/07/17/1468794115589646.abstract doi: $10.1177 / 1468794115589646$.

Popov, Gancho. (2013). Written policy statement on proposed amendments on the Law on Amendment and Addition of the Law on Public Tenders 302-01-14 / 29.08.2013. Reference number: 167/27.09.2013. MD5 Checksum: 6a74fc54993c127d49894e0e84804620 
Raychev, A. (2003). Genesis, Mutation and Degeneration of the Second Networks,

Sociological Problems, 1: 2, 5-13 [Райчев, Андрей (2003) Генезис,

Мутация и Дегенерация на Вторите Мрежи', Социологически Проблеми, $1(2), 5-13]$.

Raychev, A. \& Stoychev, S. (2008). What Happened? A Narrative about the

Transition in Bulgaria and a Bit Thereafter. Sofia: Trud [Райчев, A. \&

Стойчев, К. (2008) Какво се случи? Разказ за прехода в България и малко

след него 1989-2004. София: Труд]

Rhodes, R.A.W. \& Marsh, D. (1992). New Directions in the Study of Policy

Networks. European Journal of Political Research, 21(1-2), 181-205

Richards, D. (1996). Elite Interviewing: Approaches and Pitfalls. Politics, 16, 199204.

Richardson, J. (2000). Government, Interest Groups and Policy Change. Political Studies, 48, 1006-1025.

Ripley, R. A. \& Franklin, G. A. (1987). Congress the Bureaucracy and Public Policy.

(4th Ed.). Ohio: The Dorsey Press.

Rivera S.W., Kozyreva, P. M., \& Sarovskii, E. G. (2002). Interviewing Political

Elites: Lessons from Russia. PS: Political Science and Politics, 35 (4), 683688.

Russel, B. (1938) The Forms of Power., in Lukes, S. (ed.) (1986). Power: New York: NYUP

Sabot E.C. (1999). Dr Jekyll, Mr H(i)de: The Contrasting Face of Elites at Interview. Geoforum 30 (4): 329-335.

Seldon, A. (1998). Interviews. In: Seldon, A. (Eds.). Contemporary History: Practice and Method. Basil Blackwell: Oxford, 3-16.

Shinar, C. (2015). The Russian Oligarchs, from Yeltsin to Putin. European Review, 23 (4), 583-596.

Shlapentokh, V. (2004). Wealth versus Political Power: The Russian Case, Communist and Post-Communist Studies, 37, 135-160.

Shumenska Zarya. (2015).Issue 40, (global issue) 12420) of 27.02.2015. Copy in possession of author.

Siromahova, Sonya. (2009, September 1). Kostadin Chakarov: The Congress of BSP

Would Have the Effect of a Bandage on a Wooden Leg [Костадин Чакъров: Конгресът на БСП ще има ролята на компрес върху дървен крак], Obshtestvo, Retrieved from: http://www.obshtestvo.net/content/view/1361/6 /. 
Slavcho Hristov is assembling a New Circle "Admiral" [Славчо Христов събира нов кръг Адмирал]. (2011, January 07). Frognews, Retrieved from: http://frognews.bg/news 30454/Slavcho_Hristov_sabira_nov_krag $\%$ 20Admiral I

Smith, K. E. (2006). Problematising Power Relations in 'Elite' Interviews. Geoforum 37: 643-653.

Spirova, M. (2012). 'A Tradition We Don't Mess With' Party patronage in Bulgaria. In: Kopecky P., Mair P., Spirova M. (Eds.) Party Patronage and Party Government in European Democracies. Oxford University Press.

Stephens, N. (2007). Collecting data from elites and ultra elites: telephone and faceto-face interviews with macroeconomists. Qualitative Research, 7(2): 203216. DOI: $10.1177 / 1468794107076020$.

Sugarev, E. (2014, March 8). Who? 15. BZK - or how General Brigadir Asparuhov Saved One of the Largest Bank Thieves [Кой? 15. БЗК-или как генерал Бригадир Аспарухов спаси един от най-крупните банкови апаши]. Svobodata.com, Retrieved from, http://www.svobodata.com/page.php? pid $=13341$

Tansey, Oisin. (2007). Process Tracing and Elite Interviewing: A Case for Nonprobability Sampling. PS: Political Science and Politics, 40 (4), 1-23.

The Circle Kapital Fostered a Party [Кръгът Капитал Осинови Партия]. (2010, February 25) 19min [Деветнадесет минути], Retrieved from http://19min.bg/news/8/26914.html

Toshev, Tosho. (2004a). The Lie - Zhan, Ivan and the Rest. [Лъжата- Жан, Иван и другите]. (Vol. 1). Sofia: Trud. Retrieved from: http://www.znam.bg/com/action/showBook? bookID $=958 \&$ elementID $=1173 \&$ sectionID $=5$

Toshev, Tosho. (2004b). The Lie: Zhan, Ivan and the Highness. [Лъжата: Жан, Иван и Величеството]. (Vol.2). Sofia: Trued. Retrieved from: http://www.znam.bg/com/action/showBook? bookID $=927 \&$ elementID $=2015933336 \&$ sectionID $=5$

Van Waarden, F. (1992). Dimensions and Types of Policy Networks. European Journal of Political Research, vol. 21, 29-52.

Vladimirova, Sima. (2011a, September 26). What the Presidential Candidates Do Not Want to Talk About [За какво не обичат да говорят кандидатите за президент], Retrieved from http://www.168chasa.bg/Article.asp? $\underline{\text { ArticleId }=1053564}$ 
Vladimirova, Sima. (2011b, February 22). Monterey are suspected in relation to undercover intelligence surveillance [Подозират "Монтерей" във връзка със СРC-та], Retrieved from http://www.168chasa.bg/Article.asp? $\underline{\text { ArticleId }=765256}$

VUARR (Higher School of Agrobusiness and Regional Development), Institute for Regional Research at VUARR (VUARR-IRI), Bulgarian Construction Chamber (BCC) (2014). Status and Problems of the Construction Organizations in Bulgaria and the Role of the Chamber of Bulgarian Constructors in the Solving those Problems. Sofia: VUARR-IRI. Retrieved from http://ksb.bg/images/rezultati.pdf

[Висше Училище по Агробизнес и Развитие на Регионите (ВУАРР), Институт за Регионални Изследвания (ВУАРР-ИРИ), Камара на Строителите в България (КСБ). (2014). Състояние и Проблеми на Строителните Организации в България и Ролята на Камарата на Строителите в България при Решаване на тези Проблеми, София: ВУАРР-ИРИ]

Welch C, M-P. R., Penttinen, H. \& Tahvanainen, M. (2002). Corporate Elites as Informants in Qualitative International Business Research. International Business Review, 11(5): 611-628.

Winters, J. A. \& Page, B. I. (2009) Oligarchy in the United States?. Perspectives on Politics, 7 (4), 731-751.

Woliver, L. R. (2002). Ethical Dilemmas in Personal Interviewing. PS: Political Science and Politics, 35 (4): 677-678.

Zudin, A. (2000). Oligarchy as a Political Problem of Russian Postcommunism. Russian Social Science Review, 41(6), 4-33. 

i Each legislative proposal (to amend or promote new legislation) is accompanied by a document labelled "Motives towards", followed by respective Law's name.

ii The CPC 570 decision is accompanied by the file CPC Check list Bid-rigging final.doc, md5 2c3399221024edccd69017ceca198577, which lists the scenarios that are indicative of public tender malpractice. 